UNIVERSIDADE DE SÃO PAULO

FACULDADE DE ECONOMIA, ADMINISTRAÇÃO E CONTABILIDADE DEPARTAMENTO DE ADMINISTRAÇÃO

PROGRAMA DE PÓS-GRADUAÇÃO EM ADMINISTRAÇÃO

UM ESTUDO SOBRE A GESTÃO DA TERCEIRIZAÇÃO DE SERVIÇOS DE TECNOLOGIA DA INFORMAÇÃO BASEADOS

EM MODELOS DE GOVERNANÇA

\author{
Fulvio Cristofoli
}

Orientador: Prof. Dr. Hiroo Takaoka

Coorientador: Prof. Dr. Edmir Parada Vasques Prado

SÃo PAULO

2011 
Prof. Dr. João Grandino Rodas

Reitor da Universidade de São Paulo

Prof. Dr. Reinaldo Guerreiro

Diretor da Faculdade de Economia, Administração e Contabilidade

Prof. Dr. Adalberto Américo Fischmann

Chefe do Departamento de Administração

Prof. Dr. Lindolfo Galvão de Albuquerque

Coordenador do Programa de Pós-Graduação em Administração 


\section{FULVIO CRISTOFOLI}

\section{UM ESTUDO SOBRE A GESTÃO DA TERCEIRIZAÇÃO DE SERVIÇOS DE TECNOLOGIA DA INFORMAÇÃO BASEADOS \\ EM MODELOS DE GOVERNANÇA}

Tese apresentada ao Departamento de Administração da Faculdade de Economia, Administração e Contabilidade da Universidade de São Paulo, como requisito para obtenção do título de Doutor em Administração.

Área de Concentração: Inovação e Gestão Tecnológica.

Orientador: Prof. Dr. Hiroo Takaoka

Coorientador: Prof. Dr. Edmir Parada Vasques Prado

Versão Corrigida

(versão original disponível na Unidade que aloja o Programa)

\section{SÃO PAULO}




\section{FICHA CATALOGRÁFICA}

Elaborada pela Seção de Processamento Técnico do SBD/FEA/USP

Cristofoli, Fulvio

Um estudo sobre a gestão da terceirização de serviços de tecnologia da informação baseados em modelos de governança / Fulvio Cristofoli. - São Paulo, 2011.

$261 \mathrm{p}$.

Tese (Doutorado) - Universidade de São Paulo, 2011.

Orientador: Hiroo Takaoka.

Coorientador: Edmir Parada Vasques Prado.

1. Tecnologia da informação 2. Gestão do fornecimento 3. Terceirização

I. Universidade de São Paulo. Faculdade de Economia, Administração e

Contabilidade. II. Título.

CDD - 658.4038 
Ao meu falecido pai, Attilio Cristofoli, meu eterno inspirador. À minha mãe Dirce Cristofoli, exemplo de amor em vida.

À minha esposa Ana Carla de Paulo, eterna companheira.

$E$ às minhas estrelinhas, razões da minha vida, Giulia Cristofoli, Carina Cristofoli e Bruna de Paulo Cristofoli. 



\section{AGRADECIMENTOS}

Agradeço primeiramente a Deus, por me ter permitido chegar até onde cheguei sempre me orientando e me ajudando a vencer os desafios e as adversidades durante a minha presente passagem nesta vida.

À minha esposa Carla, por todo seu amor, companheirismo e paciência, em função de todas as adversidades que juntos passamos e por todas as noites que foi dormir sozinha, enquanto continuava meus estudos.

Aos meus pais Attilio Cristofoli (in memoriam) e Dirce Cristofoli pela educação, pelos ensinamentos, por todo o esforço que fizeram para eu estar aqui, por toda ajuda que me deram e dão sempre.

Ao meu irmão Carlo Cristofoli, pela amizade, pelo apoio e por ser um ótimo irmão.

Ao meu orientador e amigo Prof. Dr. Hiroo Takaoka, que sempre teve disposição para me orientar e ajudar como aluno, como pessoa e como profissional. Nunca demonstrou impaciência quando o trabalho não se desenvolvia no ritmo esperado.

Ao meu coorientador e amigo Prof. Dr. Edmir Parada Vasques Prado, que da mesma forma, sempre teve disposição para me orientar e ajudar.

A todos os professores do curso de Pós-Graduação em Administração da FEA-USP, pela seriedade com que fazem desta universidade uma das melhores do país e pela forma com que sempre me trataram, com profundo respeito e atenção, apesar de meu ínfimo conhecimento face aos seus. Em especial, ao Prof. Dr. Nicolau Reinhard e ao Prof. Dr. Cesar Alexandre de Souza, por todo o ensino dentro e fora das salas de aula.

À amiga Licia Mutsuko Abe, pela paciência e por toda a ajuda despreendida ao longo deste período.

Às empresas Now! Digital Business Ltda, na pessoa da Sra. Silvia Bassi - Diretora Executiva e Sra. Tatiana Americano, Editora-executiva das revistas CIO e Computerworld, pela ajuda na divulgação da pesquisa, e à empresa AKNA Software, na pessoa do Sr. Fernando Bueno Rocha e seu diretor, pela liberação de uso de seus sistemas de gerenciamento de e-mail marketing que foi fundamental para divulgação e controle do questionário eletrônico.

Aos amigos Luciano Venelli Costa, Marcelo Alves Cruz, Rafael Marcus Chiuzi e Rovílson Dias da Silva, pois passamos várias horas discutindo e aprendendo juntos diversos temas relacionados a esta pesquisa.

À Universidade Metodista de São Paulo, por ter me proporcionado crescimento profissional e acadêmico, em especial ao Prof. Dr. Marcio de Moraes, pelo apoio na liberação das minhas atividades profissionais em função do desenvolvimento deste trabalho; à Profa. Me. Elaine Lima de Oliveira, exemplo singular de amizade e confiança e à Profa. Me. Vera Lucia Gouvea Stivaletti pela amizade, companheirismo e profissionalismo. 



\section{RESUMO}

O objetivo deste trabalho é o de avaliar a gestão da terceirização de serviços de tecnologia da informação (TI) baseados nas práticas de governança de TI (GTI) por meio de revisão bibliográfica e pesquisa quantitativa em organizações brasileiras. Diversas organizações enfrentam dificuldades na gestão dos serviços terceirizados e por essa razão adotam práticas recomendadas por diversos modelos de GTI. O estudo sobre a natureza da relação entre as práticas recomendadas de gestão de TI e seus resultados partiu da análise de 37 modelos de governança, sendo 15 específicos de GTI, dos quais três modelos foram escolhidos - CObIT vs.4.1, eSCM-CL vs.1.1 e ITIL vs.3 - por representarem quase que a totalidade de processos e ações práticas de todos os outros modelos relacionados à GTI. O instrumento foi aplicado junto a 299 gestores de TI de empresas de grande e médio porte dos setores industrial, comercial e de serviços da Região Metropolitana de São Paulo, sendo realizadas análise fatorial exploratória e análise confirmatória por meio de modelagem de equações estruturais estimados por PLS (Partial Least Square). O instrumento final contém 43 itens que ficaram distribuídos em sete fatores, a saber: estratégias de serviços, operações de serviços, monitoramentos de serviços, desenvolvimento do fornecedor, trabalho tecnológico, satisfação e melhoria nos processos de negócio. Esses fatores agrupam-se em duas dimensões - práticas recomendadas e resultados esperados. A pesquisa evidencia que grande parte das organizações utiliza modelos de GTI, sendo as de grande porte sua maior parte e com predominância do modelo ITIL. Podê-se observar ainda, que os melhores resultados obtidos pelas organizações, estão associados à adoção de contratos formais detalhados com uso de service level agreement, aumentando seu foco na área de atuação em função da terceirização de serviços de TI. A expectativa era a de que a adoção de práticas recomendadas de modelos de GTI contribuísse significativamente no resultado da terceirização de serviços de TI, entretanto, isto não ficou caracterizado. A complexidade que envolve a adoção de práticas recomendadas e seus resultados leva-nos a refletir e a apontar outros aspectos que podem estar relacionados a fim de se obter resultados mais significativos da gestão da terceirização de serviços de TI. 



\begin{abstract}
The objective of this research is evaluate the management of the outsourcing of information technology (IT) practices based on IT governance (GTI) through a review and quantitative research in Brazilian organizations. Several organizations are facing difficulties in managing outsourced services and therefore adopting practices recommended derived from the various models of GTI. The study on the nature of the relationship between best practices for IT management and its results came from analysis of 37 models of governance, 15 GTI-specific, including three models were chosen-COBIT vs.4.1, eSCM CL-vs. 1.1 and ITIL vs.3 - because they represent almost the entire process and practicalities of all other models related to the GTI. The instrument was applied to 299 IT managers at large and medium-sized companies in the industrial, commercial and service sectors within São Paulo Metropolitan Region and was conducted exploratory factor analysis and confirmatory analysis using structural equation modeling estimated by PLS (Partial Least Square). The final instrument contained 43 items that were distributed in seven factors, namely: service strategies, service operations, monitoring of services, supplier development, technological work, satisfaction and business processes improvement. These factors were grouped into two dimensions - best practices and results. The research shows that most organizations use models of GTI, and the large and mostly with a predominance of ITIL. It can also be observed, is that the best results obtained by the organizations, are associated with adoption of formal contracts with detailed use of service level agreement, increasing its focus on the scope depending on the outsourcing of IT services. The expectation was that the adoption of best practices models GTI contributed significantly in the outcome of outsourcing of IT services, however, this has not been characterized. The complexity surrounding the adoption of best practices and their results leads us to reflect and point to other aspects that may be related to be the most significant results of the management of outsourcing IT services.
\end{abstract}





\section{SUMÁRIO}

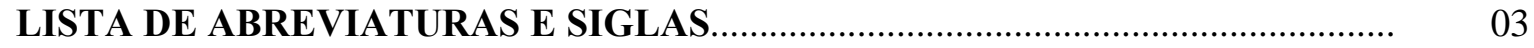

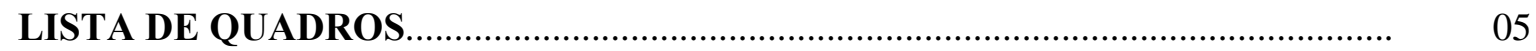

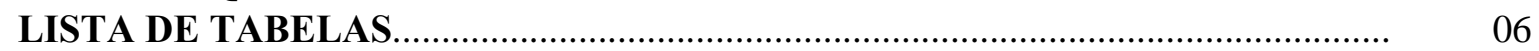

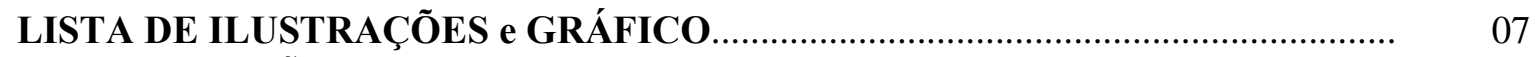

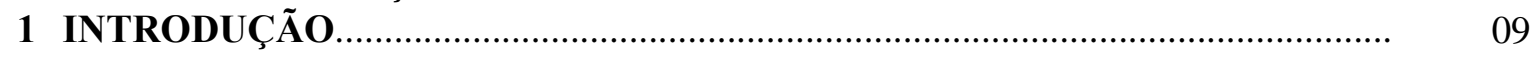

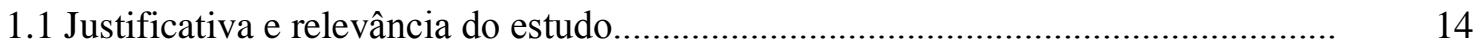

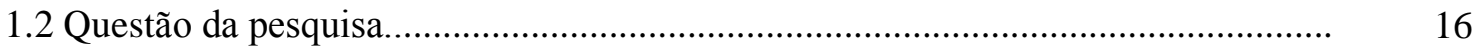

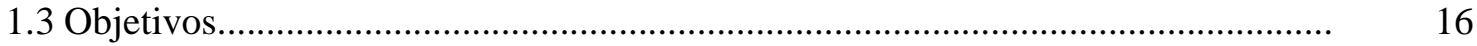

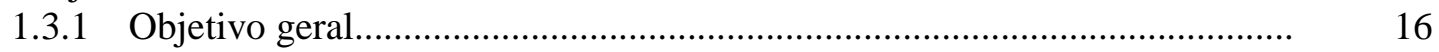

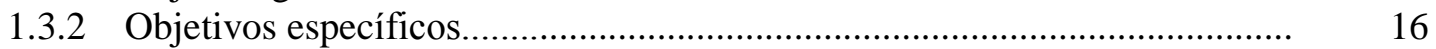

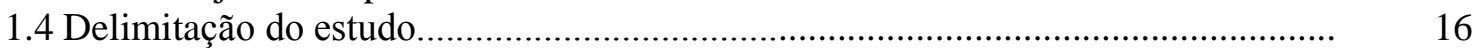

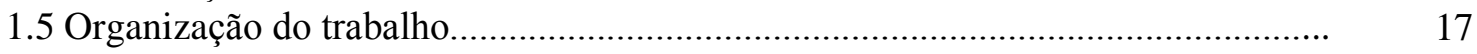

2 REFERENCIAL TEÓRICO............................................................................ 19

2.1 Histórico e conceitos sobre tecnologia da informação............................................... 19

2.1.1 Benefícios e resistências da utilização da tecnologia da informação............. 21

2.1.2 As empresas e a tecnologia da informação.................................................. 23

2.1.3 Posicionamento da tecnologia da informação nas empresas......................... 25

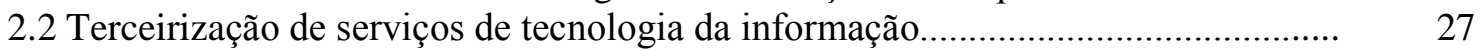

2.2.1 Conceitos sobre terceirização de serviços de tecnologia da informação....... 28

2.2.2 Aspectos da terceirização de serviços de tecnologia da informação.............. 29

2.2.3 Resultados esperados da terceirização de serviços de tecnologia da informação............................................................................................ $\quad 35$

2.3 Da governança corporativa à governança de tecnologia da informação................... 42

2.3.1 Origem e histórico da governança corporativa............................................ 42

2.3.2 Conceitos sobre governança corporativa...................................................... 43

2.3.3 Origem e histórico da governança de tecnologia da informação................... 45

2.3.4 Conceitos sobre governança de tecnologia da informação............................ 46

2.3.5 Gestão da terceirização de serviços de tecnologia da informação sob o ponto de vista da governança de tecnologia da informação............................

2.3.6 Modelos de práticas recomendadas no contexto da governança de tecnologia da informação........................................................................... 50

2.3.7 Práticas de gestão da terceirização de serviços de tecnologia da informação.......................................................................................... 77

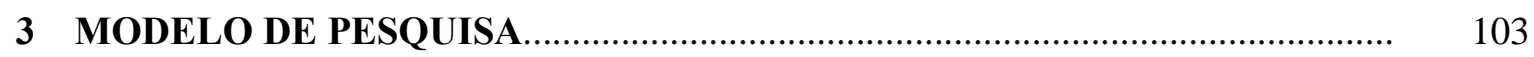

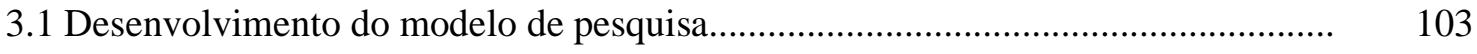

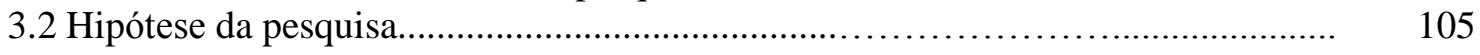

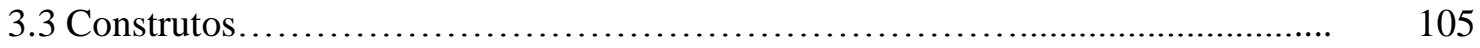

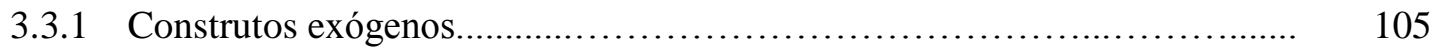

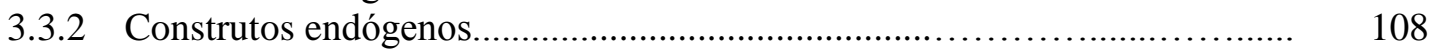

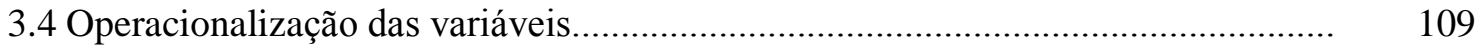

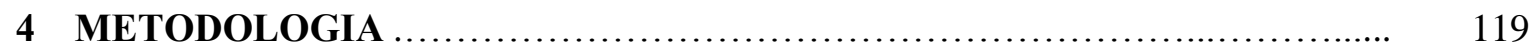

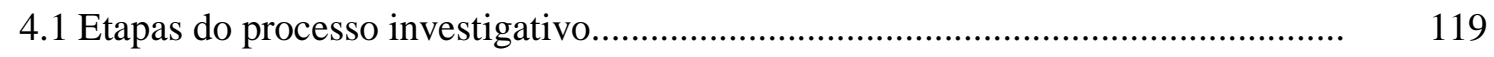

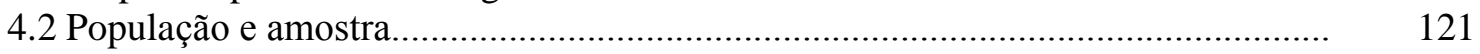

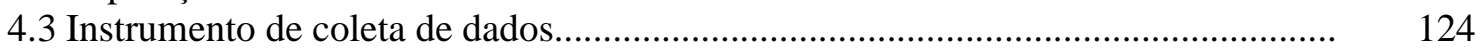




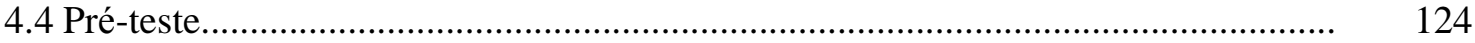

4.5 Téenicas de tratamento dos dados................................................................. 126

4.5.1 Análise fatorial exploratória.................................................................... 126

4.5.2 Modelagem de equações estruturais.............................................................. 131

5 ANÁLISE DOS DADOS E RESULTADOS............................................... 139

5.1 Método de execução e análise dos dados.......................................................... 139

5.2 Descrições e caracterização da amostra................................................................. 140

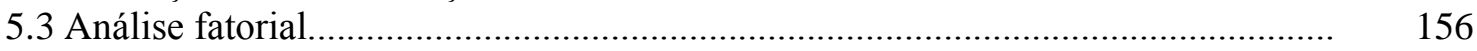

5.4 Análise confirmatória por meio da modelagem de equações estruturais.................. 170

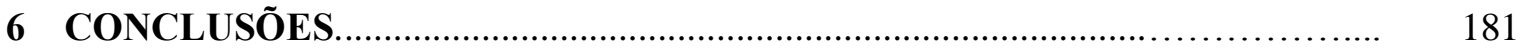

7 LIMITAÇõES E SUGESTÕES PARA ESTUDO FUTURO.................................. 187

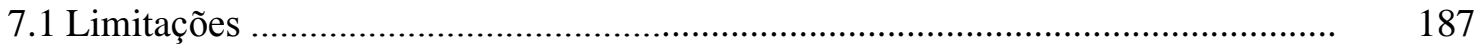

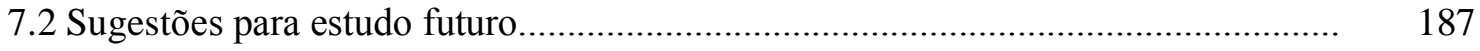

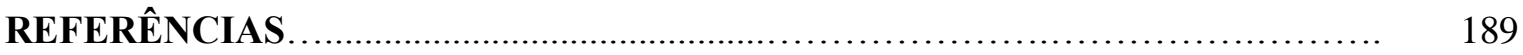

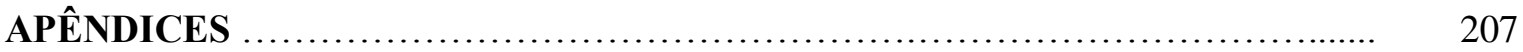

Apêndice A - Quadros com os livros de práticas de gestão............................................. 207

Apêndice B - Tela do gerenciador de e-mail - website AKNA....................................... 215

Apêndice C - Tela do gerenciador do questionário eletrônico - website Survey Monkey...................................................................................... 216

Apêndice D - Quadro das escalas intervalares.............................................................. 217

Apêndice E - Termo de consentimento - questionário eletrônico........................................ 218

Apêndice F - Instrumento completo utilizado para a pesquisa........................................ 219

Apêndice $\mathrm{G}$ - Relação das práticas recomendadas - por ordem das mais adotadas de maneira excelente............................................................................. 224

Apêndice H - Relação das práticas recomendadas - por ordem das que não são adota- 225

Apêndice I - Relação dos resultados obtidos em decorrência da terceirização de servi ços de TI - por ordem do índice "nenhum resultado"................................ 226

Apêndice J - Relação dos resultados obtidos em decorrência da terceirização de serviços de TI - por ordem do índice "obtido completamente"........................... 227

Apêndice $\mathrm{K}$ - Resultados da terceirização de serviços de TI por setor e por grau de

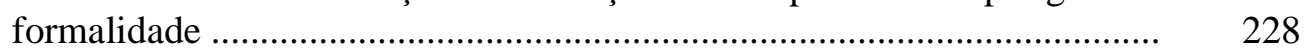

Apêndice L - Gráfico scree plot - práticas recomendadas............................................... 242

Apêndice M - Medida de adequação da mostra - práticas recomendadas........................... 243

Apêndice N - Gráfico scree plot - resultados esperados................................................. 244

Apêndice $\mathrm{O}$ - Medida de adequação da mostra - resultados esperados............................. 245

Apêndice P - Sintaxe utilizada para a análise paralela de Horn no SPSS - práticas recomendadas........................................................................................ 246

Apêndice Q - Sintaxe utilizada para a análise paralela de Horn no SPSS - resultados esperados...................................................................................... 248 


\section{LISTA DE ABREVIATURAS E SIGLAS}

$\alpha$ : Alfa de Cronbach

AFC: Análise Fatorial Confirmatória

AFE: Análise Fatorial Exploratória

ASL: Application Services Library

ASM: Applied Scientific Methods

AS 8015-2005: Australian Standard for Corporate Governance of IT

AVE: Average Variance Extracted - Variância Média Extraída

BiSL: Business Information Services Library

BPO: Business Process Outsourcing

BSC: Balanced Scorecard

BSI: British Standards Institution

CEO: Chief Information Officer - Diretor de Informática

CBGC: Código Brasileiro sobre Governança Corporativa

CIO: Chief Information Officer

COBIT: Control Objectives for Information and Related Technology

COPC: Customer Operations Performance Center

CMMI: Capability Maturity Model Integration

EDS: Electronic Data Systems

eSCM-SP: eSourcing Capability Model for Service Providers

eSCM-CL: eSourcing Capability Model for Client Organization

eTOM: Enhanced Telecom Operations Map

GC: Governança Corporativa

GTI: Governança de TI

H0: Hipótese nula

IAOP: International Association of Outsourcing Professional

IBGC: Instituto Brasileiro de Governança Corporativa

IBGE: Instituto Brasileiro de Geografia e Estatística

IBM : International Business Machines

ISSC: International Shared Service Center

IDC: International Data Corporation

IGC: Índice de Governança Corporativa

IDG: International Data Group

IPMA: International Project Management Association

IPQ: Instituto Português de Qualidade

ISO: International Organization for Standardization

ISACA: Information Systems Audit and Control Association

ISACF: Information Systems Audit and Control Foundation

ISPL: The Information Services Procurement Library

ISSC: (International Shared Service Center)

ITGI: IT Governance Institute

ITIL: Information Technology Infrastructure Library

ITS-CMM: IT Service Capability Maturity Model

ITSMF: The IT Service Management Forum

KMO: Kaiser-Meyer-Olkin

MEE: Modelagem de Equações Estruturais

MOF: Microsoft Operations Framework

MSA: Measures of Sampling Adequacy - Medidas de Adequação da Amostra 
MSP: Managing Successfull Programmes

$\mathrm{N}$ ou n: número de respondentes válidos de uma amostra

NDAS: Acordos de não divulgação

OGC: Office of Government Commerce

OI: The Outsourcing Institute

OPM: Organizational Project Management

PLS: Partial Least Squares - Mínimos Quadrados Parciais (método de estimação em MEE)

PLS-PM: PLS Path Modeling - Modelagem de Caminho por PLS

PMBoK: Project Management Body of Knowledge

PMI: Project Management Institute

PRINCE: Projects IN Controlled Environments

$\mathrm{R}^{2}$ : R Quadrado (medida de explicação da variância de uma variável sobre outra)

SAS: Statement on Auditing for Services Organizations

SEBRAE: Serviço de Apoio às Micros e Pequenas Empresas

Sig.: Significância

SLA: Service Level Agreements

SP: São Paulo

SPSS: Statistical Package for the Social Sciences (nome de um aplicativo de Estatística)

STM: Secretaria dos Transportes metropolitanos

T: valor resultante do teste $t$ de Student (teste de Estatística)

TI: Tecnologia da Informação

TQM: Total Quality Management

TOGAF: The Open Group Architecture Framework 


\section{LISTA DE QUADROS ${ }^{1}$}

Quadro 1 - Quadro com objetos terceirizáveis e respectivos autores..................... 30

Quadro 2 - Resultados esperados com a terceirização de serviços de TI......................... 41

Quadro 3 - Agrupamento dos modelos CoBIT Vs.4.1; eSCM-CL Vs.1.1; e ITIL Vs.3 75

Quadro 4 - Autores utilizados para a revisão bibliográfica sobre as dimensões do gerenciamento da terceirização de serviços de TI....................................... 100

Quadro 5-Quadro das variáveis para o grupo práticas de gestão da terceirização de

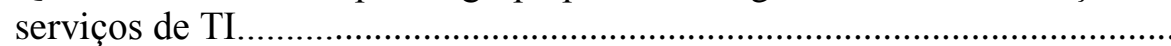

Quadro 6-Quadro das variáveis para o grupo resultados esperados em decorrência da terceirização de serviços de TI ............................................................ 114

Quadro 7 - Quadro resumo das variáveis de controle ................................................... 115

\footnotetext{
${ }^{1}$ Esta lista de quadros foi relacionada em função da sua relevância, apesar do manual para formatação e edição
} de dissertações e teses da FEA-USP sugerir a não inserção em uma lista com menos de 10 itens. 


\section{LISTA DE TABELAS}

Tabela 1 - Consistência interna obtida na amostra pré-teste ............................ 125

Tabela 2 - Frequências dos questionários respondidos .............................................. 139

Tabela 3 - Localização das organizações respondentes ................................................ 140

Tabela 4 - Setor de atividade das organizações respondentes ........................................ 140

Tabela 5 - Porte das organizações respondentes ........................................................ 142

Tabela 6 - Receita Líquida das organizações respondentes por setor............................ 143

Tabela 7 - Quantidade de funcionários das organizações respondentes ........................ 144

Tabela 8 - Quantidade de funcionários próprios e terceirizados de TI e do desenvolvimento de SI das organizações.

Tabela 9 - Gastos e investimentos em TI e desenvolvimento de SI das organizações respondentes.

Tabela 10 - Parque de computadores instalados nas organizações respondentes .......... 147

Tabela 11 - Média do parque de computadores instalados - entre os setores................ 148

Tabela 12 - Diferenças significativas entre os setores - número de computadores........ 148

Tabela 13 - Grau de formalização contratual das organizações respondentes................ 149

Tabela 14 - Adoção de modelos de governança de TI pelas organizações respondentes - porte.

Tabela 15 - Adoção de modelos de governança de TI pelas organizações respondentes - frequência.

Tabela 16 - Adoção de modelos de governança de TI pelas organizações respondentes - por setor e porte..

Tabela 17 - Adoção de modelos de governança de TI pelas organizações respondentes - por setor por grau de formalidade.

Tabela 18 - Primeira prática mais adotada de forma excelente - frequência por setor..

Tabela 19 - Segunda prática mais adotada de forma excelente - frequência por setor..

Tabela 20 - Terceira prática mais adotada de forma excelente - frequência por setor..

Tabela 21 - Resultado obtido completamente com maior apontamento pelos gestores de TI - frequência por setor..

Tabela 22 - Fatores extraídos - práticas recomendadas .......................................... 157

Tabela 23 - Análise paralela de Horn - práticas recomendadas ................................ 159

Tabela 24 - Solução de fatores - práticas recomendadas ............................................ 159

Tabela 25 - Alfa de Cronbach - fatores extraídos - práticas recomendadas ................. 160

Tabela 26 - Fatores extraídos - resultados esperados.............................................. 163

Tabela 27 - Análise paralela de Horn - resultados esperados.................................... 163

Tabela 28 - Solução de fatores - resultados esperados................................................. 164

Tabela 29 - Alfa de Cronbach - fatores extraídos - resultados esperados.................... 164

Tabela 30 - Associação entre os fatores de práticas recomendadas e resultados espe

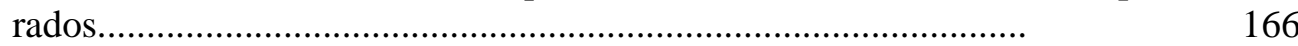

Tabela 31 - Associação entre os fatores de práticas recomendadas.............................. 167

Tabela 32 - Associação entre os fatores de resultados esperados.................................. 168

Tabela 33 - Indicadores de validade convergente dos fatores do modelo de mensuração................................................................................................ 171

Tabela 34 - Matriz de cargas dos fatores e entre os fatores do modelo........................ 172

Tabela 35 - Teste de colinearidade entre as variáveis latentes .................................. 173

Tabela 36 - Coeficientes padronizados (paths) e valores $t$ student obtidos no modelo proposto...... 


\section{LISTA DE ILUSTRAÇÕES E GRÁFICO}

Ilustração 1 - Evolução do processo de normas e padrões de segurança da informação 57

Ilustração 2 - Esquema da análise realizada nos 15 modelos de GTI.......................... 74

Ilustração 3 - Processo completo de análise dos modelos de governança ...................... 76

Ilustração 4 - Modelo conceitual.................................................................................... 104

Ilustração 5 - Etapas da investigação ......................................................................... 119

Ilustração 6 - Modelo estrutural no SMART PLS ..................................................... 170

Ilustração 7 - Processamento inicial PLS do modelo de mensuração ............................ 170

Ilustração 8 - Resultado da análise de práticas recomendadas e resultados esperados... 173

Ilustração 9 - Processamento PLS (bootstrapping - teste $t$ ) do modelo de mensuração e estrutural.............................................................................. 178

Gráfico 1 - Gráfico com percentuais - Análise dos questionários preenchidos ............ 139

\footnotetext{
${ }^{2}$ Esta lista de ilustrações e este gráfico foram relacionados em função da sua relevância, apesar do manual para formatação e edição de dissertações e teses da FEA-USP sugerir a não inserção em uma lista com menos de 10 itens.
} 



\section{INTRODUÇÃO}

O uso da tecnologia da informação (TI) é uma das práticas cada vez mais adotadas pelas empresas, tornando-se de forma crescente, um imprescindível instrumento de nossa cultura. Com o mercado globalizado, o gestor de TI é levado a lidar com uma série de novas ideias e regras para manter a competitividade. As informações devem ser providas com maior objetividade, clareza e com fácil acesso, a fim de serem utilizadas de forma rápida e dinâmica. Tais desafios das organizações estão associados aos usos crescentes da TI, sobre os quais diversos autores têm relatado esse crescimento que vem ocorrendo num ritmo sem precedentes (ALBERTIN; SANCHES, 2008; IKENAGA, 2008; PRADO, 2005; AUBERT; RIVARD; SMITH, 2004; BARTHÉLEMY, 2003).

Segundo Beal (2002, p. 26):

O principal benefício que a tecnologia da informação traz para as organizações é a sua capacidade de melhorar a qualidade e a disponibilidade de informações e conhecimentos importantes para a empresa, seus clientes e fornecedores. Os sistemas de informação mais modernos oferecem às empresas oportunidades sem precedentes para a melhoria dos processos internos e dos serviços prestados ao consumidor final.

A forte pressão que as organizações enfrentam, oriundas do desenvolvimento do mercado no contexto da globalização e das inovações tecnológicas, diante de um cenário econômico incerto, têm forçado-as a melhorar a qualidade de produtos e serviços, a reduzir seus custos organizacionais e custos relacionados ao desenvolvimento da TI (CHIESA, 2000; SANCHEZ; PEREZ, 2003).

As organizações procuram soluções inovadoras e eficazes que lhes permitam reduzir o risco, sempre melhorando a qualidade do serviço, respondendo de forma mais eficaz às necessidades do seu negócio e liberando-as, a fim de concentrar-se nas suas competências essenciais.

Essa competição global requer do processo de desenvolvimento de novos produtos e serviços meios de ação interna em suas capacidades técnicas e de recursos externos provenientes de fornecedores inovadores, (LIAO; LIAO; HUTCHINSON, 2009), sendo que cada vez mais, a 
terceirização de TI está se tornando uma alternativa viável aos métodos tradicionais (GOTTFREDSON; PURYEAR; PHILLIPS, 2005).

Algumas razões para a terceirização são apresentadas por Greaver II $(1999$, p. 4), tais como: manter o foco em suas competências principais (core business) e na melhoria do processo; razões financeiras, incluindo a possibilidade de gerar novas receitas por meio de oportunidade de novos negócios e razões que envolvem recursos humanos.

A terceirização de TI como meio de redução de custos começou por ser um meio para estabilizar os ambientes de TI, sendo uma forma eficaz de reduzir custos e focar os recursos no core business. Além disso, quando uma organização não consegue executar com eficácia determinadas tarefas, como, por exemplo, o desenvolvimento de sistemas de informações, poderá fazer uso dos melhores recursos e capacidades por meio de empresas especializadas que detém a expertise desses processos, transferindo a responsabilidade da execução de serviços de tecnologia.

Portanto, as organizações começaram a terceirizar, a fim de melhorar a sua performance (LIAO; LIAO; HUTCHINSON, 2009). Nessa perspectiva, a terceirização de alguns serviços de TI tem sido associada principalmente com a falta de capacidade interna, e /ou com o custo do projeto, e/ou com o tempo de execução reduzido, dentre outras (ZHAO; CALANTONE, 2003).

Embora os indicadores financeiros sejam determinantes na decisão de terceirização de processos de negócios, alguns aspectos diferenciadores devem ser considerados, como a excelência no serviço, a sua evolução no futuro e o valor acrescentado para o negócio (SAAD, 2006).

Para Corbett (2010) o poder real da terceirização de TI permitirá o aumento da capacidade de uma empresa para as mudanças e para o crescimento. "Os desafios de negócios para a próxima década serão muito diferente de tudo que vimos até agora e as empresas que tecem uma poderosa rede de parceiros por meio da terceirização serão os vencedores" (CORBETT, 2010 p. 02). 
A terceirização deixou de ser uma intervenção e passou a ser parte integrante da estratégia, tornando-se uma ferramenta estrutural significativa para as organizações, a fim de ajudar a estabilizar o negócio em um mundo de mudanças rápidas e imprevisíveis.

Segundo Lünendonk GmbH (2009) a maioria das empresas pretende continuar investindo em TI para conseguir aumentar sua produtividade e uma das estratégias para atingir esse objetivo é a terceirização de serviços de TI. Esse mesmo estudo aponta três novas tendências em relação à terceirização: transferência de conhecimento; a disponibilidade global de profissionais experientes e a flexibilidade de atendimento em diferentes localidades.

De acordo com a Forrester Research (2009, p. 02), a estimativa mundial de negócios relacionados à terceirização de TI é de cerca de US\$ 120 bilhões por ano e a estimativa de crescimento anual do mercado de terceirização de TI, incluindo aplicações, mainframes, redes, desktops e ambientes distribuídos, é de 7\% entre 2007 e 2012. Durante esse mesmo período, consultorias de TI e integração de sistemas terão um crescimento de a $5 \%$ e $4 \%$, respectivamente.

Para a International Association of Outsourcing Professional - IAOP (2010), o mercado de terceirização de serviços de TI em todas as atividades comerciais, independentemente do cenário econômico, tem continuado a subir entre 10 a 20\% nos últimos anos. Para o Gartner Group (2010) o mercado mundial de terceirização deverá atingir o valor de US\$324,9 bilhões, ou seja, um aumento de 21,18\% até 2012.

A região da América Latina continua sendo a que mais cresce na área de terceirização de TI, marcada pela busca de oportunidades e acomodação dos recursos, com organizações em busca de ferramentas e modelos que permitam aumentar o crescimento e ter sucesso durante a crise econômica. (IDC, 2010)

No Brasil, segundo a IDC (2009), há a previsão de que o mercado de serviços de TI cresça a uma taxa média anual de 5,1\% até 2012. Nesse contexto, a terceirização de serviços de TI representa cerca de um quinto da globalidade dos serviços de TI, e é de todos os segmentos o que mais cresce, com expectativa de crescimento de 6,3\% até 2012. 
A ASM (2010), sinaliza que o mercado de terceirização de TI no Brasil atingiu a marca de R\$ 20,4 bilhões para 2010 e a previsão para 2013 é de que se ultrapasse o valor de $\mathrm{R} \$ 31,4$ bilhões, ou seja, um crescimento de 53,92\% entre 2010 e 2013. A consultoria Stefanini (2010) apresenta uma evolução semelhante no mercado de terceirização de TI global, segmentado por IT Services. A previsão é que se atinja a marca de US\$239 bilhões para o segmento de Business Process Outsourcing (BPO), US\$ 374 bilhões para o segmento de desenvolvimento de aplicações; US\$ 358 bilhões para a infraestrutura e US\$ 98 bilhões para hardware, totalizando US\$ 1.069 trilhões até 2012 em terceirização de TI.

Em função de todo esse crescimento e como meio de alcançar a produtividade e garantir a competitividade, a terceirização de serviços de TI deve estar integrada com os objetivos da organização por meio da utilização de ferramentas e processos mais produtivos, fazendo com que se torne mais competitiva no mercado em que atua. No processo de terceirização de TI, as atividades de apoio são realizadas por uma ou mais empresas contratadas, enquanto que o domínio do processo de negócio fica sob a responsabilidade da organização contratante. Assim sendo, as organizações tendem a depender dos recursos de TI, passando a ser um fator crítico e vital para o desenvolvimento do projeto terceirizado (ABREU, 2009).

Fatos como esses exigem preocupações por parte dos executivos da empresa, bem como dos gestores de TI, uma vez que o cenário atual é caracterizado por mudanças constantes no ambiente de negócios (PRADO, 2009). Além do mais, os gestores devem estar capacitados e habilitados para conduzir novas formas de gestão e processos, bem como realizar acompanhamentos constantes sobre a gestão dos serviços prestados, a fim de garantir bons níveis de qualidade e produtividade.

Segundo Abreu (op. cit., p. 39) a gestão de TI é um desafio para os gestores do negócio "uma vez que eles se deparam com complexidade técnica, dependência face um número crescente de fornecedores de serviços, e fornecimento limitado de informações confiáveis para a monitoração dos riscos".

Sob o ponto de vista estratégico, uma má gestão da terceirização de serviços de TI pode levar a alguns riscos, tais como: perda de conhecimentos, risco de que as informações sobre a inteligência do negócio sejam repassadas aos concorrentes, desmotivação das equipes envolvidas no projeto terceirizado, contratos realizados de forma incorreta ou incompleta, 
dificuldade na realização de mudanças em função de novos cenários do negócio, entre outros (LACITY; WILLCOCKS; FEENY， 1996; DIROMUALDO; GURBAXANI， 1998; KLEPPER; JONES, 1998; AUBERT; RIVARD; PATRY, 2003; COHEN; YOUNG, 2006; PRADO, 2009).

Segundo Bhattacharya, Behara e Gundersen (2003) uma das principais questões que envolvem a terceirização de TI é a perda de controle das funções de TI para fornecedores externos, fruto de uma aceleração do fenômeno da terceirização e de uma consequente decomposição da estrutura das organizações. De acordo com os autores a utilização de modelos de governança de TI são fundamentais na redução do risco e na obtenção dos objetivos estabelecidos para esse fenômeno.

$\mathrm{Na}$ busca por reduzir o risco do processo de terceirização as organizações estão aprimorando cada vez mais suas formas de contratação e implantando modelos de governança de TI com práticas de gestão que variam de empresa para empresa (SAAD, 2006).

No universo da TI, o termo governança de TI é bem conhecido e está bem estabelecido (WEILL; ROSS, 2004). Trata-se de um subconjunto da governança corporativa centrada em TI, sistemas, sua performance e gerenciamento de risco (KOOPER; MAES; LINDGREEN, 2009). Nesse sentido, a governança de TI é um instrumento de alinhamento estratégico entre os negócios e a área de TI.

Muitas organizações enfrentam sérias dificuldades na gestão dos serviços terceirizados. São problemas que envolvem relacionamento com fornecedores, expectativas sem alinhamento estratégico, prazos que não se cumprem, quebras contratuais, custos acima do esperado, entre outros, sendo que muitos desses problemas poderiam ser resolvidos com a adoção de práticas de gestão oriundas dos modelos de governança de TI direcionadas para a gestão da terceirização de serviços de TI (AUBERT et al., 1999; ABREU, 2009; MANSUR, 2009).

Um estudo realizado com 200 empresas pelo The IT Service Management Forum, indicou que 85\% das organizações investem em modelos de governança de TI a fim de obterem práticas que auxiliem em suas gestões (ITSMF, 2009). Esse mesmo estudo revela ainda que 49\% das empresas afirmam que as maiores dificuldades são o entendimento, a adaptação e 
personalização das práticas oferecidas pelos modelos de governança de TI às necessidades específicas da companhia e dificuldades de entendimento do processo.

Embora a governança de TI seja amplamente aceita e considerada como um poderoso instrumento necessário para melhorar o valor agregado dos investimentos em TI e gerenciar os seus respectivos riscos, alguns autores argumentam que as atuais regras de governança de TI apresentam limitações e inadequações (KOOPER; MAES; LINDGREEN, 2009; BEIJER; KOOPER, 2010).

Existem riscos associados às escolhas de provimento de serviços de TI, e muitos estudos têm demonstrado relacionamentos de terceirização ou parcerias que não foram bem sucedidas, em que os custos e a qualidade esperada na prestação dos serviços não foram alcançados pela falta de acompanhamento ou até mesmo pelo uso e adequação de um modelo de governança de TI que aborde práticas de gestão da terceirização de serviços de TI (SOARES, 2007).

Portanto, o estudo de aspectos ligados à gestão da terceirização de serviços de TI é de suma importância, e diante disso, esta tese discute sobre a adoção das práticas de gestão da terceirização de serviços de TI e os resultados obtidos em decorrência dessa terceirização.

Tais resultados obtidos em decorrência da terceirização de serviços de TI podem ser entendidos como critérios que envolvam reduções de custos, níveis de serviço, satisfação, disputas entre contratante e contratada, entrega de valor, entre outros (MAISEL, 1992; LACITY; WILLCOCKS; FEENY, 1996; SIMONS, 1995; KUO, 1996; LACITY; WILLCOCKS, 1998; HSU; WU, 2006; WEBB; POLLARD; RIDLEY, 2006).

\subsection{Justificativa e relevância do estudo}

Um aspecto que demonstra a relevância deste estudo está na análise de campo pouco explorado na área de governança de TI, mais precisamente na adoção de práticas de gestão da terceirização de serviços de TI e seus resultados.

Pesquisas anteriores analisaram outras questões relacionadas à terceirização, como a de Perez (2003), que procurou identificar os principais aspectos do processo de seleção de fornecedores considerados pelas empresas contratantes do serviço. Bergamaschi (2004) teve como objetivo 
analisar práticas relacionadas à gestão da terceirização de TI por meio da caracterização de um cenário sobre tal prática em empresas brasileiras. Prado (2005), por sua vez, teve por objetivo aumentar o conhecimento sobre as práticas de contratação de terceiros e seus respectivos arranjos contratuais. Kuchenbecker (2006) apresentou uma análise sobre a terceirização de TI e a qualificação de fornecedores no âmbito da administração da cadeia logística. Lunardi (2008) objetivou verificar se a governança de TI afeta o desempenho organizacional, ou seja, verificar se as práticas ligadas à governança de TI fazem com as que as empresas melhorem seu desempenho após essa adoção. Soares (2008) investigou as implicações das premissas do modelo de governança de TI para sua adequabilidade ao contexto institucional brasileiro. Ikenaga (2008) analisou a gestão da terceirização de TI a partir da identificação de modelos de governança de TI.

De modo geral, os artigos científicos publicados sobre este tema geralmente contemplam conceitos e estrutura (WEILL; WOODHAM, 2002; WEIL, 2004; BROWN; GRANT, 2005; WILLCOCKS; FEENY; OLSON, 2006; VERHOEF, 2007); benefícios (CHIN; BROWN; HU, 2004; RAU, 2004; RIDLEY; YOUNG; CARROL, 2004; DE HAES; VAN GREMBERGEN, 2005; DE HAES; VAN GREMBERGEN, 2006); e práticas adotadas (PETERSON, 2004; HARDY, 2006).

É possível, portanto, afirmar que este estudo justifica-se pelo fato de que o tema ainda é atual e considerado para as empresas como uma preocupação, sejam as que já realizaram a terceirização parcial ou total de TI, sejam as que pensam em optar por essa prática.

Sendo assim, esta pesquisa busca contribuir significativamente com o desenvolvimento do campo acadêmico - apresentando possíveis práticas para a gestão da terceirização de serviços de TI, bem como os resultados obtidos em decorrência da terceirização de serviços de TI podendo também auxiliar outras pesquisas, tanto na área de tecnologia quanto nas da administração relacionadas à gestão da terceirização de TI por intermédio do uso de modelos de governança de TI.

Sob o ponto de vista empresarial, o estudo pretende servir como fonte de referência aos gestores de terceirização de TI, avaliando suas práticas de gestão e explicitando os pontos críticos que muitas vezes passam despercebidos, mas que poderão influenciar nos resultados oriundos da terceirização e, consequentemente, nos resultados das organizações. 


\subsection{Questão da pesquisa}

De forma a direcionar a realização do estudo, foi apresentada a seguinte questão de pesquisa: "Qual a relação entre as práticas recomendadas de gestão da terceirização de serviços de TI e seus resultados sob o ponto de vista do gestor de TI?”.

\section{$1.3 \quad$ Objetivos}

\subsubsection{Objetivo geral}

Avaliar a gestão da terceirização de serviços de TI baseados nas práticas de governança de TI em organizações brasileiras.

\subsubsection{Objetivos específicos}

Para que o objetivo geral fosse alcançado, foram estabelecidos alguns objetivos específicos, a saber:

- Identificar as principais práticas de gestão da terceirização de serviços de TI baseados nos modelos de governança de TI;

- Identificar os resultados esperados com a terceirização de serviços de TI mencionados na literatura;

- Avaliar as práticas de gestão da terceirização de serviços de TI utilizadas pelas organizações brasileiras;

- Avaliar os resultados obtidos com a terceirização de serviços de TI pelas organizações brasileiras;

- Avaliar a relação entre práticas de gestão da terceirização de serviços de TI e seus resultados.

\subsection{Delimitação do estudo}

A pesquisa abrangeu grandes e médias empresas privadas dos três setores, sediadas na Grande São Paulo e Capital. Como o estudo ocorreu no âmbito da terceirização de serviços de TI, foi realizado o estudo das empresas que tenham passado pelo processo de terceirização do 
desenvolvimento de sistemas de informação sob medida e/ou terceirização da implantação de pacotes de sistemas de informação, envolvendo todo o ciclo de vida dos sistemas, ou seja, desde a concepção até a entrega total do serviço.

A intenção de estudar especificamente o processo de terceirização de serviços de TI desenvolvimento e/ou implantação de sistemas de informação - deveu-se ao fato de que muitas organizações percebem a TI como um de seus principais ativos, e as decisões relativas à sua adoção, implantação e gerenciamento de sistemas de informação, continuam sendo bastante complexas.

De acordo com Maizlish e Handler (2005), 72\% dos projetos de TI - que envolvem sistemas de informação - apresentam atrasos na entrega, superação de seus orçamentos, problemas de funcionalidade, ou não são concluídos.

Ainda segundo os autores, dos $28 \%$ dos projetos de TI considerados como sucesso - em função de serem entregues - 45\% tiveram seu orçamento inicial superado e $68 \%$ dos projetos foram além do tempo planejado. Além de tais resultados, outro aspecto que vale ser mencionado é que grande parte dos executivos afirmam que poderiam ter obtido valor nos seus projetos de TI com 50\% dos custos utilizados e apenas $52 \%$ dos projetos concluídos obtiveram valor estratégico.

De acordo com Peterson (2004), a preocupação dos executivos de negócio e gestores de TI quanto à forma com que os serviços e investimentos de TI têm sido gerenciados, tem feito com que reconheçam que os possíveis bons resultados da TI, atualmente, não estão na tecnologia em si, mas sim na forma como a mesma é governada.

\subsection{Organização do trabalho}

A partir do exposto esta tese foi dividida em sete capítulos. O primeiro apresenta o tema, a justificativa e a relevância do estudo, a questão da pesquisa, o objetivo geral e os objetivos específicos e a delimitação do estudo.

O capítulo 2 é constituído pelo referencial teórico, tendo sido realizada a revisão bibliográfica dos aspectos relacionados à TI, terceirização de serviços de TI e governança corporativa e de 
TI. A primeira seção neste capítulo aborda o histórico e conceitos sobre TI, os benefícios e resistências da sua utilização, as empresas e sua relação com a TI, e o posicionamento da TI nas empresas. A seção seguinte traz como tema a terceirização de serviços de TI, no qual são abordados os conceitos sobre essa prática, os aspectos a ela relacionados e os resultados esperados que dela são decorrentes. A próxima seção trata do tema governança corporativa e governança de TI. Faz um breve relato sobre a origem, histórico e conceitos, aborda a gestão da terceirização de serviços de TI sob o ponto de vista da governança de TI, trazendo os modelos de práticas recomendadas nesse contexto. Ressalta as práticas de gestão da terceirização de serviços de TI na qual são apresentados os quadros com as análises realizadas a partir do estudo dos 15 modelos de governança de TI investigados. A apresentação das inadequações das práticas de governança de TI são trazidas ao final deste capítulo.

O capítulo 3 apresenta o modelo de pesquisa, a hipótese, os construtos e a operacionalização das variáveis.

O capítulo 4 trata do método investigativo e dos procedimentos para a realização da pesquisa, nos quais são descritos os meios utilizados a fim de garantir a sua integridade, o tratamento adequado dos dados coletados, bem como a qualidade da análise.

O capítulo 5 é dedicado às análises dos dados coletados e apresenta os resultados que são compreendidos por análise fatorial exploratória e confirmatória, sendo dividida por método e execução.

O capítulo 6 apresenta as conclusões e por fim, o capítulo 7 apresenta as principais limitações e sugestões para pesquisas futuras. 


\section{REFERENCIAL TEÓRICO}

Este capítulo apresenta a sustentação teórica que dá suporte para a realização desta tese enfocando os tópicos relacionados à TI, a terceirização de serviços de TI, e em especial, os modelos de governança de TI e a gestão da terceirização de serviços de TI.

\subsection{Histórico e conceitos sobre tecnologia da informação}

Ao refletir sobre a expressão tecnologia da informação, vale destacar a palavra tecnologia. Segundo Blanco e Silva (1993, p. 38), o termo tecnologia vem do grego "technê" (ofício, arte) e logos (estudo de) e refere-se à fixação dos termos técnicos, designando os utensílios, as máquinas, suas partes e as operações dos ofícios.

Segundo Reinhard (1996, p. 5) a TI teve início na década de 1960, sendo que nas décadas de 1970 e 1980, “trabalharam-se informações de uma maneira fácil, rápida, integrando departamentos e processos, assim, tornou-se uma ferramenta que originava o diferencial". A rapidez do processo de disseminação da informação passou a demandar novos domínios intelectuais dos gestores que, na conquista de sua competência, precisaram demonstrar habilidade na compilação de grandes quantidades de dados e informações relativas aos diversos níveis organizacionais.

De acordo com Cruz (1998, p. 20) a "tecnologia da informação pode ser todo e qualquer dispositivo que tenha capacidade para tratar dados e ou informações, tanto de forma sistêmica como esporádica, quer aplicada ao produto, quer esteja aplicada no processo".

Na concepção de Rezende e Abreu (2003, p. 31) "tecnologia da informação são recursos tecnológicos e computacionais para geração e uso da informação". Esse conceito enquadra-se na visão de gestão da tecnologia da informação e do conhecimento.

Sampaio, Costa e Pessoa (2006, p. 2) afirmam que as TI's:

São ferramentas utilizadas para gerir informações trabalhadas pelos diversos segmentos empresariais e dentro das diversas áreas de uma empresa, visando à obtenção de vantagem competitiva. $\mathrm{O}$ conceito vai mais além quando visa a clientes exigindo a comunicação eficaz da política da empresa. 
Para Cartwright (2005, p. 38), a TI "é a sinergia entre computadores e dispositivos de comunicação e constitui uma parte importante do mundo moderno".

Na área empresarial, a TI está cada vez mais interativa, pois tem favorecido a interação dos usuários em tempo real com recursos dinâmicos, gerando diferenciais competitivos. Segundo Gisbert et al. (1996, p. 2), o conceito de TI é definido como sendo o "novo conjunto de ferramentas, suportes e canais para o tratamento e acesso à informação que têm um caráter inovador, promovendo uma mudança tecnológica e cultural”.

Cabero (1996, p. 3) considera que a TI tem como características: "a imaterialidade; a interatividade; a instantaneidade; e a inovação". Já Bartolomé e Aliaga (2005, p. 2) consideram que o conceito de TI deve ter um sentido amplo, e como tal o define como sendo "o conjunto de meios e serviços que permitem recolher, armazenar e transmitir a informação com o auxílio de meios eletrônicos".

As organizações estruturam-se em sistemas e processos de desenvolvimento em função de demandas do mercado ou de interferências em seus processos internos. Os sistemas operacionais, processos e produtos, refletem as habilidades e competências administrativas por elas desenvolvidas.

Com esse panorama, é possível inferir que as empresas necessitam de organização de dados, estatísticas e métodos para transformar tais dados em informações e diferenciais competitivos. É nesse âmbito que a TI surge como força propulsora da disponibilização da informação que, por sua vez, permite elaborar o conhecimento que gera o suporte necessário ao processo decisório.

Portanto, a TI potencializa a eficiência das empresas, aumenta o controle do gerenciamento das operações, melhora a satisfação dos clientes, e reduz ciclo para realização dos processos.

De acordo com Turban, McLean e Wetherbe (2004) a TI está fundamentada nos seguintes componentes: Hardware e seus dispositivos e periféricos, software e seus recursos, sistemas de telecomunicações, e gestão dos dados e informações. Todos estes componentes interagem e necessitam do componente fundamental que é o recurso humano (humanware). Esse componente não faz parte da TI, mas sem ele, esta tecnologia não teria funcionalidade e 
utilidade. Logo, para que os processos da empresa funcionem plenamente, o ser humano é parte fundamental e, portanto, seus valores deverão ser respeitados, considerando suas habilidades individuais e experiências, sem esquecer, todavia, que sua capacitação é imprescindível. Essa capacitação dos recursos humanos está intimamente relacionada com a aprendizagem organizacional que envolve o aprendizado individual, bem como a capacidade da organização de fazer uso em benefício próprio.

Nesse sentido, Dutra (2003, p. 96) afirma que:

A aprendizagem pode ser pensada como um processo de mudança, provocado por estímulos diversos, mediado por emoções e que pode se manifestar ou não em modificações no comportamento de uma pessoa e demonstra que nas empresas a aprendizagem pode ocorrer no nível individual, grupal e organizacional.

Assim, a aprendizagem acontece, em princípio, no nível do indivíduo que é carregado de emoções, no nível do grupo quando compartilhado e no nível da organização quando o processo individual é partilhado com o grupo, e quando institucionalizada se expressa na estrutura, nas regras, e a organização recupera memória e informação.

\subsubsection{Benefícios e resistências da utilização da tecnologia da informação}

Os benefícios e resistências em função do uso da TI têm sido amplamente pesquisados por muitos autores. A falta de capacitação dos funcionários, o receio da perda dos postos de trabalho pela tecnologia, a cultura organizacional tradicional, ou seja, o apego às práticas de trabalho predominantes anteriormente à utilização de TI e a percepção da necessidade de alterações nas práticas de trabalho são apontadas como resistências quanto à implantação de ferramentas de TI (PRATES; OSPINA, 2004).

Em relação aos benefícios do uso de TI, os mesmos podem ser relacionados ao custo, produtividade, flexibilidade, qualidade e inovação, sendo entendidos como "a oferta que a tecnologia traz para as organizações” (ALBERTIN; ALBERTIN, 2008, p. 280). Contudo, tão importante quando a oferta é o seu aproveitamento no desempenho empresarial. Ainda para os autores os benefícios devem ser definidos e medidos pelos solicitantes e usuários de TI, ressaltando-se que devem ser benefícios para os negócios e aproveitados nos negócios. 
Segundo Gibson (1988, p. 67), os benefícios da TI podem ser relacionados "à matriz eficiência, eficácia e transformação em relação a seus beneficiários, o indivíduo, a unidade funcional e a organização toda".

Outros autores relacionam os benefícios da TI a diversas potencialidades, como por exemplo: "a integração organizacional; melhoria dos processos; e (re)planejamento" (DAVENPORT, 1994, 47); "agilidade; automatização de serviços; competitividade; comunicação interna e externa" (KLERING, 1997, p. 23); “integração entre os elos da cadeia produtiva" (CAMPOS FILHO, 1994, p. 34); "redução de custos; economia de tempo, aumento na produtividade; melhoria do nível geral de informações para o gerenciamento" (LAUDON E LAUDON, 2007, p. 78); "monitoramento e relacionamento com fornecedores; ganhos de produtividade; comunicação" (SACCOL et al., 2004, p. 11); "conhecimento do processo produtivo; aumento do controle integração funcional; velocidade de resposta" (PRATES E OSPINA, 2004, p. 12); “facilitador da aprendizagem" (ALMEIDA E MELLO, 2004, p. 17); "maior controle sobre a atividade; acesso mais rápido a informações; melhor capacidade para identificar problemas; redução de tarefas administrativas e maior exatidão nos trabalhos de escrituração" (GONÇALVES, 1994, p. 65); e "melhora na gestão de custos" (OLIVEIRA, 1996, p. 37).

Albertin e Albertin (2008, p. 276) apontam que “a TI é um dos componentes mais importantes do ambiente empresarial atual, e as organizações brasileiras têm utilizado ampla e intensamente essa tecnologia, tanto em nível estratégico como operacional". A utilização da TI oferece grandes oportunidades para as empresas que têm sucesso no aproveitamento dos benefícios oferecidos por esse uso, e também oferece desafios para a administração de TI, da qual as empresas passam a ter grande dependência e que apresenta particularidades de gerenciamento.

Os benefícios que a TI traz às empresas têm sido comprovados em algumas áreas de aplicação dessa tecnologia, enquanto que em outras permanece o debate em relação às dúvidas: se tais benefícios, de fato, têm sido alcançados, ou mesmo, se apresentam relação positiva se comparados aos investimentos necessários (ibid., p. 279).

De acordo com Turban, McLean e Wetherbe (2004, p. 463) as capacidades relacionadas à TI estão avançadas e crescem cada vez mais, permitindo novas e maiores aplicações em TI, possibilitando às empresas melhorar sua eficácia e eficiência. Porém, o uso cada vez mais 
diversificado desse novo potencial dificulta o entendimento sobre os benefícios relativos. Para os autores os benefícios relacionados à TI podem ser classificados como tangíveis e intangíveis. Os benefícios tangíveis são aqueles que afetam diretamente os resultados de uma empresa, sendo eles geração de lucros e redução de custo.

Os benefícios intangíveis são aqueles que trazem possíveis melhorias ao desempenho organizacional, não afetando diretamente os resultados da empresa, sendo eles informações gerenciais, transacionais, segurança das informações etc.

\subsubsection{As empresas e a tecnologia da informação}

A partir do século XXI, a TI vem sendo largamente utilizada, proporcionando reduções substanciais de custos nos processos operacionais, aumentando a capacidade de decisão dos executivos e atendendo às mais amplas necessidades das organizações.

Segundo Davenport (2000, p. 77) a humanidade encontra-se diante da "Era da Informação", que chegou para revolucionar a maneira de como se trabalha, se compete e até mesmo como se pensa no mercado.

Os avanços tecnológicos têm produzido grandes impactos nas empresas, exigindo alterações imediatas na forma de agir diante desta nova realidade. Nascida a pouco menos de 20 anos, "a sociedade da informação possui como principal agente de mudanças a empresa" e os pilares desta nova sociedade, que é fortalecida a cada dia, "estão baseados na TI e nos valores intangíveis" (AGRASSO NETO; ABREU, 2003, p. 28).

Entretanto, um progresso real somente irá ocorrer para aquelas empresas que "percebem e assimilam a nova sociedade da informação, que, em função da competição, fará uso intensivo da TI, requerendo agilidade, flexibilidade nos negócios e capacidade de se ajustar rapidamente às mudanças" (ibid., p. 45).

Segundo Laudon e Laudon (2007, p.12), três grandes mudanças mundiais vêm alterando o meio ambiente das organizações: "globalização - o sucesso das organizações depende e dependerá de sua capacidade em operar globalmente”. Neste contexto, cresce o valor das informações, uma vez que as mesmas passam a representar novas oportunidades mais 
abrangentes; "transformação da economia industrial - que irá basear-se em informações e conhecimentos" e por isso o setor de serviços, que se constitui fundamentalmente de informações e conhecimentos, irá se tornar mais expressivo frente aos demais; e "transformação das empresas - está havendo uma transformação nas formas de organização e gerenciamento".

Tradicionalmente, as organizações caracterizam-se pela estrutura hierárquica, centralizadora, formada por grupos de especialistas que dependem de um conjunto de procedimentos operacionais padronizados para disponibilidade de seus produtos e serviços.

As novas empresas caracterizam-se "por ter uma estrutura descentralizada e horizontal, formada por gestores e equipes flexíveis, baseando-se em informações atualizadas a fim de oferecerem um serviço ou produto mais adequado ao mercado" (LAUDON; LAUDON, 2007, p. 134).

Da mesma forma, sob o ponto de vista do gerenciamento, enquanto que as empresas tradicionais baseiam-se em planos formais, rígidas divisões do trabalho, regras formais e na lealdade de seus indivíduos para manter-se nos níveis considerados adequados de operação, um novo modelo fundamenta-se em "compromissos informais e redes de trabalho que estabelecem objetivos (ao invés do planejamento formal), em arranjos flexíveis e coordenados de grupos e indivíduos trabalhando em tarefas orientadas ao cliente, e no profissionalismo e conhecimento para manter a organização eficazmente" (ibid., p. 187, parênteses dos autores).

Para Kalakota e Robinson (2002, p. 98) a administração deve prestar muita atenção em três camadas de decisão encadeadas, ou seja, "no projeto de negócios (valor para o cliente, segmentos, prioridades, e capacidade organizacional); infraestrutura (sistemas de gestão empresarial integrados, sistemas de relacionamento com o cliente, suprimentos e vendas); e infoestrutura (servidores web, banco de dados)".

Em um ambiente no qual, variáveis múltiplas - tecnologia, exigências do cliente, cadeias de suprimento - estão mudando simultaneamente, as velhas armas de diferenciação - baixo custo, qualidade e melhoria de processo incremental - estão desempenhando um papel menor na sustentação do crescimento. O projeto de negócios não é mais uma parte opcional da estratégia empresarial; ao contrário, é a principal (p. 112). 
Os desafios previstos para as empresas, segundo Rezende e Abreu (2003, p. 55) são: "necessidade de processos de tomada de decisão mais frequentes e rápidos; necessidade de inovação organizacional mais frequente e mais rápida; necessidade de formas contínuas de aquisição de informação pelas empresas; e necessidade de adquirir e distribuir as informações adquiridas e distribuídas de forma mais rápida e eficaz”.

Com este cenário, nota-se um novo delineamento para o paradigma tecnológico. O esboço da era da inteligência em rede é marcado por diversas tendências relativas à TI. Essa nova era caracteriza-se por

\footnotetext{
uma crescente interpenetrabilidade dos computadores nas organizações; pela convergência entre a mídia, computadores e redes de telecomunicações; automação da organização; processo de trabalho com maior agregação de valor proporcionado pela TI; aceleração da competição global e difusão e adoção de padrões tecnológicos globais (CAMPOS FILHO, 1994, p. 42).
}

A informação transformada em conhecimento será a base da transformação organizacional e da vantagem competitiva, passando a ser um conjunto de recursos centrais, permitindo-lhes um alinhamento estratégico que gera as condições necessárias para alcançar os objetivos e cumprir a missão corporativa. Assiste-se, então, à aplicação da TI em toda a cadeia de negócios, desde a concepção de um produto e/ou serviço até a sua comercialização e distribuição.

\subsubsection{Posicionamento da tecnologia da informação nas empresas}

Alguns modelos, como por exemplo, modelos de diagnóstico, modelos prescritivos, modelos voltados para ações ou modelos integrativos podem ser utilizados para determinar o posicionamento da TI nas empresas. Uma das primeiras metodologias surgiu com o modelo de quatro estágios de Nolan (1973), com foco na evolução da área de TI. Sua primeira proposta baseou-se nas tecnologias utilizadas e nos orçamentos como indicadores. O modelo apresentava quatro estágios: "iniciação; contágio; controle; e maturidade" (NOLAN, 1973, p. 402).

A partir desse estudo, Nolan desenvolveu um novo modelo que representava não só o crescimento da tecnologia utilizada, mas também a aprendizagem organizacional. Esse novo modelo de seis estágios é composto por: "iniciação; contágio; controle; integração; gestão de dados; e maturidade" (NOLAN, 1979, p. 117). 
Em decorrência de tais estudos, vários autores desenvolveram modelos melhorados utilizando sempre como base, o modelo de Nolan (1979), entre eles: McFarlan, McKenney e Pyburn (1983); Bhabuta $^{3}$ (1988 apud Galliers e Sutherland, 1991, p. 92); Hirschheim et al. ${ }^{4}$ (1988 apud Galliers e Sutherland, 1991, p. 93); e Galliers (1998).

O modelo grid estratégico, apresentado por McFarlan, McKenney e Pyburn (1983) descreve "quais os possíveis posicionamentos que a TI pode assumir em uma empresa em função das aplicações de TI existentes e das aplicações de TI planejadas para o futuro" (FERREIRA; LAURINDO, 2008, p. 59).

De acordo com os autores, o quadrante estratégico se caracteriza pelo fato de que as aplicações de TI existentes nas empresas são críticas para as operações no presente e as aplicações de TI planejadas são igualmente críticas para o sucesso futuro. No quadrante transformação, as empresas não são dependentes das aplicações de TI (no presente), mas as novas aplicações de TI são vitais para os objetivos da empresa. Já as empresas situadas no quadrante fábrica dependem das aplicações de TI para o seu funcionamento diário; entretanto, as novas aplicações não significarão vantagens futuras.

Por fim, o quadrante suporte abriga aquelas empresas que não são nem dependentes das aplicações de TI, nem das aplicações futuras que trarão vantagens competitivas. (MCFARLAN; MCKENNEY; PYBURN, 1983; FERREIRA; LAURINDO, 2008, p. 59).

Esta matriz estratégica permite conclusões importantes acerca do posicionamento da TI dentro da estrutura da empresa e na forma como ela será gerida. Sendo assim, "a importância estratégica da TI depende da qual quadrante da Matriz a empresas está classificada" (FERREIRA; LAURINDO, 2008, p. 58). Prado (2005, p. 42) afirma que a caracterização da área de TI proposta por McFarlan "se mostra particularmente importante no estudo da terceirização".

\footnotetext{
${ }^{3}$ BHABUTA, L. Sustaining productivity and competitiveness by marshalling IT. Paper presented at the Information Technology Management for Productivity and Strategic Advantage, Proceedings of the IFIP TC8 Open Conference, Singapore. 1988

${ }^{4}$ HIRSCHHEIM, R.; EARL, M.; FEENY, D.; LOCKETT, M. An exploration into the management of the information systems function: Key issues and an evolutionary model. Paper presented at the Information Technology Management for Productivity and Strategic Advantage, Proceedings of the IFIP TC8 Open Conference, Singapore. 1988
} 
Fernandes e Alves (1992, p. 76) afirmam que o grau de dependência em TI está relacionado a quatro principais fatores: "maturidade da organização com o uso da TI - relaciona-se com fatores culturais; imposição do mercado - necessidade de investimento em TI para manter-se competitiva; ações gerenciais - relacionadas com a importância que o alto escalão da empresa apoia a TI para o sucesso do negócio e também com o comportamento dos gerentes com relação às inovações; natureza dos produtos/serviços - alguns produtos ou serviços possuem maior grau de inteligência em seus processos".

Outro aspecto significativo é que as empresas têm buscado a estruturação de suas unidades administrativas a fim de que possam viabilizar um maior grau de autonomia. Uma estrutura descentralizada, se por um lado traz consigo uma maior agilidade e capacidade de inovação, por outro exige a criação de instrumentos de gestão que assegurem a consecução dos objetivos globais dessas empresas (SANTOS; KELM; ABREU, 2001).

Um estudo realizado por Straub, Weill e Schwaig (2006), sob a luz da Teoria da Dependência de Recursos (RDT - do inglês Resource Dependence Theory) de Pfeffer e Salancik (1978), apresenta a preocupação das empresas pela dependência em relação aos recursos de TI. Os autores concluem que as empresas que investem estrategicamente em TI tendem a controlar mais seus recursos, obtendo um desempenho superior. Já as empresas que não investem e que possuem visão de que são dependentes estrategicamente da TI, o desempenho organizacional foi considerado inferior, pois o nível de controle é menor.

Diante desse quadro, é possível inferir que as empresas que utilizam a TI como recurso estratégico tendem a se tornar dependentes desses, seja na organização como um todo ou em algum projeto específico.

\subsection{Terceirização de serviços de tecnologia da informação}

O surgimento da terceirização de serviços de TI pode ser traçado com maior destaque a partir da década de 1960. Segundo Dibbern et al. (2004, p. 7) a terceirização de serviços de TI começou a evoluir em 1963, quando Ross Perot e sua empresa Electronic Data Systems (EDS) assinaram um acordo com a Cruz Azul de Pensilvânia para "a manipulação dos seus serviços de processamento de dados". Essa foi a primeira vez que uma grande empresa havia entregado como um todo o departamento de processamento de dados a um terceiro. 
Durante a década de 1970, outros clientes foram conquistados, como a Frito-Lay e General Motors. No entanto, o interesse real em terceirização de serviços de TI ocorreu em meados dos anos 1980, quando a EDS assinou contratos com a Continental Airlines, City First Bank e Enron. Tais ofertas sinalizaram "uma aceitação da terceirização, que até então não existia" (DIBBERN et al. 2004, p. 7).

Em 1989 a IBM criou uma divisão chamada ISSC (International Shared Service Center) para competir com a EDS e assinou seu primeiro contrato com a Eastman Kodak Company. Esse negócio iniciou o que se pode chamar de a primeira grande terceirização que revolucionou a forma como esta prática tinha sido utilizada até o momento.

Após esse feito, "o mercado começou a assimilar as possibilidades que a terceirização de serviços de TI poderia proporcionar" e outras dezenas de empresas bem conhecidas seguiram o exemplo:

General Dynamics, Delta Airlines, Continental Bank, Xerox, McDonnell Douglas, Chevron, Dupont, JP Morgan, and Bell South nos Estados Unidos; Deutsche Bank na Alemanha; Inland Revenue, Rolls Royce, BP e British Aerospace na Grã-Bretanha; KF Group na Suécia, Canadá Post no Canadá, o governo Sul-Austráliano, Telestra, LendLease e do Commonwealth Bank of Austrália, na Austrália; Swiss Bank, na Suíça, e Banco di’ Roma na Itália (DIBBERN et al. 2004, p. 7).

Cristofoli, Prado e Takaoka (2008, p. 6) relatam outro caso de terceirização de serviços de TI na década de 1980 envolvendo uma empresa do setor automobilístico brasileiro que em função de "forte recessão econômica, aliada a movimentos sindicais dentro do setor automobilístico" fez com que a empresa terceirizasse todo o seu Data Center.

\subsubsection{Conceitos sobre terceirização de serviços de tecnologia da informação}

É possível definir terceirização de serviços de TI como sendo a gestão por terceiros das atividades de TI de uma organização, cujo objetivo é o de atingir um desempenho predefinido (LACITY; HIRSCHHEIM, 1993).

De acordo com Willcocks e Lacity (1997, p. 80) a terceirização de serviços de TI pode ser definida como a decisão organizacional em transferir todas as suas funções, ou parte delas, a um ou mais prestadores de serviços externos no intuito de alcançar seus objetivos. 
Sparrow (2003, p. 13) conceitua como uma "prática que as empresas exercem em delegar gerenciamentos, planejamentos e operações de algumas funções para um provedor externo".

Segundo Saad (2006, p. 09) a terceirização de serviços de TI pode ser definida como "a utilização de relações comerciais externas para executar as atividades e processos necessários aos negócios da organização em lugar do uso de recursos internos".

Em um sentido mais amplo, a terceirização de serviços de TI visa ao repasse - total ou parcial - a um ou mais fornecedores, do gerenciamento dos recursos da área de TI, tornando-se uma opção para a empresa enfrentar, de modo mais eficaz, os desafios de gerir tais recursos.

As terminologias utilizadas nos estudos da terceirização de serviços de TI nem sempre são claras. Para Cristofoli, Prado e Takaoka (2008, p. 2) os termos relacionados à terceirização são definidos como:

Outsourcing (terceirização de serviços de TI). É a transferência de parte ou de todo o gerenciamento dos ativos, recursos ou atividades, que não representam o negócio principal da organização, para um ou mais fornecedores.

Insourcing: é o gerenciamento interno de ativos, recursos ou atividades.

Backsourcing: é a transferência de serviços terceirizados para o gerenciamento interno.

Sourcing: representa o quanto do trabalho total requerido para criar e entregar serviços de TI é feito internamente e o quanto é adquirido externamente.

Nesta pesquisa foi adotado e corroborado o conceito definido por Power, Desouza e Bonifazi (2006, p. 03), que definem terceirização de serviços de TI como "o ato de transferência do trabalho de uma entidade para outra entidade externa cujos componentes estão divididos em: cliente (tomador do serviço), vendedor (provedor do serviço) e projeto (serviço a ser terceirizado)".

\subsubsection{Aspectos da terceirização de serviços de tecnologia da informação}

A terceirização de serviços de TI ganhou espaço e relevância ao longo do tempo, surgindo diversos formatos de serviços ofertados que englobam boa parte das atividades que são consideradas prioritárias nas organizações e que até então eram fornecidas exclusivamente pelas áreas internas de TI (ALBERTIN; SANCHES, 2008).

Existem diversos serviços de TI que podem ser terceirizados, uma vez que estão presentes nas atividades organizacionais e são parte integrante de seus processos. A seguir, o quadro 1 apresenta um resumo com autores e objetos de TI terceirizáveis. 
Quadro 1 - Quadro com objetos terceirizáveis e respectivos autores

\begin{tabular}{|l|l|}
\hline \multicolumn{1}{|c|}{ Autores } & \multicolumn{1}{|c|}{ Objetos Terceirizáveis } \\
\hline Arnett e Jones (1994, p. 181) & $\begin{array}{l}\text { contratos de programação; implantação e integração de } \\
\text { sistemas; manutenção de mainframe/mini; manutenção de } \\
\text { PCs e estações; suporte de software e treinamento. }\end{array}$ \\
\hline Dekleva (1994) & $\begin{array}{l}\text { datacenters; desenvolvimento de aplicações; manutenção } \\
\text { de software; recuperação de desastres; suporte de } \\
\text { microcomputadores; e treinamento de usuários. }\end{array}$ \\
\hline Willcocks e Fitzgerald (1994) & $\begin{array}{l}\text { datacenters; manutenção de hardware; suporte a PCs; } \\
\text { treinamento e educação de usuários. }\end{array}$ \\
\hline Collins e Millen (1995) & $\begin{array}{l}\text { datacenters; desenvolvimento de aplicações; educação e } \\
\text { treinamento; manutenção de aplicações; serviços de rede; } \\
\text { e suporte de PCs. }\end{array}$ \\
\hline Apte el al. (1997) & $\begin{array}{l}\text { desenvolvimento de software; digitação; manutenção de } \\
\text { software; operação de datacenter; operações de suporte; } \\
\text { recuperação de desastres; redes; e treinamento e } \\
\text { educação. }\end{array}$ \\
\hline Grover, Cheon e Teng (1996) & $\begin{array}{l}\text { desenvolvimento, implantação e manutenção de sistemas; } \\
\text { gerenciamento de telecomunicações; operação de } \\
\text { sistemas; e suporte ao usuário final. }\end{array}$ \\
\hline Lacity e Willcoks (2000) & $\begin{array}{l}\text { helpdesk; mainframe; midrange; PCs e cliente/servidor; } \\
\text { recuperação de desastres; redes; suporte de PCs e usuário } \\
\text { final. }\end{array}$ \\
\hline
\end{tabular}

Grover, Cheon e Teng (1996, p. 92) complementam afirmando que as atividades que podem ser terceirizadas são planejamento e gerenciamento de sistemas, além de suporte ao usuário final, operação de sistemas, desenvolvimento e manutenção de sistemas e gerenciamento de redes e telecomunicações conforme exposto no quadro 1 .

Da mesma forma, Willcocks e Lacity (1997) e Lacity e Willcocks (2001), baseados em pesquisas realizadas, apresentam diversas funções de TI terceirizáveis, dentre as quais vale destacar: "desenvolvimento de aplicações e suas respectivas manutenções; operação de sistemas; gerenciamento de telecomunicações e redes; suporte ao usuário final; gerenciamento e planejamento de sistemas; e compra de softwares aplicativos".

Para Araujo (2001, p. 93) a terceirização de serviços de TI "pode ocorrer em funções da área tecnológica e funções na área administrativa". Ainda segundo o autor, as atividades que podem ser transferidas, são "sistemas de informação; serviços de processamento; e processos de negócio".

Prado (2005, p. 46) relata que "o crescimento da evolução tecnológica tem disponibilizado novos recursos tecnológicos e como consequência disto, os fornecedores de serviços têm 
diversificado os serviços oferecidos". Segundo o autor toda a parte de infraestrutura de hardware - data center/ASP; helpdesk; hospedagem/armazenamento, impressão, manutenção de hardware, redes, servidores, segurança e suporte técnico pode ser terceirizada.

Na linha de sistemas de informações, a indicação para terceirização é:

Aplicações; desenvolvimento e manutenção de sistemas; e sistemas legados. Em planejamento, organização e métodos, a indicação é: definição de metodologias; PDI, levantamento e diagnósticos; e planos de contingência. Em diversos, pode-se terceirizar: digitação; editoração eletrônica; microfilmagem; processos de negócio; e treinamento (BERNSTORFF; CUNHA, 1999, p. 5).

Cabe ressaltar que o objeto da terceirização de serviços de TI "deve relatar o comprometimento das partes, destacando as atividades e obrigações que compõem o acordo contratual" (REZENDE; ABREU, 2003, p. 300) e "não deve ser feita segundo os mesmos critérios adotados para outros serviços, pois precisa ser considerada a complexidade técnica e os riscos envolvidos." (LEITE, 1995, p. 35).

Em relação ao grau de terceirização de serviços de TI, Saad (2006, p. 70) o define como o "ritmo de progressão com o qual o projeto será implantado". Em consonância com Saad, Mancini (2006) afirma que esse grau "pode ser distinguido basicamente em duas alternativas: terceirização total; e terceirização incremental - também chamada de parcial" (p. 36). A terceirização total significa que todas as atividades que compõem a função de TI são terceirizadas de uma única vez (SAAD, 2006; MANCINI, 2006).

A terceirização parcial ou incremental é definida como "aquelas em que as atividades que compõem a função de TI são terceirizadas progressivamente, de acordo com critérios a serem estabelecidos pela organização" priorizando as funções cuja terceirização resulte em: "maior benefício financeiro; maior eficiência operacional; maior rapidez de implantação; menor complexidade de implantação; e menor risco pósimplantação" (MANCINI, 2006, p. 36).

Os modelos de terceirização de serviços de TI continuam evoluindo e acompanhando as inovações relacionadas a TI, e por conta disso muitas empresas ao constatarem que não se encontram aptas para os complexos desafios a serem enfrentados por suas áreas de TI "avaliam a alternativa de adoção de serviços terceirizados, a fim de atingir os objetivos estabelecidos" (SAAD, 2006, p. 62). 
Da mesma forma, à medida que as organizações direcionam seus esforços em focar mais em seus processos de negócios, maior será a necessidade de expertise na área de TI, pelo fato de que possibilitará a integração de novos produtos e processos que tornem suas unidades de negócio competitivas em escala global (LEITE, 1995).

Para Saad (2006) os modelos para operacionalização da terceirização de serviços de TI são terceirização com fornecedor único, terceirização seletiva com um conjunto de fornecedores, e terceirização com um consórcio de fornecedores.

A terceirização com um fornecedor de serviço único constitui-se no fornecimento de todos os serviços de TI por um único provedor. "Refere-se a um contrato único com um provedor preferencial selecionado e gerido pelo contratante". (ibid., p. 63).

Terceirização seletiva com um conjunto de fornecedores "são aquelas em que há múltiplos contratos celebrados com provedores selecionados em áreas específicas”. A seleção dos provedores e gestão dos contratos é realizada pelo contratante (ibid., p. 64).

A terceirização com um consórcio de fornecedores possue duas variantes: a primeira "referese a provedores selecionados e geridos por um provedor primário”. O provedor primário é selecionado e gerido pelo contratante. A segunda variante "refere-se a provedores selecionados pelo contratante e supervisionados operacionalmente por um provedor integrador". Todos os provedores são selecionados e geridos pelo contratante (ibid., p. 64).

Nesse sentido, cabe à empresa contratante decidir pela forma de operacionalização da terceirização de serviços de TI, em função do objeto terceirizado e dos objetivos a serem alcançados.

Como a garantia contratual inerente à terceirização de serviços de TI é realizada por meio de contrato comercial, as organizações possuem uma preocupação importante em definir corretamente o modelo de contratação em função do tipo de aquisição que será realizado.

A contratação de serviços terceirizados "requer um cuidado especial com a propriedade dos resultados dos serviços e do seu uso por terceiros" (ALBERTIN; SANCHES, 2008, p. 130). Aspectos como "a identificação das competências da organização; as conseqüências de decisões do tipo 'vamos fazer ou comprar?'; e a utilização das práticas recomendadas na 
implementação do processo, são aspectos que devem ser obrigatoriamente estudados" (SAAD, 2006, p. 134).

O processo de preparação e criação de um contrato de terceirização de serviços de TI deve ser exaustivo e completo, podendo em alguns casos, ser extremamente complexo por envolver em um único contrato aspectos como o fornecimento dos serviços, transferência de infraestrutura de hardware e software, bem como a de funcionários (ibid.).

Os contratos devem especificar os acordos e termos firmados entre as partes para o cumprimento das trocas econômicas e não será completo se não abranger as obrigações das partes envolvidas em todas as situações (AUBERT et al., 2002).

De acordo com McFarlan e Nolan (1995), Lee (1996), Aubert et al. (1999), Greaver II (1999), Kern e Willcocks (2000), Aubert, Rivard e Patry (2003) e Power, Desouza e Bonifazi (2006) as cláusulas mais comumente acordadas em contratos de terceirização e sem nenhuma ordem especial são SLA (Service Level Agreements), sistemas de penalidades e recompensas, preço, benckmarking, solicitações de mudança, opções de renegociação, responsabilidade e seguros, resolução de disputas, troca de gestores, auditoria, confidencialidade, proteção de dados e direitos de propriedade intelectual.

A gestão de uma relação de terceirização de serviços de TI "deve incluir todas as atividades que podem resultar em impactos sobre este relacionamento durante o período em vigência" (DIBBERN et al., 2004, p. 6). Lee e Kim (1999) mostram que estes fatores determinam a qualidade de uma parceria de terceirização e afetam diretamente o sucesso da terceirização de serviços de TI.

Segundo Mansur (2009) geralmente os riscos associados ao processo de terceirização de serviços de TI envolvem custos, serviços prestados com qualidade e o papel da TI. Nesse contexto, Alborz, Seddon e Scheepers (2004) apontam a importância da governança para o sucesso global de um acordo de terceirização.

Klepper (1995), McFarlan e Nolan (1995), e Willcocks e Choi (1995) reconhecem explicitamente a importância da governança de TI e a gestão do relacionamento. As medições 
e controles são fatores importantes para construir e manter um relacionamento e devem ser acordados contratualmente (HENDERSON, 1990; LACITY; HIRSCHHEIM, 1993).

Ainda segundo esses autores, o contrato de terceirização deve definir a natureza dos serviços a serem prestados e do relacionamento em si. Portanto, deve ser dada ênfase no processo de elaboração do contrato, pois é passível de ser mais importante do que o próprio contrato (MACFARLAN; NOLAN, 1995).

Cabe ressaltar que a organização contratante deve compreender claramente as perspectivas legais e comerciais dos componentes da negociação da terceirização, antes que uma avaliação dos requisitos contratuais operacionais específicos e técnicos possa ser realizada (SAAD, 2006).

Sendo o contrato um dos documentos mais importantes em um relacionamento de terceirização de serviços de TI - no qual as condições e a qualidade terão grande influência nas relações entre as partes envolvidas e no resultado final - é necessário definir corretamente o modelo de contratação em função do tipo de aquisição que será realizado, uma vez que existem formas diferentes de contratação, conforme já mencionado.

Segundo Corbett (2004, p. 151) "os acordos instaurados entre as partes tornam-se importante para que diferencie as relações" e esses acordos contratuais podem ser descritos como contratos formais - nos quais devem ser descritas claramente as responsabilidades e compromissos da organização contratante e empresa contratada, ou contratos não formais chamados de acordo, que muitas vezes acompanham a ordem de compra, ou seja, não há nenhum tipo de formalização.

Prado e Takaoka (2006, p. 11) apontam que "o grau de formalidade pode ser caracterizado como: sem contrato; por meio de contrato; e contrato com níveis de serviço".

Em se tratando de contratos com níveis de serviços, são estabelecidos alguns níveis de acordos, chamados de SLA, nos quais "a contratante lista todas as atividades que têm um impacto apreciável sobre a empresa (negócio), determinando a prioridade e o número de usuários dessas atividades. Além disso, as atividades são associadas aos serviços que lhes dão suporte (sistemas e seus componentes)" (CAVALCANTI, CAVALCANTI FILHO e LIMA, 2007, p. 105, parênteses dos autores). 
Segundo Grover, Cheon e Teng (1996) esses contratos contêm cláusulas detalhadas que medem o desempenho dos serviços e é evidente que dependem das métricas e do seu gerenciamento.

É oportuno mencionar que o não cumprimento dos acordos de níveis de serviço podem gerar punições para a empresa contratada, enquanto que para a organização contratante, apesar do abatimento no valor do contrato ou recebimento de eventual multa aplicada, haverá problemas de insatisfação com a equipe envolvida e com os usuários finais.

\subsubsection{Resultados esperados da terceirização de serviços de tecnologia da informação}

De modo geral, os resultados inerentes à terceirização de serviços de TI são acompanhados de declarações otimistas sobre os possíveis ganhos que podem resultar do processo de contratação com a empresa com a qual se estabeleceu o acordo.

Esses resultados compreendem justamente a fase final do processo de aquisição do serviço e podem ser evidenciados de diversas maneiras, como relatam alguns teóricos (CLARK; ZMUD; MCCRAY, 1995; DAVIS, 1996; KLEPPER, 1995; MCFARLAN; NOLAN, 1995; WILLCOCKS; CHOI, 1995; WEBB; POLLARD; RIDLEY, 2006). Entre essas maneiras, encontram-se tanto o sucesso quanto o fracasso.

O sucesso da terceirização de serviços de TI pode ser avaliado sob várias formas (reduções de custo; aumento na qualidade das informações; satisfação do usuário; aumento de produtividade; entre outros), o que torna problemática a sua identificação ou a determinação de medidas confiáveis. O sucesso da terceirização de serviços de TI tem sido frequentemente definido como um resultado ou consequência (WEBB; POLLARD; RIDLEY, 2006).

De acordo com o OI (2006, p. 1) - The Outsourcing Institute - vive-se a era do outsourcing 2.0, na qual algumas características prevalecem como a "falta de experiências em terceirização de serviços de TI pelas empresas tomadoras do serviço; onde não havia nenhum esforço em 
manter a propriedade intelectual; e gastos altíssimos", sendo que tais características têm levado gestores e usuários a uma insatisfação, ineficiência no processo e frustrações com a falta de resultados.

Por outro lado, ainda segundo levantamento realizado pelo instituto, os principais problemas relatados são: a falta de tempo ou conhecimento para identificar e avaliar os tipos de informações que lhes permitam melhorar a tomada de decisão no processo de terceirização; implementar as práticas recomendadas em uma base consistente e o alinhamento estratégico com a área de TI.

Da mesma forma, Alborz, Seddon e Scheepers (2004) afirmam que o alinhamento estratégico é um importante fator dentro da terceirização de serviços de TI, pois influencia seu sucesso. "Se um projeto de terceirização não está alinhado com a estratégia global da empresa contratante do serviço, o resultado pode não satisfazer os usuários" (GELLINGS, 2007, p. 222).

Já Hitt e Brynjolfsson (1996) relacionam o aumento do valor do negócio da TI com a melhoria na execução dos negócios, baseado em desempenhos e em contratos com valores flexíveis, "garantindo que o contratante só pague o que receber", a "estrutura de preços influencia positivamente no valor do negócio do contratante contribuindo para o sucesso global da terceirização de serviços de TI" (REPONEN, 1993, p. 107; LACITY; WILLCOCKS, 1998, p. 373).

Para Lacity e Willcocks (1998, p. 372) o sucesso global de um acordo de terceirização de serviços de TI pode ser afetado significativamente pela "falta de capacidade do fornecedor em realizar economias de escala, deixando de aumentar o valor entregue por meio da TI".

Numa outra linha, Reponen (1993, p. 105) relata que a terceirização tem sido indicada como "uma ferramenta para transformar custos fixos em variáveis"

Outro item relacionado diretamente ao resultado e que constitui-se em um fator importante dentro da terceirização de serviços de TI é a gestão dos riscos, que tem sido analisada por 
vários pesquisadores (AUBERT et al. 1999; AUBERT et al., 2000; BAHLI; RIVARD, 2001; GELLINGS, 2007).

Segundo Gellings (2007, p. 222) são vários os fatores de risco e possíveis resultados negativos em uma relação de terceirização de serviços de TI, sendo que os mais temidos nos riscos de terceirização são "perda de controle sobre serviços terceirizados, a perda de flexibilidade, e altos custos inesperados"

Uma gestão ativa evita os riscos de uma terceirização se transformar em um resultado negativo. Portanto, segundo Aubert, Rivard e Patry (2003, p. 184), “a gestão dos riscos contribui para o resultado positivo de um negócio de terceirização de serviços de TI”.

Além da gestão dos riscos, a execução de controles sobre o fornecedor de serviço "aumenta as chances de sucesso na terceirização" (KERN; WILLCOCKS, 2000, p. 20), sendo que os controles inerentes aos custos devem ter especial atenção (REPONEN, 1993, p. 108).

Segundo McFarlan e Nolan (1995, p. 14) normas e controles em geral, "podem fortalecer uma relação de terceirização de serviços de TI e são, portanto, fatores de sucesso essenciais".

Webb, Pollard e Ridley (2006) apontam algumas práticas para que se alcance desempenho positivo para a terceirização de serviços de TI, sendo elas:

- Alinhamento estratégico - reunião regulares entre gerentes; reuniões regulares da alta gerência; envolvimento de áreas de negócios no projeto de terceirização; solicitações de mudanças contratuais e renegociação de cláusulas.

- Entrega de valor - envolvimento de áreas de negócios no projeto de terceirização; acordos de níveis de serviços; estruturas de preços adequadas ao negócio; e cláusulas de benchmarking.

- Gerenciamento do desempenho - controle e monitoramento dos serviços entregues; acordos de níveis de serviços; e controle e monitoramento das medidas de desempenho.

- Gerenciamento de riscos - monitoramento regular, avaliação e mitigação de riscos; acordos de níveis de serviço; sistema de recompensa-penalidade; benchmarking; solicitações de mudança; renegociação de cláusulas; e obrigações e garantias. 
- Controle e prestação de contas - controle e monitoramento do acordo de terceirização; modelos adotados pelo mercado; e auditorias.

Nesse contexto, Lacity e Willcocks (1998, p. 365) definiram resultado em termos de terceirização como "uma diminuição no custo e um aumento da qualidade dos serviços prestados".

Para Lacity, Willcocks e Feeny (1996) os critérios para o sucesso da terceirização de serviços de TI variam de empresa para empresa e, em alguns casos, as percepções variam dentro de uma organização. Entretanto, os critérios são geralmente associados aos seguintes fatores:

- Se as reduções de custos foram alcançadas ou melhoradas de acordo com o previsto;

- Se os níveis de serviço foram mantidos ou melhorados;

- Se os usuários estão satisfeitos;

- Se houve poucas disputas entre tomador e fornecedores dos serviços;

- Se o fornecedor do serviço é ágil e atencioso;

- Se os objetivos e os resultados estão alinhados - comparados favoravelmente; e

- Se o contrato foi renovado.

Kuo (1996) aponta alguns indicadores para o resultado da terceirização de serviços de TI, com base em pesquisa realizada com profissionais que são responsáveis por avaliar o desempenho dos departamentos de TI de grandes empresas e classifica como:

- Impactos do direcionamento estratégico;

- Integração entre Sistema de Informação e objetivo do planejamento organizacional;

- Qualidade dos sistemas de informações;

- Contribuições financeiras;

- $\quad$ Eficiência e eficácia do trabalho;

- Satisfação dos usuários;

- $\quad$ Competência dos profissionais de TI;

- Progresso na implantação de sistemas;

- Inovação; e

- Segurança. 
Já Simons (1995), desenvolveu índices de desempenho a partir de três perspectivas:

- Um indicador financeiro que compreende o fluxo de caixa, taxa de crescimento de vendas, margem bruta e retorno dos acionistas sobre o retorno do investimento (ROI);

- Um indicador de clientes que inclui a relação de novas receitas de vendas do produto, em relação ao tempo de entrega, as vendas como uma percentagem do capital total e avaliação dos principais clientes da empresa; e

- Um indicador de funcionamento interno que compreende o tempo de retorno do processo, de custos unitários, a taxa de produção e de frequência de saída dos produtos recém-lançados.

Maisel (1992), por sua vez, afirma que a avaliação de desempenho do fornecedor para mensurar o resultado da terceirização de serviços de TI deve incluir:

- Finanças - crescimento de vendas e rentabilidade, custos de produtos e receita marginal, lucro por ação, retorno sobre ativos e ROI;

- Operações - cota de mercado, qualidade/zero defeitos, a satisfação do cliente, a eficácia do marketing, introdução de novos produtos, produtividade, competitividade e volume de negócios com base no tempo;

- Organização - ambiente interno e capacidades, a satisfação dos empregados, educação/formação, cultura corporativa, o ambiente externo e capacidades.

Com base em estudos realizados, Hsu e Wu (2006) desenvolveram um modelo com oito dimensões para avaliação do desempenho da terceirização de serviços de TI, a saber:

- Motivações para a terceirização de serviços de SI;

- $\quad$ Fatores chaves de sucesso para a terceirização de serviços de SI;

- Vantagens da terceirização de serviços de SI;

- Riscos da terceirização de serviços de SI;

- $\quad$ Fatores a serem considerados na tomada de decisões sobre terceirização;

- Índice de avaliação de desempenho para o departamento de informação;

- Índice de avaliação de desempenho para SI; e

- $\quad$ Índice de avaliação de desempenho para a organização. 
Vale destacar que a gestão do desempenho tem sido apresentada na literatura como um fator crítico de sucesso na terceirização de serviços de TI e dentro do contexto da avaliação de desempenho, o SLA tem sido indicado como uma importante ferramenta (KERN, 1997; GOO; KISHORE; RAO, 2004).

Corroborando essa questão, McFarlan e Nolan (1995, p. 12), enfatizam que "normas e controles, em geral, fortalecem o relacionamento, e assim contribuem para o resultado positivo da terceirização", enquanto que Alborz, Seddon e Scheepers (2004), salientam que "medir o desempenho fornece dados empíricos para medir o sucesso do relacionamento".

As decisões relativas à terceirização de serviços de TI "têm um impacto potencial relevante sobre os negócios de uma organização" e "nunca deveriam ser tomadas antes que ela tenha um plano estratégico consistente que detalhe sua visão, missão, competências e seus fatores chaves de sucesso" (SAAD, 2006, p. 12).

Outro ponto que merece destaque é a importância de uma estrutura de governança de TI dentro de um relacionamento de terceirização de serviços de TI. A gestão de uma relação eficaz com uma estrutura de governança de TI bem organizada é um relevante fator crítico de sucesso para atingir os benefícios esperados (CLARK; ZMUD; MCCRAY, 1995). Os verdadeiros fatores críticos de sucesso relacionados com o resultado da terceirização de serviços de TI, são "aqueles associados à governança de TI com o fornecedor do serviço" (ibid., p. 223).

Boa parte dos controles exercidos pela implantação de modelos de governança de TI objetivam confirmar as expectativas advindas sobre a capacidade de cumprimento das obrigações contratuais e do desempenho dos níveis de serviços acordados entre as partes.

Na concepção de Cuganesan, Rooney e Silvi (2006) os controles são:

Procedimentos formais de governança de TI que devem ser implantados por meio do controle de comportamento (planejamento; definição de regras; desenvolvimento de procedimentos operacionais padronizados; e procedimentos de resolução de disputas) e controles de resultado (resultados a serem alcançados; e monitoramento das metas de desempenho). (p. 12, parênteses dos autores).

Para Gellings (2007) as medidas e controles são essenciais para a construção e a sustentação de um relacionamento e devem ser acordados contratualmente. Em consonância com os 
autores, Alborz, Seddon e Scheepers (2004) ressaltam, da mesma forma, a importância da governança de TI para o sucesso global de um acordo de terceirização.

Por fim, os contratos de terceirização de serviços de TI - alinhados à governança de TI - são uma importante ferramenta para alinhar expectativas e estratégias, e contribuir desse modo, para o resultado da terceirização de serviços de TI.

Webb, Pollard e Ridley (2006) apresentam cinco aspectos que devem ser implementados em um contrato de terceirização a fim de formarem uma base para a governança de TI, sendo que esses aspectos determinam a qualidade de uma parceria de terceirização de TI e afetam diretamente o sucesso obtido. Tais aspectos indicam que a governança de TI deve incluir alinhamento estratégico, a entrega de valor ao negócio por meio da TI, gerenciamento de desempenho, gestão dos riscos e controle e responsabilidades.

O quadro 2 representa um resumo dos tópicos abordados no presente item, referindo-se aos resultados esperados com a terceirização de serviços de TI.

Quadro 2 - Resultados esperados com a terceirização de serviços de TI (continua)

\begin{tabular}{|c|c|c|}
\hline Tópicos & Conceitos & Autor(es) \\
\hline \multirow{8}{*}{$\begin{array}{l}\text { Melhoria no } \\
\text { Processo do } \\
\text { Negócio }\end{array}$} & Reduções de Custo & $\begin{array}{l}\text { Maisel (1992); Reponen (1993); Simons (1995); Hitt e } \\
\text { Brynjolfsson (1996); Kuo (1996);Lacity, Willcocks e } \\
\text { Feeny (1996); Lacity e Willcocks (1998); Hsu e Wu } \\
\text { (2006); Webb, Pollard e Ridley (2006); Gellings (2007) }\end{array}$ \\
\hline & $\begin{array}{l}\text { Segurança nos } \\
\text { Dados / } \\
\text { Informações }\end{array}$ & Kuo (1996) \\
\hline & $\begin{array}{l}\text { Integração dos } \\
\text { processos }\end{array}$ & $\begin{array}{l}\text { Kuo (1996);Webb, Pollard e Ridley (2006); Gellings } \\
\text { (2007) }\end{array}$ \\
\hline & $\begin{array}{l}\text { Foco no ponto } \\
\text { forte e estratégico } \\
\text { de atuação da } \\
\text { empresa }\end{array}$ & $\begin{array}{l}\text { OI (2006); Alborz, Seddon e Scheepers (2004); Webb, } \\
\text { Pollard e Ridley (2006) }\end{array}$ \\
\hline & $\begin{array}{c}\text { Flexibilidade nas } \\
\text { Tarefas } \\
\end{array}$ & $\begin{array}{l}\text { Lacity, Willcocks e Feeny (1996); Hsu e Wu (2006); } \\
\text { Gellings (2007) }\end{array}$ \\
\hline & $\begin{array}{l}\text { Resoluções - } \\
\text { Reduções de } \\
\text { Problemas }\end{array}$ & $\begin{array}{l}\text { Lacity, Willcocks e Feeny (1996); Lacity e Willcocks } \\
\text { (1998); Webb, Pollard e Ridley (2006); Hsu e Wu } \\
\text { (2006); Gellings (2007) }\end{array}$ \\
\hline & $\begin{array}{l}\text { Melhoria dos } \\
\text { Processos }\end{array}$ & Maisel (1992); Kuo (1996); Hsu e Wu (2006) \\
\hline & $\begin{array}{l}\text { Qualidade dos } \\
\text { Sistemas }\end{array}$ & $\begin{array}{l}\text { Maisel (1992); Kuo (1996); Lacity, Willcocks e Feeny } \\
\text { (1996); Lacity e Willcocks (1998); Hsu e Wu (2006) }\end{array}$ \\
\hline
\end{tabular}


Quadro 2 - Resultados esperados com a terceirização de serviços de TI (conclusão)

\begin{tabular}{|c|c|l|}
\hline Tópicos & Conceitos & \multicolumn{1}{|c|}{ Autor(es) } \\
\hline \multirow{4}{*}{ Satisfação } & Valores Orçados & Webb, Pollard e Ridley (2006); Hsu e Wu (2006) \\
\cline { 2 - 3 } & $\begin{array}{c}\text { Capacidade de } \\
\text { Processamento }\end{array}$ & Kuo (1996); Hsu e Wu (2006) \\
\cline { 2 - 3 } & $\begin{array}{c}\text { Realização das } \\
\text { Tarefas }\end{array}$ & Kuo (1996); Hsu e Wu (2006) \\
\cline { 2 - 4 } & $\begin{array}{c}\text { Qualidade das } \\
\text { Atividades }\end{array}$ & $\begin{array}{l}\text { Maisel (1992); Kuo (1996);Lacity, Willcocks e Feeny } \\
\text { (1996); Hsu e Wu (2006) }\end{array}$ \\
\cline { 2 - 4 } & $\begin{array}{c}\text { Qualidade da } \\
\text { Informação }\end{array}$ & Maisel (1992); Kuo (1996); Hsu e Wu (2006) \\
\cline { 2 - 3 } & Prazos & Webb, Pollard e Ridley (2006); Hsu e Wu (2006) \\
\hline
\end{tabular}

É importante observar que existe pouca literatura que trata isoladamente as informações sobre os resultados inerentes a terceirização de serviços de TI. Como em geral os resultados são visualizados dentro do contexto global da organização, torna-se mais complexa a identificação dos seus impactos isoladamente.

\subsection{Da governança corporativa à governança de tecnologia da informação}

Conscientes de uma nova realidade que influencia o comportamento das empresas, estas devem se reinventar para crescer em um ambiente altamente competitivo, de mercados instáveis e de mudanças implacáveis.

De acordo com Brown e Eisenhardt (1997, p. 48) "as líderes de mercado de hoje são aquelas empresas que encontram um equilíbrio entre o caos e a estabilidade, de modo que, permita o surgimento de uma estratégia à medida que a empresa se adapta a um ambiente de negócios imprevisível e rapidamente mutante".

Para que uma organização tenha maior agilidade operacional e resposta rápida e eficiente às demandas, é necessário que seja implantada a governança corporativa (GC), a fim de aprimorarem os quesitos de eficiência, segurança, produtividade, acuracidade e disponibilidade dos processos.

\subsubsection{Origem e histórico da governança corporativa}

O movimento GC deu-se nos Estados Unidos no início da década de 1990, em decorrência da necessidade de alguns administradores de fundos de pensão. Havia a necessidade de maior 
controle e segurança nas operações financeiras realizadas com os investimentos dos acionistas minoritários, pois lhes faltava orientações para a tomada de decisão em seus investimentos (LODI, 2000).

No Brasil, o termo "corporate governance" foi traduzido e a sua nomenclatura se incorporou ao cenário econômico como Governança Corporativa. A fim de estimular o debate sobre o tema e a adoção de práticas recomendadas, foi criado o Instituto Brasileiro de Conselheiros de Administração (IBCA) atual Instituto Brasileiro de Governança Corporativa (IBGC), no ano de 1995 (IBGC, 2009).

Em 1999, foi criado o primeiro Código Brasileiro sobre Governança Corporativa (CBGC), denominado "Código das Melhores Práticas de Governança Corporativa".

Em novembro de 2000, o IBGC realizou o $1^{\circ}$ Congresso Brasileiro de Governança Corporativa, com o intuito de divulgar os conceitos e práticas de governança. Em dezembro de 2000 a Bolsa de Valores de São Paulo (Bovespa) lançou oficialmente os segmentos diferenciados de governança corporativa (Nível 1, 2 e Novo Mercado) (IBGC, 2009).

No ano de 2001 a Bovespa criou o Índice de Governança Corporativa (IGC), com o objetivo de medir o desempenho de uma carteira composta por ações de empresas que apresentem bons níveis de governança corporativa.

Entre os anos de 2005 e 2006 o IBGC (Instituto Brasileiro de Geografia e Estatística) desenvolveu premiações nas instâncias acadêmicas, empresarial e imprensa para estimular o desenvolvimento e divulgação das práticas recomendadas de governança (IBGC, 2009).

A realização de uma boa governança corporativa é importante para os investidores, uma vez que grandes instituições atribuem à GC o mesmo peso que aos indicadores financeiros, quando da avaliação de decisões de investimento.

\subsubsection{Conceitos sobre governança corporativa}

O termo GC pode ser definido, segundo Rabelo e Silveira (1999, p. 5), como: “o sistema por meio do qual se exerce e se monitora o controle nas corporações”. Ainda segundo os autores, esse sistema está vinculado às características dos mercados de capitais, à legislação econômica, à estrutura de propriedade e às características do sistema financeiro. 
Segundo Wright, Kroll e Parnell (2000), o termo GC refere-se a um sistema de gestão ao qual são monitoradas, pelo conselho de administração, as estratégias da empresa a fim de garantir retorno para os acionistas e garantindo a administração, ou seja, tem como objetivo recuperar e garantir a confiabilidade em uma determinada empresa para os seus acionistas.

Para Carvalho (2002, p.19) é "o conjunto de mecanismos instituídos para fazer com que o controle atue de fato em benefício das partes com direitos legais sobre a empresa, minimizando o oportunismo." Lodi (2000) define como o sistema de relacionamento entre os acionistas, os auditores independentes, os executivos da empresa e os conselheiros de administração. O IBGC (2009) apresenta a seguinte definição para GC:

\begin{abstract}
Governança corporativa é o sistema que assegura aos sócios-proprietários o governo estratégico da empresa e a efetiva monitoração da diretoria executiva. A relação entre propriedade e gestão se dá por meio do conselho de administração, a auditoria independente e o conselho fiscal, instrumentos fundamentais para o exercício do controle. A boa governança corporativa garante eqüidade aos sócios, transparência e responsabilidade pelos resultados (accountability).
\end{abstract}

Weill e Ross (2004) defendem que os elementos essenciais para uma boa governança incorporam diversos elementos culturais das empresas e algumas crenças. Esses elementos são representados e definidos pela missão, objetivos, estratégia empresarial, declarações dos valores corporativos, sua estrutura e também por meio de diversos mecanismos organizacionais, sendo estes observados com maior frequência em empresas com uma performance melhor.

Os autores identificam seis ativos essenciais, sendo eles:

- Ativos financeiros: caixa, fluxo de caixa, contas a pagar, contas a receber e investimentos;

- Ativos físicos: fábricas, prédios, equipamentos, instalações, manutenções e segurança;

- Ativos de Propriedade Intelectual (PI): propriedade intelectual, know-how de produtos, serviços e de processos;

- Informação e ativos de tecnologia da informação: informações e conhecimento sobre clientes, dados digitalizados, desempenho de processos, dados financeiros e sistemas de informação; e 
- Ativos de relacionamento: relacionamentos externos bem como os internos, valor da marca no mercado e reputação junto aos clientes, fornecedores, competidores, parceiros de negócio e órgãos reguladores.

Gerenciar estes ativos requer receptividade por parte da direção e necessita, sobretudo, de elementos facilitadores na coleta, processamento e gerenciamento destas informações para amparar a tomada de decisão (WEILL; ROSS, 2004). Controlar e monitorar tais ativos não é tarefa simples e necessita de uma forte receptividade da direção da organização.

Sob tal perspectiva, dentre todos os ativos, destaca-se a informação e ativos de TI, uma vez que as informações disponibilizadas pela TI sustentarão a empresa, pois todos os controles, processos, procedimentos e métricas partirão de TI.

Corroborando com a ideia de que a governança de TI é derivada do conceito de GC, Mendes e Magalhães Filho (2005, p. 17), comparam GC com governança de TI da seguinte forma:

Governança corporativa refere-se às decisões de nível estratégico que orientam uma firma para o sucesso ou para a falência e Governança de Tecnologia de Informação (TI), por outro lado, refere-se ao processo de tomada de decisão em TI, incluindo decisões de investimento e priorização. Ambos os tipos de governança podem influenciar significativamente o desempenho da empresa.

\subsubsection{Origem e histórico da governança de tecnologia da informação}

Segundo a ISACA (2009), Information Systems Audit and Control Association, a origem do IT governance, ou governança de TI (GTI), deu-se juntamente com a TI, ou seja, surgiram pelas demandas de controle, transparência e previsibilidades das empresas.

O termo GTI foi citado pela primeira vez na literatura em 1991 por Venkatraman (LOH, 1993), definindo-a como uma ferramenta para governar os relacionamentos de negócios, por meio de um sistema baseado em TI.

Mansur (2009, p. 13) relata que a origem da GTI ocorreu:

Na década de 1990, quando questões relativas à qualidade ganharam uma enorme importância no cenário mundial, sendo vista com maior importância pelas empresas a partir do Bug do milênio e reforçada pela "Bolha" da internet, onde ficaram demonstrados os orçamentos inflados e as superestimativas de faturamento e lucros pelas empresas da nova economia. 
Apesar de ser um tema relativamente novo, o termo GTI apresenta algumas definições que foram sendo desenvolvidas e aprimoradas ao longo dos anos.

\subsubsection{Conceitos sobre governança de tecnologia da informação}

A TI tem sido utilizada como ferramenta para a melhoria no desempenho e nos processos da empresa. O termo GTI, do termo em inglês IT Governance, pode ser definido segundo Mansur (2007, p. 2), como a especificação dos direitos decisórios e do framework de responsabilidades para estimular comportamentos desejáveis na utilização de TI.

Weill e Ross (2004, p. 04) afirmam que a GTI consiste "em um ferramental para a especificação dos direitos de decisão e das responsabilidades, visando encorajar comportamentos desejáveis no uso da TI".

Segundo Gellings (2007, p. 222) "é a capacidade organizacional exercida pelo conselho de administração, gestão executiva e gestão da TI para formular, implementar e controlar estratégias de TI e desta forma assegurar o alinhamento entre negócios e a TI”.

Para abordar as preocupações de gestão que envolvem alinhar a estratégia de TI com a estratégia de negócios, estabelecer metas estratégicas para a empresa, fornecer estrutura organizacional que facilite a implementação das metas e estratégias, implementar estratégias de TI e medir seu desempenho, são necessárias medidas eficazes e oportunas que devem ser promovidas pela camada de GTI de uma empresa (ITGI, 2009). Cabe ressaltar que a aplicação efetiva de uma estrutura de GTI é de responsabilidade do conselho de administração e da gerência executiva.

De forma mais concisa, o ITGI (2009, p. 1) define GTI como "uma parte integrante da governança da empresa e consiste na liderança e estruturas organizacionais e processos que asseguram que a organização de TI sustente e estenda os objetivos das estratégias da organização". Fica evidente, após a apresentação de algumas definições de GTI, que as mesmas abordam a forma com que os recursos de TI são controlados e gerenciados (processos) e a forma concebida para a tomada de decisão de TI na organização (estrutura), buscando alinhar às estratégias corporativas com os investimentos realizados em TI. 


\subsubsection{Gestão da terceirização de serviços de tecnologia da informação sob o ponto de vista da governança de tecnologia da informação}

Um dos grandes desafios da terceirização de serviços de TI é construir alianças sustentáveis em longo prazo. A forte redução no custo da TI tem permitido aos sistemas computacionais migrarem para aplicações que oferecem significativa vantagem competitiva. Em muitos casos, a tecnologia criou uma oportunidade para as organizações repensarem suas estratégias. Como consequência, uma atenção cada vez maior vem sendo dada à construção de relacionamentos baseados em alianças estratégicas entre clientes e fornecedores de serviços de TI (MCFARLAN; NOLAN, 1995).

A construção de relacionamento tem o potencial de oferecer vantagem competitiva, mas também outras vantagens. Poppo e Lacity (2002), por exemplo, destacam que relacionamentos sociais entre o fornecedor e o cliente podem reduzir custos de transação. Para esses autores, quanto mais se investe em relacionamentos sociais, maior a satisfação da organização cliente e melhor o desempenho das atividades terceirizadas.

A celebração de um contrato consome esforço, tempo e recursos, pois um bom contrato é importante para o sucesso da terceirização (WILLCOCKS; LACITY, 1997). Entretanto, na visão de Klepper e Jones (1998), os contratos sozinhos não asseguram o sucesso da terceirização. Um bom gerenciamento da relação de terceirização é o que a organização precisa para garantir que o contrato de terceirização irá agregar valor ao negócio.

Para Smith, Smith e Stringer (2000) poucas pesquisas têm sido conduzidas para identificar as questões relevantes no gerenciamento da terceirização da TI. Uma pesquisa conduzida por Bergamaschi (2004), propôs um modelo de gestão da terceirização da TI, baseado em quatro conceitos: relacionamento, confiança, contratos e gerenciamento de nível de serviço. Este autor também classificou os diversos modos de gerenciamento da terceirização da TI em cinco categorias: contrato padronizado, contrato personalizado, remuneração por desempenho, compartilhamento de riscos e relacionamento de confiança.

A organização cliente deve ser representada por um gerente de relacionamento. Este deve ser ativo no monitoramento e na avaliação do desempenho, para construir um relacionamento sólido (GREAVER II, 1999). Algumas estratégias para a realização de um bom 
gerenciamento do relacionamento incluem:

- Conselho de supervisão - Os executivos aos quais se reportam o gerente de relacionamento e o gerente de contas (fornecedor) são os responsáveis pelo bom desempenho de cada parte. É salutar que esses indivíduos formem um grupo e ajam como um conselho de supervisão;

- Reuniões - Os gerentes de relacionamento e de contas devem se reunir semanalmente ou pelo menos uma vez por mês. Essas reuniões devem ocorrer antes da reunião do conselho e a participação de membros dos dois grupos de trabalho (cliente e fornecedor) é importante pois ajuda a desenvolver o espírito de equipe e a concordância entre os membros;

- Relatórios - Um sistema de comunicar informações de desempenho necessita ser desenvolvido. Os relatórios precisam conter o desempenho atual, o padrão e a diferença entre eles, e os membros da equipe devem saber o que é aceitável ou não.

No entendimento de Moraes e Mariano (2008) a TI não deve ser observada apenas como um elemento infraestrutural (hardware, software, redes e banco de dados), mas sim como uma forma de relacionar e aumentar os controles, aperfeiçoando as informações obtidas, melhorando a integração e qualidade das informações a fim de suprir as necessidades competitivas das organizações.

A partir dos modelos de GTI disponíveis no mercado, é possível relacionar algumas práticas de gestão, como verificação e revisão dos serviços disponibilizados (quais os serviços terceirizados); quais devem retornar (backsourcing) e quais ainda podem ser terceirizados (outsourcing), negociações com fornecedores e clientes (cotações, negociações, acordos), elaboração e ou revisão dos contratos; desenvolvimento e acompanhamento dos acordos de níveis de serviços; desenvolvimento e acompanhamento das políticas e processos de melhorias; estabelecimento das prioridades; gerenciamento financeiro (projeção de recursos e demandas); gerenciamento dos recursos humanos (aquisição e capacitação); gerenciamento da continuidade (validação dos planos de contingência e recuperação dos serviços após a ocorrência de um acidente); gerenciamento das disponibilidades (determinar os níveis de disponibilidades dos serviços de TI realizados); gerenciamento dos incidentes (tratamentos e resoluções visando o restabelecimento dos serviços); gerenciamento dos problemas (resolução final sobre as falhas relacionadas aos incidentes); gerenciamento de configurações (controlar e 
gerenciar os seus meios de produção); e gerenciamento de mudanças (assegurar que todas as mudanças necessárias e apontadas no gerenciamento de configurações sejam realizadas conforme o planejamento) (FERNANDES; ABREU, 2008; ITGI, 2009; MANSUR, 2009).

Esse elenco de práticas, por sua vez, não necessariamente precisa ser utilizado na sua totalidade ou da mesma forma pelas organizações; uma série de características da própria empresa ou negócio de atuação pode exigir diferentes configurações, evidenciando a complexidade na determinação dos mecanismos mais indicados a serem adotados.

Diferentes mecanismos e práticas procuram facilitar a implementação da GTI, levando em consideração a estrutura envolvendo as decisões de TI, os processos e as habilidades de relacionamento para direcionar e coordenar diferentes atividades associadas ao planejamento, à organização e ao controle da TI.

É oportuno observar que os argumentos apresentados encontram sustentação na teoria da agência, em função da análise dos conflitos entre o principal e o agente. "É como um contrato sob o qual uma ou mais pessoas (agente principal) contrata os serviços de outra pessoa (o agente) para executar algum serviço de seu interesse que envolva delegar autoridade de decisão para o agente” (JENSEN; MECKLING, 1976, p. 308, parênteses dos autores).

Dessa forma, tem-se uma situação em que as motivações e os interesses entre agente principal (proprietários) e agentes (administradores) envolvidos no relacionamento da organização, podem estar convergidos ou divergidos. Havendo convergência de interesses e motivações, "ambos estarão alinhados e envolvidos em objetivos e motivações comuns", porém, havendo divergência de interesses e motivações, "surgirão os conflitos que precisam ser regulados e/ou controlados de alguma forma pelo agente principal” (ibid., p. 317).

No relacionamento da agência, o agente principal e o agente irão incorrer em custos de monitoramento e de vínculo, bem como conviver com divergências em algumas decisões do agente. Os custos de monitoramento são os custos da agência, definidos como aqueles necessários para alinhar os interesses do agente com os interesses do agente principal (ibid.).

É possível inferir, em princípio, que toda relação de agência busca eficiência, uma vez que o agente principal, por não possuir as competências necessárias, designa ao agente a tarefa de gerenciamento de recursos e execução das atividades; entretanto, conforme ressaltam Jensen e 
Meckling (1976, p. 308), "Se ambas as partes do relacionamento forem maximizadores, existe boa razão para acreditar que o agente nem sempre agirá na direção dos melhores interesses do agente principal”.

Sendo assim, várias pesquisas (SANTOS; KELM; ABREU, 2001; PRADO, 2005; PELANDA, 2006; ARRUDA et al., 2008; CANTÓN, 2008; ABREU, 2009) apontam as práticas da teoria da agência como um conjunto de atividades voltadas para a gestão, regulação e controle das relações entre as partes envolvidas com a "firma", visando a eficiência dos recursos alocados e a minimização dos seus custos de agência.

Sob o ponto de vista da terceirização de serviços de TI, o foco da teoria da agência está na determinação de um contrato mais eficiente, orientado ao comportamento ou ao resultado (PRADO, 2005), ou ainda, como controles mais rígidos e transparentes do fluxo de informações, que é uma das propostas das práticas de GTI (RABELO; SILVEIRA, 1999; PELANDA, 2006).

\subsubsection{Modelos de práticas recomendadas no contexto da governança de tecnologia da informação}

Desde a década de 1990 diversos modelos de GTI vem surgindo, e alguns desses modelos são originais e outros são elaborados por meio de evoluções de modelos já existentes (MANSUR, 2009). O foco internacional sobre a GTI gerou uma proliferação de normas locais e internacionais para a gestão da TI em geral e de segurança de TI (BROWN, 2006).

Segundo Mansur (2009, p. 37) os modelos de GTI "englobam técnicas de análise, metodologias, tecnologias, ferramentas e um processo decisório de TI sustentado por uma estrutura organizacional".

Para que a estratégia e a organização da empresa tenham uma GTI eficaz, "são necessárias harmonizações referentes aos arranjos de governança de TI por meio das decisões de TI sobre princípios; arquitetura; infraestrutura; aplicações; e investimentos, além das metas de desempenho do negócio e mecanismos de governança” (WEILL; ROSS, 2006 p. 153).

De acordo com Fernandes e Abreu (2006) "Os modelos de melhores práticas auxiliam a implantação da Governança de TI; entretanto, dentro destes modelos, existem 'gaps' a serem 
resolvidos. Estes 'gaps' encontram-se no alinhamento estratégico e na decisão, compromisso, priorização e alocação de recursos.” (p. 165, grifos dos autores).

Mingay e Bittinger (2002) evidenciam que apesar dos modelos terem focos diferentes, eles não são mutuamente excludentes e podem ser combinados para prover um melhor gerenciamento da tecnologia, garantindo não só o suporte tecnológico necessário, para que a organização atinja seus objetivos estratégicos com qualidade e preço competitivo, mas também a satisfação dos seus clientes.

A combinação de vários modelos pode ser chamada de "mix de gestão". Para muitas empresas a adoção de um desses modelos pode não ser suficiente. A melhor opção seria a combinação de mais de um modelo (RUBIN, 2004).

Os modelos de GTI podem ser subdivididos em algumas áreas de atuação, onde cada modelo apresenta seu core de práticas. Com base nos modelos apresentados por Fernandes e Abreu (2006) é possível agrupar os modelos de práticas recomendadas em cinco áreas:

- Modelos relacionados a projetos (CMMI; PMBOK; PRINCE2; RUP; MSF; ISO/IEC 12207; ISO 9001; e ISO/IEC 9126);

- Aos serviços de TI (ITIL; ISO/IEC 20000; MOF; SUN TONE; e HP ITSM);

- A terceiros (SCM-SP; e SAS 70);

- A desempenho e melhoria (BSC; e SEIS SIGMA); e

- A segurança da informação (ISO/IEC 27001; ISO/IEC 17799; e ISO/IEC 15408).

Durante a revisão bibliográfica foi constatado que outros autores classificam os modelos de forma muito semelhante. Bon e Verheijen (2006) apresentam os agrupamentos de modelos de GTI categorizados por modelos relacionados à:

- Gestão da qualidade (TQM; ISO 9000; TickIT; ISO/IEC 12207; e ISO/IEC 20000);

- Gerenciamento da melhoria (ITS-CMM; Six Sigma; eSCM-SP; e BSC);

- Governança de TI (AS 8015 e Cobit);

- Gerenciamento da informação (Generic Framework; BiSL; ISPL; ITIL; eTOM; e ASL); e

- Gerenciamento do projeto (MSP; PRINCE2; PMBoK; e IPMA). 
No âmbito da auditoria de TI, ou seja, a gestão da TI, segurança, planejamento de continuidade dos negócios e do processo de auditoria em si, algumas normas táticas descrevem os processos e procedimentos, sendo apresentadas por Oud (2005), como:

- Gerenciamento de TI (BS 15000; COBIT; MOF; e ITIL);

- Gerenciamento de projetos (PMBoK; Prince2; e MAP);

- Gestão de segurança (ISO 13335; ISO 13569; ISO 17799; BS 7799-2; Padrões NIST; Baseline Protection Manual; ACSI-33; COBIT Baseline Security; ENV12924; e ISF Norma de Boas Práticas);

- Desenvolvimento de Software/aquisição de melhoria de processos (ISO 12207; ISO 15504; TickIT; CMMI; e Bootstrap);

- Gestão da qualidade (ISO 9001; EFQM; e Baldrige National Quality Plan);

- Governança de TI (COSO Internal Control-Integrated Framework; Norma australiana AS 8015; COBIT; e Guia de Implementação de Governança de TI);

- Gestão de risco (AS / NZS 4360; e COSO Enterprise Risk Management);

- Gestão de continuidade do negócio (PAS-56 - British Standards Institution; e AS / NZS 4360 e HB 221-2004 (Handbook 221); e

- Auditoria (ISO 19011; e COBIT).

Larsen, Pedersen e Andersen (2006, p. 5) apresentam uma classificação das ferramentas de GTI por meio de tipos de processos, sendo eles:

- Processos de tomada de decisão (SAS70; e COBIT);

- Processos de núcleo de negócio - core business (ITIL; CMM; CMMI; Six Sigma; BS15000; IT Audut; e IT Due Diligence); e

- Processos de suporte (ISO 17799; ASL; BS7799; PRINCE2; e SysTrust).

Frente às considerações apresentadas, como estratégia nesta pesquisa, foram identificados inicialmente 37 modelos de governança, os quais necessitaram ser analisados, a fim de verificar uma possível aderência entre esses modelos e as práticas de gestão da terceirização de serviços de TI, que é o foco deste estudo. 
Para tanto, inicialmente foi realizada uma taxonomia dos modelos de governança relacionados à TI. Segundo Gregio et al. (2005, p. 2) a taxonomia pode ser definida como "o processo científico (ou um sistema particular) de categorizar entidades, ou seja, organizá-las em grupos".

Os modelos identificados nesta fase, segundo a revisão bibliográfica realizada, foram agrupados em seis categorias, a saber:

a) Modelos de Gestão da Qualidade: BSC - Balanced Scorecard; CMMI - Capability Maturity Model Integration; EFQM - The European Foundation of Quality Management Model; Modelos ISO - International Organization for Standardisation; ISO 9000 - Standard on Total Quality Management; ITS-CMM - The IT Service Capability Maturity Model; MOF - Microsoft Operations Framework; MSP Managing Successful Programmes; P3M3 - Portfolio, Programme \& Project Management Maturity Model; Seis Sigma - Six Sigma; TickIT - Software Quality Management; TQM - Total Quality Management.

b) Modelos de Gestão dos Projetos: ICB - IPMA - Competence Baseline; OPM3 Organizational Project Management Maturity Model; PMBoK - Project Management Body of Knowledge; e PRINCE2 - Projects IN Controlled Environments.

c) Modelos de Segurança da Informação: BS 7799 - British Standard 7799; ISO/IEC 17799 - International Standard for Information Security Management; ISO/IEC 27001 - Information Security Management Systems; e ISO/IEC 27002 - Information Security Management Systems.

d) Modelo de Risco: M_o_R - Management of Risk.

e) Modelo de Call Center: COPC2000 - Customer Operations Performance Center.

f) Modelos de Governança de TI: AS 8015-2005 - Australian Standard for Corporate Governance of IT; ASL - Application Services Library; BiSL - Business Information Services Library; COBIT - Control Objectives for Information and Related Technology; eSCM-CL - The eSourcing Capability Model for Client Organization; eSCM-SP v2- The eSourcing Capability Model for Service Providers; eTOM - The 
Enhanced Telecom Operations Map; Generic Framework for Information Management; ISO/IEC 20000 - Standard on IT service management; ISO / IEC 38500 - Corporate Governance of Information Technology; ISPL - The Information Services Procurement Library; ITIL - Information Technology Infrastructure Library; SAS 70 - Statement on Auditing Standards for Services Organizations; TOGAF - The Open Group Architecture Framework; e Val IT - Value IT.

A fim de proporcionar um entendimento básico sobre cada um dos 37 modelos de governança, são apresentadas a seguir algumas características e suas definições.

AS 8015-2005 - Australian Standard for Corporate Governance of IT: o padrão AS 80152005 foi publicado em janeiro de 2005 pela Australian Standard for Corporate Governance of Information and Communication Technology (ICT) e criada no âmbito do estouro da bolha “dot.com”. Essa norma estabelece princípios orientadores para a administração das organizações (incluindo os proprietários, conselheiros, diretores, sócios, executivos seniores, ou similares) sobre a aplicação eficaz, eficiente e de uso aceitável de TIC na organização. A norma se aplica à gestão dos recursos, baseados em computador ou não, utilizados para a prestação de serviços de informação e comunicação para uma organização. Esses recursos poderiam ser fornecidos por especialistas em TIC, dentro da organização ou de prestadores de serviços externos, bem como por unidades de negócios dentro da organização.

Segundo Bon e Verheijen (2006, p. 97), essa norma é aplicável a todas as organizações, incluindo empresas públicas e privadas, entidades governamentais e sem fins-lucrativos. A norma é aplicável a organizações de todos os tamanhos do menor ao maior, independentemente do seu grau de utilização das TIC.

ASL - Application Services Library: desenvolvido no final dos anos 90 pela PinkRoccade para complementar os livros do ITIL, o ASL teve sua primeira versão lançada em 2002 pela antiga ASL Foundation (agora chamada ASL BiSL Foundation), através de uma abordagem de domínio público como uma estrutura para gerenciamento de aplicações (ASL, 2009; MANSUR, 2009).

Essa estrutura foi criada com base nas práticas recomendadas para desenvolvimento, manutenção e gerenciamento de aplicações e sua estrutura tem sido utilizada pelo mercado 
para melhorar a performance das aplicações de negócio (HOLM; KÜHN; VIBORG, 2006; MANSUR, 2009).

Segundo a ASL (2009), em maio de 2009 foi lançada na Holanda uma nova versão da ASL intitulada ASL2. Para Bon e Verheijen (2006, p. 172) o ASL pode ser resumido da seguinte forma: consiste em aplicação de gestão de processos, define processos e papéis, descreve as relações entre os processos, pode ser usado em todas as variantes do gerenciamento de aplicativos, e é independente do tipo de organização em que é utilizado.

BiSL - Business Information Services Library: segundo Bon e Verheijen (2006, p. 134) e ASL (2009), a BiSL foi criada em 1998 com o intuito de abranger a relação entre as empresas, infraestrutura e aplicações. Originalmente desenvolvido pela PinkRoccade, foi dado para o domínio público na Holanda em fevereiro de 2005. Esse framework fornece orientações para os processos e atividades que são necessárias para uma estrutura adequada de informação dentro das organizações.

Para Mansur (2009, p. 296) o BiSL:

\footnotetext{
É um modelo novo com foco principal no processo de avaliação da demanda da automação administrativa do negócio, que aborda os seguintes aspectos de tecnologia de informações e comunicações: gerenciamento das informações; gerenciamento da demanda; suporte ao usuário final; definição de novos requisitos para as funcionalidades; e gerenciamento das mudanças dos sistemas de informações.
}

BSC - Balanced Scorecard: estudo patrocinado pelo Instituto Nolan Norton - unidade de pesquisa da KPMG, no qual foi concluído no mês de dezembro de 1990 e lançado oficialmente em janeiro de 1992 por meio de um artigo intitulado "Measures That Drive Performance" pela Harvard Business Review, o Balanced Scorecard, objetivou a tradução da missão e estratégia das empresas em um conjunto abrangente de medidas de desempenho que serve de base para um sistema de medição e gestão estratégica (KAPLAN e NORTON, 1997, p. 02).

Ainda para Kaplan e Norton (1997, p. 25) o Balanced Scorecard "reflete o equilíbrio entre objetivos de curto e longo prazo, entre medidas financeiras e não financeiras, entre indicadores de tendências e ocorrências e, ainda, entre as perspectivas interna e externa de desempenho". 
Segundo Fernandes e Abreu (2008, p. 367) é possível destacar alguns objetivos do BSC: traduzir a estratégia da empresa em termos operacionais, alinhar a organização à estratégia, transformar a estratégia em tarefas de todos, converter a estratégia em processo contínuo, e mobilizar a mudança por meio da liderança executiva.

O Balanced Scorecard e o Mapa Estratégico constituem-se em uma importante ferramenta para realizar o alinhamento da TI ao negócio, bem como para desdobrar os objetivos estratégicos de TI em iniciativas que realmente contribuam para o atendimento dos objetivos estabelecidos (ibid., p. 370). Ainda para os autores, o Balanced Scorecard em tecnologia da informação deve ser utilizado no decurso do planejamento da TI, assim como na gestão do dia a dia da realização da estratégia de TI.

A tradução da missão e estratégias em objetivos e medidas foi organizada em quatro perspectivas diferentes: financeira, do cliente, dos processos internos e do aprendizado e crescimento (KAPLAN E NORTON, 1997, p.25).

BS 7799 - British Standard 7799: padrão de segurança britânico, o British Standard 7799 foi lançado ao mercado em 1995 na Inglaterra pela British Standards Institution (BSI) conhecida também como BSI Group. Esse grupo é responsável pela produção e publicação de padrões britânicos e de representação de interesses do Reino Unido em normas internacionais e europeias de organizações como o International Organization for Standardization (ISO), International Electrotechnical Commission (IEC), European Committee for Standardization (CEN), European Committee for Electrotechnical Standardization (CENELEC) e European Telecommunications Standards Institute (ETSI) (BSI, 2009).

No ano de 1996, a BS 7799 foi proposta ao International Organization for Standardization para homologação, mas foi rejeitada. Em função de tal rejeição, foi criada uma segunda parte desse documento e em 1998 foi publicado como BS 7799-2:1998 e, após revisão, em abril de 1999 foi publicado novamente junto com a primeira parte como BS 7799:1999 (CALDER, 2002, p. 67).

No referencial teórico de Mansur (2009, p. 134) o BS 7799 é dividido em duas partes, sendo a primeira parte "o código da prática para a segurança das informações contendo dez seções e controles chaves para a criação da estrutura de segurança das informações.” A segunda parte, 
chamada de "base para certificação" contém cem controles "que foram detalhados e ajustados conforme os objetivos e os controles da primeira parte."

Fernandes e Abreu (2008, p. 351), conceituam a primeira parte - BS 7799-1 - como "a parte da norma que contém introdução, definição de extensões e condições principais de uso". Essa é planejada como um documento de referência para implementar as 148 "boas práticas" de segurança na empresa, divididas em dez partes distintas: planejamento da continuidade dos negócios; controle de acesso aos sistemas; manutenção e desenvolvimento dos sistemas; segurança física e do ambiente; conformidade legal; segurança pessoal; segurança da organização; segurança da rede e dos computadores; controle e classificação dos bens; e políticas de segurança.

\section{Evolução do processo de normas e padrões de segurança da informação}

Para reforçar o entendimento do processo de Normas e Padrões de Segurança da Informação, conforme apresentado na ilustração 1 a seguir, ressalta-se que da norma BS 7799:1 do ano de 1995, evoluiu-se para o modelo BS 7799:2 do ano de 1998. O modelo BS 7799:1 culminou na publicação da norma ISO / IEC 17799 em 2000, a qual possui uma versão aplicada aos países de língua portuguesa, denominada (NBR ISO / IEC 17799:2001) e que agora foi substituída pela ISO / IEC 27002 de 2006. Já o modelo BS 7799:2 foi substituído pela ISO / IEC 27001 em 2005 que por sua vez possui uma versão aplicada aos países de língua portuguesa, denominada (NBR ISO / IEC 27001:2006) (MARTINS E SANTOS, 2005, p. 123; FERNANDES E ABREU, 2008, p. 351; MANSUR, 2009, p. 135).

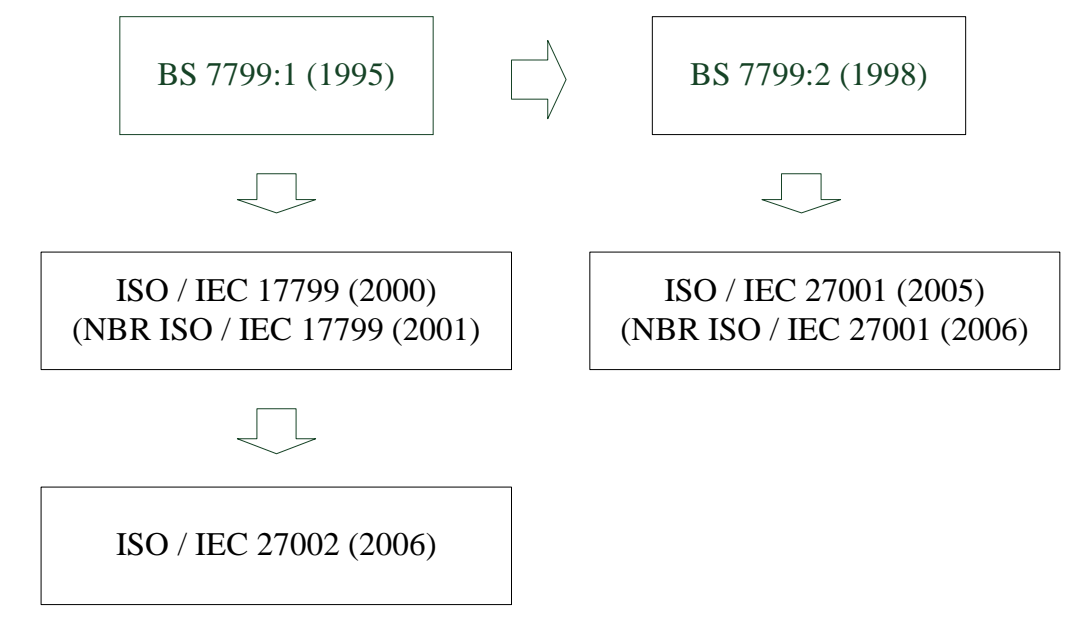

Ilustração 1 - Evolução do processo de normas e padrões de segurança da informação 
ISO/IEC 17799 - International Standard for Information Security Management: modelo que substituiu a norma BS 7799:1 em 2000 surgiu no Commercial Computer Security Center (CCSC) do Department of Trade and Industry (FERNANDES E ABREU, 2008, p. 351). Também conhecido como modelo de tecnologia da informação - Código de prática para a gestão da segurança da informação, no mês de junho do ano de 2005, foi revisado e a partir de julho de 2007 e renomeado para ISO / IEC 27002 (MARTINS E SANTOS, 2005, p. 123). O seu conceito, segundo a norma ISO/IEC 17799, é a proteção contra um grande número de ameaças às informações, de forma a assegurar a continuidade do negócio, minimizando danos comerciais e maximizando o retorno de possibilidades e investimentos.

De acordo com a ISO (2009) a norma ISO/IEC 17799 contém onze seções de controles de segurança da informação e juntas totalizam trinta e nove categorias principais de segurança e uma seção introdutória que aborda a análise/avaliação e o tratamento de riscos sendo que a norma possui cento e trinta e sete práticas no total.

\section{Evolução da família ISO / IEC 27000}

Para um entendimento mais refinado sobre as normas que envolvem a ISO/IEC 27000, segue um breve histórico, de acordo com a ISO (2009), cujas normas referem-se a:

- ISO/IEC 27000 - Tecnologia da informação - Técnicas de segurança - Sistemas de Gestão da Segurança da Informação - Visão geral - Vocabulário;

- ISO/IEC 27001 - SGSI - Tecnologia da informação - Técnicas de segurança Sistemas de Gestão da Segurança da Informação - Requisitos;

- ISO/IEC 27002 - SGSI - Tecnologia da informação - Técnicas de segurança Sistemas de Gestão da Segurança da Informação - Código de Práticas para Gestão de Segurança da Informação;

- ISO/IEC 27003 - Tecnologia da informação - Técnicas de segurança - Guia de implementação do SGSI (em desenvolvimento);

- ISO/IEC 27004 - Tecnologia da informação - Técnicas de segurança - Gestão de Medição (em desenvolvimento);

- ISO/IEC 27005 - Tecnologia da informação - Técnicas de segurança - Informações de Gestão de Riscos de Segurança; 
- ISO/IEC 27006 - Tecnologia da informação - Técnicas de Segurança - Requisitos para Organismos que prestem Serviços de Auditoria e Certificação de Sistemas de Informação de Gestão da Segurança;

- ISO / IEC 27007 - Tecnologia da informação - Técnicas de Segurança - Diretrizes para Auditoria de Sistemas de Gestão de Segurança da Informação (em desenvolvimento).

ISO/IEC 27001 - Information Security Management Systems: segundo Fernandes e Abreu (2008, p. 352) a ISO IEC 27001 "foi preparada para prover um modelo para estabelecer, implantar, operar, monitorar, rever, manter e melhorar um Sistema de Gestão da Segurança da Informação (ISMS)”, “...sendo que se pode utilizar visando a avaliação da conformidade por partes interessadas internas e externas".

A norma ISO/IEC 27001 foi baseada na BS 7799-2:2002 e especifica os requisitos para estabelecer, implementar e documentar Sistemas de Gestão da Segurança da Informação (SGSI). Especifica ainda exigências para controles de segurança a serem implementados de acordo com as necessidades individuais de organizações. Contém onze seções de controle, trinta e nove objetivos e cento e trinta e três controles (BON E VERHEIJEN, 2006, p. 43).

Para Bon e Verheijen (2006, p. 37) a norma utiliza o conhecido PDCA (Plan; Do; Check; and $A c t$ ), abordagem que também é utilizada nas normas ISO 9001 e ISO 22000, por exemplo. Esse ciclo (PDCA) também é conhecido como ciclo de Deming, que é aplicado na estrutura de todos os processos de ISMS (FERNANDES E ABREU, 2008, p. 353).

ISO/IEC 27002 - Information Security Management Systems: de acordo com Fernandes e Abreu (2008, p. 357) a ISO IEC 27002 é um conjunto de práticas elaborado para ser utilizado como uma referência para os responsáveis pela segurança da informação nas organizações.

Segundo a própria norma ABNT NBR ISO/IEC 27002 o conceito é que "estabelece diretrizes e princípios para iniciar, implementar, manter e melhorar a gestão de segurança da informação em uma organização”.

Ainda para os autores norma ISO/IEC 27001 foi baseada na BS 17799:2000. Cada uma das seções é constituída por categorias de segurança da informação, sendo que cada categoria tem 
um objetivo de controle definido, um ou mais controles que podem ser aplicados para atender ao objetivo de controle, as descrições dos controles, as diretrizes de implementação e informações adicionais (ibid., p. 358).

A ABNT NBR ISO/IEC 27002 estabelece os seguintes controles: política de segurança da informação; organizando a segurança da informação; gestão de ativos; segurança em recursos humanos; segurança física e do ambiente; gestão das operações e comunicações; controle de acesso; aquisição, desenvolvimento e manutenção de sistemas de informação; gestão de incidentes de segurança da informação; gestão da continuidade do negócio; e conformidade.

COBIT - Control Objectives for Information and Related Technology: é um guia para a gestão da TI, formulado em framework e recomendado pelo ISACA (Information Systems Audit and Control Foundation). O CObIT é um conjunto de diretrizes baseadas em auditoria para processos, práticas e controles de TI, voltado para a redução de risco, enfocando integridade, confiabilidade e segurança. (FERNANDES e ABREU, 2008, p. 174).

O principal objetivo das práticas do CObIT é contribuir para o sucesso da entrega de produtos e serviços de TI, a partir da perspectiva das necessidades do negócio (ibid., p. 175)

De acordo com o ITGI (2007) o CObIT estabelece relacionamentos com os requisitos do negócios; organiza as atividades de TI em um modelo de processos genérico; identifica os principais recursos de TI, nos quais deve haver mais investimento; e define os objetivos de controle que devem ser considerados para a gestão.

Criado em 1994 pela Information Systems Audit and Control Foundation - ISACF (ISACF, 2009), ligado à Information Systems Audit and Control Association - ISACA a partir do seu conjunto inicial de objetivos de controle. Em 1998, foi publicada sua $2^{a}$ edição com melhorias nos objetivos de controle, ferramentas e padrões para implementação. Em 2000, a $3^{\text {a }}$ edição foi lançada com o objetivo de promover melhores entendimentos sobre GTI. 2005 foi o ano do lançamento da $4^{\mathrm{a}}$ edição que priorizou o alinhamento com outros modelos de governança, a saber: ITIL, COSO e ISO/IEC. A última versão, 4.1, foi lançada em 2005 e teve como evolução o oferecimento de orientações com maior eficácia dos objetivos de controle e dos processos de verificação e divulgação dos resultados (FERNANDES; ABREU, 2008; ISACA, 2009). 
Segundo Mansur (2009, p. 304), o modelo CObIT utiliza como matriz o ciclo tradicional de melhoria contínua PDCA (Planejar, Construir, Executar e Monitorar), possuindo quatro domínios e trinta e quatro processos, a saber:

- Planejamento e Organização (PO) - refere-se às estratégias e táticas adotadas, considerando os processos para alcance das metas de negócios estipuladas definindo as questões estratégicas ligadas ao uso da TI. Seus processos são: PO1 - Definir o Plano de Alinhamento Estratégico de TI; PO2 - Definir a Arquitetura da Informação; PO3 - Determinar a Direção Tecnológica; PO4 - Definir os Processos de TI, Organização e Relações; PO5 - Gerenciar o Investimento em TI; PO6 - Comunicar Objetivos Gerenciais e Direção; PO7 - Gerenciar os Recursos Humanos relacionados à TI; PO8 - Gerenciar a Qualidade; PO9 - Gerenciar e Avaliar os Riscos de TI; e PO10 - Gerenciar Projetos.

- Aquisição e Implementação (AI): define questões de implementação da TI conforme o planejamento estratégico e dos projeto pré-definidos no plano estratégico de informática da empresa. Refere-se ainda à identificação, desenvolvimento ou aquisição de soluções para a realização da estratégia de TI, assim como sua implementação e integração aos processos de negócios. Seus processos são: AI1 Identificar Soluções Automatizadas; AI2 - Adquirir e Manter Softwares Aplicativos; AI3 - Adquirir e Manter Infraestrutura Tecnológica; AI4 - Promover Operação e Utilização da TI; AI5 - Obter Recursos de TI; AI6 - Gerenciar Mudanças; e AI7 Instalar e Garantir Soluções e Mudanças.

- Entrega e Suporte (DS): define questões operacionais ligadas ao uso da tecnologia, ou seja, cobre a entrega dos serviços requeridos, incluindo suporte aos serviços para os usuários, gerenciamento de segurança, gestão da infraestrutura operacional e gestão dos dados. Seus processos são: DS1 - Definir e Gerenciar Níveis de Serviço; DS2 Gerenciar Serviços de Terceiros; DS3 - Gerenciar Desempenho e Capacidade; DS4 Gerenciar a Continuidade dos Serviços; DS5 - Garantir Segurança de Sistemas; DS6 Identificar e Alocar Custos; DS7 - Educar e Treinar Usuários; DS8 - Gerenciar Central de Serviços e Incidentes; DS9 - Gerenciar a Configuração; DS10 - Gerenciar Problemas; DS11 - Gerenciar Dados; DS12 - Gerenciar o Ambiente Físico; e DS13 Gerenciar Operações. 
- Monitorar e Avaliar (ME): Os processos desse domínio asseguram a qualidade dos processos de TI assim como a sua conformidade com os objetivos de controle por meio de acompanhamentos regulares. Seus processos são: ME1 - Monitorar e Avaliar o Desempenho de TI; ME2 - Monitorar e Avaliar Controles Internos; ME3 Assegurar Conformidade com a Regulamentação; ME4 - Provisionar Governança de TI.

Segundo Mansur (2009, p. 306) os principais requisitos do modelo CObIT para as informações são:

- Eficácia - Gerencia a relevância da informação e pertinência aos processos de negócio bem como a sua disponibilidade em prazo apropriado, de forma correta, precisa, consistente e em formato adequado para utilização;

- Eficiência - Refere-se à provisão da informação através da melhor (mais produtiva e econômica) forma de utilização dos recursos;

- Confidencialidade - Associa-se à proteção da informação considerada privilegiada contra divulgação não autorizada;

- Integridade - Relaciona-se com a precisão e exatidão da informação, bem como sua validade de acordo com os padrões e expectativas de negócio estabelecidos;

- Disponibilidade - Provê a informação no momento em que essa for requerida pelos processos de negócio, o que inclui também a salvaguarda dos recursos;

- Conformidade - Cumpre leis, regulamentos e cláusulas contratuais aos quais um determinado processo de negócio está sujeito; e

- Confiabilidade - Relaciona-se ao fornecimento, por parte dos sistemas, de informações apropriadas aos gerentes para a tomada de decisões, relatórios financeiros precisos e informações adequadas aos órgãos de regulamentação para o cumprimento das leis, sendo que cada domínio abrange um conjunto de processos a fim de garantir a gestão da TI (Sistemas Aplicativos - soma de procedimentos manuais e automatizados; Informação - objetos de dados na sua mais abrangente concepção, isto é, estruturados, não estruturados, gráficos, sons etc; Infraestrutura - hardware, sistemas operacionais, gerenciadores de banco de dados, redes, multimídia, recursos para abrigar e suportar os sistemas de informação etc.; e Pessoas - qualificações, conscientização, produtividade e capacidade para planejar, organizar, adquirir, 
entregar, suportar e monitorar sistemas e serviços). Os Domínios englobam os conjuntos de processos relacionados à gestão ou ao ciclo de vida de TI e os Processos englobam os conjuntos de atividades/tarefas de controle.

Bon e Verheijen (2006, p.109) e Mansur (2009, p. 310) consideram que o CObIT se baseia na harmonização de padrões existentes de TI do mercado e em suas respectivas práticas recomendadas, e que foi projetado para complementar uma implementação de governança em TI junto a outro padrão ou a um conjunto de boas práticas.

\section{COPC2000 - Customer Operations Performance Center Standard on Call Center}

Operations: para a Customer Operations Performance Center Incorporated, também conhecida como COPC Inc., o COPC-2000 ${ }^{\circledR}$ PSIC foi desenvolvido em 1996 por um grupo de usuários de serviços de call center que se uniram para elaborar o primeiro padrão para medir o desempenho dos clientes de contact center para os prestadores de serviço ao cliente. A norma elaborada em 1996 se tornou a primeira edição da COPC-2000 CSP Standard.

Segundo a COPC-2000 (2003) o Sistema de Gestão de Performance COPC é um conjunto de práticas de gestão e treinamento para operações de serviço centradas no cliente, desenhadas para reduzir o custo de prover um serviço excelente, melhorar a satisfação do cliente por meio do aprimoramento do serviço e da qualidade, e aumentar os ingressos.

A versão 4.3 do modelo é composta por quatro domínios, nos quais a condução da gestão da performance focalizada no cliente, personificada nas características e atividades de liderança descritas na categoria 1.0, liderança e planejamento, na categoria 2.0, processos, e na categoria 3.0, recursos humanos, tomadas em conjunto, representam os facilitadores da organização: uma força de trabalho capacitada e motivada, usando processos bem desenhados e manejando-os com a informação apropriada. O objetivo do sistema é uma composição balanceada entre satisfação do cliente e do usuário final, performance de produto e serviço, produtividade, e satisfação do funcionário, tratados na Categoria 4.0, Performance (COPC2000, 2003, p. 8).

CMMI - Capability Maturity Model Integration: Fernandes e Abreu (2008, p. 203) relatam que este modelo foi construído a partir de uma encomenda feita pelo DoD (Departamento de Defesas Norte-Americano). Criado em 1991 pelo Software Engineering Institute (SEI), da 
Carnegie Mellon University (CMU), o Capability Maturity Model Integration, ou Modelo Integrado do Nível de Maturidade, tem por objetivo disponibilizar modelos para melhorar os processos e habilidades das corporações no desenvolvimento, compra ou manutenção de produtos e serviços (MANSUR, 2009, p.138).

Segundo o SEI (2009) o CMMI é uma abordagem de melhoria de processo que fornece às organizações os elementos essenciais de processos para aprimorar o desempenho.

Parafrasendo Fernandes e Abreu (2008) o CMMI é uma evolução do CMM (Capability Maturity Model), o qual procurou estabelecer um modelo único para o processo de melhoria corporativo, integrando diferentes disciplinas (Software Engineering (SW); Supplier Sourcing (SS); Integrated Product and Process Development (IPPD); e Systems Engineering (SE)) e modelos.

Ainda de acordo com o SEI (2009) a versão atual (2009) do CMMI é a 1.2 que apresenta três modelos distintos, sendo: CMMI for Services (CMMI-SVC), publicado em fevereiro de 2009, tem como objetivo estender a cobertura dos processos do CMMI de empresas de prestação de serviços no desenvolvimento e aquisição; O CMMI for Acquisition (CMMI-ACQ), foi publicado em novembro de 2007 e direciona-se ao suporte às decisões relacionadas aos processos de aquisição e terceirização de bens e serviços; e por fim o CMMI for Development (CMMI-DEV), cuja publicação foi realizada em agosto de 2006 e está direcionado ao processo de monitoração, mensuração e gerenciamento dos processos de desenvolvimento de produtos e serviços (FERNANDES e ABREU, 2008, p. 204).

Para os autores os modelos do CMMI possuem abordagens denominadas "Por Estágios" e "Contínua" (p. 210), possibilitando às organizações utilizarem estratégias diferentes, de acordo com o planejado. A abordagem contínua "permite que cada uma de suas áreas de processo seja implementada de forma independente e evolutiva, agrupando suas práticas genéricas e específicas em seis níveis de capacitação (Capability Level)" (ibid., p. 212). Os autores também afirmam que a abordagem por estágios consiste em práticas específicas e genéricas que integram um conjunto predefinido de áreas de processo, caracterizado por Níveis de Maturidade (Maturity Levels). 
EFQM - The European Foundation of Quality Management Model: a EFQM ou Fundação Europeia para a Gestão da Qualidade é uma organização sem fins lucrativos sediada na Bélgica, criada em 1988 por líderes de quatorze empresas (Bosch; British Telecommunications; Bull; Ciba-Geigy; Dassault Aviation; Electrolux; Fiat; KLM; Nestlé; Olivetti; Philips; Renault; Sulzer; e Volkswagen) cujo objetivo inicial era promover padrões mais elevados de gestão através do conhecimento mútuo e compartilhados (EFQM, 2009).

Segundo a EFQM (2009) esse modelo de excelência de Gestão da Qualidade incorpora os princípios de excelência em uma estrutura que ajuda as organizações a avaliar as suas capacidades e pontos fortes para alcançar seus objetivos. É utilizado para estruturar uma análise lógica e sistemática de qualquer organização, permitindo que sejam feitas comparações entre estas empresas (mesmo sendo empresas similares ou empresas muito diferentes em sua forma organizacional) e também para definir quais as capacidades e os recursos necessários para cumprir os objetivos estratégicos da organização.

O modelo possui, de acordo com o IPQ (2009), cerca de trinta subcritérios, agrupados por sua vez em torno de nove critérios, que permitem fazer o diagnóstico e a avaliação do grau de excelência alcançado por uma determinada organização e estimular, a partir daí, a sua melhoria contínua.

eSCM-SP - The eSourcing Capability Model for Service Providers: este modelo foi desenvolvido pelo IT Services Qualification Center (ITSqc) da Universidade Carnegie Mellon e por um grupo de organizações independentes. O objetivo desse modelo é prover as práticas recomendadas que os fornecedores de serviços de TI possam utilizar para desenvolver e melhorar a sua capacidade de entregar serviços de TI de alta qualidade, minimizando os custos e riscos para seus clientes, permitindo-lhes assim demonstrar a qualidade dos seus serviços.

eSCM-CL - The eSourcing Capability Model for Client Organization: também desenvolvido pelo IT Services Qualification Center (ITSqc) da Universidade Carnegie Mellon e por um grupo de organizações independentes, o eSourcing Capability Model foi criado com o objetivo de fornecer um panorama de práticas recomendadas cujos prestadores de serviços de TI pudessem utilizá-lo a fim de desenvolver e melhorar a sua capacidade de prestar e entregar serviços de TI com alta qualidade, minimizando riscos e custos para os tomadores do serviço, permitindo-lhes assim demonstrar a qualidade dos serviços prestados e 
proporcionando diferenciais competitivos em relação aos concorrentes de mercado (BON; VERHEIJEN, 2006, p. 73).

O eSCM-SP - The eSourcing Capability Model for Service Providers, teve sua primeira versão lançada em novembro de 2001 e sua versão atual (2.01) foi lançada em 2006. Possui 84 práticas divididas entre quatro fases - ongoing, iniciação, entrega e encerramento (BON; VERHEIJEN, 2006, p. 74).

Já o modelo eSCM-CL - The eSourcing Capability Model for Client Organizations foi criado 2003 e lançado em 2006 a fim de que as práticas recomendadas também fossem seguidas pelo tomador de serviços e não só pelo prestador (ibid., p. 73).

Segundo Fernandes e Abreu (2008, p. 326) os principais objetivos deste modelo são o de prover aos tomadores de serviço um conjunto de práticas, a fim de orientá-los a melhorar seu entendimento e controles em relação às atividades terceirizadas, fazendo com que haja uma gerência e melhorias contínuas, redução de riscos nas relações, criação de competências na gestão das atividades e avaliação de suas capacidades em serviços terceirizados de TI.

A diferença entre os modelos eSCM-SP e eSCM-CL é que no ciclo de sourcing, há a atividade adicional de análise (ibid., p. 327). O eSCM-CL é composto por noventa e cinco práticas distribuídas em três dimensões (Áreas de Capacitação, Níveis de Capacitação e Ciclo de Vida do Sourcing) e está dividido em 5 fases, conforme a descrição apresentada a seguir:

- Ongoing: Gestão da Estratégia de Sourcing; Gestão da Governança; Gestão do Relacionamento; Gestão do Valor; Gestão da Mudança Organizacional; Gestão das Pessoas; Gestão do Conhecimento; Gestão da Tecnologia; e Gestão das Ameaças;

- Análise: Análise de Oportunidade de Terceirização; e Abordagem da Terceirização;

- Iniciação: Planejamento da Terceirização; Avaliação do Provedor de Serviço; Acordos de Terceirização; e Transferência do Serviço;

- Execução: Gestão dos Serviços Contratados; e

- Encerramento: Conclusão da Terceirização.

Ainda segundo Fernandes e Abreu (2008, p. 333) o modelo conta com cinco níveis de capacitação apresentando o percurso de evolução que o tomador do serviço deve conseguir para atingir a excelência em gerenciamento de terceirização, a saber: 
- Nível 1 - Desempenhando o sourcing;

- Nível 2 - Gestão consistente do sourcing;

- Nível 3 - Gerenciamento organizacional do desempenho do sourcing;

- Nível 4 - Aperfeiçoamento do valor proativamente; e

- Nível 5 - Sustentação da Excelência.

Apesar de recente, o modelo eSCM-CL apresenta aceitabilidade entre as empresas como sendo uma referência no gerenciamento da prestação de serviços terceirizados de TI, tanto para o contratante quanto para o fornecedor do serviço.

eTOM - The Enhanced Telecom Operations Map: o eTOM foi fundado em 1988 pelo TeleManagement Forum e serve como modelo para a direção do processo e ponto de partida para o desenvolvimento e integração de Business and Operations Support Systems (BSS e OSS, respectivamente). Em outras palavras, o modelo eTOM descreve o escopo completo dos processos de negócio exigido por um prestador de serviços e define os principais elementos e como eles interagem.

Segundo Bon e Verheijen (2006), esse modelo possui três níveis de processo. A representação gráfica é composta por linhas e colunas. As interseções das linhas e colunas apontam para processos específicos, conforme especificado pelo eTOM. A linha superior indica o marketing voltado para o cliente, ou seja, a atividade, enquanto que a linha inferior indica as atividades apoiadas pelo fornecedor.

Generic Framework for Information Management (GFIM): este é um modelo de gestão de informação que pode ser aplicado por qualquer organização para melhor alinhar a TI com a estratégia organizacional. Elaborado a partir do modelo de alinhamento proposto por Henderson e Venkatraman, sua principal função é oferecer um enquadramento geral para a gestão da informação, para uma análise de alto nível das questões organizacionais e de responsabilidade. O GFIM fornece um mapa de todo o domínio de informação de gestão a ser utilizada para o posicionamento das questões de informação de gestão que estão atualmente em discussão na empresa, atribuindo responsabilidades (MAES, 1999).

ICB - IPMA - Competence Baseline: lançado pela International Project Management Association (IPMA) em fevereiro de 1999, com uma versão mais recente disponibilizada em 
março de 2006, o ICB pode ser utilizado para desenvolvimento de projetos de gestão em organizações e na formação de gestão de projetos. O IPMA Competence Baseline (ICB) é a base para o sistema de certificação IPMA. O ICB define o conhecimento e a experiência esperado em gestores de projetos, programas e portfólios de projetos. Contém termos básicos, práticas, métodos e ferramentas para gerenciamento de projetos profissionais.

Segundo a IPMA (2010), o ICB é o padrão de competência para a gestão de projetos e não está restrito a qualquer setor ou ramo. Foi emitido pela International Project Management Association (IPMA), com o objetivo de Igarantir a coerência e harmonização de normas para certificação. Como tal, a maioria do seu conteúdo centra-se na descrição do projeto elementos de competência de gestão.

ISO 9000 - Standard on Total Quality Management: é uma família de normas para gestão de sistemas de qualidade e é mantida pela ISO, a International Organization for Standardization. Os seis documentos obrigatórios da norma são: controle de documentos; controle de registros; auditorias internas; controle de produto/ serviço não conformes; ação corretiva; e ação preventiva. Segundo a ISO (2009), a família ISO 9000 de normas representa um consenso internacional sobre boas práticas de gestão de qualidade. É composto de normas e orientações relativas aos sistemas de gestão da qualidade e normas relacionadas com o apoio. A ISO 9001é a norma que prevê um conjunto de requisitos padronizados para um sistema de gestão da qualidade. As outras normas da família abrangem aspectos específicos, tais como fundamentos e vocabulário, melhorias de desempenho, documentação, treinamento e aspectos financeiros e econômicos.

ISO / IEC 38500 - Corporate Governance of Information Technology: essa norma estabelece os princípios orientadores para os administradores das organizações (incluindo os proprietários, conselheiros, diretores, sócios e executivos) sobre a aplicação eficaz, eficiente e de uso aceitável de TI em suas organizações. Segundo a ISO (2009) a ISO / IEC 38500 é aplicável à gestão de processos de gerenciamento de decisões e relativas às informações e serviços de comunicação utilizados por uma empresa. Esses processos podem ser controlados por especialistas em TI dentro da organização, ou de prestadores de serviços externos, ou por unidades de negócios dentro da organização.

Possui seis princípios, a saber: estabelecer responsabilidades para TI; estabelecer um plano de TI para melhor apoiar a empresa; validar os processos; certificar-se que está sendo bem 
executado; garantir que esteja em conformidade com as regras formais; e assegurar que a utilização de TI respeite os fatores humanos.

ISPL - The Information Services Procurement Library: é uma biblioteca de práticas recomendadas para a gestão de TI relacionadas à aquisição de processos. Ajuda o cliente e fornecedor da organização a alcançar a qualidade desejada por meio de métodos e práticas recomendadas para gestão de risco, gerenciamento de contratos e planejamento (ISPL, 2009). Este modelo foca também a relação entre o cliente e o fornecedor do serviço ajudando na construção e gerenciamento do contrato. (ISPL, 2009).

ITS-CMM - The IT Service Capability Maturity Model: lançado em 1993 pela Carnegie Mellon University, foi originalmente desenvolvido como uma ferramenta para avaliar a aptidão dos fornecedores em executar projetos de software.

Segundo Bon e Verheijen (2006), o CMM é utilizado como um modelo geral para auxiliar na melhoria dos processos de negócio da organização em diversas áreas, como por exemplo: engenharia de software, engenharia de sistemas, gerenciamento de projetos, manutenção de software e gestão de riscos. Inclui os seguintes aspectos: níveis de maturidade; principais áreas de processo; metas; características comuns e práticas-chave.

ITIL - Information Technology Infrastructure Library: segundo Mansur (2009, p. 29), ITIL são orientações que descrevem as práticas recomendadas a serem aplicadas em um processo integrado do gerenciamento de serviços de TI. Desenvolvido no término dos anos 1980 pela Central Computer and Telecommunications Agency - CCTA - e está atualmente sob comando da Office for Government Commerce - OGC do governo da Inglaterra. A versão 3 do ITIL foi lançada em maio de 2007 e suas competências são distribuídas em cinco estágios:

- Estratégia de Serviços: Gerenciamento Financeiro de TI; Gerenciamento do Portfólio de Serviços; e Gerenciamento da Demanda.

- Desenho de Serviço: Gerenciamento do Catálogo de Serviços; Gerenciamento do Nível de Serviço; Gerenciamento da Capacidade; Gerenciamento da Disponibilidade; Gerenciamento da Continuidade do Serviço; Gerenciamento de Segurança da Informação; e Gerenciamento do Fornecedor. 
- Transição de Serviço: Gerenciamento de Mudanças; Gerenciamento da Configuração e de Ativo de Serviço; Gerenciamento da Liberação e Implantação; Validação e Teste de Serviço; Avaliação; e Gerenciamento do Conhecimento.

- Operação de Serviço: Gerenciamento de Evento; Gerenciamento de Incidente; Cumprimento de Requisição; Gerenciamento de Problema; e Gerenciamento de Acesso.

- Melhoria de Serviço Continuada: Relatório de Serviço; e Medição de Serviço.

Na visão de Fernandes e Abreu (2008, p. 273) o modelo ITIL promove a gestão com foco no cliente e na qualidade dos serviços de TI, endereçando estruturas de processos para a gestão de uma organização de TI. Trata-se do ciclo de vida do serviço no qual constam orientações para uma abordagem integrada de gerenciamento de serviços.

Modelos ISO - International Organization for Standardisation: a Organização Internacional de Normalização, conhecido como ISO, foi fundada na Suíça em 23 de fevereiro de 1947. Enquanto a ISO define-se como uma organização não governamental, sua capacidade de estabelecer normas que, muitas vezes se tornou lei, quer por meio de tratados ou de normas nacionais, torna-se mais poderosa do que a maioria das organizações não governamentais (ISO, 2009).

MOF - Microsoft Operations Framework: lançada no final de 1999 pela Microsoft, o MOF é uma documentação que oferece recomendações para planejar, aplicar e manter processos operacionais que suportem serviços de missão crítica. Adotando as práticas do ITIL, a Microsoft adaptou para seu ambiente e juntamente a essa adaptação a empresa uniu à sua documentação as experiências e sugestões de seus funcionários, parceiros e clientes, adquiridas no dia a dia de operações e projetos (BON E VERHEIJEN, 2006).

M_o_R - Management of Risk: publicado pelo Office of Government Commerce, este modelo destina-se a ajudar as organizações a estabelecer um quadro eficaz para a tomada de decisões, informando sobre os riscos que afetam os seus objetivos de desempenho em todas as atividades organizacionais, sejam elas estratégicas, programa, projeto ou operacionais.

O quadro M_o_R fundamenta-se em quatro conceitos básicos: princípios - que são essenciais para o desenvolvimento de boas práticas de gestão de risco; approach - princípios que devem 
ser adaptados e aprovados para atender cada organização; processos - que descrevem as entradas, saídas e atividades envolvidas no sentido de garantir que os riscos são identificados, avaliados e controlados; e incorporação e revisão - que asseguram que sejam aplicados de forma coerente em toda a organização e que sua aplicação se submete à melhoria contínua (BON E VERHEIJEN, 2006).

MSP - Managing Successful Programmes: o Office of Government Commerce desenvolveu um guia de práticas recomendadas de gestão do programa chamado Managing Successful Programmes (MSP). O guia inclui um conjunto de princípios e processos para uso na gestão de um programa. Nesses princípios, são definidos os papéis e responsabilidades de todos os que precisam fazer parte da liderança de um programa (OGC, 2009).

OPM3 - Organizational Project Management Maturity Model: publicado pela Project Management Institute (PMI) nos Estados Unidos em 2003, o OPM3 é um modelo padrão de práticas recomendadas para a melhoria da empresa. Em sua segunda edição, OPM3 fornece uma maneira para as organizações compreenderem os seus processos de gerenciamento de projeto e medir as suas capacidades na preparação para a melhoria. O modelo é baseado em ciclo constituído por conhecimento, avaliação e aperfeiçoamento, e pode ajudar as organizações a alinhar suas metas organizacionais com a conclusão dos projetos e dar-lhes uma melhor compreensão de sua maturidade organizacional em gerenciamento de projetos (BON E VERHEIJEN, 2006).

PRINCE2 - Projects IN Controlled Environments: é um método para gerenciamento de projetos que abrange a gestão, controle e organização de um projeto. Marca registrada do Office of Government Commerce (OGC), sua revisão mais recente foi lançada em 2009 (OGC, 2009).

P3M3 - Portfolio, Programme \& Project Management Maturity Model: lançado também pelo Office of Government Commerce (OGC), o P3M3 descreve o portfólio, programas e atividades relacionadas ao projeto dentro das áreas de processo que contribuem para a obtenção de sucesso do projeto. Segundo o OGC (2009) o P3M3 reconhece não apenas as atividades de gerenciamento de projeto a ser realizado no nível do projeto individual, mas também as atividades que são desenvolvidas dentro de uma organização. 
PMBoK - Project Management Body of Knowledge: publicado pela primeira vez pelo Project Management Institute (PMI) como Livro Branco em 1987, em uma tentativa de documentar e padronizar informações e práticas sobre gerenciamento de projetos. A primeira edição foi publicada em 1996, e a segunda, em 2000; em 2004 foi lançada a terceira edição e em 2008, a quarta edição. De acordo com o PMI (2009), o PMBOK é um conjunto de práticas para o gerenciamento de projetos e constitue a base da metodologia de gerência de projetos do PMI. Essas práticas são compiladas na forma de um guia, chamado de Guia do Conjunto de Conhecimentos em Gerenciamento de Projetos, ou Guia PMBOK ${ }^{\circledR}$.

SAS 70 - Statement on Auditing Standards for Services Organizations: é uma declaração de auditoria emitido pelo Auditing Standards Board da American Institute of Certified Public Accountants (AICPA). Segundo Bon e Verheijen (2006) o SAS 70 fornece orientações para auditores no que se refere à avaliação dos controles internos de uma organização de serviços e emissão de relatórios das auditorias realizadas.

Seis Sigma - Six Sigma: é um conjunto de práticas originalmente desenvolvidas pela Motorola para melhorar sistematicamente os processos e eliminar defeitos. Um defeito é definido como a não conformidade de um produto ou serviço com suas especificações. Seis Sigma também é definido como uma estratégia gerencial para promover mudanças nas organizações, fazendo com que se chegue a melhorias nos processos, produtos e serviços para a satisfação dos clientes (BON E VERHEIJEN, 2006). Segundo os autores o Seis Sigma tem como prioridade a obtenção de resultados, de forma planejada e clara, tanto de qualidade, como principalmente, financeiros.

TickIT - Software Quality Management: é um programa de certificação de gestão da qualidade para software, apoiada principalmente pelo Reino Unido e indústrias de software sueco. Segundo Fernandes e Abreu (2008) além de um objetivo geral de melhorar a qualidade do software, um dos princípios da TickIT é melhorar e regulamentar o comportamento dos auditores que trabalham no setor de TI por meio da formação e certificação dos auditores.

TQM - Total Quality Management: é um conceito de gestão criado pelo W. Edwards Deming. A base do TQM é o de reduzir os erros produzidos durante o processo produtivo ou 
de serviços, aumentando a satisfação do cliente e racionalizando a gestão da cadeia de suprimentos (BON E VERHEIJEN, 2006).

TOGAF - The Open Group Architecture Framework: o TOGAF tem sido desenvolvido por membros do The Open Group desde meados da década de 1990. Sua última versão, TOGAF 9, foi lançada em 02 de fevereiro de 2009. É um quadro para arquitetura corporativa que oferece uma abordagem abrangente para o projeto, planejamento, implementação e administração de uma empresa arquitetura de informação. A arquitetura é tipicamente modelada em quatro níveis ou domínios: negócios, aplicativos, dados e tecnologia (BON E VERHEIJEN, 2006).

Val IT - Value IT: é um conjunto de documentos que fornecem um quadro para a gestão dos investimentos em TI, produzido pela IT Governance Institute (ITGI). Trata-se de uma declaração formal de princípios e processos para Gestão de portfólio de TI (ITGI, 2007).

\section{Considerações e análise dos modelos apresentados}

Cabe esclarecer que algumas literaturas indicaram a existência de modelos proprietários, desenvolvidos e customizados por organizações, de acordo com a necessidade local (ASL, 2009), mas que neste momento não serão abordados nesta pesquisa pois o foco está nos modelos oferecidos pelo mercado.

Com base nos seis agrupamentos descritos (de "a" a "f"), a segunda parte da análise dos modelos de governança partiu de um estudo pormenorizado dos 15 modelos referentes à GTI (agrupamento f) - foco da pesquisa - com o propósito de identificar em quais destes 15 modelos, as práticas de gestão da TI se fazem presentes, bem como as dimensões às quais estas práticas se referem.

As práticas existentes nos modelos de GTI estão distribuídas em diversas dimensões que são definidas como sendo a abordagem principal, e /ou áreas de abrangência ao qual o processo da prática está relacionado, sendo que cada modelo trata suas dimensões de forma diferenciada, ou seja, muitas foram distinguidas pelo entendimento das práticas propostas. Cada dimensão é formada por domínios, que por sua vez são compostos por um conjunto de processos, que visam atender a um grupo de princípios fundamentais do modelo. 
Os procedimentos utilizados para a análise foram esquematizados conforme demonstra a Ilustração 2 .

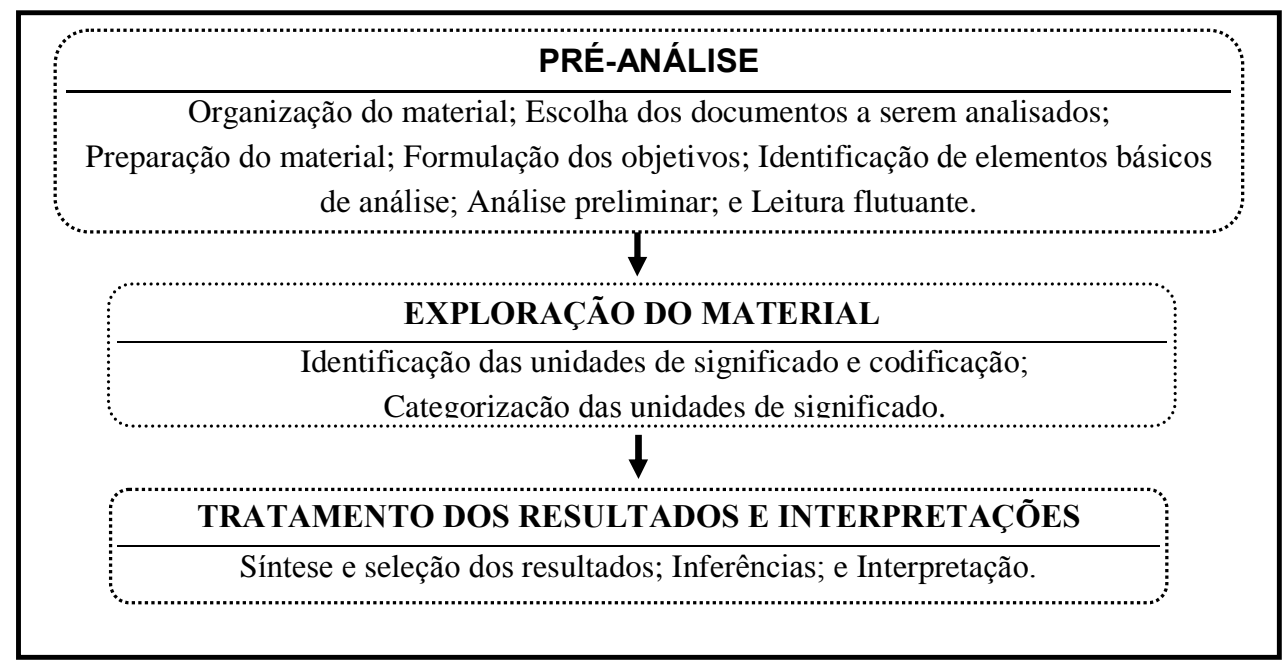

Ilustração 2 - Esquema da análise realizada nos 15 modelos de GTI

A análise foi realizada em três etapas. A primeira constituiu-se em uma pré-análise dos 15 modelos de GTI, englobando a organização do material, a escolha dos documentos a serem analisados e a preparação dos indicadores que fundamentaram a interpretação final.

A segunda etapa da análise foi a exploração do material selecionado. As práticas identificadas nesses modelos estão distribuídas por 23 dimensões, a saber: aquisição; capacidade; comunicação; conhecimento; contrato; demanda; desempenho; financeiro; incidente; infraestrutura; mercado; mudança; nível se serviço; política; problema; qualidade; relacionamento; responsabilidade; risco; segurança; sistema de informação; treinamento; e valor, conforme pode ser observado no item 2.3.7, na sequência deste estudo.

Na terceira e última fase, a opção foi pela organização dos conteúdos, realizada de forma aberta, ou seja, as categorias de análise foram construídas ao longo das etapas da própria análise. Isso se justifica devido ao fato de a pesquisa ser exploratória e ter sido aplicada em um contexto no qual se buscou aprofundar o conhecimento sobre o assunto (BARDIN, 1997).

Os resultados dessa análise apontaram três modelos de GTI que foram escolhidos por representarem quase que a totalidade de processos e ações práticas de todos os outros modelos 
relacionados à GTI encontrados na literatura, sendo eles: CObIT - versão 4.1, eSCM-CL versão 1.1 e ITIL - versão 3.

O quadro 3 apresenta o resultado final da análise e reagrupamento das dimensões desses três modelos escolhidos como base para a construção do modelo proposto.

Quadro 3 - Agrupamento dos modelos CoBIT Vs.4.1; eSCM-CL Vs.1.1; e ITIL Vs.3

\begin{tabular}{|c|c|c|c|c|c|c|c|c|c|c|c|c|c|c|c|c|c|c|c|c|c|c|c|}
\hline \multirow[b]{2}{*}{ Modelos de Governança de TI } & \multicolumn{23}{|c|}{ Dimensões - Áreas de Abrangência } \\
\hline & 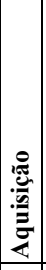 & 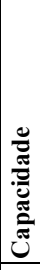 & U & 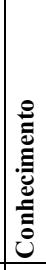 & 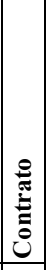 & 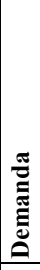 & 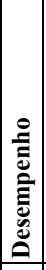 & 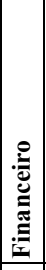 & 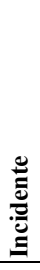 & 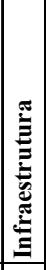 & 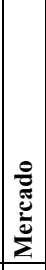 & 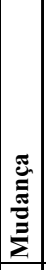 & 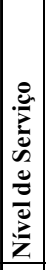 & 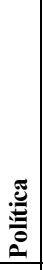 & 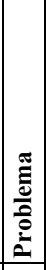 & 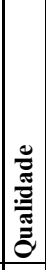 & 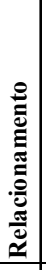 & 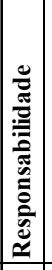 & 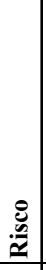 & 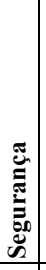 & 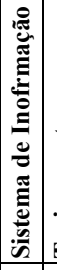 & 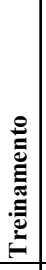 & $\begin{array}{l}x \\
\frac{0}{\pi} \\
\frac{5}{\nu}\end{array}$ \\
\hline $\begin{array}{l}\text { CObIT Vs. } 4.1 \text { - Control Objectives for } \\
\text { Information and Related Technology }\end{array}$ & $\mathrm{x}$ & $\mathrm{x}$ & $\mathrm{x}$ & & $\mathrm{x}$ & $\mathrm{x}$ & $\mathrm{x}$ & $\mathrm{x}$ & $\mathrm{x}$ & $\mathrm{x}$ & $\mathrm{x}$ & $\mathrm{x}$ & $\mathrm{x}$ & $\mathrm{x}$ & $\mathrm{x}$ & $\mathrm{x}$ & $\mathrm{x}$ & $\mathrm{x}$ & $\mathrm{x}$ & $\mathrm{x}$ & & $\mathrm{x}$ & $\mathrm{x}$ \\
\hline $\begin{array}{l}\text { eSCM-CL Vs. } 1.1 \text { - The eSourcing Capability } \\
\text { Model for Client Organization }\end{array}$ & $\mathrm{x}$ & $\mathrm{x}$ & & $\mathrm{x}$ & $\mathrm{x}$ & $\mathrm{x}$ & $\mathrm{x}$ & $\mathrm{x}$ & $\mathrm{x}$ & $\mathrm{x}$ & $\mathrm{x}$ & $\mathrm{x}$ & & $\mathrm{x}$ & $\mathrm{x}$ & $\mathrm{x}$ & $\mathrm{x}$ & $\mathrm{x}$ & $\mathrm{x}$ & $\mathrm{x}$ & $\mathrm{x}$ & & $\mathrm{x}$ \\
\hline $\begin{array}{l}\text { ITIL Vs. } 3 \text { - Information Technology } \\
\text { Infrastructure Library }\end{array}$ & & & $\mathrm{x}$ & $\mathrm{x}$ & & $\mathrm{x}$ & $\mathrm{x}$ & $\mathrm{x}$ & $\mathrm{x}$ & $\mathrm{x}$ & & $\mathrm{x}$ & $\mathrm{x}$ & & $\mathrm{x}$ & & & & & $\mathrm{x}$ & & & \\
\hline
\end{tabular}

Após a seleção dos modelos, foi realizada uma análise em cada uma das 23 dimensões, extraindo práticas que envolvessem todos os processos, bem como as relacionadas à gestão da terceirização de serviços de TI dos modelos com características “check” do ciclo PDCA.

Para essa análise foram examinadas as frequências com que as palavras e temas principais inerentes às práticas de gestão ocorreram em cada um dos três modelos de GTI selecionados, a fim de identificar o conteúdo e as características de informações presentes nas práticas de gestão recomendadas e que estão relacionadas às dimensões.

Em cada dimensão, a análise trouxe diversas práticas relacionadas à gestão da terceirização de serviços de TI que foram reagrupadas/condensadas de acordo com cada dimensão e processo. Tal análise fez com que fosse reduzida significativamente a quantidade de tais práticas com cada dimensão, sem perder com isso a importância de cada processo e prática.

Ainda nessa etapa, houve uma reorganização das dimensões identificadas, originando um novo agrupamento de dimensões. Essa reorganização foi realizada de acordo com os assuntos, nos quais os correlatos foram congruídos. A Ilustração 3, a seguir, apresenta um resumo das etapas desenvolvidas no processo de análise dos modelos de governança. 


\section{MODELOS DE \\ GOVERNANCA}

(AS 8015-2005; ASL; BiSL; BS 7799;

BSC, CMMI, COBIT, COPC2000;

EFQM; eSCM-CL; eSCM-SP; eTOM;

GFIM; ICB - IPMA; ISO / IEC 38500;

ISO 9000, ISO/IEC 17799 , ISO/IEC

20000: ISO/IEC 27001; ISO/IEC 27002;

ISPL; ITIL: ITS-CMM; M o R; Modelos

ISO, MOF, MSP, OPM $3, \overline{\mathrm{P}} 3 \overline{\mathrm{M}} 3, \mathrm{PMBOK}$,

PRIVCE2; SAS 70: Six Sigma; TickIT;

TOGAF; TQM; Val IT)

\section{TI}

(AS 8015-2005; ASL; BiSL; COBIT; eSCM-CL;

Identificação inicial dos modelos de governança

ISO/IEC 20000; ISPL; ITIL; S $\triangle S$ S 70; TOG $\triangle F$; Val

IT).

3 MODELOS DE GOVERNANÇA DE TI

(COBIT; eSCM-CL; e ITIL)

\section{Iimensões}

(Aquisição; Capacidade; Comunicação; Conhecimento; Contrato; Demanda: Desempenho: Financeira; Incidente; Infraestrutura; Mercado; Mudança; Nivel se serviço; Política; Problema; Qualidade; Relacionanento, Responsabilidade; Risco: Segurança; Sistema de Informação; Treinamento; e Valor).
Análise dos modelos de governança de TI

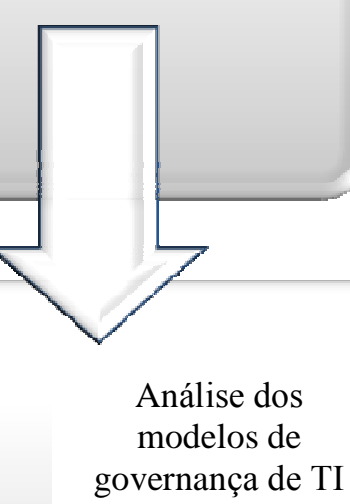




\subsubsection{Práticas de gestão da terceirização de serviços de tecnologia da informação}

A partir dos 15 modelos de GTI citados, diversas práticas de gestão da terceirização de serviços de TI podem ser descritas. Na sequência, são apresentadas as dimensões de forma a compreender adequadamente os seus objetivos.

\section{Aquisição}

A aquisição dos serviços e sua crescente importância dentro das empresas fazem dessa dimensão uma tendência de crescimento e especialização com fluxo contínuo, pressionada pela utilização de equipes de especialistas externos e reduções significativas de custos (AXELSSON; WYNSTRA, 2002, p. 9).

Segundo Hefley e Loesche (2006, p.149) e ITGI (2007) a aquisição envolve gerenciamento de parcerias, seleção de fornecedores, análise das propostas, subcontratação em terceirização de serviços de TI, modalidades de contratação, controle de recebimentos, acompanhamento da legislação pertinente, SLA e análise crítica de contratos.

Algumas práticas dessa dimensão estão focadas no gerenciamento do processo de coletar os requisitos das áreas, analisá-los e promover um acordo formal que descreva como a organização atenderá a esses requisitos (CORBETT, 2004; MANSUR, 2009).

A multiplicidade de processos que envolvem a aquisição, como a análise das opções em função das novas oportunidades, acordos sobre as funções desempenhadas, medidas de desempenho e acordos de níveis de serviços são apontados como essenciais no processo de gestão (MURRAY; KOTABE, 1999; GRÖNROOS, 2007; VAN DER VALK, 2008). O Apêndice A1 apresenta os livros consultados para obtenção das práticas do gerenciamento de aquisição da terceirização de serviços de TI.

\section{Capacidade}

A capacidade considera práticas ou agrupamento de práticas que orientam a empresa a controlar e gerenciar seus fornecedores no sentido de responderem às exigências das demandas, em termos de cronogramas, prazos e custos (HEFLEY; LOESCHE, 2006). O 
planejamento da capacidade é feito simultaneamente à identificação de necessidades e ao estabelecimento dos objetivos de desempenho e níveis de serviço, estendendo sua análise aos recursos computacionais e recursos humanos (RIPIN; SAYLES, 1999; BRAGG, 2006).

Questões como a definição dos requisitos de competência dos fornecedores e suas respectivas equipes utilizando para isso programas de qualificação e certificação, e planejamento da capacidade de recursos computacionais e de infraestrutura, são processos que devem ser monitorados com frequência atendendo aos objetivos pré-estabelecidos (FERNANDES; ABREU, 2008, p. 69; MANSUR, 2009, p. 81). O Apêndice A2 apresenta os livros consultados para obtenção das práticas do gerenciamento da capacidade de terceirização de serviços de TI.

\section{Comunicação}

O gerenciamento da comunicação realizada com a diretoria e com os fornecedores de serviços envolve a elaboração de relatórios de gestão sênior de TI com a contribuição de terceirização de serviços de TI aos negócios, especialmente em termos de programas de investimento e desempenho dos serviços prestados (GREAVER II, 1999).

O monitoramento dos objetivos previstos a fim de verificar se foram alcançados, sugerindo ações corretivas para os principais desvios, além da obtenção de relatórios de garantia de conformidade e aderência a todas as políticas internas, requisitos regulamentares ou contratuais, confirmam que as medidas corretivas necessárias têm sido tomadas pelo fornecedor do serviço em tempo hábil (CARTLIDGE et al., 2007; ITGI, 2007). O Apêndice A3 apresenta os livros consultados para obtenção das práticas do gerenciamento da comunicação inerentes à terceirização de serviços de TI.

\section{Conhecimento}

As práticas ligadas ao gerenciamento do conhecimento estão focadas no gerenciamento dos sistemas de informação e de conhecimento de tal forma que os fornecedores de serviços equipes ou pessoas individuais - envolvidos nos processos, tenham fácil acesso ao conhecimento que elas necessitam para um trabalho eficiente (HEFLEY; LOESCHE, 2006). 
Segundo Bragg (2006, p. 45) a gestão do conhecimento está associada diretamente à gestão das capacidades e habilidades, sendo que os fornecedores de serviços que forem mais competitivos, que ofereçam maior lucratividade com a realização de processos mais rápidos e produtivos resultam em diferenciais e são pontos-chave para o gerenciamento (SAAD, 2006, p. 13). Envolve ainda verificar regularmente se as pessoas inseridas em cada processo (equipes de cada fornecedor de serviço) têm a competência necessária para desempenhar os seus papéis com base em sua educação, formação e/ou experiência; define também os requisitos de competência dos grupos de trabalho e verifica se eles estão sendo mantidos e monitorados (HYDER et al., 2006; LARSEN; PEDERSEN; ANDERSEN, 2006; FERNANDES; ABREU, 2008).

O ITGI (2007, p. 61) apresenta como práticas minimizar as dependências dos indivíduos envolvidos por meio de capacitações constantes, minimização da dependência crítica em pessoas-chave por meio da captura do conhecimento (documentação), partilhamento de conhecimentos e planejamento de sucessão.

Para Cartlidge et al. (2007) devem-se incluir verificações nos processos de seleção de fornecedores, sendo que a frequência das revisões periódicas desses controles devem depender da sensibilidade e/ou criticidade da função do fornecedor do serviço. Requer do gestor de TI também uma avaliação oportuna a ser realizada em uma base regular em relação aos objetivos individuais decorrentes dos objetivos da organização, padrões estabelecidos e as responsabilidades de trabalho específicas. Os fornecedores devem receber treinamento sobre desempenhos e sobre comportamento. O Apêndice A4 apresenta os livros consultados para obtenção das práticas do gerenciamento de conhecimento inerentes à terceirização de serviços de TI.

\section{Contrato}

Processos ligados ao gerenciamento do contrato com fornecedores de serviços de TI são complexos, pois envolvem aspectos financeiros, técnicos, administrativos e legais (SAAD, 2006, p. 131). A comunicação contínua com o fornecedor, análises contratuais, monitoramento do desempenho e progresso dos serviços realizados, políticas relacionadas à administração dos contratos, tarefas inerentes a cada pessoa envolvida, registros, documentações e arquivos dos processos, controles e planejamentos, gerenciamento das 
mudanças, resolução de disputas e reclamações e rescisão contratual são algumas das práticas que devem estar acordadas e clausuladas, cujo gestor deve administrar no gerenciamento do contrato (LACITY; WILLCOCKS, 2001; PRADO, 2005; CARTLIDGE et al., 2007; FERNANDES; ABREU, 2008).

Segundo Hefley e Loesche (2006, p.42) o gerenciamento contratual envolve criação, modificação e cancelamento de contratos e deve monitorar as cláusulas acordadas sobre responsabilidades documentais, análises jurídicas, financeiras, organizacionais, desempenho, segurança, propriedade intelectual e rescisão.

Para o ITGI (2007) os contratos e alterações contratuais devem ser revistos por assessores jurídicos e devem-se aplicar práticas de supervisão adequada garantindo que os papéis e as responsabilidades sejam devidamente exercidas, avaliando se todos os fornecedores de serviços têm autoridade e recursos suficientes para executar as suas funções e responsabilidades. O Apêndice A5 apresenta os livros consultados para obtenção das práticas do gerenciamento de contrato inerentes à terceirização de serviços de TI.

\section{Demanda}

Segundo Saad (2006) deve-se gerenciar ativamente com os fornecedores de serviços, revendo e ajustando as demandas da terceirização de TI, normas, procedimentos e metodologias para garantir que os requisitos legais, regulamentares e contratuais sejam tratados e comunicados dentro dos prazos estabelecidos.

Para o ITGI (2007) o objetivo do gerenciamento da capacidade da demanda é fornecer um ponto de foco, gerindo toda a capacidade, problemas relacionados ao desempenho (tanto de serviços quanto de recursos) garantindo e correspondendo às demandas acordadas.

Práticas ligadas à introdução de medidas de redução de riscos e opções de recuperação a fim de atender às necessidades acordados, requisitos e prazos da empresa são pontos-chave para o gerenciamento da demanda (HEFLEY; LOESCHE, 2006).

O planejamento da demanda deve ser feito simultaneamente à identificação das necessidades de infraestrutura e ao estabelecimento dos objetivos de desempenho e dos níveis de serviços 
(FERNANDES; ABREU, 2008, p. 68). Os processos, controles e planejamentos inerentes às demandas devem visar não só à infraestrutura computacional, mas aos recursos humanos em termos do desempenho necessário ao desenvolvimento e cumprimento de novos projetos e à manutenção de infraestrutura já existente.

Parafraseando Cartlidge et al. (2007) a otimização da resposta às necessidades externas, a revisão e ajustes nas políticas e normas de demandas de terceirização de serviços de TI, e os procedimentos e metodologias para garantir que os requisitos legais, regulamentares e contratuais sejam tratados e comunicados, devem ser constantemente controlados e reajustados. O Apêndice A6 apresenta os livros consultados para obtenção das práticas do gerenciamento de demanda inerentes à terceirização de serviços de TI.

\section{Desempenho}

O gerenciamento do desempenho começa desde a definição dos objetivos de desempenho estabelecidos até a criação dos indicadores e métricas que serão utilizados. $\mathrm{O}$ acompanhamento da sua implantação, o monitoramento dos processos e controles, a tomada de decisão em função dos resultados obtidos e a realização de ações de melhorias são práticas inter-relacionadas que, segundo Fernandes e Abreu (2008, p. 154) devem estar operantes para fornecer as informações necessárias para essa definição.

Para Cartlidge et al. (2007) o monitoramento contínuo e dados obtidos sobre o desempenho dos fornecedores de serviços de TI devem servir a dois propósitos: manter e ajustar o desempenho atual e abordar questões como a resiliência, contingência (atuais e previstas), cargas de trabalho, planos de armazenamento e aquisição de recursos; e informar a disponibilidade do serviço prestado aos negócios, como exigido pela SLA.

Segundo Saad (2006, p. 159) a prática relacionada ao processo de melhoria contínua surge como um objetivo desejável e de mútuo e imediato interesse entre as partes, podendo ser implementado por meio do estabelecimento periódico de valores progressivamente mais elevados para os indicadores acordados e que uma vez atingidos, significarão um maior volume de negócios para a organização contratante e uma maior remuneração para o fornecedor de serviço. 
Sob o ponto de vista das métricas, Power, Desouza e Bonifazi (2006, p.193), afirmam que o gestor do desempenho deve ter em mente que se deve estabelecer um processo estável para as medidas, compreender a natureza e as variações no processo, utilizar vários tipos de medidas e nunca manipulá-las.

Ainda segundo o ITGI (2007) o acompanhamento do desempenho deve abordar medições entre o desempenho dos projetos e desempenho do projeto-chave, cronogramas, qualidades oferecidas, custos e critérios de risco. Deve ainda identificar e avaliar eventuais desvios, recomendando, implementando e monitorando ações corretivas, quando necessário, em consonância com o programa e projeto de governança. O Apêndice A7 apresenta os livros consultados para obtenção das práticas do gerenciamento de desempenho relacionados à terceirização de serviços de TI.

\section{Financeiro}

O gerenciamento financeiro envolve práticas relacionadas ao orçamento de terceirização de serviços de TI, gestão de investimento e custos de ativos terceirizados, estabelecimento de preços, e contabilidade e cobrança junto aos fornecedores de serviços (HEFLEY; LOESCHE, 2006; CARTLIDGE et al., 2007; ITGI, 2007).

Segundo Corbett (2004, p. 137) é preciso estabelecer e implementar práticas de preparar um orçamento que reflita as prioridades estabelecidas pelo portfólio da empresa, habilitando programas de investimento, que incluam os custos de operação e manutenção da infraestrutura atual. Essas práticas devem apoiar o desenvolvimento de um orçamento geral de terceirização de serviços de TI, bem como de programas individuais. Devem ainda permitir a revisão em curso, aperfeiçoamento e aprovação de tais orçamentos. (RIPIN e SAYLES, 1999, p. 65).

Para Greaver II (1999, p. 163) o gerenciamento de custos deve comparar os custos reais dos orçamentos, monitorar e comunicar as partes envolvidas quando houver desvios. Estes devem ser identificados, os possíveis impactos avaliados, e medidas corretivas apropriadas precisam ser implementadas, juntamente com o fornecedor do serviço.

Hefley e Loesche (2006), afirmam que as variações entre as previsões e os custos reais devem ser analisados e relatados, em conformidade com os sistemas da empresa de medição financeira. 
O ITGI (2007) orienta a estabelecer e utilizar um modelo de cálculo de custos de TI com base nas definições de serviços que suportam o cálculo das taxas de estorno por serviço. O modelo de custos de TI deve assegurar que o preço dos serviços seja identificável, mensurável e previsível pelos usuários para incentivar a utilização adequada dos recursos.

Na visão de Cartlidge et al. (2007) é necessário supervisionar o investimento de recursos em terceirização de serviços de TI por meio de avaliações regulares a fim de garantir recursos e alinhamento com os atuais e futuros objetivos estratégicos. O controle financeiro abrange também a função e os processos responsáveis pela gestão de um orçamento de terceirização do prestador de serviços, contabilidade e requisitos de cobrança. O Apêndice A8 apresenta os livros consultados para obtenção das práticas do gerenciamento de finanças inerentes à terceirização de serviços de TI.

\section{Incidente}

A identificação e documentação dos incidentes ocorridos na prestação de serviços devem ser monitoradas e controladas constantemente. Atributos e métodos precisam ser definidos para monitorar e resolver incidentes, colaborando com os fornecedores de serviços a fim de corrigi-los, criando planos para a tomada de ações corretivas ou preventivas (HEFLEY; LOESCHE, 2006).

Mansur (2007, p. 142) descreve quatro práticas a serem gerenciadas quando houver incidentes: deve-se controlar e alocar recursos de TI para resolver os incidentes; o tempo de resolução do incidente não pode ser extenso, pois o usuário pode encontrar uma solução; o service desk não deve estar sobrecarregado para não correr o risco de não atender a um usuário; e o service desk necessita demonstrar credibilidade.

O SLA representa o nível da prestação de serviços acordados contratualmente entre as partes envolvidas e fazem com que o número de incidentes seja reduzido significativamente (ibid., p. 143).

Um incidente é uma interrupção não planejada de um serviço de TI, ou uma redução da qualidade de um serviço de TI. O objetivo do gerenciamento de incidentes é restaurar o serviço normal o mais rapidamente possível para minimizar o impacto negativo sobre as 
operações comerciais, portanto, é preciso realizar avaliações periódicas da probabilidade e impacto de todos os incidentes identificados, utilizando métodos qualitativos e quantitativos. A probabilidade e impacto associados ao risco inerente e residual devem ser determinados individualmente, por categoria, e com base nos fornecedores de serviços existentes. (ITGI, 2007).

Para Cartlidge et al. (2007) os incidentes são frequentemente detectados pelo gerenciamento de eventos ou por usuários em contato com o service desk. O gerenciamento precisa identificar quem deve trabalhar nas ocorrências analisando tendências, e priorizar os incidentes de acordo com a urgência e impacto nos negócios.

Se um incidente não puder ser resolvido rapidamente, um planejamento escalonado deve ser realizado e uma equipe de suporte técnico com as devidas competências neessita ser acionada (FERNANDES; ABREU, 2008). O Apêndice A9 apresenta os livros consultados para obtenção das práticas do gerenciamento de incidentes relacionados à terceirização de serviços de TI.

\section{Infraestrutura}

As práticas relacionadas ao gerenciamento da infraestrutura convergem para a disponibilidade oferecida pelo fornecedor do serviço e adequações da infraestrutura utilizada objetivando auxiliar a realização e entrega dos serviços. Mansur (2009, p. 406) afirma que a manutenção preventiva e corretiva é o principal fator que afeta e impacta o custo da disponibilidade da infraestrutura tecnológica. O gerenciamento dessas práticas implica em manutenção preventiva e programada em softwares, incluindo sistemas operacionais, hardware e telecomunicações.

Segundo Fernandes e Abreu (2008, p. 66) as práticas para o gerenciamento da infraestrutura incluem: identificação de novas tecnologias ou atualizações tecnológicas, necessárias para a realização dos serviços pelos seus fornecedores de serviços; identificação da infraestrutura atual para o suporte aos objetivos de desempenho estabelecidos e aos objetivos estratégicos da empresa; avaliação do impacto das necessidades de aplicações sobre a infraestrutura; e avaliação dos riscos que representam para a continuidade do negócio. De acordo com o ITGI (2007) é preciso desenvolver uma estratégia e um plano de manutenção da infraestrutura 
utilizada ou disponibilizada pelo fornecedor de serviço, e garantir que as alterações sejam controladas de acordo com a organização do processo de gestão da mudança.

Definir e implementar procedimentos para monitorar a infraestrutura de TI e eventos relacionados, assegurar que a informação cronológica esteja sendo armazenada em registros de operações, a fim de habilitar a reconstrução, revisão e exame das sequências do tempo de operações e as outras atividades envolvendo ou suportando operações, são descritas como práticas relacionadas ao gerenciamento da infraestrutura (HEFLEY; LOESCHE, 2006; CARTLIDGE et al., 2007). O Apêndice A10 apresenta os livros consultados para obtenção das práticas do gerenciamento de infraestrutura inerentes à terceirização de serviços de TI.

\section{Mercado}

Hefley e Loesche (2006) afirmam que identificar as práticas recomendadas de processos para usar como base de comparação são procedimentos fundamentais no gerenciamento do mercado. As informações necessárias para criar a comparação de referência desejada devem ser identificadas e os dados internos sobre os processos relacionados ao gerenciamento da terceirização de serviços de TI devem ser coletados para a realização de um benckmark.

O ITGI (2007) orienta a estabelecer um processo para monitorar o setor empresarial, industrial, tecnológico, de infraestrutura, e as tendências do ambiente jurídico, incorporando as consequências dessas tendências para o desenvolvimento em ações corretivas em comum acordo com os fornecedores de serviços.

É necessário comparar o desempenho dos processos com as práticas recomendadas, identificando lacunas de desempenho e a partir disso executar ações para realizar as melhorias necessárias, comunicando os resultados do benchmarking para as partes interessadas (RIPIN; SAYLES, 1999). O Apêndice A11 apresenta os livros consultados para obtenção das práticas do gerenciamento de mercado inerentes à da terceirização de serviços de TI.

\section{Mudança}

As práticas do gerenciamento de mudança estão focadas na transferência de recursos entre o tomador do serviço, ou seja, entre a organização contratante e o fornecedor de serviço, tido como contratado. 
As estratégias de mudanças devem ser definidas de forma a manter o foco nas mudanças, inclusive as culturais; facilitar a disponibilização de recursos; definir e implementar planos de contingência; promover a discussão sobre os requisitos de serviços, assegurando sua total compreensão; estabelecer os processos a serem cumpridos durante o acordo contratual; e definir todas as tarefas a serem exercidas juntamente com os prazos e responsáveis (SAAD, 2006, p. 228).

Segundo Hefley e Loesche (2006) dentre as práticas indicadas, o gestor deve avaliar a prontidão para a mudança; estabelecer e implementar equipe para o fornecimento de mudança; comunicar a disponibilidade de mudança para as partes interessadas; analisar as implicações e impactos da mudança; criar estratégias de recursos humanos para apoiar as ações; apoiar a transição das pessoas envolvidas; revisar e atualizar periodicamente os planos e as estratégias de recursos humanos; constituir equipe de transição de serviços para o planejamento e acompanhamento ao fornecedor do serviço; realizar o planejamento da transição; analisar, revisar e aprovar os planos de transição de serviços; e verificar a prontidão para a implantação dos serviços.

Greaver II (1999, p. 255) complementa as considerações de Hefley e Loesche afirmando que o gestor deve: certificar-se com planos de continuidade do serviço durante sua transferência; implementar projetos-piloto, com base na identificação dos riscos; acompanhar o status e o progresso contra o plano de transição de serviços; identificar o pessoal a ser transferido e resolver quaisquer questões relacionadas com esta transferência; criar procedimentos de saída para o pessoal transferido; implementar planos de comunicações relativos às mudanças de recursos humanos; documentar as competências do pessoal transferido; identificar lacunas de pessoal e de competências de trabalho com base na transferência de pessoal, tomando medidas para solucionar as lacunas; criar, executar e manter registros do plano de transferência de conhecimento.

São dezenas de práticas relacionadas a mudanças, sendo elas interligadas às outras dimensões estudadas. O ITGI (2007) foca suas práticas no sentido de garantir que as alterações sejam registradas, avaliadas, autorizadas, priorizadas, planejadas, testadas, implementadas, e revistas de forma controlada.

O objetivo do processo de gestão da mudança é garantir que métodos padronizados sejam usados para o tratamento rápido e eficiente de todas as mudanças. 
A definição de métodos para gerir, controlar as alterações e documentar a prestação dos serviços realizados pelos fornecedores, a análise das alterações propostas para a prestação do serviço, a criação e coordenação de planos para as mudanças de serviços conjuntamente com os fornecedores de serviços, são procedimentos a serem realizados pelos gestores da terceirização de serviços de TI (MANSUR, 2009).

Para Cartlidge et al. (2007) é necessário realizar uma avaliação de todos os pedidos de mudança de uma forma estruturada para determinar os impactos sobre todas as áreas, assegurando que as mudanças sejam categorizadas, priorizadas e autorizadas.

É essencial estabelecer um processo para definir, sensibilizar, testar, documentar, avaliar e autorizar as alterações de emergência que não seguem o processo de mudança estabelecida, tendo em vista a implantação de um sistema de monitoramento e relatórios para documentar as mudanças rejeitadas, comunicando o status a todas as pessoas envolvidas. O Apêndice A12 apresenta os livros consultados para obtenção das práticas do gerenciamento de mudanças inerentes à terceirização de serviços de TI.

\section{Nível de Serviço}

O gerenciamento dos níveis de serviços disponibiliza uma série de práticas que possibilitam não só a gestão da qualidade dos serviços realizados pelos fornecedores de serviços, mas também o cumprimento adequado do acordo do nível de serviço (CORBETT, 2004, p. 125).

Segundo Van Grembergen, De Haes e Amalinckx (2003) as práticas que garantam que uma empresa tenha qualidade no serviço contratado devem ser regidas pelo gestor, sendo que é possível estabelecer procedimentos de controle, monitoramento e desempenho que atendam às necessidades gerenciais de controle e medição da terceirização de serviços de TI.

Lewis (1999) afirma que é preciso controlar a qualidade dos serviços estabelecendo-se métricas a partir de um padrão de qualidade. O gerenciamento deve abranger: o entendimento sobre os processos selecionando parâmetros e indicadores para prover os serviços realizados; a definição em conjunto com os fornecedores de serviços dos indicadores mais adequados para a gestão; a utilização das ferramentas para o monitoramento com objetivos de prover, divulgar e armazenar as informações; e a definição das metas, parâmetros e periodicidade de monitoração dos indicadores. 
Monitorar e comunicar continuamente com critérios de desempenho de nível de serviço; criar relatórios sobre as conquistas de níveis de serviço e oferecê-los aos interessados; analisar as estatísticas e colocá-las em prática a fim de identificar as tendências negativas e positivas para os serviços, são práticas de gerenciamento de nível de serviço identificadas pela ITGI (2007). Além destas, o gestor deve rever periodicamente os contratos estabelecidos com fornecedores de serviços a fim de garantir que eles sejam eficazes e atualizados (CARTLIDGE et al., 2007). O Apêndice A13 apresenta os livros consultados para obtenção das práticas do gerenciamento de nível de serviço inerentes à terceirização de serviços de TI.

\section{Política}

Quando tratamos de gerenciamento da terceirização de serviços de TI, cabe ao gestor eleger como um dos objetivos o gerenciamento de seus fornecedores de serviços a fim de prover diversos serviços com equipes altamente capacitadas e experientes. Para que isso ocorra é preciso estabelecer políticas internas para cumprimento das cláusulas contratuais. Os processos de relacionamento devem descrever as relações com os fornecedores de serviços e com o negócio.

Políticas de qualidade, de segurança, de gerenciamento, de mudança, financeira, de aquisição etc., devem ser definidas, estabelecidas e alinhadas à estrutura de GTI com a governança global da empresa e ambiente de controle (HEFLEY; LOESCHE, 2006). As políticas instituídas devem confirmar que a estrutura de GTI assegure a conformidade com leis e regulamentos e que esteja alinhada com as entregas dos serviços, com as estratégias da empresa e com seus objetivos.

Os princípios e as práticas de governança de TI para gerir e controlar a terceirização de serviços de TI de forma estratégica preocupam-se com dois assuntos: a mitigação dos riscos relacionados à terceirização e ao valor que isso proporciona à empresa (HARDY, 2006; ITGI, 2007). As políticas devem compreender todas as dimensões possíveis a fim de apresentarem resultados superiores aos de seus concorrentes em função da tomada de melhores decisões (ITGI, 2007).

Segundo Hefley e Loesche (2006) o gerenciamento das políticas estabelecidas deve apresentar unidades de responsabilidades; desenvolver e implementar, quando necessário, diretrizes ou 
procedimentos específicos para as suas unidades; facilitar a formação e divulgação de informações; e promover os fornecedores a uma adesão política.

Bragg (2006, p. 76) afirma que se devem adotar políticas para reger o gerenciamento da terceirização de TI da mesma forma como os procedimentos normalmente são adotados para as políticas organizacionais.

De acordo com o ITGI (2007) o gestor deve desenvolver e manter um conjunto de políticas de apoio à estratégia da terceirização de serviços de TI. Estas políticas devem incluir intenções políticas, papéis e responsabilidades; processo de exceção; abordagem de conformidade; e referências a procedimentos, normas e orientações. Sua relevância deve ser confirmada e aprovada regularmente.

Verhoef (2007, p. 249) ressalta que no gerenciamento devem ser implantadas e executadas as políticas de terceirização de TI de todo o pessoal relevante, para que seja incorporado e para que faça parte das operações da empresa.

Salle e Di-Vitantonio (2006, p. 377) defendem que a natureza da relação entre a função de TI e as linhas de negócios forma políticas de gestão dos serviços empresariais. Essas políticas empresariais de gerenciamento de serviços devem ser divididas em uma hierarquia de três camadas: controladores dos serviços - que otimizam a alocação de recursos dentro de um serviço; controladores de domínios - que regulam a alocação de recursos em um conjunto de serviços empresariais e os controladores globais - que definem prioridades entre os domínios de negócios. O Apêndice A14 apresenta os livros consultados para obtenção das práticas do gerenciamento de política inerentes à terceirização de serviços de TI.

\section{Problema}

Segundo o ITGI (2007) um problema é a causa de um ou mais incidentes. Geralmente a causa não é conhecida no momento em que um problema ocorre e os processos de gestão do problema são responsáveis por esta investigação. $O$ gestor que estiver envolvido no gerenciamento dos problemas deve evitar que incidentes ocorram eliminando todo e qualquer incidente recorrente e minimizar o impacto de incidentes que não podem ser impedidos (CORBETT, 2004, p. 182). 
Para Greaver II (1999, p. 282) os problemas relacionados à terceirização de serviços de TI podem ser segmentados em quatro áreas: pessoas; processos; tecnologia e todos as outras (orgulho, ego, posição hieráquica, fraquezas humanas etc.). De acordo com o autor, ao gestor cabe diagnosticar as causas dos problemas, determinando a resolução, e garantindo que a resolução seja implementada, mantendo registradas as informações sobre os problemas e suas respectivas resoluções.

Segundo Cartlidge et al. (2007) os problemas são categorizados de forma semelhante aos incidentes, mas o objetivo é compreender as causas, as soluções e solicitar alterações permanentemente a fim de resolver os problemas. Soluções alternativas são documentadas em um banco de dados, melhorando a eficiência e a eficácia do gerenciamento do problema. Parafraseando Hefley e Loesche (2006) o gestor deve identificar métodos para registro de problemas ou conflitos relatados pelo fornecedor do serviço e pelas áreas envolvidas, classificando as questões ou disputas.

O ITGI (2007) compartilha das ideias de Hefley e Loesche afirmando que se deve controlar as questões, disputas e litígios por meio de métodos, tanto para o tomador do serviço quanto ao fornecedor de serviços, mantendo-se registros de problemas, disputas e as suas resoluções. O Apêndice A15 apresenta os livros consultados para obtenção das práticas do gerenciamento de problema inerentes à terceirização de serviços de TI.

\section{Qualidade}

A dinâmica do ambiente terceirizado é bastante diferente do ambiente interno de uma organização. O fornecedor do serviço oferece qualidade em sua prestação, implementando melhorias de resultados, requisitos e controle de mudanças, e equipes com maior nível de habilidade e educação do que é encontrado em muitos departamentos de TI (BROWN, 2006, p. 142). Muitas vezes, o fornecedor do serviço consegue conduzir à melhoria da qualidade no planejamento e na gestão financeira do contrato.

Segundo Hefley e Loesche (2006) o potencial dos fornecedores de serviços é avaliado durante a execução dos serviços a fim de saber se está de acordo com o que foi contratado. Afirmam

que se deve atribuir responsabilidade pelo cumprimento da garantia de qualidade Quality Assurance (QA) e fornecer ao grupo sistemas adequados de QA, controles e competências de 
comunicação, assegurando que as responsabilidades e tamanho do grupo QA satisfaçam às exigências da organização.

O gestor deve criar elementos para medição de qualidade, supervisão e revisão. É necessário definir, planejar e implementar, controlar e registrar medidas para continuar a fiscalizar o cumprimento do QA, bem como o valor que o QA proporciona. As informações devem ser utilizadas pelo gestor a fim de tomar as ações corretivas e preventivas (ITGI, 2007).

Quando os objetivos acordados não forem cumpridos, ou seja, o progresso da prestação do serviço não foi como o esperado, a prática de gestão de revisão deve criar ações de reparação, apoiada por relatórios a fim de permitir que as partes interessadas revejam o planejamento estratégico em direção aos novos objetivos (GREAVER II, 1999, p. 274).

De acordo com o ITGI (2007) o gerenciamento deve ser no sentido de criar modelos para acompanhar de perto o andamento do projeto para o sucesso final, bem como para elevar a qualidade do curso em serviços gerenciados. Além desses aspectos, também é preciso melhorar a eficiência, aumentar a efetividade e reduzir riscos, trazendo otimização e racionalização; fornecer códigos de práticas no suporte da qualidade; e prover aderência e conformidade com o modelo utilizado com as práticas de governança.

A gestão da melhoria da qualidade provê às organizações elementos essenciais para a eficácia dos processos. A implantação e gerenciamento da qualidade dos serviços prestados pelos fornecedores devem atender às necessidades de negócio (VAN GREMBERGEN; DE HAES; GULDENTOPS, 2004, p. 12). O gestor deve ter habilidade de monitorar a eficiência e eficácia da qualidade, melhorando-as se necessário. O Apêndice A16 apresenta os livros consultados para obtenção das práticas de qualidade inerentes à terceirização de serviços de TI.

\section{Relacionamento}

No gerenciamento, as práticas estão focadas nos relacionamentos com os stakeholders, incluindo usuários, fornecedores e parceiros envolvidos no fornecimento de serviços. Nesse sentido, é necessário gerenciar e motivar as pessoas envolvidas no processo de forma que os serviços sejam efetivamente entregues (POWER; DESOUZA; BONIFAZI, 2006). 
O gestor deve adotar práticas que tratam do entendimento das competências de pessoal e força de trabalho necessária, que preencham as necessidades e incentivem o comportamento das pessoas para uma entrega de serviço efetiva (MANSUR, 2009).

Corroborando com Mansur, Hefley e Loesche (2006) orientam a definir os papéis e responsabilidades necessários para atingir os objetivos definidos: identificar as competências de pessoal necessárias para a interação com o fornecedor de serviços, bem como os pontos de contato com o fornecedor de serviços e alternativas de substituição destes fornecedores; acompanhar os assuntos e decisões tomadas, e tomar medidas de resolução, quando necessário.

Para Fernandes e Abreu (2008) o gestor deve identificar pessoas-chave de contato junto aos fornecedores de serviços, estabelecendo relações com as equipes, proporcionando canais regulares de comunicação e revendo periodicamente o status do relacionamento com cada prestador de serviço.

A identificação dos fornecedores serviços para os quais é fundamental para estabelecer relacionamentos colaborativos deve ser uma prática constante (BON; VERHEIJEN, 2006, p. 80)

Albertin e Sanches, (2008) descrevem que o incentivo a participação e o envolvimento dos fornecedores de serviços por meio de equipes multifuncionais em abordagens participativas sobre os seus serviços devem ser práticas constantes.

De acordo com o ITGI (2007) processos para gerenciar em conjunto com os fornecedores de serviços a fim de satisfazer os objetivos definidos; co-implementar a gestão do desempenho de relações com os fornecedores de serviços; incentivar o uso de solução conjunta de problemas e tomada de decisão; proporcionar oportunidades de desenvolvimento de habilidades tanto para o tomador do serviço quanto para os fornecedores de serviços; formalizar o processo de gestão do relacionamento com fornecedores para cada fornecedor, são portanto, práticas a serem adotadas pelo gestor do relacionamento.

Os gestores de relacionamento devem acompanhar os acordos contratuais estabelecidos com os fornecedores nas questões que garantam a qualidade do relacionamento baseado na 
confiança e transparência, como por exemplo, o SLA. O Apêndice A17 apresenta os livros consultados para obtenção das práticas do gerenciamento de relacionamento inerentes à terceirização de serviços de TI.

\section{Responsabilidade}

Na gestão da terceirização de serviços de TI uma das principais tarefas do gestor é a definição dos papéis, responsabilidades e autoridades necessárias para cumprir os requisitos acordados.

Segundo Hefley e Loesche (2006) as práticas inerentes à gestão da responsabilidade incluem a identificação das competências dos fornecedores de serviços e suas respectivas equipes, identificação das lacunas nas competências de cada stakeholders; estabelecimento de papéis e responsabilidades para cada fornecedor e equipe, comunicando para o pessoal de TI, usuários finais e a todos os responsáveis pelo processo.

Mansur (2007, p. 22) afirma que a gestão das responsabilidades está diretamente ligada à gestão dos incidentes, pois esse processo define as atividades e responsabilidades para minimizar impactos e atender os níveis de serviços acordados.

Ainda segundo Mansur (2007, p. 89) “as responsabilidades dos usuários e do gerenciamento dos serviços de TI devem estar claramente definidas nos SLA”.

Para Bon e Verheijen (2006) o gerenciamento de responsabilidades inclui as atribuições ao suporte de problemas e segurança. Todas as responsabilidades devem ser comunicadas e confirmadas por todos os envolvidos no processo.

Práticas que estabeleçam um framework de controle consistente com o ambiente de controle da empresa, o qual deve estabelecer claramente as responsabilidades de forma não ambígua, bem como a definição de responsabilidades pela obtenção dos benefícios para o negócio, entrega de capacitações e controle de custos, devem ser claramente atribuídas aos envolvidos e adotas pelo gestor (FERNANDES; ABREU, 2008). Ainda segundo os autores, o gestor deve "formular um plano de tratamento de riscos que identifique ações gerenciais, recursos, 
responsabilidades e prioridades.” (p. 354), além de definir como as responsabilidades serão atribuídas entre todos os envolvidos.

É necessário assegurar que os fornecedores de serviços e equipes conheçam e cumpram as políticas da organização para que eles atendam ao que foi acordado e às suas respectivas exigências contratuais (ITGI, 2007). Definir, acompanhar e supervisionar as funções, responsabilidades e estruturas de remuneração de pessoal, incluindo a exigência de aderir às políticas e procedimentos de gestão, o código de ética e práticas profissionais, são práticas que devem ser aplicadas pelo gestor da terceirização de serviços de TI (ITGI, 2007).

Fernandes e Abreu (2008, p. 329) apresentam, ainda como prática, o estabelecimento de um acordo formal com os fornecedores de serviços que articule claramente as responsabilidades e compromissos de ambas as partes. O Apêndice A18 apresenta os livros consultados para obtenção das práticas do gerenciamento de responsabilidade inerentes à terceirização de serviços de TI.

\section{Risco}

As práticas estão focadas na identificação e gerenciamento que de alguma forma influenciam o atendimento dos objetivos e requisitos do cliente. Segundo Bragg (2006) práticas que tenham atenção aos riscos associados com segurança, confidencialidade, infraestrutura e desastres, que podem causar interrupção e falhas nos serviços e podem impactar no atendimento dos requisitos do cliente, devem ser monitoradas constantemente.

Mansur (2007, p. 130) descreve que o gerenciamento dos riscos representa "a probabilidade e o impacto de um possível ataque ao ambiente e varia de ambiente para ambiente, mas é constante dentro de um ambiente específico”.

Algumas práticas inerentes ao gerenciamento dos riscos são a realização de análise de riscos como parte do plano de continuidade dos negócios e com base nestas, devem gerar os planos de recuperação dos serviços de TI.

Tal procedimento inclui três atividades sendo que duas referem-se à análise de riscos (uma se dá a partir da verificação do valor, das ameaças e das vulnerabilidades e a outra ocorre com 
base no Computer Risk Analysy and Management Methodology (CRAMM)). A terceira é inerente ao gerenciamento dos riscos com avaliação das contramedidas, do planejamento e do gerenciamento de atividades para os desastres potenciais (MANSUR, 2007).

Para ITGI (2007) o gestor deve identificar e mitigar os riscos relativos à capacidade dos fornecedores para continuar a prestação efetiva dos serviços de uma maneira segura e eficiente em uma base contínua, bem como garantir que os contratos estejam em conformidade com os padrões comerciais adotados e com os requisitos legais e regulamentares.

A gestão dos riscos deve aprofundar acordos de não divulgação (NDAS), os contratos, a viabilidade da continuação como fornecedor de serviço, as conformidades com os requisitos de segurança, os fornecedores alternativos, sanções e recompensas etc. (VAN GREMBERGEN; DE HAES; GULDENTOPS, 2004, p. 18).

Priorizar e planejar as atividades de controle em todos os níveis para implementar as respostas aos riscos identificados, incluindo a identificação dos custos, benefícios e responsabilidades para sua execução, são práticas do gerenciamento de risco (ITGI, 2007).

É necessário ainda obter aprovação para as ações que serão realizadas e aceitação de riscos residuais, acompanhando a execução dos planos e relatoriando todo e qualquer desvio à gerência superior.

Hefley e Loesche (2006) orientam a adotar práticas em relação aos riscos como: identificá-los para cada fornecedor de serviço; avaliar sua exposição para a empresa; priorizar e determinar a forma de responder aos riscos encontrados na sua avaliação; identificar as responsabilidades (sobre cada risco) do tomador do serviço e dos fornecedores de serviços; verificar se as respostas aos riscos estão alinhadas com os objetivos definidos com os fornecedores; documentar suas avaliações e suas respectivas respostas; analisar e aprovar os procedimentos e métodos para implementar respostas aos riscos tanto para o tomador do serviços quanto para os fornecedores de serviços; acompanhar as respostas aos riscos, tomando as medidas apropriadas; manter sua avaliação, juntamente com o fornecedor do serviço, conforme o caso; definir métodos para avaliar o impacto das medidas propostas; documentar os riscos, exposições aos riscos e suas respostas, priorizando-os de acordo com a avaliação realizada. $\mathrm{O}$ 
Apêndice A19 apresenta os livros consultados para obtenção das práticas do gerenciamento de risco inerentes à terceirização de serviços de TI.

\section{Segurança}

O gerenciamento de segurança está ligado a várias dimensões: segurança da informação referente ao controle de acessos e privilégios; segurança da informação em aplicativos; segurança da infraestrutura de TI; e segurança de dados. As práticas inerentes a estas dimensões podem ser aplicadas isoladamente ou de forma conjunta (FERNANDES; ABREU, 2008; MANSUR, 2009).

Cartlidge et al. (2007) afirmam que o processo do gerenciamento de segurança é alinhar a segurança de TI com a segurança do negócio, garantindo que seja gerido de forma eficaz em todos os serviços e atividades prestadas, de modo que a informação: esteja disponível e utilizável quando necessário (disponibilidade); seja vista apenas por aqueles que têm o direito de acesso (confidencialidade); e esteja completa, precisa e protegida contra a utilização e modificação (integridade).

O ITGI (2007) estabelece que é preciso definir e implementar políticas e procedimentos para identificar e utilizar os requisitos de segurança aplicáveis ao recebimento, processamento, armazenamento e saída de dados para atingir os objetivos de negócio, a política de segurança da organização e os requisitos regulamentares. A gestão da segurança, portanto deve estar em conformidade com os requisitos de negócios.

Para haver um completo gerenciamento de segurança, o gestor deve adotar as seguintes práticas que identifiquem: confidencialidade, integridade e requisitos de disponibilidade; requisitos de controle de acesso, autenticação e responsabilidades; requisitos de segurança física; exigências de dados; necessidades de privacidade; deve também identificar e analisar as ameaças potenciais à organização; a infraestrutura a proteger e documentar as razões para a decisão; criar soluções de segurança, junto com os fornecedores de serviços, conforme o caso, com base nas necessidades identificadas e nas ameaças; acompanhar as ameaças aos ativos da organização, tomando as medidas apropriadas (HEFLEY; LOESCHE, 2006). 
Segundo Bon e Verheijen (2006) indicadores de desempenho do gerenciamento da segurança devem ser implantados, sendo que o acompanhamento deve ser feito em conjunto com os fornecedores de serviços. O Apêndice A20 apresenta os livros consultados para obtenção das práticas do gerenciamento de segurança inerentes à terceirização de serviços de TI.

\section{Sistemas de Informação}

Turban, McLean e Wetherbe (2004) apontam alguns motivos que dificultam o gerenciamento dos sistemas de informações: projetos de desenvolvimento remendados; falhas técnicas; e aumento dos custos inerentes aos sistemas de informação se benefícios aparentes.

Para Stair (1998) o gestor deve direcionar práticas que verifiquem a qualidade das informações, bem como a qualidade do formato destas, e o tempo em que as informações são geradas e processadas.

Na concepção de Fernandes e Abreu (2008, p. 153) o gestor deve implantar sistemas de informações que deem apoio à operação da terceirização de serviços de TI. Deve, também, adotar práticas que identifiquem fontes e classes de informações necessárias para apoiar os objetivos organizacionais; criar plano para a criação e manutenção de terceirização do conhecimento dentro do sistema de conhecimento; coletar, organizar e analisar as informações adquiridas; rastrear o uso do conhecimento disponível; e ainda tomar medidas, quando necessário, para corrigir eventuais falhas.

Identificar requisitos de licenças de tecnologia; acordar os licenciamentos adquiridos pelo tomador de serviços ou pelo fornecedor do serviço; coordenar com o fornecedor de serviços a transferência das licenças necessárias, com base em requisitos de identificação; revisão das licenças transferidas, verificando se cumprem os requisitos acordados; manter um inventário de licenças de tecnologia com base em acordos com o fornecedor de serviços, e sua respectiva documentação, são práticas que devem ser adotadas na gestão dos sistemas de informações (HEFLEY; LOESCHE, 2006).

Greaver II (1999) aponta que as práticas estão focadas no gerenciamento da disponibilidade e adequação da infraestrutura tecnológica utilizada para auxiliar a entrega de serviços. Essas práticas incluem atividades que controlam a tecnologia existente, gerenciam alterações nessas 
tecnologias e apropriadamente integram a infraestrutura tecnológica com o cliente, fornecedores e parceiros que efetivamente participam da entrega do serviço. O Apêndice A21 apresenta os livros consultados para obtenção das práticas do gerenciamento de sistema de informação inerentes à terceirização de serviços de TI.

\section{Treinamento}

O gerenciamento de treinamento realizado junto aos fornecedores de serviços visam fornecer orientações adequadas quando contratados e formação contínua para manter os seus conhecimentos, habilidades, capacidades, controles internos e de sensibilização para a segurança no nível necessário para atingir os objetivos organizacionais estabelecidos (ITGI, 2007).

Fernandes e Abreu (2008) ressaltam a importância de se estabelecer ações de desenvolvimento profissional. "Aderir à política de educação profissional continuada da ISACA (que envolve uma quantidade mínima de horas anuais de treinamento).” (p. 202, parênteses dos autores).

Para Mansur (2007) os treinamentos são investimentos que devem ser feitos na capacitação de todos os envolvidos de forma a garantir o seu correto uso e performance.

O processo de contratação de terceiros implica em uma certificação da capacidade de prestar o serviço, representar a empresa e dominar a tecnologia envolvida, na qual se deve oferecer treinamento preparatório para os terceiros mantendo toda a "rede" atualizada em relação à evolução das ofertas e aos problemas que são registrados, a fim de agir de forma preventiva (ALBERTIN; SANCHEZ, 2008, p. 53).

Para os autores o gestor deve pensar em algum tipo de e-Learning, site de relacionamento com terceiros, pesquisas de satisfação junto aos clientes com feedback para os avaliados, e premiação por alcançar níveis de satisfação ou de produtividade desejados. "Assegurar e providenciar treinamento de atualizações técnicas, com prazos, assuntos e qualidade especificados pela contratante, para os profissionais disponibilizados para a execução dos serviços, cabendo à contratada arcar com os correspondentes custos do treinamento.” (p. 125).

Segundo o ITGI (2007), algumas práticas podem ser adotadas, entre elas vale destacar: a identificação das necessidades de educação e formação; o estabelecimento e atualização 
regular de um currículo para cada grupo-alvo de fornecedores de serviços, considerando as necessidades estratégicas (atuais e futuras) e de negócios; a implementação de softwares de apoio para o treinamento; o estabelecimento das competências atuais e futuras, dos perfis de competência e de certificação e/ou necessidades de credenciamento; a definição das formas de entrega do treinamento (por exemplo, sala de aula, educação a distância), do tamanho do grupo-alvo, da acessibilidade e do calendário.

Power, Desouza e Bonifazi (2006) apresentam a importância de avaliar a educação e a formação dos cursos ministrados com aspectos de relevância, qualidade, eficácia, retenção do conhecimento, custo e valor. O resultado dessa avaliação deve servir como base para a definição dos treinamentos futuros. O Apêndice A22 apresenta os livros consultados para obtenção das práticas do gerenciamento de treinamento dos envolvidos na terceirização de serviços de TI.

\section{Valor}

Organizações que anteriormente desenvolviam e comercializavam exclusivamente produtos vêm, de forma crescente, incorporando serviços na sua atividade, representando assim os serviços uma importância também crescente na criação de valor (VAN DER VALK, 2008).

Fornecedores de serviços são capazes de continuamente inovar e agregar valor aos serviços fornecidos aos clientes e a outros envolvidos em função de poder customizar os serviços de acordo com seus clientes e potenciais clientes e prever seu desempenho com base em experiências anteriores. (GREAVER II, 1999)

Albertin e Sanchez (2008) afirmam que em terceirização de serviços de TI, a contribuição para geração de valor ao tomador do serviço está nos domínios de seus processos transacionais com o objetivo de produzir conhecimentos estratégicos baseados nos dados e nas informações, das capacidades de desempenhar suas competências e habilidades, da velocidade em inovar e de se adaptar às mudanças.

Para o ITGI (2007) o gestor deve gerenciar os investimentos realizados, ativos terceirizados de TI e serviços para garantir que eles repassem o maior valor possível no apoio à estratégia da empresa e aos objetivos estabelecidos. Práticas como a implementação de um processo para monitorar os benefícios da criação e manutenção de valor; identificação e documentação 
de todo o processo, no qual os relatórios devem ser revistos, quando da existência de oportunidades para melhorar a contribuição de valor, devem ser definidas e implementadas.

“A criação quantificável de valor entre os parceiros; a determinação e medição do valor da aliança; e a melhoria contínua da performance do relacionamento por um acompanhamento metodológico são aspectos que possibilitam um padrão sustentável na criação de valor". (ALBERTIN; SANCHEZ, 2008, p. 100)

De acordo com Bon e Verheijen (2006, p. 76) o gestor "deve se certificar de que os processos estão operando de um modo que agrega valor sem impor excessos desnecessários”. Já para Mansur (2007, p. 3), “as decisões sobre as necessidades que geram valor ao negócio, devem encontrar equilíbrio entre criatividade e disciplina".

As comparações entre o desempenho do fornecedor de serviços com os objetivos de negócios propostos a fim de saber se está gerando valor para a empresa, bem como a identificação e documentação do aumento ou não no valor para a empresa, devem ser colocadas em prática constantemente pelo gestor (HEFLEY; LOESCHE, 2006).

Ao alcançar o nível de parte integrante do negócio, o fornecedor de serviço passa a ser centro de investimento e ganhar importância, significância e valor dentro da empresa. O Apêndice A23 apresenta os livros consultados para obtenção das práticas do gerenciamento de valor proporcionado pela terceirização de serviços de TI.

O quadro 4 apresenta um resumo geral com as dimensões e seus respectivos autores, utilizados para composição e conceituação de cada dimensão.

Quadro 4 - Autores utilizados para a revisão bibliográfica sobre as dimensões do gerenciamento da terceirização de serviços de TI (continua)

\begin{tabular}{|l|l|}
\hline \multicolumn{1}{|c|}{ Dimensão } & \multicolumn{1}{c|}{ Autores } \\
\hline Aquisição & $\begin{array}{l}\text { Murray e Kotabe (1999); Axelsson e Wynstra (2002); Corbett (2004); Hefley e } \\
\text { Loesche (2006); Grönroos (2007); ITGI (2007); Van der Valk (2008); Mansur } \\
\text { (2009) }\end{array}$ \\
\hline Capacidade & $\begin{array}{l}\text { Ripin e Sayles (1999); Bragg (2006); Hefley e Loesche (2006); Fernandes e Abreu } \\
\text { (2008); Mansur (2009) }\end{array}$ \\
\hline Comunicação & Greaver II (1999); Cartlidge et al. (2007); ITGI (2007) \\
\hline
\end{tabular}


Quadro 4 - Autores utilizados para a revisão bibliográfica sobre as dimensões do gerenciamento da terceirização de serviços de TI (conclusão)

\begin{tabular}{|c|c|}
\hline Dimensão & \\
\hline Conhecimento & $\begin{array}{l}\text { Bragg (2006); Hefley e Loesche (2006); Hyder, Heston e Paulk (2006); Larsen, } \\
\text { Pedersen e Andersern (2006); Saad (2006); Cartlidge et al. (2007); ITGI (2007); } \\
\text { Fernandes e Abreu (2008) }\end{array}$ \\
\hline Contrato & $\begin{array}{l}\text { Lacity e Willcocks (2001); Prado (2005); Hefley e Loesche (2006); Saad (2006); } \\
\text { Cartlidge et al. (2007); ITGI (2007); Fernandes e Abreu (2008) }\end{array}$ \\
\hline Demanda & $\begin{array}{l}\text { Hefley e Loesche (2006); Saad (2006); Cartlidge et al. (2007); ITGI (2007); } \\
\text { Fernandes e Abreu (2008) }\end{array}$ \\
\hline Desempenho & $\begin{array}{l}\text { Power, Desouza e Bonifazi (2006); Cartlidge et al. (2007); ITGI (2007); Fernandes e } \\
\text { Abreu (2008) }\end{array}$ \\
\hline Financeiro & $\begin{array}{l}\text { Greaver II (1999); Ripin e Sayles (1999); Corbett (2004); Hefley e Loesche (2006); } \\
\text { Cartlidge et al. (2007); ITGI (2007) }\end{array}$ \\
\hline Incidente & $\begin{array}{l}\text { Hefley e Loesche (2006); Cartlidge et al. (2007); ITGI (2007); Mansur (2007); } \\
\text { Fernandes e Abreu (2008) }\end{array}$ \\
\hline Infraestrutura & $\begin{array}{l}\text { Hefley e Loesche (2006); Cartlidge et al. (2007); ITGI (2007); Fernandes e Abreu } \\
\text { (2008); Mansur (2009) }\end{array}$ \\
\hline Mercado & Ripin e Sayles (1999); Hefley e Loesche (2006); ITGI (2007) \\
\hline Mudança & $\begin{array}{l}\text { Greaver II (1999); Hefley e Loesche (2006); Saad (2006); Cartlidge et al. (2007); } \\
\text { ITGI (2007); Mansur (2009) }\end{array}$ \\
\hline Nível de serviço & $\begin{array}{l}\text { Lewis (1999); Van Grembergen, De Haes e Amalinckx (2003); Corbett (2004); } \\
\text { Cartlidge et al. (2007); ITGI (2007) }\end{array}$ \\
\hline Política & $\begin{array}{l}\text { Bragg (2006); Hardy (2006); Hefley e Loesche (2006); Salle e Di-Vitantonio (2006); } \\
\text { ITGI (2007); Verhoef (2007) }\end{array}$ \\
\hline Problema & $\begin{array}{l}\text { Greaver II (1999); Corbett (2004); Hefley e Loesche (2006); Cartlidge et al. (2007); } \\
\text { ITGI (2007) }\end{array}$ \\
\hline Qualidade & $\begin{array}{l}\text { Greaver II (1999); Van Grembergen, De Haes e Guldentops (2004); Brown (2006); } \\
\text { Hefley e Loesche (2006); ITGI (2007) }\end{array}$ \\
\hline Relacionamento & $\begin{array}{l}\text { Bon e Verheijen (2006); Hefley e Loesche (2006); Power, Desouza e Bonifazi (2006); } \\
\text { ITGI (2007); Albertin e Sanchez (2008); Fernandes e Abreu (2008); Mansur (2009) }\end{array}$ \\
\hline Respons abilidade & $\begin{array}{l}\text { Bon e Verheijen (2006); Hefley e Loesche (2006); ITGI (2007); Mansur (2007); } \\
\text { Fernandes e Abreu (2008) }\end{array}$ \\
\hline Risco & $\begin{array}{l}\text { Van Grembergen, De Haes e Guldentops (2004); Bragg (2006); Hefley e Loesche } \\
\text { (2006); ITGI (2007); Mansur (2007) }\end{array}$ \\
\hline Segurança & $\begin{array}{l}\text { Bon e Verheijen (2006); Hefley e Loesche (2006); Cartlidge et al. (2007); ITGI } \\
\text { (2007); Fernandes e Abreu (2008); Mansur (2009) }\end{array}$ \\
\hline $\begin{array}{l}\text { Sistemas de } \\
\text { Informação }\end{array}$ & $\begin{array}{l}\text { Stair (1998); Greaver II (1999); Turban, McLean e Wetherbe (2004); Hefley e } \\
\text { Loesche (2006); Fernandes e Abreu (2008) }\end{array}$ \\
\hline Treinamento & $\begin{array}{l}\text { Power, Desouza e Bonifazi (2006); ITGI (2007); Mansur (2007); Albertin e Sanchez } \\
\text { (2008); Fernandes e Abreu (2008) }\end{array}$ \\
\hline Valor & $\begin{array}{l}\text { Greaver II (1999); Bon e Verheijen (2006); Hefley e Loesche (2006); ITGI (2007); } \\
\text { Mansur (2007); Albertin e Sanchez (2008); Van der Valk (2008) }\end{array}$ \\
\hline
\end{tabular}

É possível destacar que todo processo de implementação de GTI passa por diversas dimensões - como as citadas - sempre buscando aperfeiçoar o relacionamento entre as equipes envolvidas no processo e que contemple a plena definição das estruturas para 
tomadas de decisão e seus mecanismos de implementação, estando alinhados aos desafios de negócio e visão estratégica de cada organização.

O que se busca, na verdade, é um processo de GTI que possua ao mesmo tempo eficiência e eficácia, de forma a agregar valor ao negócio, enquanto utiliza a TI como suporte às suas necessidades.

Os aspectos ligados à eficiência e eficácia dos processos de GTI estão associados ao gerenciamento e à percepção das expectativas por parte de todos os envolvidos no projeto de implementação, principalmente o alto escalão, o qual deve possuir uma visão da importância da TI para a empresa diferente da visão da mesma TI por parte das áreas de negócio. 


\section{MODELO DE PESQUISA}

Com o propósito de atingir os objetivos deste estudo, inicialmente foi realizada a revisão da literatura existente sobre os temas contemplados (capítulo 2), para que tais temas servissem de auxílio na elaboração do modelo de pesquisa. A partir de tal procedimento este capítulo foi dividido em três seções, a saber: desenvolvimento do modelo de pesquisa, hipótese da pesquisa e construtos e variáveis.

\subsection{Desenvolvimento do modelo de pesquisa}

O modelo conceitual apresenta os inter-relacionamentos entre as práticas adotadas pelo gestor de TI na gestão da terceirização de serviços de TI, e os resultados esperados dessa terceirização, a partir da questão de pesquisa proposta.

A literatura pesquisada indica que existe uma importância significativa de uma estrutura de GTI dentro de um relacionamento de terceirização de serviços de TI e que a gestão com uma estrutura de GTI bem organizada é um importante fator crítico de sucesso para atingir os benefícios esperados. (CLARK; ZMUD; MCCRAY, 1995; DAVIS, 1996; KLEPPER, 1995; MCFARLAN; NOLAN, 1995; WILLCOCKS; CHOI, 1995).

Segundo Clark, Zmud e Mccray (1995) os verdadeiros fatores críticos de sucesso relacionados com o resultado da terceirização de serviços de TI são aqueles associados à GTI com o fornecedor do serviço.

No que se refere às práticas recomendadas de gestão da terceirização de serviços de TI vale complementar que os contratos sozinhos não asseguram o sucesso da terceirização (KLEPPER; JONES, 1998). Um bom gerenciamento da terceirização é o que a organização necessita para garantir que o contrato de terceirização trará os resultados esperados (POPPO; LACITY, 2002).

Já nos resultados obtidos em decorrência da terceirização de serviços de TI, a gestão tem sido apresentada na literatura como um fator crítico de sucesso (KERN, 1997). Dentro do contexto 
da avaliação de resultados, o SLA tem sido indicado como uma importante ferramenta e ajuda a controlar o comportamento do fornecedor do serviço (GELLINGS, 2007). Da mesma forma, a execução de controles sobre o fornecedor de serviço aumenta as chances de sucesso na terceirização (HSU; WU, 2006; WEBB; POLLARD; RIDLEY, 2006; GELLINGS, 2007).

Amparados nesses argumentos, o modelo conceitual (ilustração 4) indica que a adoção de práticas de gestão abordando as dimensões apontadas na ilustração pode levar a um resultado positivo desta terceirização.

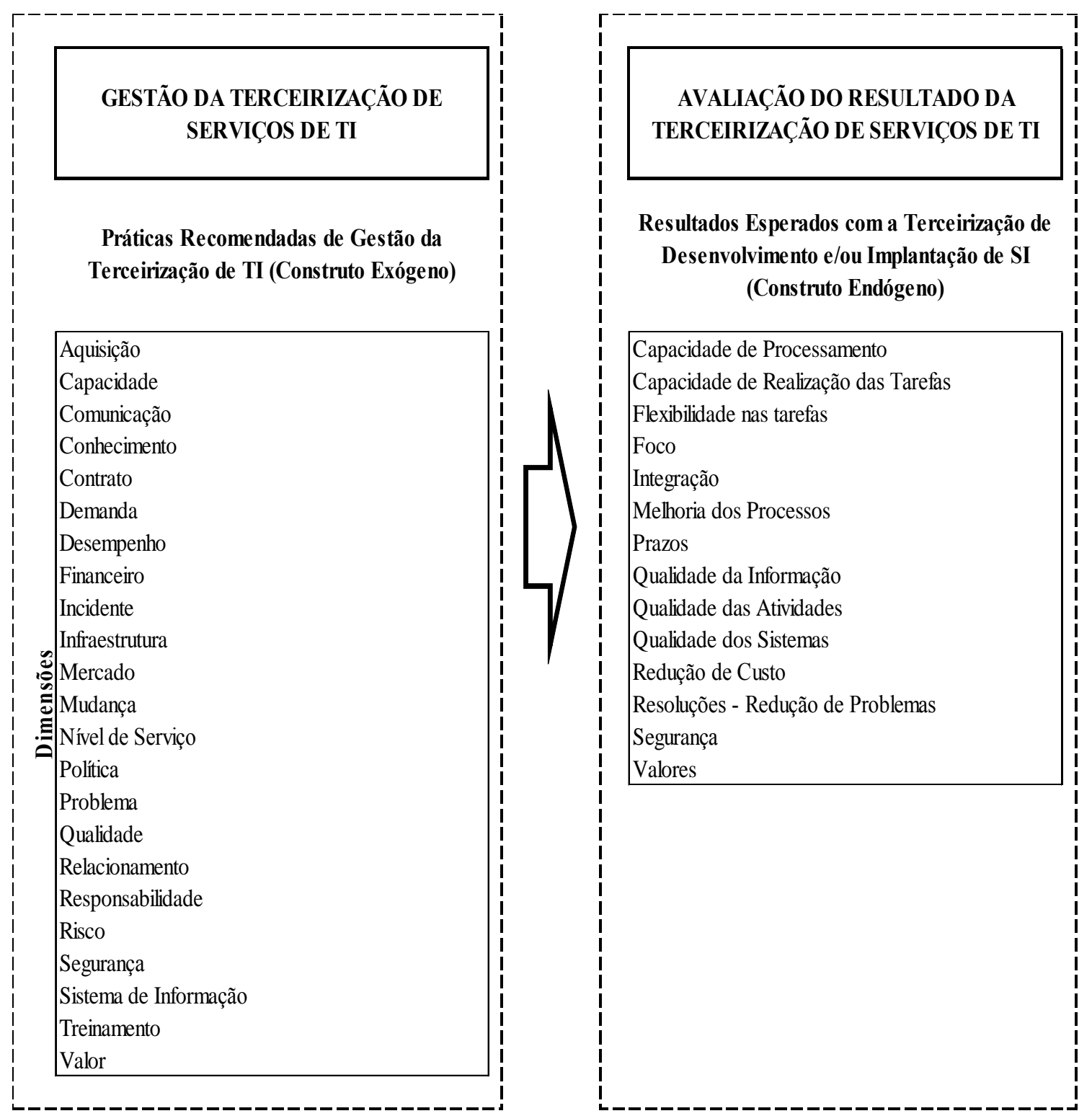




\subsection{Hipótese da pesquisa}

Segundo Lakatos e Marconi (2007, p. 139) a hipótese constitui-se de uma "suposta, provável e provisória resposta a um problema, cuja adequação será verificada através da pesquisa". Considerando os atributos percebidos por meio das práticas adotadas pelo gestor de TI na gestão da terceirização de serviços de TI e os resultados obtidos em decorrência da terceirização de serviços de TI a hipótese a ser testada é:

H1 - A adoção de práticas recomendadas de gestão da terceirização de serviços de TI impacta positivamente nos resultados desta terceirização.

A hipótese proposta envolve a relação entre conceitos não observáveis diretamente, expressos em termos de construtos. A natureza e formas de mensuração desses construtos são abordados na sequência.

\subsection{Construtos}

Segundo Cooper e Schindler (2003, p 53) um construto é "uma imagem ou idéia inventada especificamente para uma determinada pesquisa e/ou criação de teoria”. Hair Jr. et al. (2009) concebem construto como conceitos teóricos a serem utilizados pelos pesquisadores, podendo ser definidos em termos abstratos, no entanto, medidos de forma direta ou sem erro.

\footnotetext{
Um construto pode ser definido em diversos graus de especificidade, variando de conceitos muito limitados até aqueles mais complexos ou abstratos, como inteligência ou emoções. Não importa qual o seu nível de especificidade, porém, um construto não pode ser medido direta e perfeitamente, mas deve ser medido aproximadamente por indicadores múltiplos (ibid., p. 540).
}

Os construtos são obtidos a partir de combinações de conceitos mais simples em termos de assertivas ou variáveis, as quais serão apresentadas mais adiante neste estudo.

Quando se busca relacionar construtos latentes, ou seja, inobserváveis diretamente, a fim de testar possíveis influências, os mesmos são caracterizados como construtos exógenos (causa) e endógenos (consequência), os quais podem ser de primeira ou de ordem superior.

\subsubsection{Construtos exógenos}

Segundo Hair Jr. et al. (2009) o construto exógeno é representado por uma variável estatística obtida da combinação linear de variáveis independentes observáveis diretamente - construto 
de $1^{\text {a }}$ ordem ou a partir de outros construtos, neste caso, tornando-se um construto de ordem superior. O construto de práticas recomendadas de gestão da terceirização de serviços de TI será mensurado a partir de construtos de $1^{\mathrm{a}}$ ordem, os quais são apresentados a seguir e representam:

Aquisição e Contrato - os processos inerentes ao gerenciamento da aquisição do serviço pela empresa, englobando inclusive a análise dos processos anteriores ao da gestão atual, além do gerenciamento de parcerias, seleção de fornecedores, análise das propostas, subcontratação em terceirização de serviços de TI, modalidades de contratação, controle de recebimentos, acompanhamento da legislação pertinente, definição do SLA e análise crítica de contratos; e ainda, as análises contratuais, políticas relacionadas à administração dos contratos, tarefas inerentes de cada pessoa envolvida no projeto, registros, documentações e arquivos dos processos, controles e planejamentos, gerenciamento das mudanças, resolução de disputas, reclamações e rescisão contratual. Estas são algumas das práticas que devem estar acordadas e clausuladas, e cujo gestor deve administrar no gerenciamento do contrato (MURRAY; KOTABE, 1999; LACITY; WILLCOCKS, 2001; AXELSSON; WYNSTRA, 2002; CORBETT, 2004; HEFLEY; LOESCHE, 2006; SAAD, 2006; CARTLIDGE et al., 2007).

Nível de Serviço, Demanda e Capacidade - a gestão dos serviços realizados pelos fornecedores de serviços de acordo com os níveis de serviços estipulados em contrato; o gerenciamento ativo com os fornecedores de serviços, revendo e ajustando as demandas de terceirização de TI da empresa, normas, procedimentos e metodologias para garantir que os requisitos legais, regulamentares e contratuais sejam tratados e comunicados dentro dos prazos estabelecidos; e ainda, as práticas que orientam a empresa a controlar e gerenciar seus fornecedores no que dizem respeito a responderem às exigências das demandas, em termos de cronogramas, prazos e custos (LEWIS, 1999; RIPIN; SAYLES, 1999; VAN GREMBERGEN; DE HAES; AMALINCKX, 2003; CORBETT, 2004; BRAGG, 2006; HEFLEY; LOESCHE, 2006; SAAD, 2006; CARTLIDGE et al., 2007; ITGI, 2007; FERNANDES; ABREU, 2008; MANSUR, 2009).

Desempenho e Qualidade - a definição dos objetivos de desempenho estabelecidos até a criação dos indicadores e métricas que serão utilizados, bem como o monitoramento do desempenho e progresso dos serviços realizados; e ainda, a qualidade dos serviços prestados, estabelecendo avaliações durante a execução dos serviços a fim de saber se está de acordo 
com o que foi contratado (GREAVER II, 1999; BROWN, 2006; HEFLEY; LOESCHE, 2006; POWER; DESOUZA; BONIFAZI, 2006; CARTLIDGE et al., 2007; ITGI, 2007; FERNANDES; ABREU, 2008).

Incidente, Problema, Risco e Mudança - os incidentes ocorridos na prestação de serviços que devem ser monitorados e controlados constantemente; o gerenciamento dos problemas a fim de que os mesmos não ocorram e/ou minimizando o impacto daqueles que não pode ser impedidos; a identificação e gerenciamento dos riscos inerentes a cada etapa do processo de terceirização de serviços de TI que de alguma forma influenciam o atendimento dos objetivos e requisitos do cliente; e ainda, a transferência de recursos entre o tomador do serviço, ou seja, a organização contratante e o fornecedor de serviço (contratado), bem como os processos de mudança que devem ser gerenciados quando da entrega do serviço (GREAVER II, 1999; CORBETT, 2004; VAN GREMBERGEN; DE HAES; GULDENTOPS, 2004; BRAGG, 2006; HEFLEY; LOESCHE, 2006; SAAD, 2006; CARTLIDGE et al., 2007; ITGI, 2007; MANSUR, 2007; 2009; FERNANDES; ABREU, 2008).

Infraestrutura, Segurança e Política - a disponibilidade oferecida pelo fornecedor do serviço e adequações da infraestrutura utilizada para auxiliar a realização e entrega dos serviços; o alinhamento da segurança de TI com a segurança do negócio, garantindo que seja gerido de forma eficaz em todos os serviços e atividades prestadas; e ainda, o estabelecimento de políticas internas para cumprimento das cláusulas contratuais (BON; VERHEIJEN, 2006; BRAGG, 2006; HARDY, 2006; HEFLEY; LOESCHE, 2006; SALLE; DI-VITANTONIO, 2006; CARTLIDGE et al., 2007; ITGI, 2007; VERHOEF, 2007; FERNANDES; ABREU, 2008; MANSUR, 2009).

Financeira, Valor, Mercado e Responsabilidade - as práticas relacionadas ao orçamento da terceirização de serviços de TI, genciamento do investimento e custos de ativos de terceirização de TI, estabelecimento de preços, contabilidade e renegociações junto aos fornecedores de serviços; a inovação e agregação de valor aos serviços fornecidos aos clientes e a outros envolvidos; a identificação das melhores práticas de processos do mercado para usar como base de comparação; e ainda, a identificação das responsabilidades dos fornecedores de serviços e suas respectivas equipes (GREAVER II, 1999; RIPIN; SAYLES, 1999; CORBETT, 2004; BON; VERHEIJEN, 2006; HEFLEY; LOESCHE, 2006; CARTLIDGE et al., 2007; ITGI, 2007; MANSUR, 2007; ALBERTIN; SANCHEZ, 2008; FERNANDES; ABREU, 2008; VAN DER VALK, 2008). 
Relacionamento, Comunicação, Sistema de Informação e Treinamento - as práticas que estão focadas nos relacionamentos com os stakeholders, incluindo usuários, fornecedores e parceiros envolvidos no fornecimento de serviços; o gerenciamento de conhecimento adquirido ao longo do fornecimento do serviço de tal forma que os fornecedores de serviços equipes ou pessoas individuais - envolvidos nos processos, tenham fácil acesso ao conhecimento que ela(s) necessita(am) para um trabalho eficiente; a comunicação contínua com o fornecedor, a elaboração de relatórios de gestão sênior de TI com a contribuição da terceirização de serviços de TI aos negócios, especialmente em termos de programas de investimento e desempenho dos serviços prestados; as ações que devem ser feitas para a capacitação de todos os envolvidos de forma a garantir o seu correto uso e performance; e ainda, a implantação e gerenciamento dos sistemas de informações que dão apoio à operação de terceirização (STAIR, 1998; GREAVER II, 1999; BON; VERHEIJEN, 2006; HEFLEY; LOESCHE, 2006; POWER; DESOUZA; BONIFAZI, 2006; CARTLIDGE et al., 2007; ITGI, 2007; MANSUR, 2007; ALBERTIN; SANCHEZ, 2008; FERNANDES; ABREU, 2008).

\subsubsection{Construtos endógenos}

Segundo Hair Jr. et al. (2009) o construto endógeno é representado por uma variável estatística obtida da combinação linear de variáveis dependentes, ou seja, é um construto ou variável que representa o resultado de uma relação causal. À semelhança do construto exógeno, pode ser obtido por meio de variáveis ou de construtos.

Da mesma forma que o construto de práticas recomendadas, o construto de resultados esperados obtidos em decorrência da terceirização de serviços de TI, também será mensurado a partir de construtos de $1^{\text {a }}$ ordem, os quais são apresentados a seguir e representam:

Lucratividade, Confiabilidade e Credibilidade - os fatores sobre as reduções de custos obtidas com a terceirização de serviços de TI e aspectos financeiros; a redução das incertezas e riscos na execução dos serviços; o aumento da qualidade da tomada de decisão pelos usuários finais; os aspectos sobre o aumento da proteção nos dados e informações contra possíveis fraudes ou roubo de informações na empresa; fatores relacionados ao aumento da integração entre processos, pessoas e habilidades; e ainda, sobre a empresa focar no core business, ou seja, nas suas competências em função da terceirização de serviços de TI (LACITY; WILLCOCKS; FENNY, 1996; GREAVER II, 1999; JOHNSTON; CLARK, 2002; 
ALBORZ; SEDDON; SCHEEPERS, 2004; HSU; CHU, 2006; WEBB; POLLARD; RIDLEY, 2006).

Competência, Novos Conhecimentos e Maturidade - o fiel cumprimento do orçamento financeiro para o projeto do sistema terceirizado até a sua entrega final, bem como os prazos estipulados para este projeto, ou seja, se foram cumpridos na integra até a entrega final; fatores sobre a flexibilidade na execução das tarefas por parte dos usuários em termos de horários e formas de execução, bem como a capacidade de resposta às mudanças no ambiente; e ainda, fatores que verificam se houve redução dos problemas inerentes aos sistemas em uso por parte dos usuários, a fim de melhorar a resolução de incidentes (CLARK; ZMUD; MCCRAY, 1995; LACITY; WILLCOCKS; FENNY, 1996; JOHNSTON; CLARK, 2002; HSU; CHU, 2006; WEBB; POLLARD; RIDLEY, 2006; GELLINGS, 2007).

Produtividade - o aumento na capacidade de execução de serviços por parte dos usuários finais, bem como os fatores sobre a melhoria nos processos da empresa em função da terceirização; fatores relacionados à melhoria nos níveis de execução de serviços por parte dos usuários finais; e ainda, fatores sobre o aumento da velocidade na execução dos serviços por parte dos usuários finais em função da terceirização de serviços de TI realizada, sem perder, é claro, a qualidade na execução (CLARK; ZMUD; MCCRAY, 1995; LACITY; WILLCOCKS; FENNY, 1996; LACITY; WILLCOCKS, 1998; JOHNSTON; CLARK, 2002; HSU; CHU, 2006).

Satisfação com o Fornecedor - fatores de satisfação e qualidade com a entrega do serviço terceirizado, ou seja, sobre a satisfação dos usuários em relação aos novos sistemas em utilização em decorrência da terceirização de serviços de TI; o salto de qualidade na realização das atividades-fim dos usuários, melhoria na qualidade do uso (usabilidade) do sistema terceirizado (desenvolvido ou implantado); e ainda, a melhoria na qualidade dos dados/informações oriundos do sistema terceirizado (LACITY; WILLCOCKS; FENNY, 1996; JOHNSTON; CLARK, 2002; CUGANESAN; ROONEY; SILVI, 2006; HSU; CHU, 2006).

\subsection{Operacionalização das variáveis}

A variável, por sua vez, é usada na prática como sinônimo de assertiva, sendo um símbolo para o qual se atribui numeral ou valores (COOPER; SCHINDLER, 2003). 
Para Richardson (1999) a operacionalização das variáveis consiste em atribuir sentido observável, permitindo que sejam operadas e medidas. Podem ser classificadas em variáveis independentes, dependentes, moderadoras (controle), estranhas, e intervenientes. Segundo Cooper e Schindler (2003) a variável independente é aquela que produz um determinado fenômeno, ou ainda, "causa presumida de qualquer mudança na variável dependente" (HAIR JR. et al., 2009, p. 22). A variável dependente é aquela que é produzida e que sofre os efeitos da variável independente (COOPER; SCHINDLER, 2003). Para Hair Jr. et al. (2009, p. 22) é "um efeito presumido, ou resposta, a uma mudança na(s) variável(eis) independente(s)".

A criação dos construtos teve como pressuposto a definição de Kerlinger (1979). O autor afirma que para medir confiavelmente um construto, o mesmo deve ter itens suficientes para mensurá-lo. Essa quantidade não deve ser inferior a dois itens. Da mesma forma, Hair Jr. et al. (2009) indicam a utilização de no mínimo três itens por construto.

As escalas de mensuração utilizadas na pesquisa são do tipo intervalar. Segundo Hair Jr. et al. (2009, p. 184) uma escala intervalar utiliza números para classificar objetos ou eventos de modo que a distância entre os números seja igual. No presente trabalho, foi adotada a escala de likert da seguinte forma: assertivas sobre práticas adotadas pelo gestor de TI na gestão da terceirização de serviços de TI - 5 pontos, sendo: 1 - "Esta prática não é adotada" e 5 - "Esta

prática é adotada de maneira excelente". Assertivas sobre resultados obtidos em decorrência da terceirização de serviços de TI - 10 pontos, sendo: 1 - "Nenhum resultado" e 10 "Resultado obtido completamente".

Em função da questão de pesquisa "Qual a relação entre as práticas recomendadas de gestão da terceirização de serviços de TI e seus resultados sob o ponto de vista do gestor de TI?" foram definidas as variáveis como sendo as questões ligadas às práticas adotadas pelo gestor de TI, e questões ligadas aos resultados obtidos em decorrência da terceirização de serviços de TI.

\section{Variáveis - Práticas de gestão da terceirização de serviços de tecnologia da informação}

As variáveis do construto de práticas de gestão da terceirização de serviços de TI englobam as possíveis práticas adotadas pelo gestor de TI na respectiva gestão da terceirização de serviços 
de TI. O quadro 5 apresenta o construto de ordem superior $\left(2^{\mathrm{a}}\right.$ ordem $)$, os construtos de $1^{\mathrm{a}}$ ordem, as dimensões, a descrição das dimensões, os autores utilizados, os nomes das variáveis e as assertivas, no qual pode ser observado que a quantidade de itens utilizados por construto atende à indicação teórica.

Quadro 5 - Quadro das variáveis para o grupo práticas de gestão da terceirização de serviços de TI (continua)

\begin{tabular}{|c|c|c|c|c|c|}
\hline $\begin{array}{l}\text { Construtos } \\
\text { de Ordem } \\
\text { Superior }\end{array}$ & $\begin{array}{l}\text { Construtos } \\
\text { de Primeira } \\
\text { Ordem }\end{array}$ & Dimensões & $\begin{array}{l}\text { Descrição das } \\
\text { Dimensões }\end{array}$ & Autores & Nome da Variável e Assertiva \\
\hline \multirow{4}{*}{ 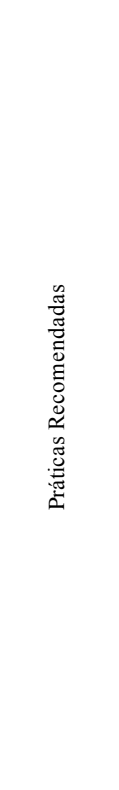 } & \multirow{4}{*}{$\begin{array}{l}\text { Aquisição e } \\
\text { Contrato }\end{array}$} & $\begin{array}{l}\text { Aquisição - } \\
\text { Processo }\end{array}$ & $\begin{array}{l}\text { Grau de adoção de } \\
\text { práticas de processos } \\
\text { de aquisição do serviço } \\
\text { terceirizado. }\end{array}$ & $\begin{array}{l}\text { Murray e Kotabe (1999); } \\
\text { Corbett (2004); Hefley e } \\
\text { Loesche (2006); ITGI } \\
\text { (2007); Van der Valk } \\
\text { (2008); Mansur (2009). }\end{array}$ & $\begin{array}{l}\text { (VP1-1.1) Verifico todos os processos de aquisição } \\
\text { referentes à terceirização do desenvolvimento de SI } \\
\text { sob medida e/ou terceirização da implantação de } \\
\text { pacotes de SI efetuados anteriormente. }\end{array}$ \\
\hline & & $\begin{array}{l}\text { Contrato- } \\
\text { Documentação }\end{array}$ & $\begin{array}{l}\text { Grau de adoção de } \\
\text { práticas de } \\
\text { documentação dos } \\
\text { processos de } \\
\text { contratação de } \\
\text { serviços. }\end{array}$ & $\begin{array}{l}\text { Lacity e Willcocks (2001); } \\
\text { Saad (2006); Cartlidge et } \\
\text { al. (2007); ITGI (2007); } \\
\text { Fernandes e Abreu (2008). }\end{array}$ & $\begin{array}{l}\text { (VP2-1.2) Documento todos os processos de } \\
\text { contratação de serviços (aquisição; relatórios de } \\
\text { conformidade; alterações contratuais; etc.), para } \\
\text { estudos e ações futuras. }\end{array}$ \\
\hline & & $\begin{array}{l}\text { Aquisição - } \\
\text { Normatização }\end{array}$ & $\begin{array}{l}\text { Grau de adoção de } \\
\text { práticas sobre normas } \\
\text { de selecionamento de } \\
\text { fornecedores. }\end{array}$ & $\begin{array}{l}\text { Axelsson e Wynstra } \\
\text { (2002); Corbett (2004); } \\
\text { Hefley e Loesche (2006); } \\
\text { Grönroos (2007); ITGI } \\
\text { (2007); Mansur (2009). }\end{array}$ & $\begin{array}{l}\text { (VP3-1.3) Utilizo normas (próprias ou de melhores } \\
\text { práticas de mercado) para seleção do fornecedor do } \\
\text { serviço. }\end{array}$ \\
\hline & & $\begin{array}{l}\text { Contrato - } \\
\text { Processos }\end{array}$ & $\begin{array}{l}\text { Grau de adoção de } \\
\text { práticas de } \\
\text { acompanhamento dos } \\
\text { processos de } \\
\text { contratação dos } \\
\text { serviços. }\end{array}$ & $\begin{array}{l}\text { Lacity e Willcocks (2001); } \\
\text { Hefley e Loesche (2006); } \\
\text { Cartlidge et al. (2007); } \\
\text { ITGI (2007); Fernandes e } \\
\text { Abreu (2008). }\end{array}$ & $\begin{array}{l}\text { (VP4-1.4) Asseguro que o departamento jurídico } \\
\text { acompanhe e participe de todos os processos de } \\
\text { contratação dos serviços (alterações contratuais; } \\
\text { litígios; etc.). }\end{array}$ \\
\hline \multirow{5}{*}{ 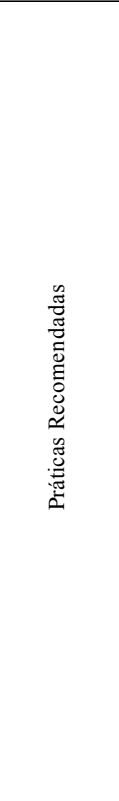 } & \multirow{5}{*}{$\begin{array}{l}\text { Nível de Serviço, } \\
\text { Demanda e } \\
\text { Capacidade }\end{array}$} & $\begin{array}{l}\text { Capacidade - } \\
\text { Solicitações }\end{array}$ & $\begin{array}{l}\text { Grau de adoção de } \\
\text { práticas de alinhamento } \\
\text { da capacidade empresa } \\
\text { (contratante) - } \\
\text { fornecedor } \\
\text { (contratado). }\end{array}$ & $\begin{array}{l}\text { Ripin e Sayles (1999); } \\
\text { Bragg (2006); Hefley e } \\
\text { Loesche (2006); ITGI } \\
\text { (2007); Fernandes e Abreu } \\
\text { (2008); Mansur (2009). }\end{array}$ & $\begin{array}{l}\text { (VP5-2.1) Alinho as solicitações provenientes das } \\
\text { áreas com as capacidades de atendimento do } \\
\text { fornecedor do serviço. }\end{array}$ \\
\hline & & Demanda & $\begin{array}{l}\text { Grau de adoção de } \\
\text { práticas de controle de } \\
\text { demanda. }\end{array}$ & $\begin{array}{l}\text { Hefley e Loesche (2006); } \\
\text { Saad (2006); Cartlidge et } \\
\text { al. (2007); ITGI (2007); } \\
\text { Fernandes e Abreu (2008). }\end{array}$ & $\begin{array}{l}\text { (VP6-2.2) Analiso, controlo e documento as } \\
\text { alterações solicitadas pelas áreas usuárias. }\end{array}$ \\
\hline & & Nível de Serviço & $\begin{array}{l}\text { Práticas de } \\
\text { acompanhamento de } \\
\text { SLA's. }\end{array}$ & $\begin{array}{l}\text { Lewis (1999); Van } \\
\text { Grembergen, et al. (2003); } \\
\text { Corbett (2004); Cartlidge } \\
\text { et al. (2007); ITGI (2007). }\end{array}$ & (VP7-2.3) Acompanho os SLA's firmados. \\
\hline & & $\begin{array}{l}\text { Capacidade - } \\
\text { Planejamento }\end{array}$ & $\begin{array}{l}\text { Grau de adoção de } \\
\text { práticas de } \\
\text { planejamento da } \\
\text { capacidade do } \\
\text { fornecedor. }\end{array}$ & $\begin{array}{l}\text { Ripin e Sayles (1999); } \\
\text { Hefley e Loesche (2006); } \\
\text { ITGI (2007); Fernandes e } \\
\text { Abreu (2008). }\end{array}$ & $\begin{array}{l}\text { (VP8-2.4) Controlo os planejamentos e/ou } \\
\text { investimentos realizados pelo fornecedor do serviço } \\
\text { durante a vigência do contrato a fim de } \\
\text { comprovação da capacidade técnica e/ou produtiva. }\end{array}$ \\
\hline & & $\begin{array}{l}\text { Capacidade - } \\
\text { Avaliações }\end{array}$ & $\begin{array}{l}\text { Grau de adoção de } \\
\text { práticas de acompanho } \\
\text { da capacidade técnica. }\end{array}$ & $\begin{array}{l}\text { Bragg (2006); Hefley e } \\
\text { Loesche (2006); ITGI } \\
\text { (2007); Mansur (2009). }\end{array}$ & $\begin{array}{l}\text { (VP9-2.5) Acompanho a capacidade técnica do } \\
\text { fornecedor do serviço. }\end{array}$ \\
\hline
\end{tabular}


Quadro 5 - Quadro das variáveis para o grupo práticas de gestão da terceirização de serviços de TI (continuação)

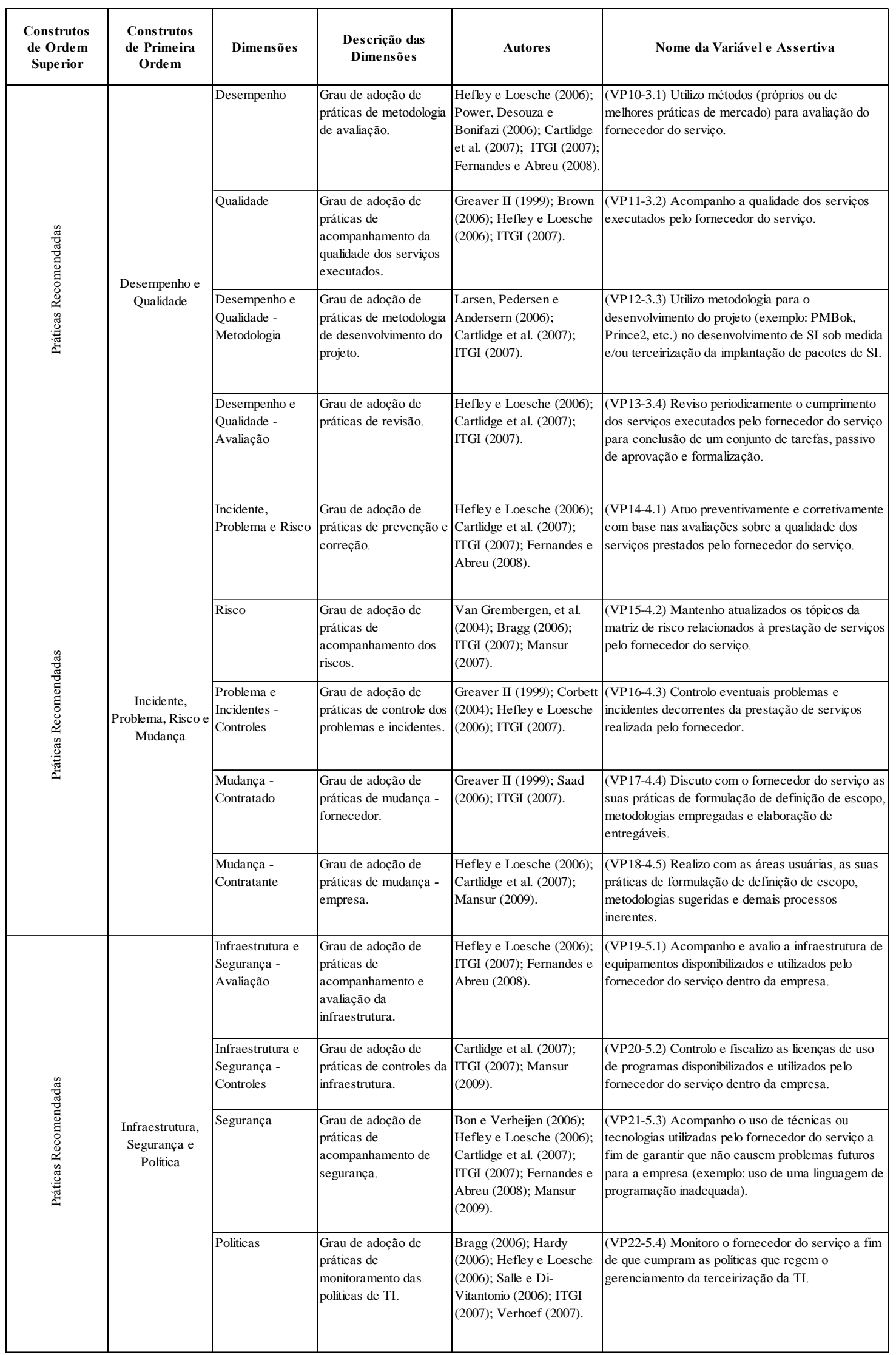


Quadro 5 - Quadro das variáveis para o grupo práticas de gestão da terceirização de serviços de TI (conclusão)

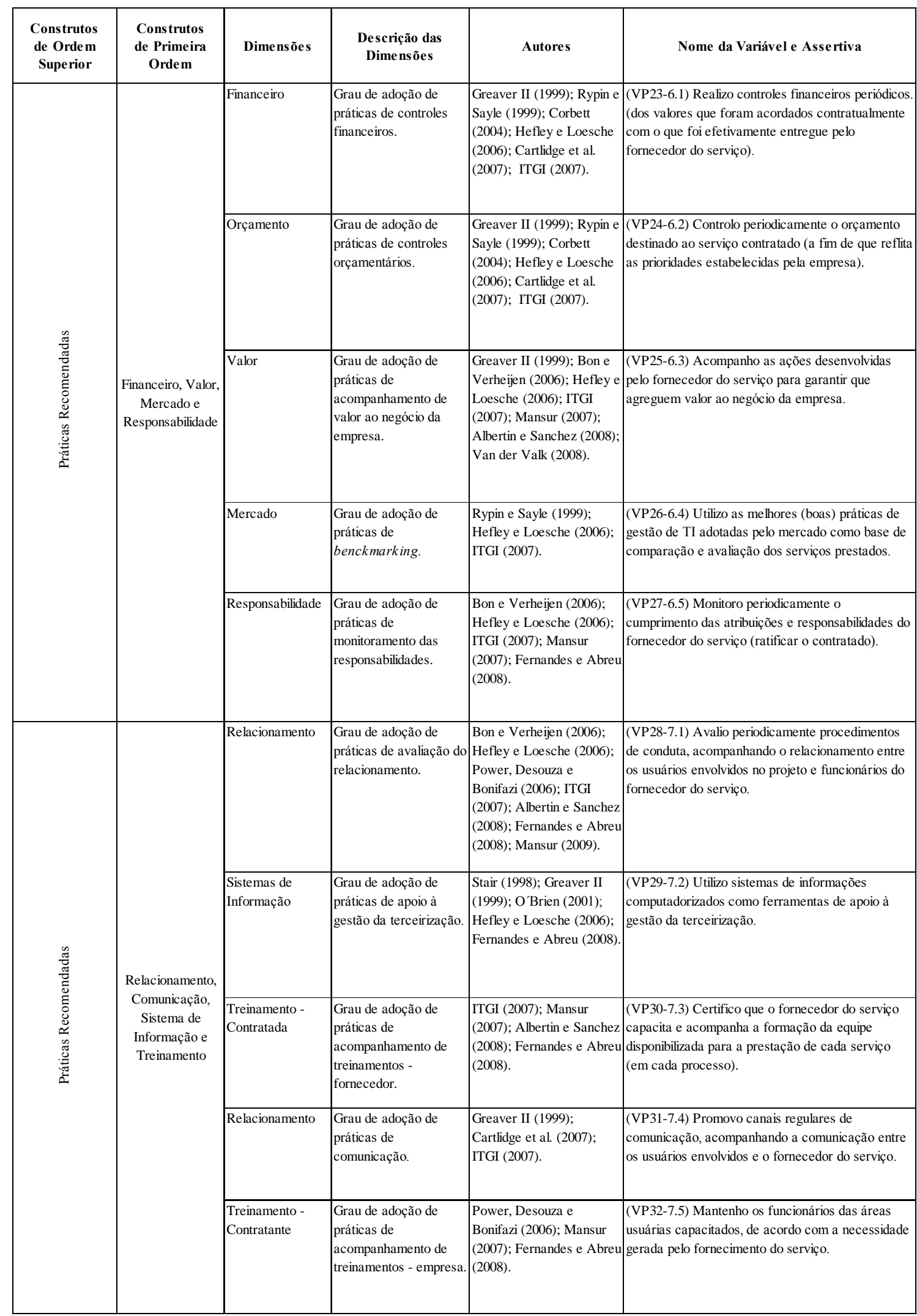




\section{Variáveis - Resultados esperados em decorrência da terceirização de serviços de tecnologia da informação}

As variáveis do construto resultados esperados enfatizam os possíveis resultados a serem obtidos em decorrência da terceirização do desenvolvimento de serviços de TI. Da mesma forma, o quadro 6 apresenta o construto de ordem superior $\left(2^{\mathrm{a}}\right.$ ordem $)$, os construtos de $1^{\mathrm{a}}$ ordem, as dimensões, a descrição das dimensões, os autores utilizados, os nomes das variáveis e as assertivas.

Quadro 6 - Quadro das variáveis para o grupo resultados esperados em decorrência da terceirização de serviços de TI (continua)

\begin{tabular}{|c|c|c|c|c|c|}
\hline $\begin{array}{c}\text { Construtos } \\
\text { de Orde m } \\
\text { Superior }\end{array}$ & $\begin{array}{l}\text { Construtos } \\
\text { de Primeira } \\
\text { Ordem }\end{array}$ & Dimensões & $\begin{array}{l}\text { Descrição das } \\
\text { Dimensões }\end{array}$ & Autores & Nome da Variável e Assertiva \\
\hline \multirow{4}{*}{ 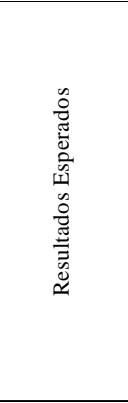 } & \multirow{4}{*}{$\begin{array}{l}\text { Lucratividade, } \\
\text { Confiabilidade e } \\
\text { Credibilidade }\end{array}$} & Redução de Custo & $\begin{array}{l}\text { Grau de obtenção de } \\
\text { reduções de custos. }\end{array}$ & $\begin{array}{l}\text { Lacity, Willcocks e Fenny } \\
\text { (1996); Greaver II (1999); } \\
\text { Hsu e Chu (2006) }\end{array}$ & $\begin{array}{l}\text { (VR1-1.1) A empresa obteve reduções de custos } \\
\text { em função do sistema terceirizado (desenvolvido ou } \\
\text { implantado)? }\end{array}$ \\
\hline & & Segurança & $\begin{array}{l}\text { Grau de obtenção de } \\
\text { segurança nos } \\
\text { dados/informações. }\end{array}$ & $\begin{array}{l}\text { Lacity, Willcocks e Fenny } \\
\text { (1996); Johnston e Clark } \\
(2002) ; \text { Hsu e Chu (2006) }\end{array}$ & $\begin{array}{l}\text { VR2-1.2) O sistema terceirizado (desenvolvido ou } \\
\text { implantado) proporcionou maior segurança nos } \\
\text { dados/informações para a empresa? }\end{array}$ \\
\hline & & Integração & $\begin{array}{l}\text { Grau de obtenção da } \\
\text { integração dos } \\
\text { processos. }\end{array}$ & $\begin{array}{l}\text { Lacity, Willcocks e Fenny } \\
(1996) ; \text { Hsu e Chu (2006) }\end{array}$ & $\begin{array}{l}\text { (VR3-1.3) Obteve-se aumento da integração dos } \\
\text { processos em função do sistema terceirizado } \\
\text { (desenvolvido ou implantado)? }\end{array}$ \\
\hline & & Foco & $\begin{array}{l}\text { Grau de obtenção de } \\
\text { aumentou de foco } \\
\text { (core business })\end{array}$ & \begin{tabular}{|l|} 
Alborz, Seddon e \\
Scheepers (2004); Hsu e \\
Chu (2006); Webb, Pollard \\
e Ridley (2006) \\
\end{tabular} & $\begin{array}{l}\text { (VR4-1.4) A empresa aumentou seu foco no ponto } \\
\text { forte e estratégico de atuação (core business) em } \\
\text { função do sistema terceirizado (desenvolvido ou } \\
\text { implantado)? }\end{array}$ \\
\hline \multirow{4}{*}{ 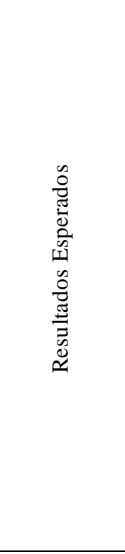 } & \multirow{4}{*}{$\begin{array}{l}\text { Competência, } \\
\text { Novos } \\
\text { Conhecimentos e } \\
\text { Maturidade }\end{array}$} & Valores & $\begin{array}{l}\text { Grau de obtenção dos } \\
\text { valores orçados para o } \\
\text { projeto. }\end{array}$ & $\begin{array}{l}\text { Lacity, Willcocks e Fenny } \\
\text { (1996); Hsu e Chu (2006); } \\
\text { Webb, Pollard e Ridley } \\
\text { (2006); Gellings (2007). }\end{array}$ & $\begin{array}{l}\text { (VR5-2.1) Os valores "orçados" para o projeto do } \\
\text { sistema terceirizado (desenvolvido ou implantado) } \\
\text { foram "realizados" (cumpridos na integra) até a } \\
\text { entrega final? }\end{array}$ \\
\hline & & Prazos & $\begin{array}{l}\text { Grau de obtenção dos } \\
\text { prazos estipulados para } \\
\text { o projeto }\end{array}$ & $\begin{array}{l}\text { Clark, Zmud e Mccray } \\
\text { (1995); Lacity, Willcocks e } \\
\text { Fenny (1996); Hsu e Chu } \\
(2006)\end{array}$ & $\begin{array}{l}\text { (VR6-2.2) Os prazos "estipulados" para o projeto do } \\
\text { sistema terceirizado (desenvolvido ou implantado) } \\
\text { foram "cumpridos na integra" até a entrega final? }\end{array}$ \\
\hline & & $\begin{array}{l}\text { Flexibilidade nas } \\
\text { tarefas }\end{array}$ & $\begin{array}{l}\text { Grau de obtenção da } \\
\text { flexibilidade na } \\
\text { realização das tarefas. }\end{array}$ & $\begin{array}{l}\text { Lacity, Willcocks e Fenny } \\
\text { (1996); Johnston e Clark } \\
(2002) ; \text { Hsu e Chu (2006) }\end{array}$ & $\begin{array}{l}\text { (VR7-2.3) Após a disponibilização do sistema } \\
\text { terceirizado (desenvolvido ou implantado), houve } \\
\text { aumento da flexibilidade na realização das tarefas } \\
\text { pelos usuários finais? }\end{array}$ \\
\hline & & $\begin{array}{l}\text { Resoluções - } \\
\text { Redução de } \\
\text { Problemas }\end{array}$ & \begin{tabular}{|l} 
Grau de obtenção de \\
redução de problemas \\
inerentes aos processos \\
ou execução dos \\
serviços.
\end{tabular} & $\begin{array}{l}\text { Hsu e Chu (2006); Gellings } \\
(2007)\end{array}$ & $\begin{array}{l}\text { (VR8-2.4) De uma forma geral, houve redução no } \\
\text { número ou na complexidade dos problemas } \\
\text { inerentes aos processos ou execução dos serviços } \\
\text { em função do sistema terceirizado (desenvolvido ou } \\
\text { implantado)? }\end{array}$ \\
\hline \multirow{3}{*}{ 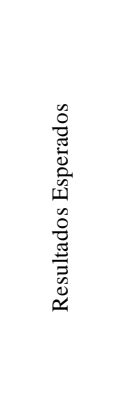 } & \multirow{3}{*}{ Produtividade } & $\begin{array}{l}\text { Capacidade de } \\
\text { Processamento }\end{array}$ & $\begin{array}{l}\text { Grau de obtenção no } \\
\text { aumento da capacidade } \\
\text { de processamento. }\end{array}$ & $\begin{array}{l}\text { Clark, Zmud e Mccray } \\
\text { (1995); Lacity, Willcocks e } \\
\text { Fenny (1996); Hsu e Chu } \\
(2006)\end{array}$ & $\begin{array}{l}\text { (VR9-3.1) Houve aumento na capacidade de } \\
\text { processamento dos dados em função do sistema } \\
\text { terceirizado (desenvolvido ou implantado)? }\end{array}$ \\
\hline & & $\begin{array}{l}\text { Melhoria dos } \\
\text { Processos }\end{array}$ & \begin{tabular}{|l|} 
Grau de obtenção de \\
otimização/melhoria nos \\
processos executados \\
pelos usuários finais.
\end{tabular} & $\begin{array}{l}\text { Lacity, Willcocks e Fenny } \\
\text { (1996); Johnston e Clark } \\
\text { (2002); Hsu e Chu (2006) }\end{array}$ & $\begin{array}{l}\text { (VR10-3.2) A empresa obteve otimização / } \\
\text { melhoria nos processos executados pelos usuários } \\
\text { finais, em função do sistema terceirizado } \\
\text { (desenvolvido ou implantado)? }\end{array}$ \\
\hline & & $\begin{array}{l}\text { Capacidade de } \\
\text { Realização das } \\
\text { Tarefas }\end{array}$ & $\begin{array}{l}\text { Grau de obtenção de } \\
\text { aumento da } \\
\text { produtividade dos } \\
\text { usuários finais. }\end{array}$ & $\begin{array}{l}\text { Lacity e Willcocks (1998); } \\
\text { Lacity, Willcocks e Fenny } \\
\text { (1996); Hsu e Chu (2006) }\end{array}$ & $\begin{array}{l}\text { (VR11-3.3) A empresa obteve aumento da } \\
\text { produtividade dos usuários finais (capacidade de } \\
\text { realização dos serviços executados) em função do } \\
\text { sistema terceirizado (desenvolvido ou implantado)? }\end{array}$ \\
\hline
\end{tabular}


Quadro 6 - Quadro das variáveis para o grupo resultados esperados em decorrência da terceirização de serviços de TI (conclusão)

\begin{tabular}{|c|c|c|c|c|c|}
\hline $\begin{array}{l}\text { Construtos } \\
\text { de Ordem } \\
\text { Superior }\end{array}$ & $\begin{array}{l}\text { Construtos } \\
\text { de Primeira } \\
\text { Ordem }\end{array}$ & Dimensões & $\begin{array}{l}\text { Descrição das } \\
\text { Dimensões }\end{array}$ & Autores & Nome da Variável e Assertiva \\
\hline \multirow{3}{*}{ 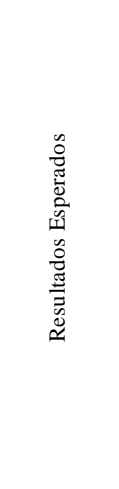 } & \multirow{3}{*}{$\begin{array}{l}\text { Satisfação com o } \\
\text { Fornecedor }\end{array}$} & $\begin{array}{l}\text { Qualidade das } \\
\text { Atividades }\end{array}$ & $\begin{array}{l}\text { Grau de obtenção de } \\
\text { qualidade na realização } \\
\text { das atividades-fim dos } \\
\text { usuários. }\end{array}$ & $\begin{array}{l}\text { Lacity, Willcocks e Fenny } \\
\text { (1996); Johnston e Clark } \\
\text { (2002); Cuganesan, } \\
\text { Rooney e Silvi (2006); Hsu } \\
\text { e Chu (2006) }\end{array}$ & $\begin{array}{l}\text { (VR12-4.1) Após a disponibilização do sistema } \\
\text { terceirizado (desenvolvido ou implantado), houve um } \\
\text { salto de qualidade na realização das atividades-fim } \\
\text { dos usuários finais? }\end{array}$ \\
\hline & & $\begin{array}{l}\text { Qualidade dos } \\
\text { Sistemas }\end{array}$ & $\begin{array}{l}\text { Grau de obtenção de } \\
\text { melhoria na qualidade } \\
\text { do uso (usabilidade) do } \\
\text { sistema. }\end{array}$ & $\begin{array}{l}\text { Lacity, Willcocks e Fenny } \\
\text { (1996); Cuganesan, } \\
\text { Rooney e Silvi (2006); Hsu } \\
\text { e Chu (2006) }\end{array}$ & $\begin{array}{l}\text { (VR13-4.2) Houve melhoria na qualidade do uso } \\
\text { (usabilidade) do sistema terceirizado (desenvolvido } \\
\text { ou implantado) por parte dos usuários finais? }\end{array}$ \\
\hline & & $\begin{array}{l}\text { Qualidade da } \\
\text { Informação }\end{array}$ & $\begin{array}{l}\text { Grau de obtenção de } \\
\text { melhoria na qualidade } \\
\text { dos dados/informações; } \\
\text { oriundos do sistema } \\
\text { terceirizado } \\
\text { (desenvolvido ou } \\
\text { implantado)? }\end{array}$ & $\begin{array}{l}\text { Lacity, Willcocks e Fenny } \\
\text { (1996); Cuganesan, } \\
\text { Rooney e Silvi (2006); Hsu } \\
\text { e Chu (2006) } \\
\end{array}$ & $\begin{array}{l}\text { (VR14-4.3) A empresa obteve melhoria na } \\
\text { qualidade dos dados/informações oriundos do } \\
\text { sistema terceirizado (desenvolvido ou implantado)? }\end{array}$ \\
\hline
\end{tabular}

O questionário de pesquisa foi instrumentalizado com base nas assertivas expressas nos quadros 5 e 6 .

\section{Variáveis de controle}

Segundo Lakatos e Marconi (2007, p. 145) "variável de controle é aquele fator, fenômeno ou propriedade que o investigador neutraliza ou anula propositalmente em uma pesquisa, com a finalidade de impedir que interfira na análise da relação entre as variáveis independente e dependente". Neste estudo, as variáveis de controle, podem ser observadas no quadro 7.

Quadro 7 - Quadro resumo das variáveis de controle (continua)

\begin{tabular}{|c|c|c|c|c|}
\hline $\begin{array}{c}\text { Variáveis de } \\
\text { Controle }\end{array}$ & Descrição & Autor(es) & $\begin{array}{l}\text { Nome da } \\
\text { Variável }\end{array}$ & Tipo \\
\hline Cidade & Representa a cidade na qual a organização está inserida. & Sebrae (2010b) & VE1 & Nominal \\
\hline Setor de Atividade & $\begin{array}{l}\text { Representa o setor no qual a organização atua, podendo ser } \\
\text { classificadas pela atividade econômica que desenvolvem. Foram } \\
\text { utilizadas como base as definições propostas pelo SEBRAE } \\
\text { (2010b). }\end{array}$ & Sebrae (2010b) & VE2 & Nominal \\
\hline $\begin{array}{l}\text { Porte da } \\
\text { Organização }\end{array}$ & $\begin{array}{l}\text { Representa o porte das organizações estudadas e foram } \\
\text { utilizados fatores relacionados ao faturamento para definição do } \\
\text { porte. Para o setor industrial a empresa é considerada de grande } \\
\text { porte se tiver, no exercício social anterior, ativo total superior a } \\
\mathrm{R} \$ 240.000 .000,00 \text { (duzentos e quarenta milhões de reais) ou } \\
\text { receita bruta anual superior a } \mathrm{R} \$ 300.000 .000,00 \text { (trezentos } \\
\text { milhões de reais). Para empresas de médio porte, são } \\
\text { consideradas aquelas que tiverem mais de } \mathrm{R} \$ 2.400 .000,00 \\
\text { (dois milhões e quatrocentos mil reais) de receita bruta anual. Já } \\
\text { para ser considerada empresa de pequeno porte, é necessário } \\
\text { que a mesma tenha receita bruta anual entre } \mathrm{R} \$ 240.000,00 \text { a R } \$ \\
2.400 .000,00 \text {. Por fim, a microempresa é a pessoa jurídica com } \\
\text { receita bruta anual igual ou inferior a } \mathrm{R} \$ 240.000,00 \text { (SEBRAE, } \\
2010 \mathrm{a} \text { ). }\end{array}$ & 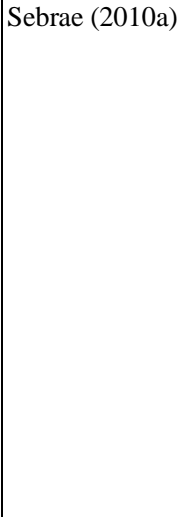 & VE3 & Nominal \\
\hline
\end{tabular}


Quadro 7 - Quadro resumo das variáveis de controle (continuação)

\begin{tabular}{|c|c|c|c|c|}
\hline $\begin{array}{l}\text { Variáveis de } \\
\text { Controle }\end{array}$ & Descrição & Autor(es) & $\begin{array}{l}\text { Nome da } \\
\text { Variável }\end{array}$ & Tipo \\
\hline Receita Líquida & $\begin{array}{l}\text { Representa a receita líquida bruta obtida no ano de } 2009 \text { pelas } \\
\text { organizações estudadas. Foram utilizadas as faixas determinadas } \\
\text { pelo SEBRAE (2010a) para o porte das empresas como base } \\
\text { para as métricas. }\end{array}$ & Sebrae (2010a) & VE4 & Ordinal \\
\hline $\begin{array}{l}\text { Quantidade Total de } \\
\text { Funcionários da } \\
\text { Organização }\end{array}$ & $\begin{array}{l}\text { Representa o número total de funcionários das organizações } \\
\text { estudadas. Foram utilizadas as faixas abordadas nas pesquisas } \\
\text { do IBGE (2010) como base para as métricas. Segundo o } \\
\text { SEBRAE (2010a), para o setor industrial a empresa é } \\
\text { considerada de grande porte se tiver mais de } 500 \text { funcionários. } \\
\text { No caso de empresas do setor de comércio ou serviços, aquelas } \\
\text { que possuírem mais de } 100 \text { funcionários são consideradas de } \\
\text { grande porte. As empresas industriais que possuem de } 100 \text { a } \\
499 \text { empregados são consideradas de médio porte, bem como } \\
\text { as empresas dos setores comercial ou de serviços que detenham } \\
\text { de } 50 \text { a } 99 \text { empregados. Para ser considerada de pequeno porte, } \\
\text { a empresa deverá ter de } 20 \text { a } 99 \text { funcionários (no setor industrial) } \\
\text { e de } 10 \text { a } 49 \text { funcionários (nos setores comercial ou de serviços). } \\
\text { Já a microempresa, se for do setor industrial deve ter até } 19 \\
\text { funcionários e se for do setor de comércio ou serviços, não } \\
\text { poderá exceder } 9 \text { funcionários. }\end{array}$ & $\begin{array}{l}\text { IBGE (2010); } \\
\text { Sebrae (2010a) }\end{array}$ & VE5 & Ordinal \\
\hline $\begin{array}{l}\text { Quantidade Total de } \\
\text { Funcionários na área } \\
\text { de TI da } \\
\text { Organização - }\end{array}$ & $\begin{array}{l}\text { Representa o número total de funcionários próprios alocados na } \\
\text { área de TI da organização. }\end{array}$ & Sebrae (2010a) & VE6 & Ordinal \\
\hline $\begin{array}{l}\text { Quantidade Total de } \\
\text { Funcionários na área } \\
\text { de TI da } \\
\text { Organização - } \\
\text { Terceirizado }\end{array}$ & $\begin{array}{l}\text { Representa o número total de funcionários terceirizados alocados } \\
\text { na área de TI da organização. }\end{array}$ & Sebrae (2010a) & VE7 & Ordinal \\
\hline $\begin{array}{l}\text { Quantidade total de } \\
\text { funcionários } \\
\text { alocados no } \\
\text { desenvolvimento de } \\
\text { SI sob medida e/ou } \\
\text { implantação de } \\
\text { pacotes de SI - } \\
\text { Próprio }\end{array}$ & $\begin{array}{l}\text { Representa o número total de funcionários próprios alocados na } \\
\text { área de desenvolvimento de SI sob medida e/ou implantação de } \\
\text { pacotes de SI da organização. }\end{array}$ & Sebrae (2010a) & VE8 & Ordinal \\
\hline $\begin{array}{l}\text { Quantidade total de } \\
\text { funcionários } \\
\text { alocados no } \\
\text { desenvolvimento de } \\
\text { SI sob medida e/ou } \\
\text { implantação de } \\
\text { pacotes de SI - } \\
\text { Terceirizado }\end{array}$ & $\begin{array}{l}\text { Representa o número total de funcionários terceirizados alocados } \\
\text { na área de desenvolvimento de SI sob medida e/ou implantação } \\
\text { de pacotes de SI da organização. }\end{array}$ & Sebrae (2010a) & VE9 & Ordinal \\
\hline $\begin{array}{l}\text { Gastos e } \\
\text { Investimentos com } \\
\text { TI }\end{array}$ & $\begin{array}{l}\text { Representa o total gasto entre despesas e investimentos em } \\
\text { tecnologia da informação no ano de } 2009 \text { em relação ao total da } \\
\text { receita líquida bruta. }\end{array}$ & Meirelles (2009) & VE10 & Ordinal \\
\hline
\end{tabular}


Quadro 7 - Quadro resumo das variáveis de controle (conclusão)

\begin{tabular}{|c|c|c|c|c|}
\hline $\begin{array}{c}\text { Variáveis de } \\
\text { Controle }\end{array}$ & Descrição & Autor(es) & $\begin{array}{l}\text { Nome da } \\
\text { Variável }\end{array}$ & Tipo \\
\hline $\begin{array}{l}\text { Gastos e } \\
\text { Investimentos em } \\
\text { desenvolvimento de } \\
\text { SI sob medida e/ou } \\
\text { implantação de } \\
\text { pacotes de SI - } \\
\text { Terceirizado }\end{array}$ & $\begin{array}{l}\text { Representa o total gasto entre despesas e investimentos em } \\
\text { terceirização de desenvolvimento de SI sob medida e/ou } \\
\text { implantação de pacotes de SI no ano de } 2009 \text { em relação ao } \\
\text { total de gastos e investimentos da TI. }\end{array}$ & Meirelles (2009) & VE11 & Ordinal \\
\hline $\begin{array}{l}\text { Número Total de } \\
\text { Computadores }\end{array}$ & Representa o total de computadores instalados na organização. & Meirelles (2009) & VE12 & Ordinal \\
\hline $\begin{array}{l}\text { Grau de Formalidade } \\
\text { do Contrato }\end{array}$ & $\begin{array}{l}\text { Representa o grau de formalidade do contrato adotado pela } \\
\text { contratante do serviço em relação ao prestador do serviço. }\end{array}$ & $\begin{array}{l}\text { Williamson (1996); } \\
\text { Corbett (2004); } \\
\text { Prado e takaoka } \\
\text { (2006); Saad } \\
\text { (2006); Cavalcanti } \\
\text { et al. (2007) }\end{array}$ & VE13 & Nominal \\
\hline Modelo de Gestão & $\begin{array}{l}\text { Representa os modelos de governança de TI mais indicados para } \\
\text { a gestão da terceirização de serviços de TI. }\end{array}$ & \begin{tabular}{|l|} 
Oud (2005); Bon \\
e Verheijen \\
(2006); Fernandes \\
e Abreu (2006); \\
Larsen, Pedersen e \\
Andersen (2006)
\end{tabular} & VE14 & Nominal \\
\hline Projeto Indicado & $\begin{array}{l}\text { Representa o objeto terceirizado ao qual estará se baseando } \\
\text { para responder o instrumento de pesquisa sobre práticas de } \\
\text { gestão e resultados da terceirização. }\end{array}$ & \begin{tabular}{|l|} 
Arnett e Jones \\
(1994); Willcocks \\
e Lacity (1997); \\
Lacity e Willcocks \\
(2001)
\end{tabular} & VE15 & Nominal \\
\hline
\end{tabular}

O apêndice D apresenta os quadros com as escalas intervalares utilizados para o instrumento de pesquisa. 


\section{METODOLOGIA}

A pesquisa caracteriza-se por um estudo empírico, exploratório e descritivo quantitativo. Empírico, pois foi baseado em conhecimentos práticos devidos à experiência alcançada pelos sujeitos da pesquisa (gestores da terceirização de serviços de TI); exploratório, pois teve como objetivo familiarizar-se com o fenômeno estudado a fim de obter novas percepções e descobrir novas ideias. De acordo com Cervo e Bervian (2002, p. 69) "recomenda-se o estudo exploratório quando há poucos conhecimentos sobre o problema a ser estudado.”; e descritivo quantitativo, pois teve ainda como objetivo verificar a frequência com que algo ocorre e descobrir ou verificar a ligação entre determinadas variáveis. Para Selltiz et al. (1975) nos estudos descritivos uma consideração fundamental é a exatidão e, portanto, é necessário um planejamento que amplie a precisão da prova obtida.

\subsection{Etapas do processo investigativo}

A Ilustração 5 apresenta de forma esquemática as etapas de investigação que foram seguidas para a realização do projeto de pesquisa. O conjunto de etapas tem por objetivo demonstrar como foi construído o conhecimento ao longo desta pesquisa.

\section{Etapa I}

- Exploração do tema

- Formulação dos objetivos e questão da pesquisa

Etapa II

- Construção do quadro teórico-conceitual da pesquisa

Etapa III

- Revisão bibliográfica concernente à validação da metodologia de pesquisa

Etapa IV

- Elaboração da análise dos modelos de governança e modelos de GTI

Ilustração 5 - Etapas da investigação (continua) 
Etapa V

- Seleção das organizações e sujeitos da pesquisa

Etapa VI

- Desenvolvimento do instrumento de pesquisa

- Realização do pré-teste do instrumento de pesquisa

- Preparação para a coleta de dados

- Realização da pesquisa de campo

Etapa VII

- Validação e análise dos dados

Etapa VIII

- Conclusão da tese, limitações e sugestões para estudo futuro

Ilustração 5 - Etapas da investigação (conclusão)

A primeira etapa (I) foi a de explorar os temas relacionados à TI: terceirização de serviços de TI e suas características, governança corporativa e GTI, bem como a gestão da terceirização de serviços de TI e seus respectivos resultados. Surgiu no interesse de investigar com maior profundidade as práticas recomendadas inerentes à gestão da terceirização de serviços de TI e seus resultados.

Segundo a IDC (2009), há a previsão de que o mercado de serviços de TI cresça a uma taxa média anual de 5,1\% até 2012. Nesse contexto, a terceirização de serviços de TI representa cerca de um quinto da globalidade dos serviços de TI, e é de todos os segmentos o que mais cresce, sendo esperado que o faça a um nível de cerca de 6,3\% até 2012.

A segunda etapa (II) destinou-se a uma extensa revisão bibliográfica, abrangendo autores e livros e periódicos da área de TI e das práticas dos modelos de GTI estudados.

Para a terceira etapa (III) foi realizado levantamento e revisão bibliográfica concernente à validação da metodologia de pesquisa utilizada.

A quarta etapa (IV) foi constituída de análise dos modelos de governança, bem como os modelos de GTI. 
A partir deste momento, a pesquisa passa para a etapa cinco (V) na qual foram selecionadas organizações capazes de apoiar e validar os construtos formulados. A escolha dessas organizações encontra-se descrita na sequência deste estudo.

Em paralelo, a etapa seis (VI) apresenta a transformação das proposições em medidas operacionais, que possibilitaram a coleta dos dados, com definição e adequação do instrumento de pesquisa, conforme as necessidades de investigação e aplicação do questionário.

Na sétima etapa (VII), as evidências coletadas são analisadas a fim de validar o modelo conceitual.

A oitava etapa (VIII) traz o desenvolvimento das conclusões com base nas análises realizadas o que permitiu a elaboração das considerações finais sobre as proposições da tese, apontando possíveis limitações e sugestões para estudo futuro.

\subsection{População e amostra}

A população da pesquisa abrangeu as organizações de grande e médio porte dos setores industrial, comercial e de serviços da Região Metropolitana de São Paulo. Esta, por ser a região em que, segundo a STM (2010, p. 1), “concentram-se as sedes das grandes empresas e a maior parte dos centros de pesquisas e produtores de informação existentes no território brasileiro".

Para Santos e Silveira (2001, p. 429) a região é considerada a metrópole informacional, pela densidade técnica de que dispõe nesta área, "assumindo papel estratégico, pois é o lugar sede da produção e controle da nova vaga de modernizações que reorganiza o território nacional". Posto isso, a expressiva representatividade das organizações destes setores em relação às demais existentes no país justifica a delimitação do estudo.

\section{Unidades de amostra e elementos da amostragem}

Os respondentes são os profissionais da área de TI, ocupando cargos de chefia, coordenação ou liderança, sendo responsáveis pela gestão da terceirização de serviços de TI nas 
organizações pesquisadas. Independentemente da posição hierárquica dessas pessoas, elas deveriam participar ou ter participado da fase de planejamento, contratação e gestão dos serviços de TI e deveriam também possuir uma visão abrangente da gestão dos serviços terceirizados de TI.

Unidades de amostra: o plano amostral para esta pesquisa também reconheceu o universo a que se refere este estudo, a população alvo que foi estudada e sua unidade amostral.

Embora haja o reconhecimento de que para tratar de temas complexos como o proposto nesta pesquisa, o método da entrevista seja melhor do que o questionário (SELLTIZ et al., 1975), por permitir ao entrevistador repetir e reformular as questões para garantir melhor entendimento e também para esclarecer mais precisamente o significado de uma resposta, a opção pela segunda alternativa ocorreu pelas seguintes razões:

- Número de pesquisas extremamente reduzido que tratam do tema desta pesquisa;

- Busca pelas relações entre diversos tipos de variáveis;

- Uso de entrevistas pessoais em profundidade, com a amostra selecionada, exigiria recursos financeiros e tempo não disponíveis do autor.

A amostra utilizada foi considerada como sendo não probabilística. Segundo Hair Jr. et al. (2009, p. 246) a amostragem não probabilística não é necessariamente feita com o objetivo de ser estatisticamente representativa da população. Dentro da amostra não probabilística, foi utilizada também, a amostragem por conveniência.

Ainda segundo Hair Jr. et al. (2009, p. 247) a amostragem por conveniência envolve a seleção de itens da amostra que estejam mais disponíveis para tornar-se parte do estudo, oferecendo as informações necessárias. A utilização de uma amostra não probabilística por conveniência pode ser justificada devido às dificuldades para garantir a aplicação por meio de uma técnica de amostragem probabilística.

Foi utilizada uma base de dados com 8.000 organizações de grande e médio porte, englobando os três setores estudados, para as quais foi enviada mensagem eletrônica individualizada e personalizada, por meio da contratação dos serviços da empresa "Akna 
Tecnologia da Informação - http://www.akna.com.br/”, especializada em administrar grandes volumes de mensagens.

Os serviços compreendidos foram: gerenciamento da entrega direcionada de mensagens aos destinatários, monitoramento das ações individuais e obtenção de indicadores relevantes sobre a performance das ações estabelecidas. $\mathrm{O}$ apêndice $\mathrm{B}$ apresenta a tela inicial da página da empresa com o login do pesquisador. A mensagem eletrônica continha a carta convite para a pesquisa, juntamente com o link de acesso ao questionário eletrônico autoadministrado que foi hospedado no Survey Monkey - http://pt.surveymonkey.com. O apêndice C apresenta a tela resumo com o login do pesquisador.

Além do envio das mensagens eletrônicas individuais e personalizadas, a pesquisa obteve apoio da Now!Digital Business Ltda, parceira exclusiva do International Data Group (IDG) no Brasil, que divulgou a carta convite e o link da pesquisa para a comunidade de Chief Information Officer (CIO) o qual ela administra. O grupo é composto atualmente por cerca de 200 profissionais que atuam como líderes de TI em organizações de grande e médio porte.

Ao longo da pesquisa, foram realizados acompanhamentos das respostas - por meio do sistema de gerenciamento da empresa AKNA e do site Survey Monkey, bem como intervenções, a fim de aumentar os índices de resposta. As intervenções foram constituídas de ligações telefônicas diretas aos respondentes - sujeitos da pesquisa, além de mensagem eletrônica, enfatizando a importância da participação na pesquisa.

Hair Jr. et al. (2009) recomenda um mínimo de 100 casos e, preferencialmente, 200 para análises multivariadas ou 5 casos por variável proposta. Da mesma forma, Bentler e Chou (1988) estipulam 5 casos por parâmetro estimado incluindo os coeficientes estruturais e a estimativa de erro.

Segundo Cohen (1988) as diferenças entre grupos do tamanho da amostra podem ser obtidas por meio da significância estatística especificada e pelo efeito do tamanho da amostra. Para este estudo, o número de assertivas é de 46, portanto, 230 respondentes seriam suficientes para estimar os construtos e analisar a relação proposta entre eles. A seguir, são apresentados os procedimentos utilizados na elaboração do instrumento de coleta dos dados. 


\subsection{Instrumento de coleta de dados}

Os dados a serem coletados são do tipo primário. Para Mattar (1999) dados primários são aqueles que não foram anteriormente coletados, estando de posse dos pesquisados, e cuja coleta tem o propósito de atender às necessidades da pesquisa. A vantagem desse instrumento está no custo de aplicação e na uniformidade de mensuração. Malhotra (2001) também aponta o questionário como a melhor forma de coletar informações de um grande número de respondentes. Como instrumento de coleta de dados nesta pesquisa foi adotado um questionário autoadministrado disponibilizado eletronicamente.

O questionário utilizado foi composto por três blocos de questões fechadas e abertas conforme Apêndices E e F. O primeiro bloco tratou das respectivas instruções para preenchimento, questões iniciais (de abertura) relativas à organização com descrição dos objetivos, e questões sobre terceirização de serviços de TI. O segundo bloco abordou questões referentes às práticas adotadas pelo gestor de TI na gestão da terceirização de serviços de TI. Por fim, o terceiro bloco contemplou os resultados obtidos em decorrência dessa terceirização.

\subsection{Pré-teste}

Para o pré-teste do instrumento de pesquisa, o questionário foi submetido a 10 gestores de TI que atuam no mercado, com características semelhantes às da população alvo, escolhidos por conveniência do pesquisador, a fim de que analisassem a aplicabilidade em seus ambientes de atuação e fizessem comentários e sugestões quanto às explicações e questões que não estivessem concisas e claras evitando ambiguidades, questões dominantes e falhas de interpretação.

Hair Jr. et al. (2009, p. 230) orientam a aplicar o pré-teste a um mínimo de 4 ou 5 indivíduos e o máximo não excedendo a 30. Em seguida, os comentários foram analisados e alguns inseridos no instrumento. Houve ainda, a preocupação em formatar as perguntas com vocabulário comum à área e com significados padronizados, com alternativas adequadas dentro do que estava sendo perguntado, sem apresentar uma redação complexa.

Logo no início da aplicação do questionário eletrônico, uma amostra pré-teste com 40 respondentes foi selecionada aleatoriamente do total de respondentes que havia até o momento, com o objetivo de verificar o teste de consistência interna dos indicadores. 
De acordo com Yu (2001) o teste de Alfa de Cronbach é reconhecido como o mais popular e mais usado por pesquisadores de diversas áreas. $\mathrm{O}$ cálculo do coeficiente em questão mostra se a proporção da variabilidade nas respostas resulta nas diferenças dos inquiridos ou de algum tipo de inconsistência do questionário, o que pode levar a diferentes interpretações por parte dos sujeitos da pesquisa, provocando vieses significativos nos dados obtidos.

Segundo Hair Jr. et al. (2009) a medida de confiabilidade do Alfa de Cronbach considera os valores de 0,60 a 0,70 como o limite inferior de aceitabilidade. Para esta análise, foi utilizado o programa Statistical Package for the Social Sciences (SPSS), versão 17.0 para Microsoft ${ }^{\circledR}$ Windows ${ }^{\circledR}$. O resultado do teste de Alfa de Cronbach realizado para verificar o grau de consistência interna da escala resultou nas estatísticas constantes na tabela 1.

Tabela 1 - Consistência interna obtida na amostra pré-teste

Práticas adotadas pelo gestor de TI na gestão da terceirização de serviços de TI

\begin{tabular}{lc}
\hline \multicolumn{1}{c}{ Construtos e Indicadores } & Alfa de Cronbach \\
\hline $\begin{array}{l}\text { Aquisição e Contrato } \\
\text { (VP1-1.1; VP2-1.2; VP3-1.3; VP4-1.4) }\end{array}$ & 0,645 \\
\hline $\begin{array}{l}\text { Nível de Serviço, Demanda e Capacidade } \\
\text { (VP5-2.1; VP6-2.2; VP7-2.3; VP8-2.4; VP9-2.5) }\end{array}$ & 0,870 \\
\hline $\begin{array}{l}\text { Desempenho e Qualidade } \\
\text { (VP10-3.1; VP11-3.2; VP12-3.3; VP13-3.4) }\end{array}$ & 0,722 \\
\hline $\begin{array}{l}\text { Incidente, Problema, Risco e Mudança } \\
\text { (VP14-4.1; VP15-4.2; VP16-4.3; VP17-4.4; VP18-4.5) }\end{array}$ & 0,815 \\
\hline $\begin{array}{l}\text { Infraestrutura, Segurança e Política } \\
\text { (VP19-5.1; VP20-5.2; VP21-5.3; VP22-5.4) }\end{array}$ & 0,746 \\
\hline $\begin{array}{l}\text { Financeiro, Valor, Mercado e Responsabilidade } \\
\text { (VP23-6.1; VP24-6.2; VP25-6.3; VP26-6.4; VP27-6.5) }\end{array}$ & 0,834 \\
\hline $\begin{array}{l}\text { Relacionamento, Comunicação, Sistema de Informação e Treinamento } \\
\text { (VP28-7.1; VP29-7.2; VP30-7.3; VP31-7.4; VP32-7.5) }\end{array}$ & 0,774 \\
\hline
\end{tabular}

Resultados esperados em decorrência da terceirização de serviços de TI

\begin{tabular}{lc}
\hline \multicolumn{1}{c}{ Construtos e Indicadores } & Alfa de Cronbach \\
\hline $\begin{array}{l}\text { Lucratividade, Confiabilidade e Credibilidade } \\
\text { (VR1-1.1; VR2-1.2; VR3-1.3; VR4-1.4) }\end{array}$ & 0,864 \\
\hline $\begin{array}{l}\text { Competência, Novos Conhecimentos e Maturidade } \\
\text { VR5-2.1; VR6-2.2; VR7-2.3; VR8-2.4 }\end{array}$ & 0,837 \\
\hline $\begin{array}{l}\text { Produtividade } \\
\text { VR9-3.1; VR10-3.2; VR11-3.3 }\end{array}$ & 0,866 \\
\hline Satisfação com o Fornecedor & 0,919 \\
\hline VR12-4.1; VR13-4.2; VR14-4.3
\end{tabular}


Uma vez que os objetivos dessa pré-análise foram alcançados, ou seja, os índices de confiabilidade - Alfa de Cronbach - foram acima de 0,60 , foi dada continuidade à pesquisa.

\subsection{Técnicas de tratamento dos dados}

Com o intuito de atender aos objetivos da pesquisa, a primeira etapa da análise de dados foi a de inserção dos dados em um software estatístico. Para tal, utilizou-se o programa Statistical Package for the Social Sciences (SPSS), versão 17.0 para Microsoft ${ }^{\circledR}$ Windows $^{\circledR}$. Segundo Pasquali (1999), não se pode definir antes das análises estatísticas se um instrumento é unidimensional ou não. Dessa forma, foi realizada uma análise fatorial para verificar quais itens deveriam efetivamente compor cada fator.

\subsubsection{Análise fatorial exploratória}

A análise fatorial tem como objetivo principal encontrar um modo de condensar a informação contida em diversas variáveis originais em um conjunto menor de novas variáveis (fatores) com uma perda mínima de informação.

Identificando relações e combinando variáveis em fatores, a análise fatorial pode simplificar a compreensão dos dados e partir das correlações observadas entre as variáveis originais, a AF estima os fatores comuns que são subjacentes às variáveis e que não são diretamente observáveis (FAVERO et al., 2009).

Segundo Aranha e Zambaldi (2008, p. 31), a análise fatorial:

É uma técnica estatística cujo objetivo é caracterizar um conjunto de variáveis diretamente mensuráveis, chamadas de variáveis observadas, como a manifestação visível de um conjunto menor de variáveis hipotéticas e latentes (não mensuráveis diretamente), denominadas fatores comuns, e de um conjunto de fatores únicos, cada um deles atuando apenas sobre uma das variáveis observadas.

Da mesma forma, Hair Jr. et al. (2009) afirmam que o propósito principal da análise fatorial é definir a estrutura inerente entre as variáveis de análise, fornecendo as ferramentas para analisar a estrutura das inter-relações, também conhecida como correlações, em um grande número de variáveis, definindo conjuntos de variáveis que são fortemente inter-relacionadas, conhecidas como fatores. 
É comum serem encontradas variáveis com características e naturezas diferentes, e é nesse sentido que a análise fatorial auxilia na determinação de índices que evidenciem essas diferenças (MINGOTI, 2005).

Se o conjunto de variáveis que representam características da amostra for muito grande e o objetivo for resumir essas características, deve-se aplicar a análise fatorial $\mathrm{R}$ a uma matriz de correlação dessas variáveis, identificando-se assim dimensões latentes das mesmas. Além disso, a análise fatorial pode identificar variáveis representativas de um conjunto muito maior de variáveis ou criar um conjunto inteiramente novo de variáveis que substituam parcial ou completamente um conjunto original maior para uso em análises ou técnicas multivariadas subsequentes. (HAIR JR. et al., 2009).

Além de reduzir o número de variáveis, o pesquisador pode se beneficiar com a estimação empírica de relações, bem como a visão do fundamento conceitual e interpretação dos resultados. Porém, "se o pesquisador incluir indiscriminadamente um grande número de variáveis e esperar que a análise fatorial faça revelações, a possibilidade de resultados pobres será alta" (ibid., p. 96). O uso de análise fatorial não exclui a necessidade de uma base conceitual para quaisquer variáveis analisadas.

Quanto ao tamanho da amostra, os autores sugerem um número mínimo de observações superior a cinco vezes o número de variáveis a serem analisadas. O pesquisador sempre deve obter a maior razão - casos por variável - para minimizar chances de "super ajustar" os dados. Uma das formas é trabalhar com um conjunto de variáveis mais parcimoniosos, guiado por considerações conceituais e práticas, e então obtendo um tamanho adequado de amostra para o número de variáveis observadas. Em um número pequeno de casos por variável, qualquer descoberta deve ser interpretada com precaução.

Na pesquisa realizada, a quantidade de casos obtida foi 299 para um total de 46 variáveis, o que gera uma proporção de 6,5 casos por variável.

Do ponto de vista estatístico, os desvios da normalidade, da homoscedasticidade e da linearidade aplicam-se apenas no nível em que elas diminuem as correlações observadas. "A normalidade é necessária somente se um teste estatístico é aplicado para a significância dos fatores, mas estes testes raramente são usados" (ibid., p. 98). 
Quanto à existência ou não de fatores nos dados, as correlações parciais devem ser pequenas, ou seja, aquelas correlações entre variáveis quando os efeitos de outras variáveis são levados em consideração. Se as correlações parciais são altas, então não há fatores latentes e a análise fatorial é inadequada. O SPSS fornece a matriz de correlação anti-imagem, que é simplesmente o valor negativo da correlação parcial.

Outra medida para detectar a adequação de análise fatorial é o teste de esfericidade de Barlett aplicado à matriz de correlação inteira. Tal teste fornece a probabilidade estatística que a matriz de correlação tenha correlações significantes entre pelo menos algumas das variáveis. Há ainda a medida de adequação da amostra (MSA), que varia de 0 a 1 , na qual o valor 1 representa a previsão perfeita da variável livre de erro pelas outras variáveis. O valor aceitável de MSA para cada variável deve ser superior a 0,50. De modo geral, o importante é que matriz de dados tenha um número substancial de correlações superiores a 0,30 (HAIR JR. et al., 2009).

\section{Método de extração}

Segundo Hair Jr. et al. (2009) a seleção do método depende do objetivo do pesquisador. A análise de componentes principais é usada quando o objetivo é resumir a maior parte da informação original (variância) a um número mínimo de fatores para propósitos de previsão.

Já a análise de fatores comuns é usada para identificar fatores ou dimensões latentes que reflitam o que as variáveis têm em comum. A análise de fatores comuns considera apenas as dimensões latentes (variância compartilhada) ignorando as variâncias específicas de cada variável e do erro, devido a não confiabilidade no processo de agrupamento dos dados, no erro de medida ou em uma componente aleatória no fenômeno medido.

Embora a análise de fatores comuns seja vista como teoricamente mais fundamentada, ela sofre de indeterminância fatorial, pois não há solução única, como ocorre com a análise de componentes (ou componentes principais). Apesar de haver muito debate sobre qual modelo é mais apropriado, as pesquisas têm apresentado resultados análogos em muitos casos, e costuma chegar a resultados idênticos quando o número de variáveis excede a 30 ou as comunalidades excedem a 0,60 para a maioria das variáveis. 
No caso desta pesquisa, a quantidade de variáveis é 46 e as comunalidades da maior parte das variáveis excedem a 0,60. Portanto, a opção foi analisar pelo método dos componentes principais.

\title{
Número de fatores
}

Aranha e Zambaldi (2008) afirmam que um critério frequentemente utilizado para a escolha do número de fatores é pelos autovalores (eigenvalues). O software SPSS apresenta os autovalores para " $\mathrm{n}$ " fatores em ordem decrescente, sendo " $\mathrm{n}$ " igual ao número de variáveis da análise fatorial. A quantidade de fatores sugerida é igual ao número de fatores cujo autovalor é maior que 1. Segundo Hair Jr. et al. (2009, p. 101):

\begin{abstract}
Após a determinação inicial, o pesquisador computa diversas soluções alternativas adicionais - geralmente um fator a menos que o número inicial e dois ou três fatores a mais do que o inicialmente determinado. Então, com base na informação obtida das análises de alternativas, as matrizes fatoriais são examinadas e a melhor representação dos dados é usada para ajudar na determinação do número de fatores a extrair.
\end{abstract}

\section{Variância explicada}

Hair Jr. et al. (2009, p. 102) afirmam que em ciências naturais, o processo de obtenção de fatores não deveria ser parado até que estes explicassem pelo menos $95 \%$ da variância, mas nas ciências sociais, nas quais as informações são menos precisas, não é raro considerar uma solução que explique $60 \%$ da variância total como satisfatória.

\section{Rotação fatorial}

Segundo Hair Jr. et al. (2009) uma ferramenta importante na interpretação dos fatores é a rotação fatorial. Em soluções não rotacionadas, os fatores são extraídos na ordem de sua importância, com o primeiro fator tendendo a ser um fator geral com quase toda a variável com carga significante. A rotação pode ser ortogonal ou oblíqua. Na rotação ortogonal (método varimax no SPSS), mantêm-se os eixos de referência com ângulos de $90^{\circ}$, indicado quando os fatores forem matematicamente independentes entre si. Já na rotação oblíqua (oblimin), os eixos não precisam ser ortogonais, ou seja, ela é mais realista, pois as dimensões inerentes que são teoricamente importantes podem ser correlacionadas entre si, fato este mais condizente com a realidade na pesquisa em ciências sociais onde raramente um fenômeno é 
completamente independente do outro. Na pesquisa A, os fatores foram extraídos utilizando método de rotação oblimin.

\section{Cargas fatoriais mínimas}

Hair Jr. et al. (2009) também apontam que amostras com até 50 respondentes devem ser analisadas considerando cargas fatoriais acima de 0,75; de 85 a 100 respondentes, cargas superiores a 0,60; de 150 a 200 respondentes, cargas acima de 0,45; de 250 a 350 respondentes, cargas acima de 0,35, e para amostras acima de 350 respondentes, cargas mínimas iguais a 0,30. Os autores ainda sugerem que se as variáveis forem muitas, o nível aceitável de cargas significantes pode ser menor. Porém, se houver muitos fatores, mais altas devem ser as cargas significantes. Para a amostra total $(n=299)$ será considerada a carga mínima igual a 0,35 ; conforme a sugestão dos autores.

\section{Interpretação}

Para a interpretação, Hair Jr. et al. (2009) afirmam que, em uma rotação oblíqua, são apresentadas duas matrizes fatoriais de carga: a matriz padrão e a matriz de estrutura fatorial. $\mathrm{Na}$ matriz de estrutura fatorial, como as cargas contêm tanto a variância única entre as variáveis e fatores, quanto a correlação entre fatores, torna-se extremamente complexo distinguir quais variáveis têm cargas únicas em cada fator na matriz, sendo, portanto, costume dos pesquisadores utilizar a matriz padrão. Os autores sugerem os seguintes passos para a interpretação da matriz fatorial:

- Identificar em qual fator a variável tem maior carga - variáveis com carga fatorial igualmente distribuída em muitos fatores é séria candidata à eliminação;

- Avaliar as comunalidades das variáveis - a comunalidade representa a quantia de variância explicada pela solução fatorial para cada variável - se o seu valor é menor que 0,50 significa que não tem explicação suficiente;

- Nomear os fatores - pelas variáveis que têm maior carga no fator, o pesquisador deve interpretar intuitivamente o que pode haver de variável latente (fator ou dimensão) que manteve essas variáveis com alta correlação entre si.

Aranha e Zambaldi (2008) afirmam que é importante interpretar uma solução exploratória com base teórica. Havendo diferenças entre os subgrupos, a escolha seguirá o critério da solução fatorial que mais se aproximar da esperada teoricamente. 


\subsubsection{Modelagem de equações estruturais}

A análise exploratória apenas define possíveis relações de forma geral. O pesquisador não busca "confirmar" quaisquer relações especificadas anteriormente, mas deixa o método e os dados definirem a natureza das relações. Já a análise confirmatória é o uso de uma técnica multivariada para testar uma relação pré-especificada (HAIR JR. et al., 2009, p. 466), normalmente obtida justamente por meio da análise fatorial exploratória.

Segundo os autores uma das formas de confirmar as relações obtidas da teoria ou de uma análise exploratória é avaliar a repetitividade dos resultados, seja com uma amostra fracionada do conjunto de dados originais, seja com uma amostra separada. A comparação de resultados é sempre problemática, mas uma forma de confirmação também pode ser realizada submetendo as relações a uma análise por modelagem de equações estruturais (MEE).

A MEE é uma família de modelos estatísticos que buscam explicar as relações entre múltiplas variáveis (ibid., 2009). Pode ser considerada ainda uma técnica robusta, que pertence a segunda geração de técnicas estatísticas multivariadas para análise de dados (CAMPANA; TAVARES; SILVA, 2009).

Segundo Hair Jr. et al. (2009, p. 470) a MEE “É uma técnica multivariada que combina aspectos de regressão múltipla (examinando relações de dependência) e análise fatorial (representando conceitos não medidos - fatores - com múltiplas variáveis) para estimar uma série de relações de dependência inter-relacionadas simultaneamente.”. Ainda para os autores a MEE se distingue por possibilitar a estimação de relações de dependência múltiplas e interrelacionadas e por possuir a habilidade de representar conceitos não observados nessas relações explicando o erro de mensuração no processo de estimação. A MEE ainda prevê um método direto, com eficiência estatística, para trabalhar simultaneamente com múltiplos relacionamentos de dependência, explorando-os de maneira aprofundada, gerando análises exploratórias e confirmatórias e permitindo a representação de conceitos não observáveis nestes relacionamentos.

Para Souza (2004, p. 128) a MEE "fornece então medidas de ajuste geral do modelo (goodness-of-fit measures) que são obtidas a partir das diferenças existentes entre a matriz de covariâncias observada e a matriz que pode ser predita a partir do modelo proposto". 
De acordo com Gefen, Straub e Boudreau (2000) a MEE permite responder a uma série de perguntas inter-relacionadas de forma simples, abrangente e sistemática, modelando simultaneamente as relações entre múltiplos construtos dependentes e independentes.

Parafraseando Bilich, Silva e Ramos (2006, p. 94) a MEE, também denominada de análise fatorial confirmatória ou análise de variáveis latentes, é considerada uma técnica de análise multivariada, distinguindo-se das demais técnicas de mesma natureza, por estimar, simultaneamente, uma série de regressões múltiplas, de forma individualizada e, no entanto, interdependente, por intermédio da especificação de modelos estruturais.

Nesse sentido, os dados foram processados com o método de estimação Partial Least Squares (PLS). Para tal, foi utilizado o software SmartPLS Versão 2.0M3 para validação do modelo estrutural proposto.

A justificativa de uso do PLS para o processamento da MEE se dá por três aspectos: o primeiro é em função de que o PLS é um modelo com objetivos preditivos, ou seja, tem o efeito de prognosticar e podem-se modelar variáveis latentes com indicadores formativos ou reflexivos.

Segundo Bido et al. (2010, p. 248) os indicadores são formativos "quando explicam o construto e não é esperado que haja correlação entre eles" e são indicadores reflexivos, "quando são explicados pelos construtos (indicadores-efeito)".

O segundo aspecto está relacionado com o método de processamento utilizado pelo PLS que se dá com base na especificação preditiva, na qual diferentemente do método likelihood, não há uma rígida limitação quanto ao pressuposto de normalidade (LOHMOLLER, 1989; VINZI et al., 2010).

O terceiro aspecto é que tal método é menos sensível à consideração sobre o tamanho da amostra. Segundo Souza (2004, p. 140) o "tamanho da amostra recomendado para MEE pelo método likelihood é de no mínimo 200 casos”. Uma das considerações trazidas por Hair Jr. et al. (2009, p. 565) e que se enquadram neste estudo, é que se "alguma comunalidade for modesta $(0,45-0,55)$, ou se o modelo contém construtos de três itens, então o tamanho exigido para a amostra é da ordem de 200”. 
Como os dados foram obtidos por escalas intervalares, o pressuposto de normalidade geralmente é violado. Para Finney e Di Stefano (2006, p. 302) "a presença de dados nãonormais provenientes de escalas ordinais nas pesquisas aplicadas desafiam o pesquisador não somente a reconhecer as propriedades de seus dados, mas também, a utilizar técnicas que as acomodem".

\section{Etapas do processo de modelagem de equações estruturais}

Hair Jr. et al. (2009, p. 560-580) explicitam que a MEE pode ser descrita em um processo de decisão em seis estágios, a saber: 1 - Definir construtos individuais; 2 - Desenvolver o modelo de mensuração geral; 3 - Planejar um estudo para produzir resultados empíricos; 4 Avaliar a validade do modelo de mensuração; 5 - Especificar o modelo estrutural; e 6 Avaliar a validade do modelo estrutural. Para a realização da análise, adotaram-se as etapas descritas na sequência:

Etapa 1 - Da mesma forma que para a AFE, foi realizada uma análise exploratória do banco de dados para verificar dados omissos, distribuição normal, outliers, bem como a consistência e coerência das respostas.

Etapa 2 - Análise do modelo de mensuração. A MEE se enquadra em função dos testes e modificações graduais a fim de ajustá-lo aos dados coletados e principalmente permitindo uma explicação lógica sobre as relações identificadas. Esta estratégia é chamada de "desenvolvimento de modelos", em que o propósito do esforço "é melhorar o modelo por meio de modificações dos modelos estrutural e/ou de mensuração". O modelo de mensuração é "uma especificação da teoria de mensuração que mostra como construtos são operacionalizados por conjuntos de variáveis medidas" (HAIR JR. et al., 2009, p. 588).

Nessa análise, foram verificadas e avaliadas:

- Cargas Fatoriais: verifica a carga de cada variável observada do modelo no seu construto. Cargas altas sobre um fator indicariam que elas convergem para algum ponto em comum e todas as cargas devem ser estatisticamente significantes (HAIR JR. et al. , 2009). A regra estabelece que a estimativa de cargas padronizadas deve ser de 0,50 ou mais, e idealmente de 0,70 para cima (HAIR JR. et al., 2009; BIDO, 2010). 
Cargas fatoriais abaixo de 0,70 podem ser consideradas significantes, mas há mais variância de erro do que a explicada na variância de medida.

- Confiabilidade: segundo Hair Jr. et al, (2007, p. 24) é a extensão em que uma variável ou conjunto de variáveis é consistente com o que se pretende medir, ou seja, se medidas repetidas forem executadas, as medidas confiáveis serão consistentes em seus valores. Realiza cálculo para cada variável dependente (explicada ou endógena) e variável latente (explicativas ou exógenas) por meio do grau de confiabilidade (Alfa de Cronbach). Quando há uma elevada confiabilidade no construto significa que todas as medidas consistentemente representam o mesmo construto latente e a regra para qualquer estimativa de confiabilidade é que seja 0,70 ou superior, mas índices entre 0,60 e 0,70 são aceitáveis desde que os outros indicadores de validade do construto sejam bons (HAIR JR. et al. , 2009).

- Validade convergente: avalia o grau em que duas medidas do mesmo conceito estão correlacionadas. $\mathrm{O}$ teste empírico pode incluir a análise de correlação entre medidas alternativas de um conceito e a escala múltipla, esperando-se altos valores de correlação (HAIR JR. et al, 2005, p. 112). Para este estudo, a validade convergente foi avaliada pelos valores da variância média extraída (Average Variance Extracted AVE) dos fatores igual ou superior a 0,50 , pois estes que representam a alta correlação com seus itens ou variáveis (ZWICKER; SOUZA; BIDO, 2008), pelo índice de confiabilidade (Alfa de Cronbach) superior a 0,60 e pelo valor de confiabilidade composta superior a 0,70 .

- Validade discriminante: consiste no grau em que dois conceitos similares são distintos. Nesse caso, o teste empírico também avalia a correlação entre medidas, porém a escala múltipla está correlacionada com uma medida semelhante, mas conceitualmente distinta, esperando-se valores de correlação baixos. (HAIR JR. et al, 2007, p. 112). Segundo Zwicker, Souza e Bido (2008) há validade discriminante quando o valor da raiz quadrada da AVE de um construto (ou variável latente) é maior que as correlações entre os construtos ou quando as cargas cruzadas entre os construtos são menores que suas respectivas variáveis componentes.

- Confiabilidade Composta (composite reliability): avalia os resultados de confiabilidade composta para cada variável latente. A confiabilidade composta é uma 
medida de consistência interna dos indicadores do construto, descrevendo o grau em que eles indicam o construto latente em comum. A regra determina que o valor não deve ser menor do que 0,60 (CHIN, 1998), mas segundo Hair Jr. et al. (2009), um valor de referência comumente utilizado para confiabilidade aceitável é 0,70 , embora não seja um padrão absoluto, sendo aceitáveis valores abaixo de 0,70 no caso de pesquisas de natureza exploratória.

- Colinearidade: verifica as colinearidades entre as variáveis estudadas. Segundo Hair Jr. et al. (2009) a colinearidade expressa a relação entre duas ou mais variáveis independentes.

Etapa 3 - Modelo Estrutural - Validação. Segundo Hair Jr. et. al (2009, p. 644) o modelo estrutural "é o conjunto de uma ou mais relações de dependência conectando os construtos hipotetizados do modelo". Ainda para os autores, o modelo de mensuração "especifica os indicadores para cada construto e avalia a confiabilidade de cada construto para estimar as relações causais.”.

Para esta etapa foram verificados:

- Os valores do coeficiente de determinação de variância $-\mathrm{R}^{2}$. Segundo Hair Jr. et al. (2009), o R é uma medida da proporção da variância da variável dependente em torno de sua média que é explicada pelas variáveis independentes. Como regra, os valores variam de 0 a 1 e quanto maior o valor de $\mathrm{R}^{2}$, maior a explicação.

- A fim de testar a hipótese de que os coeficientes de correlação sejam iguais a zero, foi realizado o teste $t$ de student por meio do Bootstrapping. Como regra, o resultado deve ser igual ou superior a 1,99 .

\section{Modelos de mensuração e estrutural}

Modelo de mensuração é um submodelo em MEE que especifica os indicadores para cada construto e avalia a confiabilidade de cada construto para estimar as relações causais. É semelhante à análise fatorial, porém é o pesquisador que especifica quais variáveis são 
indicadoras de cada construto, com as demais variáveis sem carga, exceto aquelas em seu construto especificado (HAIR JR. et al., 2009, p. 469).

Jarvis, Mackenzie e Podsakoff (2003) apresentam quatro critérios conceituais para distinguir se o construto deve ser modelado como tendo indicadores formativos ou reflexivos, a saber: a direção da causalidade; a intercambialidade dos indicadores; a covariância entre os indicadores; e a rede nomológica dos indicadores.

Já o modelo estrutural, segundo Hair Jr. et al. (2009, p. 469) "é o conjunto de uma ou mais relações de dependência conectando os construtos hipotetizados do modelo”.

\section{Técnica Bootstrapping}

Segundo Hair Jr. et al. (2009, p. 466) bootstrapping é uma forma de reamostragem na qual os dados originais são repetidamente amostrados com substituição para estimação do modelo. Para avaliação do modelo estrutural, a técnica bootstrapping, no SMART PLS, apresenta os resultados do teste da distribuição $t$ de Student considerando várias amostras.

De acordo com o valor de $t$ pode-se definir se os coeficientes padronizados (path coefficients) são significantes. A hipótese H0 é que os coeficientes sejam iguais à zero. Para altos valores de $n$ (quantidade de casos da amostra), o $t$ de Student superior a 1,99 indica que há menos de $5 \%$ de risco de rejeitar $\mathrm{H} 0$. Quanto maior o $t$, menor o risco de rejeitar $\mathrm{H} 0$ e, portanto, com $\mathrm{H} 0$ rejeitada, a correlação é significante.

Critérios de convergência:

- Cargas fatoriais: das variáveis no fator superiores a 0,50;

- Variância extraída: AVE (Average Variance Extracted) superior a 0,50;

- Confiabilidade: Alfa de Cronbach superior a 0,60;

- Confiabilidade Composta (composite reliability): é uma medida de consistência interna dos indicadores do construto, descrevendo o grau em que eles indicam o construto latente em comum - superior a 0,70 . 
Critério de discriminância:

- Validade discriminante: os indicadores devem ter cargas fatoriais mais altas nas suas respectivas variáveis latentes (raiz quadrada da AVE) do que em relação às outras variáveis latentes (esta informação é obtida da matriz de correlação entre as variáveis latentes no SMART PLS)

Critérios de validade nomológica:

- Todas as cargas estruturais devem ser significativas, ou seja, os valores $t$ de Student obtidos a partir do Bootstrapping devem ser superiores a 1,96. Para amostras próximas a 100 , o $t$ de Student deve ser superior a 1,99. 


\section{ANÁLISE DOS DADOS E RESULTADOS}

Este capítulo apresenta a consolidação da pesquisa a partir da estruturação teórica articulada nos capítulos anteriores, abordando os resultados somente quando estes são relevantes para as decisões das próximas etapas. O capítulo 6 trata especificamente da discussão teórica dos resultados obtidos nestas análises.

\subsection{Método de execução e análise dos dados}

Após o encerramento da pesquisa eletrônica, que foi compreendida entre agosto e outubro de 2010, o total de questionários respondidos foi de 358, como pode ser observado na tabela 2. Desse total, 15 questionários $-4,2 \%$ foram invalidados por terem sido preenchidos de forma repetida em um dos graus da escala; 19 questionários - 5,3\% foram invalidados por apresentarem respostas incompletas; e 25 questionários - 7,0\% foram invalidados, pois os respectivos respondentes não se enquadravam no perfil desejado (gráfico 1).

Tabela 2 - Frequências dos questionários respondidos

\begin{tabular}{lccrr}
\hline & Frequência & $\begin{array}{c}\text { Frequência } \\
\text { Acumulada }\end{array}$ & \% & $\begin{array}{r}\text { \% } \\
\text { Acumulada }\end{array}$ \\
\hline Questionários válidos & 299 & 299 & 83,5 & 83,5 \\
Invalidados por erro & 15 & 314 & 4,2 & 87,7 \\
Invalidados por estarem incompletos & 19 & 333 & 5,3 & 93,0 \\
Invalidados por não se enquadrarem no perfil & 25 & 358 & 7,0 & 100,0 \\
\hline Total & $\mathbf{3 5 8}$ & & $\mathbf{1 0 0 , 0}$ & \\
\hline
\end{tabular}

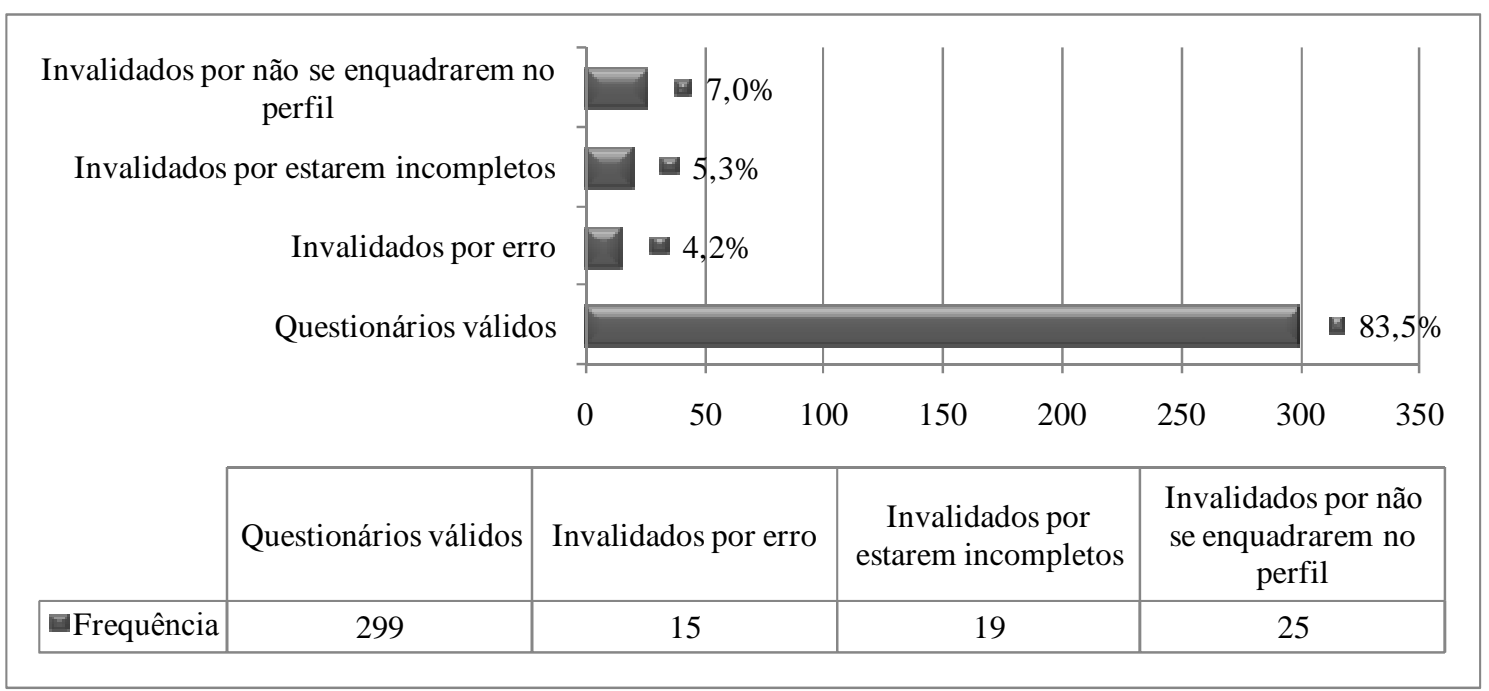

Gráfico 1 - Gráfico com percentuais - Análise dos questionários preenchidos 


\subsection{Descrições e caracterização da amostra}

A amostra apresentou respondentes de organizações de 11 cidades da Região Metropolitana de São Paulo, a maioria das organizações $(61,5 \%)$ concentrada na cidade de São Paulo conforme pode ser observado na tabela 3. Dos respondentes, 107 (35,7\%) estão situados nos municípios que compreendem a região do Grande ABCD. Cabe ressaltar que as organizações que foram agrupadas em “outra na Grande SP”, pertencem aos municípios de Barueri, Guarulhos e Osasco.

Tabela 3 - Localização das organizações respondentes

\begin{tabular}{lcccc}
\hline \multicolumn{1}{c}{ Cidades } & Frequência & $\begin{array}{c}\text { Frequência } \\
\text { Acumulada }\end{array}$ & \% & $\begin{array}{c}\text { \% } \\
\text { Acumulada }\end{array}$ \\
\hline São Paulo & 184 & 184 & 61,5 & 61,5 \\
São Caetano do Sul & 12 & 196 & 4,0 & 65,6 \\
São Bernardo do Campo & 39 & 235 & 13,0 & 78,6 \\
Santo André & 20 & 255 & 6,7 & 85,3 \\
Diadema & 15 & 270 & 5,0 & 90,3 \\
Mauá & 15 & 285 & 5,0 & 95,3 \\
Ribeirão Pires & 5 & 290 & 1,7 & 97,0 \\
Rio Grande da Serra & 1 & 291 & 0,3 & 97,3 \\
Outra na Grande SP & 8 & 299 & 2,7 & 100,0 \\
\hline Total & 299 & \multicolumn{3}{c}{100,0} \\
\hline
\end{tabular}

\section{Setor de atividade}

Já em relação ao setor de atividade das organizações respondentes, a maior parte $(\mathbf{4 6 , 8 \% )}$ pertence ao setor industrial, $40,1 \%$ são do setor de serviços e $13 \%$ do setor de comércio, conforme pode ser observado na tabela 4.

Tabela 4 - Setor de atividade das organizações respondentes (continua)

\begin{tabular}{llcccc}
\hline \multirow{2}{*}{ Cidade } & & \multicolumn{3}{c}{ Setor } & \\
\cline { 3 - 5 } & & Indús tria & Comércio & Serviço & Total \\
\hline São Paulo & Frequência Absoluta & 58 & 35 & 91 & 184 \\
& \% em relação à Cidade & 31,5 & 19,0 & 49,5 & 100,0 \\
& \% em relação ao Setor & 41,4 & 89,7 & 75,8 & 61,5 \\
& \% em relação ao Total & 19,4 & 11,7 & 30,4 & 61,5 \\
\hline
\end{tabular}


Tabela 4 - Setor de atividade das organizações respondentes (conclusão)

\begin{tabular}{|c|c|c|c|c|c|}
\hline \multirow{2}{*}{ Cidade } & & \multicolumn{3}{|c|}{ Setor } & \multirow[b]{2}{*}{ Total } \\
\hline & & Indústria & Comércio & Serviço & \\
\hline \multirow[t]{4}{*}{ São Caetano do Sul } & Frequência Absoluta & 5 & 0 & 7 & 12 \\
\hline & $\%$ em relação à Cidade & 41,7 & 0,0 & 58,3 & 100,0 \\
\hline & \% em relação ao Setor & 3,6 & 0,0 & 5,8 & 4,0 \\
\hline & \% em relação ao Total & 1,7 & 0,0 & 2,3 & 4,0 \\
\hline \multirow[t]{4}{*}{ São Bernardo do Campo } & Frequência Absoluta & 30 & 1 & 8 & 39 \\
\hline & $\%$ em relação à Cidade & 76,9 & 2,6 & 20,5 & 100,0 \\
\hline & $\%$ em relação ao Setor & 21,4 & 2,6 & 6,7 & 13,0 \\
\hline & $\%$ em relação ao Total & 10,0 & 0,3 & 2,7 & 13,0 \\
\hline \multirow[t]{4}{*}{ Santo André } & Frequência Absoluta & 12 & 0 & 8 & 20 \\
\hline & \% em relação à Cidade & 60,0 & 0,0 & 40,0 & 100,0 \\
\hline & \% em relação ao Setor & 8,6 & 0,0 & 6,7 & 6,7 \\
\hline & \% em relação ao Total & 4,0 & 0,0 & 2,7 & 6,7 \\
\hline \multirow[t]{4}{*}{ Diadema } & Frequência Absoluta & 13 & 1 & 1 & 15 \\
\hline & \% em relação à Cidade & 86,7 & 6,7 & 6,7 & 100,1 \\
\hline & \% em relação ao Setor & 9,3 & 2,6 & 0,8 & 5,0 \\
\hline & $\%$ em relação ao Total & 4,3 & 0,3 & 0,3 & 5,0 \\
\hline \multirow[t]{4}{*}{ Mauá } & Frequência Absoluta & 14 & 0 & 1 & 15 \\
\hline & \% em relação à Cidade & 93,3 & 0,0 & 6,7 & 100,0 \\
\hline & \% em relação ao Setor & 10,0 & 0,0 & 0,8 & 5,0 \\
\hline & \% em relação ao Total & 4,7 & 0,0 & 0,3 & 5,0 \\
\hline \multirow[t]{4}{*}{ Ribeirão Pires } & Frequência Absoluta & 5 & 0 & 0 & 5 \\
\hline & \% em relação à Cidade & 100,0 & 0,0 & 0,0 & 100,0 \\
\hline & \% em relação ao Setor & 3,6 & 0,0 & 0,0 & 1,7 \\
\hline & \% em relação ao Total & 1,7 & 0,0 & 0,0 & 1,7 \\
\hline \multirow[t]{4}{*}{ Rio Grande da Serra } & Frequência Absoluta & 0 & 1 & 0 & 1 \\
\hline & \% em relação à Cidade & 0,0 & 100,0 & 0,0 & 100,0 \\
\hline & \% em relação ao Setor & 0,0 & 2,6 & 0,0 & 0,3 \\
\hline & \% em relação ao Total & 0,0 & 0,3 & 0,0 & 0,3 \\
\hline \multirow[t]{4}{*}{ Outra na Grande SP } & Frequência Absoluta & 3 & 1 & 4 & 8 \\
\hline & \% em relação à Cidade & 37,5 & 12,5 & 50,0 & 100,0 \\
\hline & \% em relação ao Setor & 2,1 & 2,6 & 3,3 & 2,7 \\
\hline & $\%$ em relação ao Total & 1,0 & 0,3 & 1,3 & 2,7 \\
\hline \multirow[t]{4}{*}{ Total } & Frequência Absoluta Total & 140 & 39 & 120 & 299 \\
\hline & \% em relação à Cidade & 46,8 & 13,0 & 40,2 & 100,0 \\
\hline & \% em relação ao Setor & 100,0 & 100,0 & 100,0 & 100,0 \\
\hline & \% em relação ao Total Geral & 46,8 & 13,0 & 40,2 & 100,0 \\
\hline
\end{tabular}

\section{Porte da empresa}

Em relação ao porte da empresa, de acordo com o Sebrae (2010a), os mesmos estão subdivididos por setor, ou seja, para o setor industrial a empresa é considerada de grande 
porte se tiver, no exercício social anterior, ativo total superior a $\mathrm{R} \$ 240.000 .000,00$ (duzentos e quarenta milhões de reais) ou receita bruta anual superior a $\mathrm{R} \$ 300.000 .000,00$ (trezentos milhões de reais). Para empresas de médio porte, são consideradas aquelas que tiverem mais de $\mathrm{R} \$ 2.400 .000,00$ (dois milhões e quatrocentos mil reais) de receita bruta anual. O resultado foi o de 241 empresas de grande porte $(80,6 \%)$ e 58 empresas de médio porte $(19,4 \%)$. A tabela 5 ilustra as frequências e universo dentro de cada cidade.

Tabela 5 - Porte das organizações respondentes (continua)

\begin{tabular}{|c|c|c|c|c|}
\hline & \multirow{2}{*}{ Cidade } & \multicolumn{2}{|c|}{ Porte } & \multirow{2}{*}{ Total } \\
\hline & & Grande & Médio & \\
\hline \multirow[t]{4}{*}{ São Paulo } & Frequência Absoluta & 151 & 33 & 184 \\
\hline & \% em relação à Cidade & 82,1 & 17,9 & 100,0 \\
\hline & \% em relação ao Porte & 62,7 & 56,9 & 61,5 \\
\hline & \% em relação ao Total & 50,5 & 11,0 & 61,5 \\
\hline \multirow[t]{4}{*}{ São Caetano do Sul } & Frequência Absoluta & 10 & 2 & 12 \\
\hline & \% em relação à Cidade & 83,3 & 16,7 & 100,0 \\
\hline & \% em relação ao Porte & 4,1 & 3,4 & 4,0 \\
\hline & \% em relação ao Total & 3,3 & 0,7 & 4,0 \\
\hline \multirow[t]{4}{*}{ São Bernardo do Campo } & Frequência Absoluta & 34 & 5 & 39 \\
\hline & \% em relação à Cidade & 87,2 & 12,8 & 100,0 \\
\hline & \% em relação ao Porte & 14,1 & 8,6 & 13,0 \\
\hline & \% em relação ao Total & 11,4 & 1,7 & 13,0 \\
\hline \multirow[t]{4}{*}{ Santo André } & Frequência Absoluta & 17 & 3 & 20 \\
\hline & \% em relação à Cidade & 85,0 & 15,0 & 100,0 \\
\hline & \% em relação ao Porte & 7,1 & 5,2 & 6,7 \\
\hline & \% em relação ao Total & 5,7 & 1,0 & 6,7 \\
\hline \multirow[t]{4}{*}{ Diadema } & Frequência Absoluta & 9 & 6 & 15 \\
\hline & \% em relação à Cidade & 60,0 & 40,0 & 100,0 \\
\hline & \% em relação ao Porte & 3,7 & 10,3 & 5,0 \\
\hline & \% em relação ao Total & 3,0 & 2,0 & 5,0 \\
\hline \multirow[t]{4}{*}{ Mauá } & Frequência Absoluta & 10 & 5 & 15 \\
\hline & \% em relação à Cidade & 66,7 & 33,3 & 100,0 \\
\hline & \% em relação ao Porte & 4,1 & 8,6 & 5,0 \\
\hline & \% em relação ao Total & 3,3 & 1,7 & 5,0 \\
\hline \multirow[t]{4}{*}{ Ribeirão Pires } & Frequência Absoluta & 3 & 2 & 5 \\
\hline & \% em relação à Cidade & 60,0 & 40,0 & 100,0 \\
\hline & \% em relação ao Porte & 1,2 & 3,4 & 1,7 \\
\hline & \% em relação ao Total & 1,0 & 0,7 & 1,7 \\
\hline \multirow[t]{4}{*}{ Rio Grande da Serra } & Frequência Absoluta & 1 & 0 & 1 \\
\hline & \% em relação à Cidade & 100,0 & 0,0 & 100,0 \\
\hline & \% em relação ao Porte & 0,4 & 0,0 & 0,3 \\
\hline & \% em relação ao Total & 0,3 & 0,0 & 0,3 \\
\hline
\end{tabular}


Tabela 5 - Porte das organizações respondentes (conclusão)

\begin{tabular}{llccc}
\hline \multirow{2}{*}{ Cidade } & \multicolumn{2}{c}{ Porte } & \multirow{2}{*}{ Total } \\
\cline { 3 - 4 } & & Grande & Médio & \\
\hline Outra na Grande SP & Frequência Absoluta & 6 & 2 & 8 \\
& \% em relação à Cidade & 75,0 & 25,0 & 100,0 \\
& \% em relação ao Porte & 2,5 & 3,4 & 2,7 \\
& \% em relação ao Total & 2,0 & 0,7 & 2,7 \\
\hline Total & Frequência Absoluta Total & 241 & 58 & 299 \\
& \% em relação à Cidade & 80,6 & 19,4 & 100,0 \\
& \% em relação ao Porte & 100,0 & 100,0 & 100,0 \\
& \% em relação ao Total Geral & 80,6 & 19,4 & 100,0 \\
\hline
\end{tabular}

\section{Receita líquida}

A receita foi escalonada pelas faixas propostas pelo SEBRAE (2010a). Das organizações respondentes, $101(33,8 \%)$ possuem receita líquida acima dos $\mathrm{R} \$ 300$ milhões. Apenas 11 estão na faixa que varia de $\mathrm{R} \$ 2.4$ a $\mathrm{R} \$ 10$ milhões representando apenas $3,7 \%$ da amostra. A tabela 6 ilustra os resultados de acordo com cada setor.

Tabela 6 - Receita Líquida das organizações respondentes por setor

\begin{tabular}{|c|c|c|c|c|c|c|c|}
\hline \multirow{2}{*}{ Setor } & & \multicolumn{5}{|c|}{ Receita } & \multirow{2}{*}{ Total } \\
\hline & & $\mathbf{A}$ & B & $\mathbf{C}$ & D & $\mathbf{E}$ & \\
\hline \multirow[t]{4}{*}{ Indústria } & Frequência Absoluta & 3 & 12 & 27 & 46 & 52 & 140 \\
\hline & \% em relação ao Setor & 2,1 & 8,6 & 19,3 & 32,9 & 37,1 & 100,0 \\
\hline & \% em relação à Receita & 27,3 & 40,0 & 41,5 & 50,0 & 51,5 & 46,8 \\
\hline & \% em relação ao Total & 1,0 & 4,0 & 9,0 & 15,4 & 17,4 & 46,8 \\
\hline \multirow[t]{4}{*}{ Comércio } & Frequência Absoluta & 1 & 6 & 5 & 16 & 11 & 39 \\
\hline & \% em relação ao Setor & 2,6 & 15,4 & 12,8 & 41,0 & 28,2 & 100,0 \\
\hline & $\%$ em relação à Receita & 9,1 & 20,0 & 7,7 & 17,4 & 10,9 & 13,0 \\
\hline & \% em relação ao Total & 0,3 & 2,0 & 1,7 & 5,4 & 3,7 & 13,0 \\
\hline \multirow[t]{4}{*}{ Serviço } & Frequência Absoluta & 7 & 12 & 33 & 30 & 38 & 120 \\
\hline & \% em relação ao Setor & 5,8 & 10,0 & 27,5 & 25,0 & 31,7 & 100,0 \\
\hline & \% em relação à Receita & 63,6 & 40,0 & 50,8 & 32,6 & 37,6 & 40,1 \\
\hline & \% em relação ao Total & 2,3 & 4,0 & 11,0 & 10,0 & 12,7 & 40,1 \\
\hline \multirow[t]{2}{*}{ Total } & Frequência Absoluta Total & 11 & 30 & 65 & 92 & 101 & 299 \\
\hline & \% em relação ao Total Geral & 3,7 & 10,0 & 21,7 & 30,8 & 33,8 & 100,0 \\
\hline
\end{tabular}

Legenda das $\mathrm{A}=$ De $\mathrm{R} \$ 2.400 .000,01$ a $\mathrm{R} \$ 10.000 .000,00$

Faixas de $\quad B=D e R \$ 10.000 .000,01$ a $R \$ 100.000 .000,00$

Receita:

$\mathrm{C}=\mathrm{De} \mathrm{R} \$ 100.000 .000,01$ a $\mathrm{R} \$ 200.000 .000,00$

$\mathrm{D}=\mathrm{De} \mathrm{R} \$ 200.000 .000,01$ a $\mathrm{R} \$ 300.000 .000,00$

$\mathrm{E}=$ Acima de $\mathrm{R} \$ 300.000 .000,00$ 


\section{Quantidade de funcionários da empresa}

Sobre a quantidade total de funcionários, a média englobando os três setores e o porte foi de 3.409 funcionários. Este número fica distorcido em função de englobar os três setores com portes diferentes, o que caracteriza na amostra grande pluralidade de situações.

Para que haja um entendimento mais refinado sobre o número de funcionários são destacados os principais índices de acordo com cada setor e faixa de funcionários, a saber:

Das 140 organizações do setor industrial (46,8\%), a maior representatividade está na última faixa, ou seja, 59 organizações $(42,1 \%$ da amostra do setor) possuem acima de 1000 funcionários; no setor comercial, das 39 organizações (13\%), 18 (46,2\% da amostra do setor) possuem entre 100 e 499 funcionários; já no setor de serviços, das 120 organizações $(40,1 \%)$, 47 (39,2\% da amostra do setor) também possuem entre 100 e 499 funcionários. A tabela 7 ilustra tal cenário.

Tabela 7 - Quantidade de funcionários das organizações respondentes

\begin{tabular}{|c|c|c|c|c|c|c|}
\hline \multirow[b]{2}{*}{ Setor } & & \multicolumn{4}{|c|}{ Total de Funcionários } & \multirow[b]{2}{*}{ Total } \\
\hline & & De 01 a 99 & $\begin{array}{c}\text { De } 100 \text { a } \\
499\end{array}$ & $\begin{array}{c}\text { De } 500 \text { a } \\
999\end{array}$ & $\begin{array}{c}\text { Acima de } \\
1000\end{array}$ & \\
\hline \multirow[t]{4}{*}{ Indústria } & Frequência Absoluta & 3 & 37 & 41 & 59 & 140 \\
\hline & \% em relação ao Setor & 2,1 & 26,4 & 29,3 & 42,1 & \\
\hline & \% em relação à Faixa & 12,5 & 36,3 & 65,1 & 53,6 & \\
\hline & \% em relação ao Total & 1,0 & 12,4 & 13,7 & 19,7 & 46,8 \\
\hline \multirow[t]{4}{*}{ Comércio } & Frequência Absoluta & 1 & 18 & 10 & 10 & 39 \\
\hline & \% em relação ao Setor & 2,6 & 46,2 & 25,6 & 25,6 & \\
\hline & \% em relação à Faixa & 4,2 & 17,6 & 15,9 & 9,1 & \\
\hline & \% em relação ao Total & 0,3 & 6,0 & 3,3 & 3,3 & 13,0 \\
\hline \multirow[t]{4}{*}{ Serviço } & Frequência Absoluta & 20 & 47 & 12 & 41 & 120 \\
\hline & \% em relação ao Setor & 16,7 & 39,2 & 10,0 & 34,2 & \\
\hline & \% em relação à Faixa & 83,3 & 46,1 & 19,1 & 37,3 & \\
\hline & \% em relação ao Total & 6,7 & 15,7 & 4,0 & 13,7 & 40,1 \\
\hline \multirow[t]{2}{*}{ Total } & Frequência Absoluta Total & 24 & 102 & 63 & 110 & 299 \\
\hline & \% em relação ao Total Geral & 8,0 & 34,1 & 21,1 & 36,8 & 100,0 \\
\hline
\end{tabular}

Quantidade de funcionários próprios e terceirizados na área de tecnologia da informação e no desenvolvimento de sistemas de informação sob medida e/ou implantação de pacotes de sistemas de informação

Nesta questão, a pesquisa demonstrou uma variedade grande de situações envolvendo a alocação, tanto de funcionários próprios quanto terceirizados, seja na área de TI de forma geral como no desenvolvimento e/ou implantação de SI. 
No setor industrial, a média geral de funcionários próprios que trabalham na área de TI sobre o total de funcionários da organização é de $4,8 \%$ e a de terceirizados é de $2,9 \%$. Na alocação de funcionários que trabalham exclusivamente do desenvolvimento e/ou implantação de SI, a média dos funcionários próprios sobre o total de funcionários da área de TI é de $8,1 \%$ e a de terceirizados é de $1,6 \%$.

No setor comercial, os índices foram um pouco maiores, possibilitando ressaltar que, em média, 5,6\% dos funcionários da área de TI são terceirizados e destes, 3,0\% estão alocados no desenvolvimento e/ou implantação de SI da organização.

O setor de serviços é o que mais terceiriza tanto na área de TI $(12,2 \%)$ quanto no desenvolvimento e/ou implantação de SI (4,6\%). A tabela 8 ilustra todos os índices apurados. É possível afirmar que o número de funcionários terceirizados que trabalham, tanto na área de TI (6,9\%) como os alocados exclusivamente no desenvolvimento e/ou implantação (3,1\%), é baixo.

Esta situação apresentada na questão de terceirizados no desenvolvimento e/ou implantação, pode denotar a preocupação que as organizações têm em manter internamente a maior parte do seu quadro de funcionários da área, ou seja, os recursos próprios devem concentrar-se nas suas competências essenciais e terceirizar apenas as atividades que não possuem uma necessidade estratégica (CRISTOFOLI; PRADO, 2009).

Tabela 8 - Quantidade de funcionários próprios e terceirizados de TI e do desenvolvimento de SI das organizações (continua)

\begin{tabular}{|c|c|c|c|c|c|c|c|c|c|c|}
\hline \multirow[b]{2}{*}{ Setor } & \multirow[b]{2}{*}{ Funcionários } & \multicolumn{8}{|c|}{ Total de Funcionários } & \multirow[b]{2}{*}{$\begin{array}{c}\text { Média } \\
\%\end{array}$} \\
\hline & & $\begin{array}{c}\text { De } 01 \\
\text { a } 99\end{array}$ & $\%$ & $\begin{array}{c}\text { De } 100 \\
\text { a } 499\end{array}$ & $\%$ & $\begin{array}{c}\text { De } 500 \\
\text { a } 999\end{array}$ & $\%$ & $\begin{array}{c}\text { Acima } \\
\text { de } \\
1000 \\
\end{array}$ & $\%$ & \\
\hline \multirow{5}{*}{ 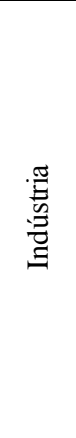 } & Média de Funcionários & 73 & & 323 & & 675 & & 7290 & & \\
\hline & $\begin{array}{l}\text { Média do Total de Funcionários na } \\
\text { área de TI - Próprio }\end{array}$ & 4 & $5,5 \%$ & 16 & $5,0 \%$ & 33 & $4,9 \%$ & 280 & $3,8 \%$ & $4,8 \%$ \\
\hline & $\begin{array}{l}\text { Média do Total de Funcionários na } \\
\text { área de TI - Terceirizado }\end{array}$ & 2 & $2,7 \%$ & 11 & $3,4 \%$ & 26 & $3,9 \%$ & 117 & $1,6 \%$ & $2,9 \%$ \\
\hline & $\begin{array}{l}\text { Média do Total de Funcionários } \\
\text { alocados no Desenvolvimento de SI - } \\
\text { Próprio }\end{array}$ & 21 & $28,8 \%$ & 4 & $1,2 \%$ & 9 & $1,3 \%$ & 70 & $1,0 \%$ & $8,1 \%$ \\
\hline & $\begin{array}{l}\text { Média do Total de Funcionários } \\
\text { alocados no Desenvolvimento de SI - } \\
\text { Terceirizado }\end{array}$ & 1 & $1,4 \%$ & 6 & $1,9 \%$ & 16 & $2,4 \%$ & 56 & $0,8 \%$ & $1,6 \%$ \\
\hline
\end{tabular}


Tabela 8 - Quantidade de funcionários próprios e terceirizados de TI e do desenvolvimento de SI das organizações (conclusão)

\begin{tabular}{|c|c|c|c|c|c|c|c|c|c|c|}
\hline \multirow[b]{2}{*}{ Setor } & \multirow[b]{2}{*}{ Funcionários } & \multicolumn{8}{|c|}{ Total de Funcionários } & \multirow[b]{2}{*}{$\begin{array}{l}\text { Média } \\
\%\end{array}$} \\
\hline & & $\begin{array}{c}\text { De } 01 \\
\text { a } 99\end{array}$ & $\%$ & $\begin{array}{l}\text { De } 100 \\
\text { a } 499\end{array}$ & $\%$ & $\begin{array}{c}\text { De } 500 \\
\text { a } 999\end{array}$ & $\%$ & $\begin{array}{c}\text { Acima } \\
\text { de } \\
1000 \\
\end{array}$ & $\%$ & \\
\hline \multirow{5}{*}{ ن } & Média de Funcionários & 84 & & 255 & & 666 & & 4613 & & \\
\hline & $\begin{array}{l}\text { Média do Total de Funcionários na } \\
\text { área de TI - Próprio }\end{array}$ & 12 & $16,4 \%$ & 18 & $5,6 \%$ & 46 & $6,8 \%$ & 176 & $2,4 \%$ & $7,8 \%$ \\
\hline & $\begin{array}{l}\text { Média do Total de Funcionários na } \\
\text { área de TI - Terceirizado }\end{array}$ & 10 & $13,7 \%$ & 9 & $2,8 \%$ & 33 & $4,9 \%$ & 76 & $1,0 \%$ & $5,6 \%$ \\
\hline & $\begin{array}{l}\text { Média do Total de Funcionários } \\
\text { alocados no Desenvolvimento de SI - } \\
\text { Próprio }\end{array}$ & 18 & $24,7 \%$ & 5 & $1,5 \%$ & 10 & $1,5 \%$ & 41 & $0,6 \%$ & $7,1 \%$ \\
\hline & $\begin{array}{l}\text { Média do Total de Funcionários } \\
\text { alocados no Desenvolvimento de SI - } \\
\text { Terceirizado }\end{array}$ & 5 & $6,8 \%$ & 7 & $2,2 \%$ & 18 & $2,7 \%$ & 36 & $0,5 \%$ & $3,0 \%$ \\
\hline \multirow{5}{*}{$\sum_{\substack{\infty \\
\infty}}^{\infty}$} & Média de Funcionários & 74 & & 214 & & 714 & & 11509 & & \\
\hline & $\begin{array}{l}\text { Média do Total de Funcionários na } \\
\text { área de TI - Próprio }\end{array}$ & 10 & $13,7 \%$ & 26 & $8,0 \%$ & 59 & $8,7 \%$ & 801 & $11,0 \%$ & $10,4 \%$ \\
\hline & $\begin{array}{l}\text { Média do Total de Funcionários na } \\
\text { área de TI - Terceirizado }\end{array}$ & 6 & $8,2 \%$ & 27 & $8,4 \%$ & 196 & $29,0 \%$ & 241 & $3,3 \%$ & $12,2 \%$ \\
\hline & $\begin{array}{l}\text { Média do Total de Funcionários } \\
\text { alocados no Desenvolvimento de SI - } \\
\text { Próprio }\end{array}$ & 6 & $8,2 \%$ & 8 & $2,5 \%$ & 17 & $2,5 \%$ & 362 & $5,0 \%$ & $4,5 \%$ \\
\hline & $\begin{array}{l}\text { Média do Total de Funcionários } \\
\text { alocados no Desenvolvimento de SI - } \\
\text { Terceirizado }\end{array}$ & 5 & $6,8 \%$ & 16 & $5,0 \%$ & 35 & $5,2 \%$ & 106 & $1,5 \%$ & $4,6 \%$ \\
\hline \multirow{5}{*}{$\stackrel{\frac{\pi}{0}}{\Theta}$} & Média de Funcionários & 231 & & 792 & & 2055 & & 23412 & & \\
\hline & $\begin{array}{l}\text { Média do Total de Funcionários na } \\
\text { área de TI - Próprio }\end{array}$ & 26 & $11,9 \%$ & 60 & $6,2 \%$ & 138 & $6,8 \%$ & 1257 & $5,7 \%$ & $7,7 \%$ \\
\hline & $\begin{array}{l}\text { Média do Total de Funcionários na } \\
\text { área de TI - Terceirizado }\end{array}$ & 18 & $8,2 \%$ & 47 & $4,9 \%$ & 255 & $12,6 \%$ & 434 & $2,0 \%$ & $6,9 \%$ \\
\hline & $\begin{array}{l}\text { Média do Total de Funcionários } \\
\text { alocados no Desenvolvimento de SI - } \\
\text { Próprio }\end{array}$ & 45 & $20,5 \%$ & 17 & $1,8 \%$ & 36 & $1,8 \%$ & 473 & $2,2 \%$ & $6,6 \%$ \\
\hline & $\begin{array}{l}\text { Média do Total de Funcionários } \\
\text { alocados no Desenvolvimento de SI - } \\
\text { Terceirizado }\end{array}$ & 11 & $5,0 \%$ & 29 & $3,0 \%$ & 69 & $3,4 \%$ & 198 & $0,9 \%$ & $3,1 \%$ \\
\hline
\end{tabular}

\section{Gastos e investimentos}

A média total dos gastos e investimentos em TI no ano de 2009 pelas organizações pesquisadas foi de $8,10 \%$ e o gasto médio em desenvolvimento e/ou implantação de SI foi de $5,86 \%$ sobre a Receita Líquida. O setor que mais investe em TI é o de comércio $(8,68 \%)$ seguido pelo setor industrial $(8,24 \%)$ e de serviços $(7,39 \%)$. Na tabela 9 , a seguir, é possível notar que em relação aos gastos com desenvolvimento e/ou implantação de SI o setor que mais investe é o de indústria $(6,60 \%)$, seguido pelo de serviços $(6,07 \%)$ e de comércio $(4,91 \%)$. 
Tabela 9 - Gastos e investimentos em TI e desenvolvimento de SI das organizações respondentes

\begin{tabular}{|c|c|c|c|c|c|c|c|c|c|}
\hline \multirow{3}{*}{ Setor } & & \multicolumn{4}{|c|}{ Gastos e Investimentos } & \multicolumn{4}{|c|}{ Total } \\
\hline & & \multicolumn{2}{|c|}{$\begin{array}{l}\text { Tecnologia da } \\
\text { Informação }\end{array}$} & \multicolumn{2}{|c|}{$\begin{array}{l}\text { Desenvolvimento e } \\
\text { Implantação de SI }\end{array}$} & \multirow{2}{*}{$\begin{array}{c}\text { Tecnologia } \\
\text { da } \\
\text { Informação }\end{array}$} & \multirow{2}{*}{$\begin{array}{l}\text { Desenvolvimento } \\
\text { e Implantação de } \\
\text { SI }\end{array}$} & \multicolumn{2}{|c|}{ Geral } \\
\hline & & Grande & Médio & Grande & Médio & & & Grande & Médio \\
\hline \multirow[t]{2}{*}{ Indústria } & Frequência Absoluta & 106 & 34 & 106 & 34 & & 140 & 106 & 34 \\
\hline & Média dos Gastos e Investimentos & $10,11 \%$ & $6,36 \%$ & $7,51 \%$ & $5,69 \%$ & $8,24 \%$ & $6,60 \%$ & $8,81 \%$ & $6,03 \%$ \\
\hline \multirow[t]{2}{*}{ Comércio } & Frequência Absoluta & 36 & 3 & 36 & 3 & & 39 & 36 & 3 \\
\hline & Média dos Gastos e Investimentos & $10,69 \%$ & $6,66 \%$ & $6,81 \%$ & $3,00 \%$ & $8,68 \%$ & $4,91 \%$ & $8,75 \%$ & $4,83 \%$ \\
\hline \multirow[t]{2}{*}{ Serviços } & Frequência Absoluta & 99 & 21 & 99 & 21 & & 120 & 99 & 21 \\
\hline & Média dos Gastos e Investimentos & $8,61 \%$ & $6,16 \%$ & $9,51 \%$ & $2,63 \%$ & $7,39 \%$ & $6,07 \%$ & $9,06 \%$ & $4,40 \%$ \\
\hline \multirow[t]{2}{*}{ Total } & Frequência Absoluta Total & 241 & 58 & 241 & 58 & & 299 & 241 & 58 \\
\hline & Média dos Gastos e Investimentos & $9,80 \%$ & $6,39 \%$ & $7,94 \%$ & $3,77 \%$ & $8,10 \%$ & $5,86 \%$ & $8,87 \%$ & $5,08 \%$ \\
\hline
\end{tabular}

\section{Computadores instalados}

Em número de computadores, foi possível observar, durante a análise, que houve uma variedade muito grande nas quantidades. Isto se deve ao fato de que foram abrangidos os três setores, com organizações de grande e médio porte. A tabela 10 ilustra essa variedade no parque instalado das organizações.

Tabela 10 - Parque de computadores instalados nas organizações respondentes

\begin{tabular}{|c|c|c|c|c|c|c|c|c|}
\hline \multirow[b]{2}{*}{ Setor } & & \multicolumn{6}{|c|}{ Total de Computadores } & \multirow[b]{2}{*}{ Total } \\
\hline & & $\begin{array}{c}\text { De } 0 \text { a } \\
49\end{array}$ & $\begin{array}{c}\text { De } 50 \text { a } \\
99\end{array}$ & $\begin{array}{c}\text { De } 100 \\
\text { a } 249\end{array}$ & $\begin{array}{c}\text { De } 250 \\
\text { a } 499\end{array}$ & $\begin{array}{c}\text { De } 500 \\
\text { a } 999\end{array}$ & $\begin{array}{l}\text { Acima } \\
\text { de } 1000\end{array}$ & \\
\hline \multirow{5}{*}{ 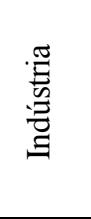 } & Frequência Absoluta & 3 & 19 & 51 & 24 & 10 & 33 & 140 \\
\hline & Média & 38 & 73 & 143 & 351 & 635 & 3698 & \\
\hline & \% em relação ao Setor & 2,14 & 13,57 & 36,43 & 17,14 & 7,14 & 23,57 & \\
\hline & \% em relação à Faixa & 15,79 & 35,85 & 58,62 & 52,17 & 41,67 & 47,14 & \\
\hline & \% em relação ao Total & 1,00 & 6,35 & 17,06 & 8,03 & 3,34 & 11,04 & 46,82 \\
\hline \multirow{5}{*}{ 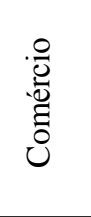 } & Frequência Absoluta & 3 & 5 & 11 & 10 & 4 & 6 & 39 \\
\hline & Média & 35 & 67 & 172 & 354 & 663 & 4065 & \\
\hline & \% em relação ao Setor & 7,69 & 12,82 & 28,21 & 25,64 & 10,26 & 15,38 & \\
\hline & \% em relação à Faixa & 15,79 & 9,43 & 12,64 & 21,74 & 16,67 & 8,57 & \\
\hline & \% em relação ao Total & 1,00 & 1,67 & 3,68 & 3,34 & 1,34 & 2,01 & 13,04 \\
\hline \multirow{5}{*}{$\stackrel{8}{\stackrel{0}{d}}$} & Frequência Absoluta & 13 & 29 & 25 & 12 & 10 & 31 & 120 \\
\hline & Média & 38 & 69 & 157 & 345 & 673 & 5614 & \\
\hline & \% em relação ao Setor & 10,83 & 24,17 & 20,83 & 10,00 & 8,33 & 25,83 & \\
\hline & \% em relação à Faixa & 68,42 & 54,72 & 28,74 & 26,09 & 41,67 & 44,29 & \\
\hline & $\%$ em relação ao Total & 4,35 & 9,70 & 8,36 & 4,01 & 3,34 & 10,37 & 40,13 \\
\hline \multirow{2}{*}{ Total } & Frequência Absoluta Total & 19 & 53 & 87 & 46 & 24 & 70 & 299 \\
\hline & \% em relação ao Total Geral & 6,35 & 17,73 & 29,10 & 15,38 & 8,03 & 23,41 & 100,00 \\
\hline
\end{tabular}

A fim de identificar possíveis diferenças significativas entre os setores, foi realizada uma análise de variância (ANOVA) entre as faixas de número de computadores e os setores pesquisados. 
Como resultado, a média (da faixa de número de computadores instalados) no setor industrial foi de 3,85 , ou seja, quase 500 computadores instalados. No setor comercial, a média foi de 3,64 e no de serviços, 3,58, correspondendo, da mesma forma que o setor industrial em um número de computadores entre 100 e 499, conforme pode ser observado nas tabelas 10 e 11 .

Tabela 11 - Médias do parque de computadores instalados - entre os setores

\begin{tabular}{lccc}
\hline \multicolumn{1}{c}{ Setor } & N & Média & $\begin{array}{c}\text { Desvio } \\
\text { Padrão }\end{array}$ \\
\hline Indústria & 140 & 3,85 & 1,439 \\
Comércio & 39 & 3,64 & 1,460 \\
Serviço & 120 & 3,58 & 1,766 \\
Total & 299 & 3,72 & 1,581 \\
\hline
\end{tabular}

Contudo, cabe ressaltar que não foram encontradas diferenças significativas entre o número de computadores (faixa) comparando os três setores estudados ( $\mathrm{p} \leq 0,381$ ), conforme apresenta a tabela 12 .

Tabela 12 - Diferenças significativas entre os setores - número de computadores

\begin{tabular}{lccc}
\hline \multirow{2}{*}{ Setor } & & Erro Padrão & Significância \\
\hline \multirow{2}{*}{ Indústria } & Comércio &, 263 &, 709 \\
& Serviço &, 202 &, 385 \\
\hline \multirow{2}{*}{ Comércio } & Indústria &, 263 &, 709 \\
& Serviço &, 284 &, 978 \\
\hline \multirow{2}{*}{ Serviço } & Indústria &, 202 &, 385 \\
& Comércio &, 284 &, 978 \\
\hline \multicolumn{2}{c}{ Total entre os 3 setores } & &, 381 \\
\hline
\end{tabular}

\section{Grau de formalidade}

No que concerne ao grau de formalidade na contratação de serviços de TI, das 299 organizações pesquisadas, $172(57,5 \%)$ utilizam contratos formais detalhados com SLA, conforme pode ser observado na tabela 13 a seguir. O setor que mais adota contratos com SLA é o da indústria, com 82 organizações, seguido pelo setor de serviço com 70 organizações. Outro destaque da pesquisa foi a utilização de contratos sem detalhamento, onde 66 organizações $(22,1 \%)$ adotam este tipo de contratação. 
Tabela 13 - Grau de formalização contratual das organizações respondentes

\begin{tabular}{|c|c|c|c|c|c|c|}
\hline \multirow{2}{*}{ Grau de Formalização } & \multirow{2}{*}{ Porte } & \multicolumn{3}{|c|}{ Setor } & \multirow{2}{*}{ Subtotal } & \multirow{2}{*}{ Percentual } \\
\hline & & Indústria & Comércio & Serviço & & \\
\hline \multirow{3}{*}{ Informal (sem contrato) } & Grande & 1 & 1 & 0 & 2 & \multirow{3}{*}{$1,3 \%$} \\
\hline & Médio & 1 & 0 & 1 & 2 & \\
\hline & Total & 2 & 1 & 1 & 4 & \\
\hline \multirow{3}{*}{$\begin{array}{l}\text { Contrato formal sem detalhamento } \\
\text { (cláusulas padrão) }\end{array}$} & Grande & 17 & 9 & 18 & 44 & \multirow{3}{*}{$22,1 \%$} \\
\hline & Médio & 11 & 0 & 11 & 22 & \\
\hline & Total & 28 & 9 & 29 & 66 & \\
\hline \multirow{3}{*}{$\begin{array}{l}\text { Contrato formal detalhado - sem } \\
\text { SLA }\end{array}$} & Grande & 19 & 7 & 16 & 42 & \multirow{3}{*}{$19,1 \%$} \\
\hline & Médio & 9 & 2 & 4 & 15 & \\
\hline & Total & 28 & 9 & 20 & 57 & \\
\hline \multirow{3}{*}{$\begin{array}{l}\text { Contrato formal detalhado - com } \\
\text { SLA }\end{array}$} & Grande & 69 & 19 & 65 & 153 & \multirow{3}{*}{$57,5 \%$} \\
\hline & Médio & 13 & 1 & 5 & 19 & \\
\hline & Total & 82 & 20 & 70 & 172 & \\
\hline Total Geral & & 140 & 39 & 120 & 299 & $100 \%$ \\
\hline
\end{tabular}

\section{Modelo de governança de tecnologia da informação adotados}

As análises demonstraram que, das 299 organizações pesquisadas, 219 (73,2\%) utilizam algum tipo de modelo de GTI e 80 (26,8\%) não utilizam nenhum modelo formal, conforme os dados da tabela 14. A pesquisa apresenta ainda que a maioria $(86,3 \%)$ das organizações que fazem a utilização de algum modelo são de grande porte.

Tabela 14 - Adoção de modelos de governança de TI pelas organizações respondentes - porte

\begin{tabular}{|c|c|c|c|c|c|c|}
\hline & \multicolumn{4}{|c|}{ Porte } & \multirow{2}{*}{ Total } & \multirow{2}{*}{$\%$} \\
\hline & Grande & $\%$ & Médio & $\%$ & & \\
\hline Utiliza & 189 & 86,3 & 30 & 13,7 & 219 & $73,2 \%$ \\
\hline Não Utiliza & 52 & 65,0 & 28 & 35,0 & 80 & $26,8 \%$ \\
\hline \multicolumn{5}{|c|}{ Total de Empresas } & 299 & $100,0 \%$ \\
\hline
\end{tabular}

Dos modelos existentes, o mais utilizado pelas organizações é o ITIL, com 157 organizações (52,5\%), seguido pelo CobIT - 110 organizações $(36,8 \%)$, conforme pode ser observado na tabela 15 a seguir. $\mathrm{O}$ resultado da pesquisa mostra claramente a predominância de uso do modelo de GTI ITIL pelas organizações, corroborando o resultado do estudo realizado pela Dimension Data em 2008, que ouviu 370 gestores de TI, onde o resultado foi que $66 \%$ das organizações pesquisadas utilizam ITIL (COMPUTERWORLD, 2008). 
Tabela 15 - Adoção de modelos de governança de TI pelas organizações respondentes - frequência

\begin{tabular}{lcc}
\cline { 2 - 3 } & Frequência & $\mathbf{\%}$ \\
\hline Não utiliza & 80 & 26,8 \\
CobIT & 110 & 36,8 \\
ITIL & 157 & 52,5 \\
e-SCM & 32 & 10,7 \\
ValIT & 8 & 2,7 \\
Outros & 21 & 7,0 \\
\hline
\end{tabular}

A tabela 16 revela que o setor industrial é o que mais utiliza algum tipo de modelo de GTI (165 organizações), seguido pelo setor de serviço e comércio. Os modelos de GTI classificados como "outros" e citados pelas organizações foram: CMMI; TOGAF; SOX, RUP; PMBOK e Proprietários.

Tabela 16 - Adoção de modelos de governança de TI pelas organizações respondentes - por setor e porte

\begin{tabular}{llcccccc}
\hline \multirow{2}{*}{ Setor } & \multirow{2}{*}{ Porte } & \multicolumn{7}{c}{ Modelos de GTI } \\
\cline { 3 - 7 } & & CobIT & ITIL & e-SCM & Val IT & Outros & Total \\
\hline \multirow{2}{*}{ Indústria } & Grande & 46 & 67 & 18 & 5 & 8 & \multirow{2}{*}{165} \\
& Médio & 7 & 12 & 0 & 0 & 2 & \\
\hline \multirow{2}{*}{ Comércio } & Grande & 11 & 15 & 5 & 1 & 4 & \multirow{2}{*}{37} \\
& Médio & 0 & 1 & 0 & 0 & 0 & \multirow{2}{*}{ Serviço } \\
\cline { 3 - 7 } & Grande & 41 & 56 & 9 & 2 & 6 & \multirow{2}{*}{126} \\
\cline { 3 - 7 } Total & Médio & 5 & 6 & 0 & 0 & 1 & \\
\hline
\end{tabular}

\section{Relação entre grau de formalidade e modelo de governança de tecnologia da informação}

Em relação à utilização de modelos de GTI, associados ao grau de formalidade da contratação, a pesquisa demonstrou que grande parte das organizações que adota algum modelo de GTI o fazem com a aplicação de contrato formal detalhado com SLA (ver tabela 17). Isso se deve ao fato de que os modelos de GTI abarcam com ênfase, práticas relacionadas ao contrato com características de níveis de serviços, ou seja, cláusulas detalhadas que medem o desempenho dos serviços, sendo que o não cumprimento dos acordos de níveis de serviço podem gerar punições para a empresa contratada (GROVER; CHEON; TENG, 1996). Da mesma forma, a pesquisa indicou que as organizações que não utilizam modelos de GTI tendem a estabelecer contratos sem detalhamento (padrão). 
Tabela 17 - Adoção de modelos de governança de TI pelas organizações respondentes - por setor e por grau de formalidade

\begin{tabular}{|c|c|c|c|c|c|c|c|c|c|c|c|c|c|c|c|c|c|c|c|c|c|}
\hline \multirow{3}{*}{ Setor } & \multirow{3}{*}{ Porte } & \multicolumn{20}{|c|}{ Modelos de GTI } \\
\hline & & \multicolumn{4}{|c|}{ CobIT } & \multicolumn{4}{|c|}{ ITL } & \multicolumn{4}{|c|}{ e-SCM } & \multicolumn{4}{|c|}{ Val IT } & \multicolumn{4}{|c|}{ Outros } \\
\hline & & $\mathbf{I}$ & II & III & IV & $\mathbf{I}$ & II & III & IV & $\mathbf{I}$ & II & III & IV & $\mathbf{I}$ & II & III & IV & $\mathbf{I}$ & II & III & IV \\
\hline \multirow{2}{*}{ Indústria } & Grande & 0 & 3 & 6 & 37 & 0 & 7 & 10 & 50 & 0 & 1 & 2 & 15 & 0 & 0 & 0 & 5 & 0 & 0 & 2 & 6 \\
\hline & Médio & 0 & 3 & 3 & 1 & 1 & 2 & 1 & 8 & 0 & 0 & 0 & 0 & 0 & 0 & 0 & 0 & 0 & 1 & 0 & 1 \\
\hline \multirow{2}{*}{ Comércio } & Grande & 0 & 1 & 3 & 7 & 0 & 3 & 3 & 9 & 0 & 1 & 0 & 4 & 0 & 0 & 0 & 1 & 0 & 0 & 0 & 4 \\
\hline & Médio & 0 & 0 & 0 & 0 & 0 & 0 & 1 & 0 & 0 & 0 & 0 & 0 & 0 & 0 & 0 & 0 & 0 & 0 & 0 & 0 \\
\hline \multirow{2}{*}{ Serviço } & Grande & 0 & 4 & 4 & 33 & 0 & 7 & 4 & 45 & 0 & 0 & 0 & 9 & 0 & 0 & 0 & 2 & 0 & 0 & 1 & 5 \\
\hline & Médio & 0 & 2 & 1 & 2 & 0 & 0 & 3 & 3 & 0 & 0 & 0 & 0 & 0 & 0 & 0 & 0 & 0 & 1 & 0 & 0 \\
\hline \multicolumn{2}{|c|}{ Subtotal } & 0 & 13 & 17 & 80 & 1 & 19 & 22 & 115 & 0 & 2 & 2 & 28 & 0 & 0 & 0 & 8 & 0 & 2 & 3 & 16 \\
\hline \multicolumn{2}{|c|}{$\begin{array}{c}\text { Total Geral } \\
\text { (Frequência Absoluta) }\end{array}$} & \multicolumn{4}{|c|}{110} & \multicolumn{4}{|c|}{157} & \multicolumn{4}{|c|}{32} & \multicolumn{4}{|c|}{8} & \multicolumn{4}{|c|}{21} \\
\hline Formalidade: & $\begin{array}{l}\text { I - Informal (s } \\
\text { II - Contrato } \\
\text { III - Contrato } \\
\text { IV - Contrato }\end{array}$ & & & & SLA & & & & & & & & & & & & & & & & \\
\hline
\end{tabular}

\section{Adoção das práticas recomendadas}

A análise realizada a fim de identificar as principais práticas de gestão da terceirização de serviços de TI mostrou que das 32 práticas recomendadas apresentadas na pesquisa, a prática com maior adoção entre as organizações pesquisadas foi a que se refere a "asseguro que o departamento jurídico acompanhe e participe de todos os processos de contratação dos serviços (alterações contratuais; litígios; etc.)", conforme pode ser observado na tabela 18.

Dos 299 participantes da pesquisa, 181 gestores de TI adotam esta prática de maneira excelente, ou seja, os contratos e alterações contratuais devem ser revistos por assessores jurídicos. A relação completa das práticas recomendadas e suas respectivas frequências encontram-se no apêndice G deste estudo. Ainda sobre esta prática, vale observar que os três setores apresentaram a adoção de forma excelente, ou seja, a visão sobre a preocupação em adotar esta prática é compartilhada entre os setores.

Tabela 18 - Primeira prática mais adotada de forma excelente - frequência por setor (continua)

\begin{tabular}{|c|c|c|c|c|c|c|c|}
\hline \multicolumn{8}{|c|}{$\begin{array}{l}\text { VP4-1.4 - Ass eguro que o departamento jurídico acompanhe e participe de todos os processos de } \\
\text { contratação dos serviços (alterações contratuais; litígios; etc). }\end{array}$} \\
\hline Setor & & $\begin{array}{c}\text { Esta } \\
\text { prática } \\
\text { não é } \\
\text { adotada }\end{array}$ & $\begin{array}{c}\text { Esta } \\
\text { prática é } \\
\text { ins uficiente } \\
\text { mente } \\
\text { adotada } \\
\end{array}$ & $\begin{array}{c}\text { Esta } \\
\text { prática é } \\
\text { suficiente } \\
\text { mente } \\
\text { adotada }\end{array}$ & $\begin{array}{c}\text { Esta } \\
\text { prática é } \\
\text { plenamente } \\
\text { adotada }\end{array}$ & $\begin{array}{c}\text { Esta } \\
\text { prática é } \\
\text { adotada de } \\
\text { maneira } \\
\text { excelente }\end{array}$ & Total \\
\hline \multirow{2}{*}{ Indústria } & Frequência Absoluta & 10 & 4 & 18 & 24 & 84 & 140 \\
\hline & $\%$ em relação ao Total & $3,3 \%$ & $1,3 \%$ & $6,0 \%$ & $8,0 \%$ & $28,1 \%$ & $46,8 \%$ \\
\hline
\end{tabular}


Tabela 18 - Primeira prática mais adotada de forma excelente - frequência por setor (conclusão)

VP4-1.4 - Ass eguro que o departamento jurídico acompanhe e participe de todos os processos de contratação dos serviços (alterações contratuais; litígios; etc).

\begin{tabular}{llcccccc}
\hline \multirow{2}{*}{ Setor } & & $\begin{array}{c}\text { Esta } \\
\text { prática } \\
\text { não é } \\
\text { adotada }\end{array}$ & $\begin{array}{c}\text { Esta } \\
\text { prática é } \\
\text { insuficiente } \\
\text { mente } \\
\text { adotada }\end{array}$ & $\begin{array}{c}\text { Esta } \\
\text { prática é } \\
\text { suficiente } \\
\text { mente } \\
\text { adotada }\end{array}$ & $\begin{array}{c}\text { Esta } \\
\text { prática é } \\
\text { plenamente } \\
\text { adotada }\end{array}$ & $\begin{array}{c}\text { Esática é } \\
\text { adotada de } \\
\text { maneira } \\
\text { excelente }\end{array}$ & Total \\
\hline \multirow{2}{*}{ Comércio } & Frequência Absoluta & 1 & 0 & 2 & 15 & 21 & 39 \\
& $\%$ em relação ao Total &, $3 \%$ &, $0 \%$ &, $7 \%$ & $5,0 \%$ & $7,0 \%$ & $13,0 \%$ \\
\hline \multirow{2}{*}{ Serviço } & Frequência Absoluta & 5 & 4 & 18 & 17 & 76 & 120 \\
& $\%$ em relação ao Total & $1,7 \%$ & $1,3 \%$ & $6,0 \%$ & $5,7 \%$ & $25,4 \%$ & $40,1 \%$ \\
\hline \multirow{2}{*}{ Total } & Frequência Absoluta Total & 16 & 8 & 38 & 56 & 181 & 299 \\
& $\%$ em relação ao Total Geral & $5,4 \%$ & $2,7 \%$ & $12,7 \%$ & $18,7 \%$ & $60,5 \%$ & $100,0 \%$ \\
\hline
\end{tabular}

A segunda prática mais adotada de forma excelente, externalizada por 155 gestores de TI foi a de controle e fiscalização de licenças de uso de programas disponibilizados e utilizados pelo fornecedor do serviço dentro da organização. Da mesma forma, esta prática foi adotada de forma excelente pelos três setores, como apresenta a tabela 19, corroborando com o fato de que se devem aplicar práticas de supervisão adequada, garantindo que os papéis e as responsabilidades sejam devidamente exercidos, avaliando se todos os fornecedores de serviços têm autoridade e recursos suficientes para executar as suas funções e responsabilidades (ITGI, 2007).

Tabela 19 - Segunda prática mais adotada de forma excelente - frequência por setor

VP20-5.2 - Controlo e fiscalizo as licenças de uso de programas disponibilizados e utilizados pelo fornecedor do serviço dentro da empresa.

\begin{tabular}{llcccccc}
\hline \multirow{2}{*}{ Setor } & & $\begin{array}{c}\text { Esta } \\
\text { prática } \\
\text { não é } \\
\text { adotada }\end{array}$ & $\begin{array}{c}\text { Esta } \\
\text { prática é } \\
\text { insuficiente } \\
\text { mente } \\
\text { adotada }\end{array}$ & $\begin{array}{c}\text { Esta } \\
\text { prática é } \\
\text { suficiente } \\
\text { mente } \\
\text { adotada }\end{array}$ & $\begin{array}{c}\text { Esta } \\
\text { prática é } \\
\text { plenamente } \\
\text { adotada }\end{array}$ & $\begin{array}{c}\text { Estática é } \\
\text { adotada de } \\
\text { mane ira } \\
\text { excelente }\end{array}$ & Total \\
\hline \multirow{2}{*}{ Indústria } & Frequência Absoluta & 7 & 5 & 21 & 35 & 72 & 140 \\
& $\%$ em relação ao Total & $2,3 \%$ & $1,7 \%$ & $7,0 \%$ & $11,7 \%$ & $24,1 \%$ & $46,8 \%$ \\
\hline \multirow{2}{*}{ Comércio } & Frequência Absoluta & 1 & 5 & 6 & 10 & 17 & 39 \\
& $\%$ em relação ao Total &, $3 \%$ & $1,7 \%$ & $2,0 \%$ & $3,3 \%$ & $5,7 \%$ & $13,0 \%$ \\
\hline \multirow{2}{*}{ Serviço } & Frequência Absoluta & 5 & 7 & 18 & 24 & 66 & 120 \\
& $\%$ em relação ao Total & $1,7 \%$ & $2,3 \%$ & $6,0 \%$ & $8,0 \%$ & $22,1 \%$ & $40,1 \%$ \\
\hline \multirow{2}{*}{ Total } & Frequência Absoluta Total & 13 & 17 & 45 & 69 & 155 & 299 \\
& $\%$ em relação ao Total Geral & $4,3 \%$ & $5,7 \%$ & $15,1 \%$ & $23,1 \%$ & $51,8 \%$ & $100,0 \%$ \\
\hline
\end{tabular}


A terceira prática mais adotada pelos gestores de TI de forma excelente foi a realização de controles financeiros periódicos (dos valores que foram acordados contratualmente com o que foi efetivamente entregue pelo fornecedor do serviço) e foi informada por 151 gestores de TI pesquisados como pode ser observado na tabela 20.

Tabela 20 - Terceira prática mais adotada de forma excelente - frequência por setor

\begin{tabular}{|c|c|c|c|c|c|c|c|}
\hline \multicolumn{8}{|c|}{$\begin{array}{l}\text { VP23-6.1 - Realizo controles financeiros periódicos (dos valores que foram acordados contratualmente } \\
\text { com o que foi efe tivamente entregue pelo fornecedor do serviço). }\end{array}$} \\
\hline \multicolumn{2}{|l|}{ Setor } & $\begin{array}{c}\text { Esta } \\
\text { prática } \\
\text { não é } \\
\text { adotada }\end{array}$ & $\begin{array}{c}\text { Esta } \\
\text { prática é } \\
\text { insuficiente } \\
\text { mente } \\
\text { adotada } \\
\end{array}$ & $\begin{array}{c}\text { Esta } \\
\text { prática é } \\
\text { suficiente } \\
\text { mente } \\
\text { adotada }\end{array}$ & $\begin{array}{c}\text { Esta } \\
\text { prática é } \\
\text { plenamente } \\
\text { adotada }\end{array}$ & $\begin{array}{c}\text { Esta } \\
\text { prática é } \\
\text { adotada de } \\
\text { maneira } \\
\text { excelente } \\
\end{array}$ & Total \\
\hline \multirow{2}{*}{ Indústria } & Frequência Absoluta & 2 & 4 & 27 & 40 & 67 & 140 \\
\hline & $\%$ em relação ao Total &, $7 \%$ & $1,3 \%$ & $9,0 \%$ & $13,4 \%$ & $22,4 \%$ & $46,8 \%$ \\
\hline \multirow{2}{*}{ Comércio } & Frequência Absoluta & 0 & 0 & 7 & 11 & 21 & 39 \\
\hline & $\%$ em relação ao Total &, $0 \%$ &, $0 \%$ & $2,3 \%$ & $3,7 \%$ & $7,0 \%$ & $13,0 \%$ \\
\hline \multirow{2}{*}{ Serviço } & Frequência Absoluta & 2 & 5 & 16 & 34 & 63 & 120 \\
\hline & \% em relação ao Total &, $7 \%$ & $1,7 \%$ & $5,4 \%$ & $11,4 \%$ & $21,1 \%$ & $40,1 \%$ \\
\hline \multirow{2}{*}{ Total } & Frequência Absoluta Total & 4 & 9 & 50 & 85 & 151 & 299 \\
\hline & \% em relação ao Total Geral & $1,3 \%$ & $3,0 \%$ & $16,7 \%$ & $28,4 \%$ & $50,5 \%$ & $100,0 \%$ \\
\hline
\end{tabular}

Já em relação às práticas que não são adotadas pelos gestores de TI, a utilização de metodologia para o desenvolvimento do projeto (exemplo: PMBok, Prince2 etc.) não é adotada por 163 gestores de TI, seguido pela utilização de sistemas de informações computadorizados como ferramentas de apoio à gestão da terceirização com 155 gestores de TI não adotando-a e a certificação de que o fornecedor do serviço capacita e acompanha a formação da equipe disponibilizada para a prestação de cada serviço (em cada processo) com 31 gestores de TI informando a não adoção da mesma. A relação completa das práticas não adotadas encontra-se no apêndice $\mathrm{H}$ deste estudo.

Cabe evidenciar que duas práticas destacaram-se por ser adotadas de forma insuficiente, sendo elas: "Certifico que o fornecedor do serviço capacita e acompanha a formação da equipe disponibilizada para a prestação de cada serviço (em cada processo)” com 176 apontamentos realizados pelos gestores de TI e "mantenho atualizados os tópicos da matriz de risco relacionados à prestação de serviços pelo fornecedor do serviço" com 143 gestores de TI 
adotando-as de forma insuficiente. Nesse caso, cabe ressaltar a preocupação dos gestores de TI em melhorar a forma de gestão destas práticas uma vez que as mesmas podem impactar diretamente no resultado do objeto terceirizado.

\section{Dos resultados esperados em decorrência da terceirização de serviços de tecnologia da informação}

As análises demonstraram que, dos 14 possíveis resultados inerentes à terceirização de serviços de TI, apenas dois tiveram algum índice de resultado alcançado, ou seja, por menor que seja, as organizações conseguiram obtê-los. Estes dois resultados são: “A empresa obteve melhoria na qualidade dos dados/informações oriundos do sistema terceirizado (desenvolvido ou implantado)?" e “Após a disponibilização do sistema terceirizado (desenvolvido ou implantado), houve um salto de qualidade na realização das atividades-fim dos usuários finais?”. Todos os demais 12 resultados mensurados tiveram casos em que a organização pesquisada não obteve nenhum resultado. A relação completa desses resultados pode ser observada no apêndice I e J deste estudo.

Dos resultados obtidos completamente, o item "A empresa obteve melhoria na qualidade dos dados/informações oriundos do sistema terceirizado (desenvolvido ou implantado)?” foi o que mais se destacou, sendo este item apontado por 205 gestores de TI .

A tabela 21 apresenta a consolidação desse resultado por setor. O índice de apontamento foi alto nos três setores $(68,6 \%)$. A somatória do percentual "obtido completamente" e "acima da média”, eleva este índice para $91,3 \%$ das organizações.

Tabela 21 - Resultado obtido completamente com maior apontamento pelos gestores de TI - frequência por setor (continua)

\begin{tabular}{ccccccccc}
\hline \multicolumn{2}{c}{ VR14-4.3 - A empresa obteve melhoria na qualidade dos dados/informações oriundos do sistema terceirizado } \\
(desenvolvido ou implantado)?
\end{tabular}


Tabela 21 - Resultado obtido completamente com maior apontamento pelos gestores de TI - frequência por setor (conclusão)

\begin{tabular}{|c|c|c|c|c|c|c|c|}
\hline \multicolumn{8}{|c|}{$\begin{array}{l}\text { VR14-4.3 - A empresa obteve melhoria na qualidade dos dados/informações oriundos do sistema terceirizado } \\
\text { (desenvolvido ou implantado)? }\end{array}$} \\
\hline \multirow[t]{2}{*}{ Setor } & & & & & $\begin{array}{c}\text { Acima da } \\
\text { Mé dia mas } \\
\text { não }\end{array}$ & Obtido & \\
\hline & & $\begin{array}{l}\text { Nenhum } \\
\text { resultado }\end{array}$ & $\begin{array}{c}\text { Pouco } \\
\text { Resultado } \\
\end{array}$ & $\begin{array}{c}\text { Resultado } \\
\text { Mediano } \\
\end{array}$ & $\begin{array}{c}\text { completamen } \\
\text { te }\end{array}$ & $\begin{array}{c}\text { Completamen } \\
\text { te }\end{array}$ & Total \\
\hline \multirow{2}{*}{ Serviço } & Frequência Absoluta & 0 & 2 & 12 & 25 & 81 & 120 \\
\hline & \% em relação ao Total &, $0 \%$ &, $7 \%$ & $4,0 \%$ & $8,4 \%$ & $27,1 \%$ & $40,1 \%$ \\
\hline \multirow{2}{*}{ Total } & Frequência Absoluta Total & 0 & 3 & 23 & 68 & 205 & 299 \\
\hline & \% em relação ao Total Geral &, $0 \%$ & $1,0 \%$ & $7,7 \%$ & $22,7 \%$ & $68,6 \%$ & $100,0 \%$ \\
\hline
\end{tabular}

O segundo, terceiro e quarto resultados com maiores apontamentos de "obtido completamente" são respectivamente "A empresa obteve aumento da produtividade dos usuários finais (capacidade de realização dos serviços executados) em função do sistema terceirizado (desenvolvido ou implantado)?” com 199 apontamentos; “Após a disponibilização do sistema terceirizado (desenvolvido ou implantado), houve um salto de qualidade na realização das atividades-fim dos usuários finais?” com 192 apontamentos; e "Os valores "orçados" para o projeto do sistema terceirizado (desenvolvido ou implantado) foram "realizados" (cumpridos na íntegra) até a entrega final?" com 186 apontamentos.

Vale afirmar, diante de tais apontamentos, que os quatro primeiro resultados obtidos de forma completa referem-se à melhoria na qualidade dos dados, aumento da produtividade, aumento da qualidade das atividades dos usuários finais e aumento na capacidade de processamento. É possível inferir, a partir destes resultados, que o processo de terceirização de serviços de TI colaborou significativamente com a qualidade do sistema de informação desenvolvido e/ou implantado.

Em relação aos resultados não obtidos, o item "Os prazos 'estipulados' para o projeto do sistema terceirizado (desenvolvido ou implantado) foram "cumpridos na íntegra" até a entrega final?" foi o que mais teve problemas. Ao todo, 25 gestores de TI apontaram não ter tido nenhum resultado e 177 gestores de TI apontaram com pouco resultado, conforme pode ser observado no Apêndice K6.

Um resultado que merece destaque é o que trata "Se os valores orçados para o projeto do sistema terceirizado (desenvolvido ou implantado) foram realizados (cumpridos na íntegra) 
até a entrega final?". Neste caso, 28 gestores apontaram-no como não obtido ou pouco resultado e 186 gestores como obtido completamente. Do total de organizações que tiveram seus resultados obtidos completamente, 120 os conseguiram utilizando contrato formal detalhado com SLA, conforme pode ser observado no Apêndice K5.

Tal resultado desvela que o maior problema dentro da terceirização de serviços de TI é o aspecto relacionado aos custos realizados acima do previsto. Apesar do resultado referente ao prazo de entrega ter sido apontado por grande parte das organizações estudadas como obtido completamente, quase $10 \%$ das organizações tiverem resultados pífios, alertando para o fato de que os gestores de TI devem ter cuidado no controle sobre este item. Gellings (2007) e Reponen (1993) apontam que os mais temidos riscos na terceirização de serviços de TI são: perda de controle sobre serviços terceirizados, a perda de flexibilidade e altos custos inesperados.

Os maiores resultados foram obtidos em função do uso de contratos com SLA, conforme pode ser observado nas tabelas e gráficos que compõem o Apêndice K. Os contratos de terceirização de serviços de TI, orientados por modelos de GTI, são uma importante ferramenta para alinhar expectativas e estratégias, e assim contribuir para o resultado da terceirização de serviços de TI (AUBERT; RIVARD; PATRY, 2003; POWER; DESOUZA; BONIFAZI, 2006).

\subsection{Análise fatorial}

No estudo das práticas de gestão da terceirização de serviços de TI e dos resultados esperados pela terceirização foram consideradas 46 variáveis com base no referencial teórico, conforme mencionado anteriormente, divididas da seguinte forma: 32 variáveis sobre práticas de gestão da terceirização de serviços de TI e 14 variáveis sobre resultado da terceirização.

\section{Das práticas de gestão da terceirização de serviços de tecnologia da informação}

Diante desse conjunto de variáveis, foi utilizada a análise fatorial (AF) como técnica estatística multivariada com objetivo de reduzir o número de características em menor número de fatores que poderiam representar relações entre as variáveis que, supostamente, poderiam estar inter-relacionadas. 
As variáveis que tratam das práticas de gestão da terceirização de serviços de TI foram submetidas à extração dos fatores por meio da análise dos seus componentes principais (principal components Analysis). Desta análise reduziram-se as 32 variáveis a cinco fatores.

Vale salientar que, para efeitos de ajuste na $\mathrm{AF}$, duas variáveis apresentaram baixa comunalidade, e a opção foi pela exclusão das mesmas com vistas à melhor adequação da composição dos fatores. São elas: VP17-4.4 (0,485) - (Discuto com o fornecedor do serviço as suas práticas de formulação de definição de escopo, metodologias empregadas e elaboração de entregáveis); e VP24-6.2 $(0,479)$ - (Controlo periodicamente o orçamento destinado ao serviço contratado (a fim de que reflita as prioridades estabelecidas pela empresa). Isto significa que estas duas variáveis compartilhavam pouca quantidade total de variância com as demais variáveis do estudo.

Os procedimentos utilizados para a construção do instrumento de pesquisa envolveram uma criteriosa construção de itens, bem como instruções para preenchimento do questionário. Apesar da análise da estrutura das questões e das alternativas, talvez tenha havido problemas de construção dos itens que, se forem reelaborados, podem vir a medir os atributos com mais precisão e aprimorar a validade da estrutura fatorial.

Há também que ser considerado as peculiaridades da amostra estudada em relação à linguagem utilizada pelo pesquisador. Contudo, a avaliação da quantidade total de itens, permite afirmar que o número de exclusões é pequeno e que não teve maiores impactos no estudo das relações entre as variáveis.

Os cinco fatores, juntos, explicam $61,82 \%$ da variância das 30 variáveis incluídas na $\mathrm{AF}$, de acordo também, com o critério de porcentagem mínima de 3\% de explicação para os fatores extraídos, conforme pode ser observado na tabela 22. Segundo Hair Jr. et al. (2009) uma solução que explique $60 \%$ ou mais da variância total é considerada como satisfatória.

Tabela 22 - Fatores extraídos - práticas recomendadas

\begin{tabular}{cccc}
\hline Fatores & Total & \% da Variância & \% Acumulada \\
\hline 1 & 9,560 & 31,865 & 31,865 \\
2 & 5,461 & 18,205 & 50,070 \\
3 & 1,430 & 4,768 & 54,838 \\
4 & 1,079 & 3,597 & 58,435 \\
5 & 1,015 & 3,385 & 61,820 \\
\hline
\end{tabular}

Método de Extração: Análise de componentes principais. Método de rotação oblíqua 
Na sequência, foi realizada a análise dos fatores utilizando rotação oblíqua (direct oblimin) a fim de verificar a matriz de correlações e a existência de valores significativos para ajustar a utilização da técnica.

A rotação fatorial oblíqua foi utilizada em função de não restringir arbitrariamente a rotação fatorial a uma solução ortogonal (HAIR JR. et al., 2009). Em outras palavras, a rotação ortogonal (varimax) produz fatores que não se correlacionam entre si (ou possuem apenas uma frágil relação) e que são interpretados por meio dos seus pesos. Já na rotação oblíqua (oblimin) os fatores estão correlacionados e para interpretação da solução torna-se necessário considerar simultaneamente a matriz de correlação e as cargas fatoriais (PASQUALI, 2005).

O próximo passo foi a verificação do índice Kaiser-Meyer-Olkin (KMO) cujo objetivo é o de comparar as correlações simples com as correlações parciais do modelo. O valor de KMO próximo de 0 (zero) indica correlação fraca entre as variáveis e quanto mais próximo de 1 (um), mais adequado ao restante das análises estará (FAVERO et al. 2009, p. 241). O índice KMO encontrado foi de 0,910 e o teste de esfericidade de Bartlett que examina a matriz de correlações e verifica a adequação da análise fatorial para a mesma foi de 5130,0642 (gl = 435; p<0,001), indicando que a matriz do estudo é passível de análises e interpretações propostas.

A indicação obtida foi de até cinco fatores, de acordo com os critérios de distribuição dos valores próprios superiores a 1 e análise gráfica por meio do gráfico Scree Plot conforme apresentado no apêndice L.

Como a análise do Scree Plot sugere a presença de 1 até provavelmente 3 ou 5 fatores, foi realizada uma análise paralela (AP) de Horn (PASQUALI, 2005; HAIR JR. et al., 2009), objetivando comparar os autovalores (valores próprios - eigenvalues) obtidos empiricamente com os autovalores obtidos por meio de matrizes que contém variáveis randômicas não correlacionadas, tendo tamanhos de amostra iguais aos da matriz de correlação empiricamente obtida (PASQUALI, 2005), a fim de verificar o número de fatores. A sintaxe utilizada no SPSS para obtenção da AP das práticas recomendadas encontra-se no apêndice P.

Segundo Reise, Waller e Comrey (2000, p. 289) "é pertinente reter um componente apenas na medida em que este explica maior variância do que o componente correspondente nos dados 
aleatórios. Assim, no momento em que o autovalor dos dados aleatórios é superior ao dos dados empíricos, não é mais adequado reter esse componente".

Com base na tabela 23, a AP demonstrou que o terceiro componente é o último em que os autovalores empíricos são superiores aos aleatórios. Já no quarto componente, os valores empíricos são menores do que os valores aleatórios. Posto isto, a AP sugere a existência de três componentes.

Tabela 23 - Análise paralela de Horn - práticas recomendadas

\begin{tabular}{lccccc}
\hline \multirow{2}{*}{ Autovalores } & \multicolumn{5}{c}{ Componentes } \\
\cline { 2 - 6 } & 1 & 2 & 3 & 4 & 5 \\
\hline Aleatório & 1,670 & 1,580 & 1,510 & 1,451 & 1,399 \\
Empírico & 10,348 & 5,485 & 1,558 & 1,080 & 1,027 \\
\hline
\end{tabular}

Foi feita então, mais uma rodada de análise fatorial. Dessa vez foi realizada uma fatoração pelo método dos eixos principais (principal axis factoring) utilizando a rotação oblíqua (direct oblimin), varimax e livre com os cinco fatores constitutivos da estrutura empírica da medida. A estrutura obtida com a rotação oblíqua foi a mais satisfatória, pois a distribuição dos itens nos fatores se apresentou parcimoniosa e teoricamente defensável, contando ainda com os melhores indicadores numéricos.

Segundo Hair Jr. et al. (2009) para amostras de 250 a 350 respondentes (amostra total $n=299$ ), cargas acima de 0,35 são consideradas aceitáveis. O primeiro fator, denominado Estratégias de Serviços, ficou constituído por 10 itens, cujas cargas fatoriais oscilaram entre 0,58 e 0,82; o segundo fator, Operações de Serviços, com 8 itens, com cargas variando entre 0,43 e 0,81; o terceiro fator, Trabalho Tecnológico, com 3 itens e cargas variando entre 0,71 e 0,76; o quarto fator, Desenvolvimento do Fornecedor, com 6 itens, com cargas variando entre 0,44 e 0,74; e o quinto fator, Monitoramentos de Serviços, com 3 itens, com cargas variando entre 0,48 e 0,58 . Na tabela 24 são apresentadas as variáveis de cada fator com suas respectivas cargas fatoriais, comunalidade, média e desvio padrão.

Tabela 24 - Solução de fatores - práticas recomendadas (continua)

\begin{tabular}{|c|c|c|c|c|c|c|c|c|}
\hline \multirow{2}{*}{ Variável } & \multicolumn{5}{|c|}{ Fatores } & \multirow{2}{*}{ Comunalidade } & \multirow{2}{*}{ Média } & \multirow{2}{*}{$\begin{array}{l}\text { Desvio } \\
\text { Padrão }\end{array}$} \\
\hline & 1 & 2 & 3 & 4 & 5 & & & \\
\hline VP23-6.1 &, 82 & & & & & 0,62 & 4,2 & 0,9 \\
\hline VP7-2.3 & ,76 & & & & & 0,62 & 3,8 & 0,9 \\
\hline VP4-1.4 &, 75 & & & & & 0,57 & 3,2 & 0,7 \\
\hline VP26-6.4 &, 70 & & & & & 0,62 & 3,6 & 0,9 \\
\hline
\end{tabular}


Tabela 24 - Solução de fatores - práticas recomendadas (conclusão)

\begin{tabular}{|c|c|c|c|c|c|c|c|c|}
\hline \multirow{2}{*}{ Variável } & \multicolumn{5}{|c|}{ Fatores } & \multirow{2}{*}{ Comunalidade } & \multirow{2}{*}{ Média } & \multirow{2}{*}{$\begin{array}{l}\text { Desvio } \\
\text { Padrão }\end{array}$} \\
\hline & 1 & 2 & 3 & 4 & 5 & & & \\
\hline VP6-2.2 & 65 & & & & & 0,59 & 3,8 & 0,8 \\
\hline VP13-3.4 & ,62 & & & & & 0,56 & 3,7 & 0,7 \\
\hline VP18-4.5 & ,61 & & & & & 0,55 & 3,8 & 0,8 \\
\hline VP2-1.2 &, 59 & & & & & 0,53 & 3,7 & 0,8 \\
\hline VP10-3.1 &, 58 & & & & & 0,55 & 3,7 & 0,8 \\
\hline VP3-1.3 &, 58 & & & & & 0,51 & 3,7 & 0,7 \\
\hline VP16-4.3 & & ,81 & & & & 0,61 & 3,4 & 0,7 \\
\hline VP15-4.2 & & ,76 & & & & 0,63 & 2,7 & 1,0 \\
\hline VP14-4.1 & & ,69 & & & & 0,62 & 3,2 & 0,7 \\
\hline VP25-6.3 & & ,64 & & & & 0,51 & 3,4 & 0,8 \\
\hline VP32-7.5 & & ,61 & & & & 0,57 & 3,3 & 0,7 \\
\hline VP27-6.5 & & 61 & & & & 0,64 & 3,4 & 0,8 \\
\hline VP28-7.1 & &, 59 & & & & 0,54 & 3,3 & 0,8 \\
\hline VP5-2.1 & & ,43 & & & & 0,55 & 3,4 & 0,7 \\
\hline VP12-3.3 & & & ,76 & & & 0,59 & 1,9 & 1,1 \\
\hline VP30-7.3 & & & ,72 & & & 0,45 & 2,3 & 0,9 \\
\hline VP29-7.2 & & & ,71 & & & 0,59 & 1,9 & 1,1 \\
\hline VP11-3.2 & & & & ,74 & & 0,64 & 4,2 & 0,9 \\
\hline VP19-5.1 & & & & ,73 & & 0,70 & 4,1 & 1,1 \\
\hline VP20-5.2 & & & & ,71 & & 0,62 & 4,1 & 1,1 \\
\hline VP31-7.4 & & & & ,66 & & 0,56 & 3,5 & 0,8 \\
\hline VP8-2.4 & & & & ,61 & & 0,63 & 3,7 & 0,8 \\
\hline VP9-2.5 & & & & ,44 & & 0,45 & 3,8 & 0,7 \\
\hline VP1-1.1 & & & & &, 58 & 0,52 & 3,3 & 0,7 \\
\hline VP21-5.3 & & & & &, 51 & 0,43 & 3,4 & 0,9 \\
\hline VP22-5.4 & & & & &, 48 & 0,52 & 3,4 & 0,8 \\
\hline
\end{tabular}

A estrutura encontrada se mostrou adequada, obtendo elevada consistência interna, calculada pelo Alfa de Cronbach, em cada fator, conforme os dados da tabela 25. Segundo Hair Jr. et al. (2009) índices entre 0,60 e 0,70 são aceitáveis desde que os outros indicadores de validade do construto sejam bons.

Tabela 25 - Alfa de Cronbach - fatores extraídos - práticas recomendadas

\begin{tabular}{lcccccc}
\hline Fatores & $\begin{array}{c}\text { Alfa de } \\
\text { Cronbach }\end{array}$ & $\begin{array}{c}\text { Alfa } \\
\text { Cronbach } \\
\text { Padronizado }\end{array}$ & $\begin{array}{c}\text { Número de } \\
\text { Itens }\end{array}$ & Média & Variância & $\begin{array}{c}\text { Desvio } \\
\text { Padrão }\end{array}$ \\
\hline FP1 &, 900 &, 903 & 10 & 38,19 & 36,739 & 6,061 \\
FP2 &, 884 &, 888 & 8 & 25,98 & 21,335 & 4,619 \\
FP3 &, 781 &, 783 & 3 & 6,04 & 6,696 & 2,588 \\
FP4 &, 849 &, 853 & 6 & 23,50 & 16,996 & 4,123 \\
FP5 &, 687 &, 689 & 3 & 10,12 & 3,350 & 1,830 \\
\hline
\end{tabular}


A medida de adequação da amostra (MSA) quantifica o grau de intercorrelação entre as variáveis e a adequação da análise fatorial. A medida pode ser interpretada da seguinte forma: 0,80 ou acima - admirável; 0,70 ou acima - mediano; 0,60 ou acima - medíocre; 0,50 ou acima - ruim; e abaixo de 0,50 - inaceitável (HAIR JR. et al., 2009). No estudo, a análise apresentou apenas duas intercorrelações abaixo de 0,80, com índices de 0,757 (VP12-3.3) e 0,789 (VP30-7.3) respectivamente, indicando adequação da matriz de correlação para procedência à $\mathrm{AF}$, conforme pode ser observado no apêndice $\mathrm{M}$.

Os itens que formam o primeiro fator de práticas recomendadas (FP1) - Estratégias de Serviços trata de práticas que preveem e ajudam o processo de negócio. Segundo Feeny e Willcocks (1998), muitos gestores investem em procedimentos ineficientes ou até mesmo em novos procedimentos que foram planejados sem considerar a capacidade atual de TI. Ainda segundo os autores, o desafio é complexo, pois envolve avaliação e possível adoção de novas prescrições de gestão de TI, inclusive com métodos radicalmente diferentes, a fim de alcançar um maior desempenho na operação dos serviços existentes. Os gestores assumem compromissos significativos para a terceirização de serviços de TI e SI, concentrando-se na gestão dos fornecedores existentes e os novos recursos necessários (ibid.).

Ações de análise, acompanhamento e controle do processo de terceirização devem ser pensadas holisticamente a fim de que os gestores demonstrem mudanças em suas competências e habilidades interpessoais (EARL; FEENY, 1994; FEENY; WILLCOCKS, 1998).

O segundo fator (FP2) - Operações de Serviços designa ações que favoreçam o cumprimento do contrato pelo fornecedor, garantindo que os problemas e conflitos oriundos de todas as áreas envolvidas no projeto possam ser resolvidos de forma justa e rápida dentro de um contexto de acordos e relacionamentos (FEENY; WILLCOCKS, 1998).

Práticas de acompanhamento do contrato tornaram-se um núcleo de capacidade, garantindo que a posição do negócio da empresa esteja protegida em todos os momentos. Por vezes os gestores subestimam a extensão da tarefa fazendo-os a tomar decisões instantâneas (ibid.).

O terceiro fator (FP3) - Trabalho Tecnológico trata de práticas para que se alcance rapidamente o progresso técnico necessário. Exige muito da visão de um gestor planejador, com orientação pragmática e de curto prazo (ibid.). 
O quarto fator (FP4) - Desenvolvimento do Fornecedor visa identificar o valor potencial dos

fornecedores de serviço. É do interesse da empresa maximizar a contribuição de fornecedores existentes. No desenvolvimento de fornecedores, os gestores devem olhar para além das disposições contratuais existentes para explorar o potencial de longo prazo, a fim de criar situações "ganha-ganha" onde o fornecedor aumente suas receitas pela prestação de serviços e que aumente os benefícios do negócio (ibid.).

Por fim, o quinto fator (FP5) - Monitoramentos de Serviços envolve o desenvolvimento de compreensão de suas potencialidades, ajudando os usuários e fornecedores a trabalharem em conjunto garantindo satisfação.

\section{Dos resultados esperados pela terceirização de serviços de tecnologia da informação}

Diante do conjunto de 14 variáveis sobre os resultados esperados com a terceirização de serviços de TI foram utilizados procedimentos similares às das práticas de gestão, ou seja, a análise fatorial (AF) como técnica estatística multivariada com objetivo de reduzir o número de características em um número relativamente pequeno de fatores que poderão representar relações entre as variáveis que supostamente podem estar inter-relacionadas.

As variáveis que tratam dos resultados esperados em decorrência da terceirização de serviços de TI foram submetidas à AF com método de extração dos fatores por meio da análise dos seus componentes principais (Principal Components Analysis - PC). Dessa análise, foram reduzidas as 14 variáveis para dois fatores.

Uma questão significativa é que, para efeitos de ajuste na $\mathrm{AF}$, uma variável apresentou baixa comunalidade, e a opção foi pela exclusão da mesma com vistas à melhor adequação da composição dos fatores. Sendo ela: VR6-2.2 (0,450) (Os prazos "estipulados" para o projeto do sistema terceirizado (desenvolvido ou implantado) foram "cumpridos na íntegra" até a entrega final?), ou seja, esta variável compartilhava pouca quantidade total de variância com as demais variáveis do estudo.

Os dois fatores, em conjunto, explicam 59,24\% da variância das 13 variáveis incluídas na AF, de acordo também com o critério de porcentagem mínima de 3\% de explicação para os fatores extraídos, conforme demonstra a tabela 26 , a seguir. 
Tabela 26 - Fatores extraídos - resultados esperados

\begin{tabular}{cccc}
\hline Fatores & Total & \% da Variância & \% Acumulada \\
\hline 1 & 6,325 & 48,656 & 48,656 \\
2 & 1,375 & 10,580 & 59,236 \\
\hline
\end{tabular}

Método de Extração: Análise de componentes principais. Método de rotação oblíqua

A pesquisa seguiu com a análise dos seus componentes principais (principal components Analysis - PC) utilizando a rotação oblíqua (direct oblimin) a fim de verificar a matriz de correlações e se existem valores significativos para ajustar a utilização da técnica.

O valor do KMO foi de 0,919 e o teste de esfericidade de Bartlett foi de 1944,965 (gl = 78; p $<0,001$ ), indicando que a matriz do estudo é passível de análises e interpretações propostas. Lembrando que, segundo Favero et al. (2009), o valor de KMO próximo de 0 (zero) indica correlação fraca entre as variáveis e quanto mais próximo de 1 (um), mais adequado ao restante das análises estará.

A indicação obtida foi de até dois fatores, de acordo com os critérios de distribuição dos valores próprios superiores a 1 e análise gráfica por meio do Scree Plot, conforme apêndice N. Como a análise do scree plot sugere a presença de 1 até provavelmente 2 ou 3 fatores, foi realizada uma análise paralela (AP) com o objetivo de comparar os autovalores. Conforme pode ser observado na tabela 27 , a AP demonstrou que o segundo componente é o último em que os autovalores empíricos são menores aos aleatórios. Já no terceiro componente, os valores empíricos são menores do que os valores aleatórios. Posto isso, a AP sugere a existência de dois componentes, sendo que a sintaxe utilizada no SPSS para obtenção da AP dos resultados esperados encontra-se no apêndice Q.

Tabela 27 - Análise paralela de Horn - resultados esperados

\begin{tabular}{lcccc}
\hline \multirow{2}{*}{ Autovalores } & \multicolumn{4}{c}{ Componentes } \\
\cline { 2 - 5 } & 1 & 2 & 3 & 4 \\
\hline Aleatório & 1,670 & 1,580 & 1,510 & 1,451 \\
Empírico & 6,331 & 1,599 & 0,859 & 0,802 \\
\hline
\end{tabular}

$\mathrm{Na}$ sequência, foi realizada a fatoração dos eixos principais (principal axis factoring - PAF) utilizando a rotação oblíqua (direct oblimin), varimax e livre com os dois fatores constitutivos da estrutura empírica da medida. A estrutura obtida com a rotação oblíqua foi a mais satisfatória, pois a distribuição dos itens nos fatores se apresentou parcimoniosa e teoricamente defensável, contando ainda com os melhores indicadores numéricos. 
O primeiro fator, Melhoria nos Processos de Negócio, ficou constituído por 8 itens, cujas cargas fatoriais oscilaram entre 0,60 e 0,86 e o segundo fator, Satisfação, com 5 itens, com cargas variando entre 0,67 e 0,82. Para amostras de 250 a 350 respondentes (amostra total n=299), cargas acima de 0,35 são consideradas aceitáveis (HAIR JR. et al., 2009). Na tabela 28 são apresentadas as variáveis de cada fator com suas respectivas cargas fatoriais, comunalidade, média e desvio padrão.

Tabela 28 - Solução de fatores - resultados esperados

\begin{tabular}{llllll}
\hline \multirow{2}{*}{ Variável } & \multicolumn{2}{c}{ Fatores } & Comunalidade & Média & Desvio Padrão \\
\cline { 2 - 5 } & $\mathbf{1}$ & $\mathbf{2}$ & & & \\
\hline VR10-3.2 &, 86 & & 0,63 & 4,2 & 0,6 \\
VR8-2.4 &, 80 & & 0,65 & 4,0 & 0,7 \\
VR4-1.4 &, 76 & 0,52 & 4,0 & 0,7 \\
VR7-2.3 &, 70 & & 0,49 & 3,9 & 0,7 \\
VR1-1.1 &, 64 & & 0,51 & 3,9 & 0,7 \\
VR2-1.2 &, 64 & & 0,52 & 4,0 & 0,7 \\
VR3-1.3 &, 64 & & 0,53 & 4,0 & 0,7 \\
VR13-4.2 &, 60 & & 0,50 & 4,1 & 0,7 \\
\hline VR5-2.1 & &, 82 & 0,57 & 4,3 & 1,1 \\
VR9-3.1 & &, 81 & 0,65 & 4,4 & 0,8 \\
VR11-3.3 & &, 75 & 0,73 & 4,5 & 0,8 \\
VR12-4.1 & &, 68 & 0,73 & 4,5 & 0,8 \\
VR14-4.3 & &, 67 & 0,69 & 4,6 & 0,7 \\
\hline
\end{tabular}

A estrutura encontrada mostrou-se adequada, sendo que uma elevada consistência interna foi obtida em cada fator conforme as informações presentes na tabela 29. Hair Jr. et al. (2009), índices entre 0,60 e 0,70 são aceitáveis desde que os outros indicadores de validade do construto sejam bons.

Tabela 29 - Alfa de Cronbach - fatores extraídos - resultados esperados

\begin{tabular}{ccccccc}
\hline Fatores & $\begin{array}{c}\text { Alfa de } \\
\text { Cronbach }\end{array}$ & $\begin{array}{c}\text { Alfa } \\
\text { Cronbach } \\
\text { Padronizado }\end{array}$ & $\begin{array}{c}\text { Número de } \\
\text { Itens }\end{array}$ & Média & Variância & $\begin{array}{c}\text { Desvio } \\
\text { Padrão }\end{array}$ \\
\hline FR1 &, 875 &, 876 & 8 & 32,29 & 16,569 & 4,071 \\
FR2 &, 853 &, 870 & 5 & 22,34 & 11,259 & 3,355 \\
\hline
\end{tabular}

A medida de adequação da amostra (MSA) se apresentou satisfatória, pois todas as intercorrelações tiveram valores acima de 0,80 , conforme pode ser observado no apêndice $\mathrm{O}$. 
Lembrando que a medida de adequação da amostra (MSA) pode ser interpretada da seguinte forma: 0,80 ou acima - admirável; 0,70 ou acima - mediano; 0,60 ou acima-medíocre; 0,50 ou acima - ruim; e abaixo de 0,50 - inaceitável (HAIR JR. et al., 2009).

Os itens que formam o primeiro fator de resultados esperados (FR1) - Melhoria nos Processos de Negócio tratam de resultados diretos nas atividades do SI para o negócio, que de alguma forma trouxeram aumento de ganhos produtivos para a empresa, seja no âmbito financeiro, seja na execução das atividades do dia a dia.

De acordo com DeLone e McLean (1992) e Kuo (1996) o sucesso da terceirização de serviços de TI pode ser subdividido em áreas de qualidade do sistema, qualidade de informações, uso do sistema, satisfação dos usuários, influência no usuário final e impactos sobre a organização.

Carlson e McNurlin (1989) desenvolveram uma estrutura para avaliar a terceirização de SI constituída de cinco fatores, dentre eles, a eficiência e a produtividade.

O segundo fator (FR2) - Satisfação designa resultados que direcionam para a satisfação dos stakeholders com a qualidade de uma forma geral. Segundo Bailey e Pearson (1983) os fatores de satisfação estão associados ao desempenho operacional. Da mesma forma, Maisel (1992) e Simons (1995) apontam fatores financeiros, satisfação do cliente, ambiente interno e capacidades como outros fatores.

\section{Associação entre fatores de práticas recomendadas e resultados esperados - Correlação bivariada}

Com o objetivo de verificar as relações existentes entre os fatores de práticas recomendadas e resultados esperados, foi realizada a análise de correlação bivariada pelo método Spearman (não paramétrico) conforme demonstra a tabela 30, na próxima página.

A correlação, segundo Hair Jr. et al. (2009) é uma medida da qualidade da aproximação da relação entre dois fatores ou duas variáveis por uma reta, ou seja, a correlação mede a força da associação linear entre dois fatores ou duas variáveis. Ainda, segundo os autores, o coeficiente de correlação varia entre -1 e 1 . O valor 0 (zero) significa que não há relação linear, o valor 1 indica uma relação linear perfeita e o valor -1 também indica uma relação 
linear perfeita mas inversa, ou seja quando uma das variáveis aumenta a outra diminui. Quanto mais próximo estiver de 1 ou -1 , mais forte é a associação linear entre as duas variáveis, ao passo que, quanto mais próximo de zero (positivo ou negativo), menor a força de relação entre as variáveis.

Para Bryman e Cramer (1995), citando Cohen e Holliday (1982), consideram os seguintes valores: abaixo de 0,2 - correlação muito fraca e sem significância; 0,2 à 0,39 - correlação fraca; 0,4 à 0,69 - correlação moderada; 0,7 à 0,89 - correlação forte; e 0,9 à 1 - correlação muito elevada.

Em outro estudo, Hair Jr. et al. (2007) afirmam que o coeficiente de correlação de Pearson requer a normalidade na distribuição de frequência. Já o coeficiente de correlação Spearman, é uma medida de correlação não paramétrica, não requerendo normalidade dos dados.

Tabela 30 - Associação entre os fatores de práticas recomendadas e resultados esperados

\begin{tabular}{llcccccc}
\hline & & \multicolumn{3}{c}{ FP3 - } & \multicolumn{2}{c}{ FP4 - } & \\
& & FP1 - & FP2 - & Monitoramen Desenvolvime & FP5 - \\
to de & Estratégias de do \\
Serviços & $\begin{array}{c}\text { Operações } \\
\text { de Serviços }\end{array}$ & $\begin{array}{c}\text { Trabalho } \\
\text { Serviços }\end{array}$ & Fornecedor & Tecnológico \\
\hline FR1 - Melhoria Processos & Coeficiente de Correlação &, 086 &, $285^{* *}$ &, $200^{* *}$ &,- 008 &, 039 \\
Negócio & Sig. (2-tailed) &, 140 &, 000 &, 000 &, 888 &, 497 \\
FR2 - Satisfação & Coeficiente de Correlação &, $524^{* *}$ &,$- 194^{* *}$ &,$- 237^{* *}$ &, $561^{* *}$ &,$- 489^{* *}$ \\
& Sig. (2-tailed) &, 000 &, 001 &, 000 &, 000 &, 000 \\
\hline
\end{tabular}

Spearman's rho

**. Correlation is significant at the 0.01 level (2-tailed).

*. Correlation is significant at the 0.05 level (2-tailed).

\section{Associação entre fatores de práticas de gestão da terceirização de serviços de tecnologia da informação e dos resultados esperados - Correlação bivariada}

Com o objetivo de verificar as relações existentes somente entre os fatores das práticas de gestão da terceirização de serviços de TI e dos resultados esperados, da mesma forma, foi realizada a análise de correlação bivariada pelo método Spearman (não paramétrico).

A análise apresentou algumas correlações significativas entre os fatores de práticas de gestão da terceirização de serviços de TI. As mais altas correlações foram entre:

Fator FP1 - Estratégias de Serviços e FP4 - Desenvolvimento do Fornecedor (0,77): o uso de práticas que verificam o desenvolvimento do fornecedor relaciona-se fortemente com as 
práticas que são utilizadas visando ao negócio da organização como um todo, ou seja, a partir do momento em que o gestor da terceirização de serviços de TI preocupa-se em acompanhar o desenvolvimento do seu fornecedor, automaticamente refletirá nas práticas de gestão que refletem por sua vez, nos negócios da organização.

FP2 - Operações de Serviços e FP3 - Monitoramentos de Serviços $(0,70)$ : as práticas que compõem o fator FP2 - Operações de Serviços tratam das dimensões que envolvem incidentes, problemas e riscos, bem como capacidade de atendimento do fornecedor, responsabilidades e questões de relacionamento, os quais possuem forte associação com as práticas que envolvem aquisição, políticas e segurança. Desta forma, não há como dissociar estas práticas, uma vez que estão atreladas conjuntamente ao processo.

FP4 - Desenvolvimento do Fornecedor e FP5 - Trabalho Tecnológico (0,50): da mesma forma, as práticas de gestão associadas ao desenvolvimento do fornecedor estão diretamente relacionadas às práticas que envolvem questões ligadas a treinamento, desempenho e metodologias aplicadas pelo fornecedor.

É necessário evidenciar que os fatores FP2 e FP3 não apresentaram correlações significativas com o fator FP1. A tabela 31, apresentada a seguir, revela os resultados das associações entre os fatores.

Tabela 31 - Associação entre os fatores de práticas recomendadas

\begin{tabular}{|c|c|c|c|c|c|c|}
\hline & & $\begin{array}{c}\text { FP1 - } \\
\text { Estratégias de } \\
\text { Serviços }\end{array}$ & $\begin{array}{c}\text { FP2 - } \\
\text { Operações de } \\
\text { Serviços }\end{array}$ & $\begin{array}{c}\text { FP3 - Monitora } \\
\text { mento de } \\
\text { Serviços }\end{array}$ & $\begin{array}{c}\text { FP4 - } \\
\text { Desenvolvimen } \\
\text { to do } \\
\text { Fornecedor } \\
\end{array}$ & $\begin{array}{c}\text { FP5 - Trabalho } \\
\text { Tecnológico }\end{array}$ \\
\hline \multirow{2}{*}{$\begin{array}{l}\text { FP1 - Estratégias de } \\
\text { Serviços }\end{array}$} & Coeficiente de Correlação & 1 & ,046 & ,022 &, $776^{* *}$ &,$- 367 *$ \\
\hline & Sig. (2-tailed) & & ,431 &, 704 &, 000 &, 000 \\
\hline \multirow{2}{*}{$\begin{array}{l}\text { FP2 - Operações de } \\
\text { Serviços }\end{array}$} & Coeficiente de Correlação & ,046 & 1 &, $705 * *$ &,$- 116^{*}$ &, $430 * *$ \\
\hline & Sig. (2-tailed) & 431 & &, 000 &, 044 &, 000 \\
\hline \multirow{2}{*}{$\begin{array}{l}\text { FP3 - Monitoramentos de } \\
\text { Serviços }\end{array}$} & Coeficiente de Correlação & ,022 & ,705** & 1 &,$- 138 *$ & $439 * *$ \\
\hline & Sig. (2-tailed) &, 704 &, 000 & &, 017 &, 000 \\
\hline \multirow{2}{*}{$\begin{array}{l}\text { FP4 - Desenvolvimento do } \\
\text { Fornecedor }\end{array}$} & Coeficiente de Correlação & ,776** &,$- 116^{*}$ &,$- 138^{*}$ & 1 &,$- 500^{* *}$ \\
\hline & Sig. (2-tailed) &, 000 &, 044 &, 017 & & 0 \\
\hline \multirow{2}{*}{ FP5 - Trabalho Tecnológico } & Coeficiente de Correlação &,$- 367 * *$ & $430 * *$ & $439 * *$ &,$- 500 * *$ & 1 \\
\hline & Sig. (2-tailed) &, 000 &, 000 &, 000 &, 000 & \\
\hline
\end{tabular}

Spearman's rho

** Correlation is significant at the 0.05 level (2-tailed).

* Correlation is significant at the 0.05 level (2-tailed)

Da mesma forma, foi verificado o grau de correlação entre os fatores inerentes ao resultado, com base na correlação bivariada Spearman. Nesse caso, houve baixa correlação $(0,211)$, porém com significância estatística entre os dois fatores. Apesar da baixa correlação, é possível inferir que todos os itens que compõem os resultados estão, de algum modo, 
relacionados entre si em função do objeto terceirizado ao qual está sendo medido o resultado. A tabela 32 apresenta os resultados da correlação bivariada.

Tabela 32 - Associação entre os fatores de resultados esperados

\begin{tabular}{llcc}
\hline & $\begin{array}{c}\text { FR1 - Melhoria } \\
\text { Processos } \\
\text { Negócio }\end{array}$ & $\begin{array}{c}\text { FR2 - } \\
\text { Satisfação }\end{array}$ \\
\hline FR1 - Melhoria Processos & Coeficiente de Correlação & 1 &, $211^{* *}$ \\
Negócio & Sig. (2-tailed) &, $211^{* *}$ &, 000 \\
\hline FR2 - Satisfação & Coeficiente de Correlação &, 000 & 1 \\
\hline $\begin{array}{l}\text { Spearman's rho } \\
\text { ** Correlation is significant at the } 0.05 \text { level (2-tailed). }\end{array}$ & & \\
\hline
\end{tabular}

A técnica de correlação bivariada foi utilizada a fim de extrair, a partir dos dados, a maior quantidade de relações e interpretações possíveis. Os resultados demonstraram que novas investigações seriam necessárias, utilizando técnicas estatísticas mais avançadas devido à complexidade das relações entre as variáveis. Em função disso, a opção foi pelo uso da técnica de modelagem de equação estrutural, que visa à mensuração especificada de uma série de relações representadas por construtos latentes, ou seja, que não são diretamente mensurados (HAIR JR. et al., 2009).

Cabe ressaltar que os fatores, tanto os de práticas de gestão da terceirização de serviços de TI quanto os de resultados, apresentaram correlações, o que viabiliza o uso de construtos de $2^{\mathrm{a}}$ ordem dentro da MEE.

Segundo Garver e Mentzer (1999) o modelo de medida de $2^{\text {a }}$ ordem surge quando os diversos indicadores que explicam e representam as variáveis latentes de $1^{\mathrm{a}}$ ordem agem como múltiplos indicadores que são causados pela variável latente de $2^{\mathrm{a}}$ ordem e, para tal, é necessário que haja correlações entre os construtos de $1^{\mathrm{a}}$ ordem.

No contexto do método PLS esse modelo é implementado seguindo-se as recomendações de Wold (1982, p. 41), ou seja, os indicadores das variáveis latentes de $1^{\mathrm{a}}$ ordem são reutilizados como indicadores reflexivos da VL de $2^{\text {a }}$ ordem também. Da mesma forma, Lohmöller (1989) 
afirma que para poder estimar este tipo de variável latente, é necessário repetir os indicadores das variáveis latentes de $1^{\mathrm{a}}$ ordem na sua variável latente de $2^{\mathrm{a}}$ ordem.

O modelo estrutural proposto é composto por construtos de $1^{\mathrm{a}}$ e $2^{\mathrm{a}}$ ordem, uma vez que, para formular uma afirmação mais significativa quanto à dimensionalidade dos construtos de práticas de gestão, a criação do construto de $2^{\mathrm{a}}$ ordem, postula que os fatores de $1^{\mathrm{a}}$ ordem são na realidade subdimensões de um construto mais amplo e mais geral.

A variável latente de $2^{\mathrm{a}}$ ordem (práticas recomendadas) retrata a utilização de práticas de gestão da terceirização de serviços de TI, baseadas na influência das práticas de gestão dos subprocessos estratégias de serviços; operações de serviços, trabalho tecnológico, desenvolvimento do fornecedor e monitoramentos de serviços; já a variável latente de $2^{\mathrm{a}}$ ordem (resultados esperados), retrata os resultados provenientes e baseados de melhoria nos processos de negócio e satisfação.

Com essa característica, o fator de $2^{\mathrm{a}}$ ordem torna-se exógeno, ao passo que os fatores de $1^{\mathrm{a}}$ ordem são endógenos. Com isso, é possível afirmar que o fator de $2^{\mathrm{a}}$ ordem é a causa dos fatores de $1^{\mathrm{a}}$ ordem. Cabe ressaltar ainda, que este construto é completamente latente e não observável.

Neste estudo, o modelo é reflexivo, pois os construtos (práticas recomendadas e resultados esperados) não são formados pelo conjunto das variáveis de medida, ou seja, eles existem de forma independente, e algumas variáveis medidas guardam uma parcela da variável latente.

O modelo estrutural proposto está representado na ilustração 6 , a seguir, onde os círculos representam variáveis latentes (ou "fatores"). Estratégias de Serviços, Operações de Serviços, Monitoramentos de Serviços, Desenvolvimento Fornecedor, Trabalho Tecnológico são fatores de $1^{\text {a }}$ ordem ou dimensões de conjuntos de fatores das Práticas Recomendadas. Melhoria no Processo de Negócio e Satisfação são fatores de $1^{a}$ ordem ou dimensões de conjuntos de fatores dos Resultados Esperados. Os construtos compreendidos na área pontilhada representam o modelo estrutural. 


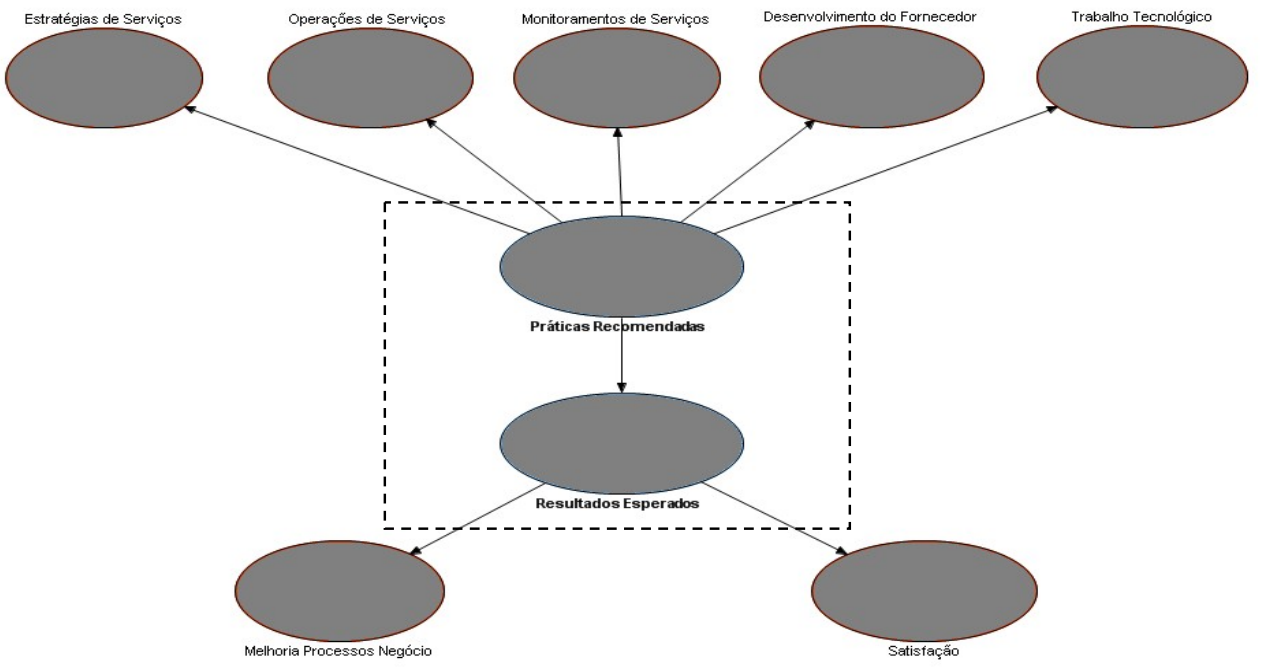

Ilustração 6 - Modelo estrutural no SMART PLS

\subsection{Análise confirmatória por meio da modelagem de equações estruturais}

A ilustração 7 apresenta os valores obtidos com o processamento do modelo original proposto pela pesquisa. Como mencionado anteriormente, foi utilizada a técnica PLS - Partial Least Square.

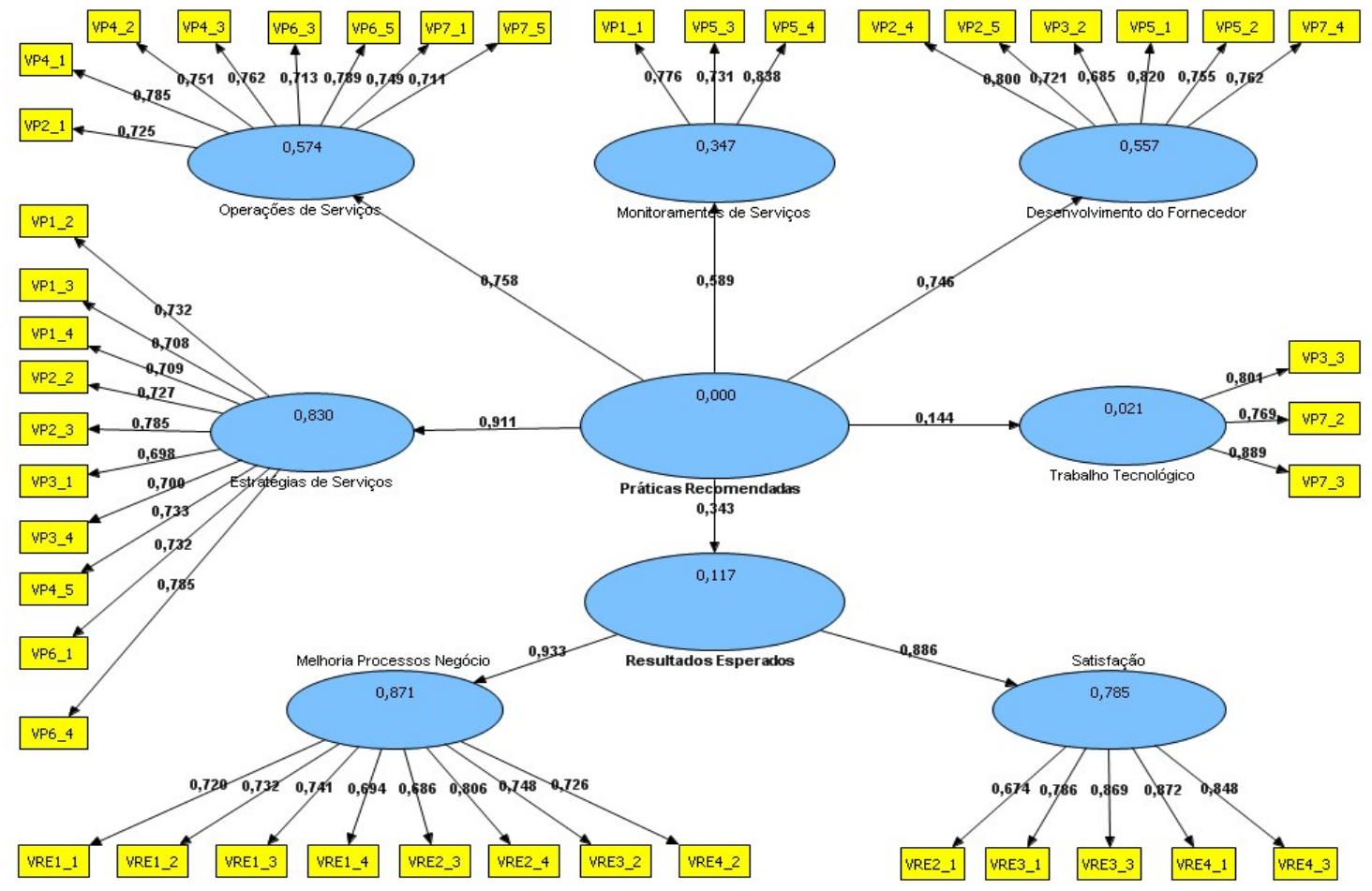

Ilustração 7 - Processamento inicial PLS do modelo de mensuração 
É importante notar na ilustração 7 que algumas variáveis apresentaram cargas fatoriais muito próximas ao limite, sendo elas: VP3_1 $(0,698)$ do construto Estratégias de Serviços; VP3_2 $(0,685)$ do construto Desenvolvimento do Fornecedor; VRE1_4 $(0,694)$ e VRE2_3 $(0,686)$ do construto Melhoria Processos Negócio; e VRE2_1 $(0,674)$ do construto Satisfação. A regra estabelece que a estimativa de cargas padronizadas deva ser de 0,50 ou mais, e idealmente de 0,70 para cima (HAIR JR. et al., 2009; BIDO, 2010).

Todas as demais variáveis de todos os outros construtos apresentaram cargas fatoriais significantes. Um novo processamento foi realizado sem estas variáveis e os novos valores afetaram pouco (terceira casa decimal) os novos coeficientes calculados. Em função disto, a opção foi por mantê-las no modelo.

A tabela 33 a seguir, demonstra que foram satisfatórios os resultados gerais obtidos para a validade convergente, avaliada pelos valores da variância média extraída (AVE) - fatores igual ou superior a 0,50 , pois estes que representam a alta correlação com seus itens ou variáveis (ZWICKER; SOUZA; BIDO, 2008), pelo índice de confiabilidade (Alfa de Cronbach) superior a 0,70 e pelo valor de confiabilidade composta superior a 0,70 .

Tabela 33 - Indicadores de validade convergente dos fatores do modelo de mensuração

\begin{tabular}{lccccc}
\hline \multicolumn{1}{c}{ Construtos } & AVE & $\begin{array}{c}\text { Confiabilidade } \\
\text { Composta }\end{array}$ & $\begin{array}{c}\text { Alfa } \\
\text { Cronbach }\end{array}$ & Comunalidade & Raiz AVE \\
\hline Estratégias de Serviços & 0,54 & 0,92 & 0,90 & 0,54 & 0,73 \\
Operações de Serviços & 0,56 & 0,91 & 0,89 & 0,56 & 0,75 \\
Monitoramentos de Serviços & 0,61 & 0,83 & 0,69 & 0,61 & 0,78 \\
Desenvolvimento do Fornecedor & 0,58 & 0,89 & 0,85 & 0,58 & 0,76 \\
Trabalho Tecnológico & 0,67 & 0,86 & 0,78 & 0,67 & 0,82 \\
Melhoria Processos Negócio & 0,54 & 0,90 & 0,88 & 0,54 & 0,73 \\
Satisfação & 0,66 & 0,91 & 0,87 & 0,66 & 0,81 \\
\hline
\end{tabular}

O único construto que apresentou um valor de Alfa de Cronbach muito próximo ao limite foi o de Monitoramentos de Serviços com 0,69, o que é aceitável, uma vez que, como informado anteriormente, índices entre 0,60 e 0,70 são aceitáveis desde que os outros indicadores de validade do construto sejam bons (HAIR JR. et al. , 2009), o que é o caso. Os resultados obtidos apontam uma confiabilidade das medidas e validade convergente.

Para uma explicação melhor dos resultados obtidos, foram colocados na diagonal da tabela 34 os valores obtidos da raiz quadrada da variância média explicada. Hair Jr. et al. (2009) 
recomendam que, em relação às estimativas da raiz de AVE, devam ser maiores do que o quadrado da correlação entre os dois fatores (variáveis latentes), para fornecer evidência de validade discriminante.

Tabela 34 - Matriz de cargas dos fatores e entre os fatores do modelo

\begin{tabular}{|c|c|c|c|c|c|c|c|}
\hline & $\begin{array}{c}\text { Desenvolvimen } \\
\text { to do } \\
\text { Fornecedor } \\
\end{array}$ & $\begin{array}{l}\text { Estratégias } \\
\text { de Serviços }\end{array}$ & $\begin{array}{c}\text { Melhoria } \\
\text { Processos } \\
\text { Negócio } \\
\end{array}$ & $\begin{array}{c}\text { Monitoramentos } \\
\text { de Serviços }\end{array}$ & $\begin{array}{c}\text { Operações } \\
\text { de Serviços }\end{array}$ & Satisfação & $\begin{array}{c}\text { Trabalho } \\
\text { Tecnológico }\end{array}$ \\
\hline Desenvolvimento do Fornecedor & 0,7586073 & & & & & & \\
\hline Estratégias de Serviços & 0,7830280 & 0,7315238 & & & & & \\
\hline Melhoria Processos Negócio & 0,1744060 & 0,2904370 & 0,7323135 & & & & \\
\hline Monitoramentos de Serviços & 0,1240870 & 0,3280840 & 0,1816340 & 0,7832024 & & & \\
\hline Operações de Serviços & 0,2360520 & 0,4727810 & 0,2200320 & 0,7065400 & 0,7486982 & & \\
\hline Satisfação & 0,4559390 & 0,4780420 & 0,6605420 & $-0,0797590$ & 0,0054670 & 0,8132423 & \\
\hline Trabalho Tecnológico & $-0,1708620$ & $-0,0589390$ & $-0,0609210$ & 0,4123920 & 0,3683790 & $-0,3408080$ & $\mathbf{0 , 8 2 1 3 4 7 7}$ \\
\hline
\end{tabular}

Tal fato se confirmou, com exceção dos construtos Estratégias de Serviços e Desenvolvimento do Fornecedor. Hair Jr. et al. (2009) sugerem que quando há um valor para a raiz de AVE menor que a correlação entre as variáveis, elas devem ser agrupadas. Apesar da indicação de agrupamento, a opção foi por manter os construtos separados, uma vez que as práticas ligadas ao desenvolvimento do fornecedor não convergem com as práticas de estratégias de serviços.

Segundo Handfield et al. (2000) o desenvolvimento do fornecedor está ligado diretamente a qualquer esforço realizado por uma empresa tomadora do serviço com um fornecedor, para aumentar seu desempenho e suas capacidades a fim de atender as necessidades de longo e curto prazo.

De Toni e Nassimbeni (2000) afirmam que o desenvolvimento de fornecedores pode abranger desde uma avaliação superficial do fornecedor e exigir aumento de desempenho, quanto esforços no sentido de gestionar treinamentos da equipe envolvida, bem como investimentos nas operações do mesmo.

A fim de testar a multicolinearidade entre as variáveis independentes que afetam a variável latente FR1 - Melhoria nos Processos de Negócio e FR2 - Satisfação, foi utilizada a análise dos escores fatoriais desses construtos por meio da regressão linear. Segundo Hair Jr. et al. (2009, p.142), “A colinearidade é a associação, medida como a correlação, entre duas variáveis independentes.

A multicolinearidade refere-se à correlação entre três ou mais variáveis independentes (evidenciada quando uma é regressada em relação às outras). Apesar de haver uma distinção 
precisa em termos estatísticos, é prática comum usar os termos alternadamente. Como regra, se o modelo de regressão apresentar um VIF acima de 10 ou tolerância abaixo de 0,10, indicaria uma alta colinearidade (HAIR JR. et al., 2009). A tabela 35 apresenta o resultado do teste, no qual não foram detectados problemas de colinearidade.

Tabela 35 - Teste de colinearidade entre as variáveis latentes

\begin{tabular}{lcc}
\multicolumn{2}{c}{ Fatores } & \multicolumn{2}{c}{ Colinearidade } \\
& Tolerância & VIF \\
\hline FP1 - Estratégias de Serviços &, 280 & 3,573 \\
FP2 - Operações de Serviços &, 423 & 2,363 \\
FP3 - Monitoramentos de Serviços &, 485 & 2,060 \\
FP4 - Desenvolvimento do Fornecedor &, 325 & 3,074 \\
FP5 - Trabalho Tecnológico &, 691 & 1,447 \\
\hline \multicolumn{2}{c}{ Fatores } & \multicolumn{2}{c}{ Colineariável Dependente: FR1 - Melhoria Processos Negócio } \\
\multicolumn{3}{c}{ Tolerância } \\
\multicolumn{3}{c}{ VIF } \\
\hline FP1 - Estratégias de Serviços &, 280 & 3,573 \\
FP2 - Operações de Serviços &, 423 & 2,363 \\
FP3 - Monitoramentos de Serviços &, 485 & 2,060 \\
FP4 - Desenvolvimento do Fornecedor &, 325 & 3,074 \\
FP5 - Trabalho Tecnológico &, 691 & 1,447 \\
\hline a. Dependent Variable: FR2 - Satisfação & \multicolumn{2}{c}{. }
\end{tabular}

Considerando os atributos percebidos pelas práticas adotadas pelo gestor de TI na gestão da terceirização de serviços de TI e os resultados obtidos em decorrência da terceirização de serviços de TI, a análise demonstrou que a adoção de práticas recomendadas de gestão da terceirização de serviços de TI impacta positivamente, sendo significativa, mas a relevância prática foi baixa nos resultados desta terceirização, ou seja, a adoção conjunta de práticas recomendadas explica $11,7 \%$ dos resultados esperados conforme pode ser observado na ilustração 8 .

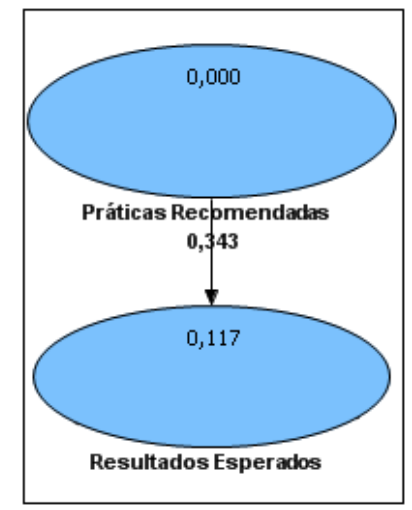

Ilustração 8 - Resultado da análise de práticas recomendadas e resultados esperados 


\section{Análise da modelagem - Práticas recomendadas e Resultados esperados}

Após o processamento do modelo proposto não foi necessário realizar ajustes no mesmo. $\mathrm{Na}$ verdade, o que surge com relevância é uma análise sobre os resultados obtidos, a saber:

O fator Estratégias de Serviços, dentre todos os outros quatro fatores, é o fator que possui maior comunalidade $(83 \%)$ com práticas recomendadas. A comunalidade é a quantia total de variância explicada por outro construto, isto é, o quanto de variância tem compartilhada com o outro construto (HAIR JR. et al., 2009).

Esse construto trata de práticas de gestão ligadas ao registro e documentação dos processos de aquisição; utilização de práticas recomendadas do mercado para a gestão e para a seleção do fornecedor; envolvimento da área jurídica nos processos; gestão das solicitações das áreas e dos SLA; avaliações dos fornecedores, inclusive do cumprimento dos serviços realizados; definição em conjunto com as áreas envolvidas sobre o escopo do projeto; e controles financeiros.

A adoção dessas práticas envolve atividades recorrentes para o aumento da produtividade interna das equipes, sempre assegurando a melhor relação custo benefício para a organização. Cabe ressaltar que o trabalho executado deve ser realizado de forma integrada e interrelacionada, fazendo com que todos os envolvidos entendam e se responsabilizem por suas atividades, antecipando-se inclusive, em relação aos processos nos quais exista uma maior probabilidade de erros, além de criar medidas preventivas e corretivas (MANSUR, 2009).

Devem ainda, ser realizados de forma detalhada e descrever exatamente os processos de execução, variando de uma área para outra, assim como de uma atividade para outra (HEFLEY; LOESCHE, 2006). Erros na condução podem comprometer a entrega do serviço contratado ocasionando sérios riscos ao negócio (ITGI. 2007).

O fator Operações de Serviços possui 57,4\% de comunalidade com práticas recomendadas e apresenta práticas de gestão ligadas às avaliações, tanto dos riscos, problemas e incidentes, quanto de conduta e da qualidade dos serviços prestados pelo fornecedor do serviço, bem como a gestão do cumprimento das atribuições e responsabilidades e ações que agreguem valor ao negócio. 
As práticas exercidas dentro do contexto Operações de Serviços podem ser consideradas críticas, pois erros na condução, controle e gestão das atividades do dia a dia operacional poderão comprometer totalmente a disponibilidade do serviço. Essas práticas visam à regularidade da entrega do serviço contratado nos níveis preestabelecidos, dentro de um ambiente sujeito a mudanças frequentes e, muitas vezes, imprevisíveis. Com a gestão destas práticas, é necessário encontrar um ponto de equilíbrio entre conjuntos de prioridade totalmente conflitantes, a fim de minimizar riscos (FERNANDES; ABREU, 2008).

A regularidade da entrega do serviço contratado nos níveis preestabelecidos, dentro de um ambiente sujeito a mudanças frequentes e, muitas vezes, imprevisíveis, deve ser prática comum aos gestores que visam encontrar um ponto de equilíbrio entre conjuntos de prioridade totalmente conflitantes, a fim de minimizar os riscos (MANSUR, 2009).

O fator Monitoramento de Serviços possui 34,7\% de comunalidade com práticas recomendadas. As práticas ligadas a esse construto relacionam-se com monitoramento e acompanhamento dos processos de aquisição, com uso de técnicas ou tecnologias utilizadas pelo fornecedor do serviço, e com o cumprimento das políticas que regem o gerenciamento da terceirização da TI.

O desenvolvimento de compreensão de suas potencialidades na gestão, ajudando os usuários e fornecedores a trabalharem em conjunto a fim de garantir resultados satisfatórios, é uma condição estabelecida para a multiplicidade de processos dentro do aspecto de monitoramento de serviços (GRÖNROOS, 2007; VAN DER VALK, 2008).

As práticas de monitoramento, a fim de garantir o acordo de nível de serviço, o cumprimento das políticas instituídas e a execução dos serviços são cruciais não só para o fornecedor do serviço, como para a organização contratante e a falta disto pode inviabilizar o acompanhamento dos serviços executados, deixando de observar o desempenho, a confiabilidade e a disponibilidade desses serviços que estão sendo executados pelo fornecedor (FERNANDES; ABREU, 2008).

A gestão do monitoramento de serviços visa ainda, garantir que qualquer mudança que ocorra no decorrer do projeto seja realizada de forma que os usuários finais possam continuar a realizar os seus serviços (ITGI, 2007). 
O fator Desenvolvimento do Fornecedor possui 55,7\% de comunalidade com práticas recomendadas e com um item (VP3_2) com carga fatorial $(0,685)$ um pouco abaixo do padrão $(0,70)$. As práticas ligadas a esse construto, ou seja, acompanhamentos, controles e planejamentos: dos investimentos realizados pelo fornecedor; da capacidade técnica do fornecedor; da infraestrutura disponibilizada pelo fornecedor; das licenças de uso de programas específicos disponibilizados pelo fornecedor; e da comunicação entre usuários finais e equipes dos fornecedores, denotam a preocupação que o gestor deve ter com o desenvolvimento do seu fornecedor.

Segundo Willcocks e Choi (1995) existe uma tendência na relação entre empresa contratante e fornecedor de serviço que é a valorização da entrega no tempo contratado e a qualidade do serviço executado.

Braga (2009) afirma que para haver sucesso na gestão do desenvolvimento do fornecedor, alguns fatores devem ser considerados como críticos, a saber: excelentes habilidades interpessoais do gestor, perspectivas de longo prazo no relacionamento e ampla comunicação entre as partes envolvidas. Ainda segundo o autor, pode ser considerado um erro fatal negligenciar o potencial das práticas de desenvolvimento do fornecedor, pois possuem uma significativa contribuição para a posição competitiva das suas organizações.

Ainda segundo o autor, pode ser considerado um erro fatal negligenciar o potencial das práticas de desenvolvimento do fornecedor, pois possuem uma significativa contribuição para a posição competitiva das suas organizações.

A falta de controle do desenvolvimento do fornecedor certamente comprometerá o desenvolvimento do projeto terceirizado, uma vez que devido ao aumento concorrencial, alguns benefícios podem ser alcançados em função de diferenciais que o fornecedor venha a trazer para a organização por meio do projeto terceirizado (MANSUR, 2009).

O fator Trabalho Tecnológico possui $0,02 \%$ de comunalidade com práticas recomendadas, apesar dos itens possuírem cargas fatoriais altas.

Uma possível justificativa é que as variáveis que constam no construto Trabalho Tecnológico (VP3_3; VP7_2; e VP7_3) dizem respeito a práticas de gestão inerentes às metodologias para 
desenvolvimento do projeto; utilização de SI para apoio; e acompanhamento da capacitação da equipe disponibilizada pelo fornecedor do serviço. Tais práticas dão suporte para que o projeto terceirização atinja seu objetivo final.

A ausência dessas práticas pode trazer impactos ao desenvolvimento do projeto, uma vez que a falta de metodologia denotará desorganização na execução do projeto, colocando em risco o cronograma de execução, bem como todos os processos envolvidos (FERNANDES; ABREU, 2008). Da mesma forma, a falta de uso de um SI de apoio na execução do processo, resultará em um esforço de controle grande por parte do gestor, fazendo que o mesmo despenda um tempo maior nos controles inerentes (MANSUR, 2009). Por sua vez, a falta de capacitação da equipe responsável, pode trazer graves consequências ao projeto final, colocando em risco não só os cumprimentos de prazos, mas a qualidade final do SI a ser entregue ao contratante (FERNANDES; ABREU, 2008).

O fator Melhoria nos Processos de Negócios possui 87,1\% de comunalidade com resultados esperados. Este construto trata de resultados sobre as reduções de custos e aspectos financeiros; fatores sobre a redução das incertezas e riscos na execução dos serviços, bem como no aumento da proteção nos dados e informações; fatores relacionados ao aumento da integração entre processos, pessoas e habilidades; fatores sobre a flexibilidade na execução das tarefas por parte dos usuários em termos de horários e formas de execução, bem como a capacidade de resposta às mudanças no ambiente; e fatores sobre a organização focar nas suas competências.

O fator Satisfação possui $78,5 \%$ de comunalidade com resultados esperados. Este construto trata de resultados sobre a satisfação e qualidade com a entrega do serviço terceirizado, ou seja, fatores sobre a satisfação dos usuários em relação aos novos sistemas em utilização salto de qualidade na realização das atividades-fim dos usuários - melhoria na qualidade do uso (usabilidade) do sistema terceirizado (desenvolvido ou implantado) - melhoria na qualidade dos dados/informações para a tomada de decisão; e fatores sobre produtividade, como: o aumento na capacidade de execução de serviços, bem como os fatores sobre a melhoria nos processos da organização, no aumento da velocidade e na melhoria nos níveis de execução de serviços. 


\section{Análise da validação dos modelos de mensuração e estrutural}

Na ilustração 7 (apresentada na página 170) podem ser observadas as cargas fatoriais entre as variáveis observadas e os construtos de $1^{\mathrm{a}}$ ordem; entre os construtos de $1^{\mathrm{a}}$ ordem e $2^{\mathrm{a}}$ ordem; bem como o coeficiente de regressão da relação estrutural.

Para a análise da estabilidade dos parâmetros estimados a partir dos resultados oriundos da técnica bootstrapping via PLS, com parâmetro 500 repetições para o número de 299 casos. De acordo com Hair Jr. et al. (2009) a técnica consiste em um tipo de reamostragem aleatória com repetição, ou seja, no caso aplicado, foram realizadas 500 simulações com o conjunto de dados para a obtenção dos resultados do teste da distribuição $t$ de student.

O teste $t$ de student testa a hipótese de que os coeficientes de correlação/regressão sejam iguais a zero, sendo que, caso o resultado seja igual ou superior a 1,99, a hipótese é rejeitada, o que significa que a correlação/regressão é significativa (HAIR JR. et al. , 2009).

A ilustração 9 apresenta os resultados obtidos com o bootstrapping, onde observa-se que todas as variáveis latentes de Práticas Recomendadas e Resultados Esperados foram superiores a 1,99 .

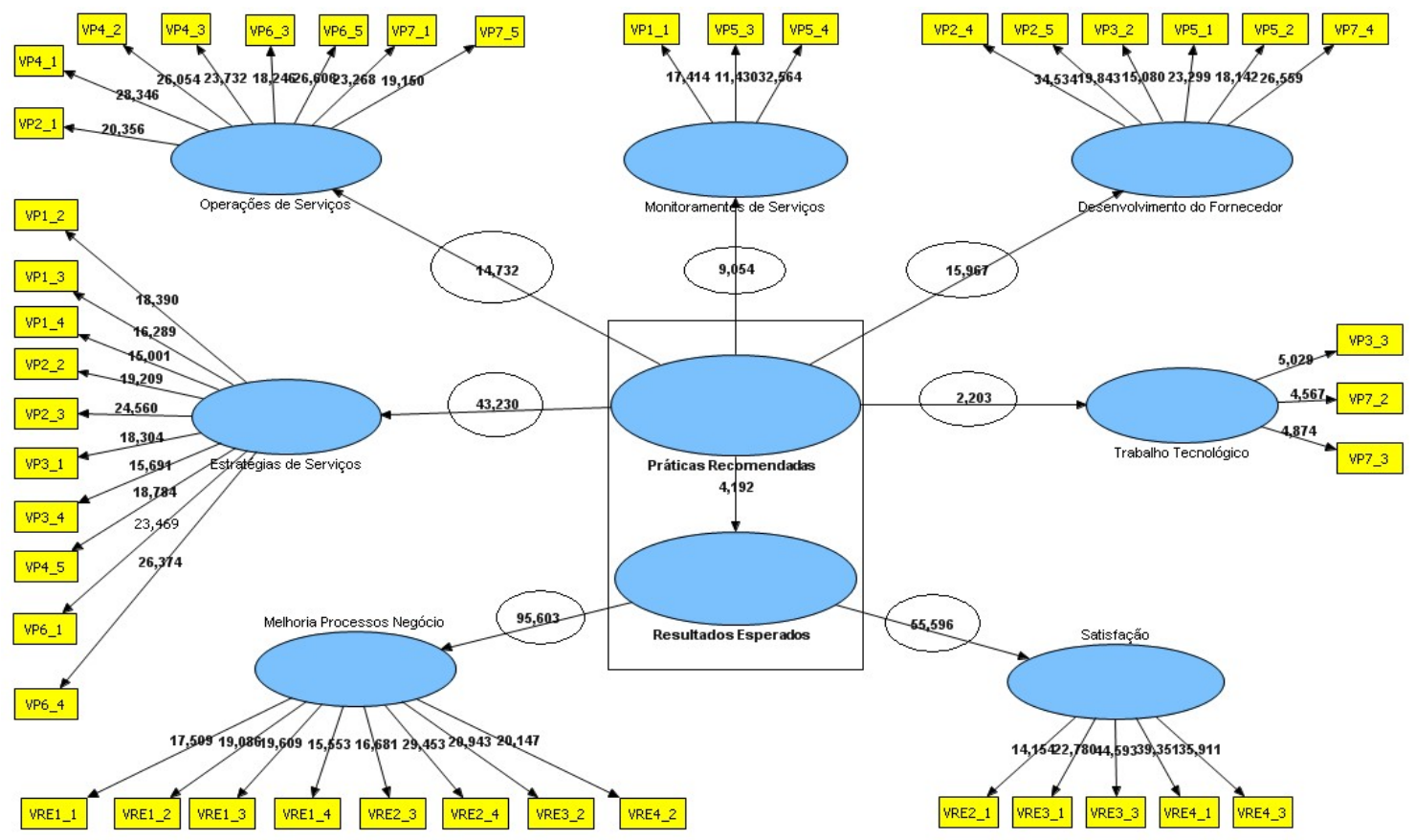

Ilustração 9 - Processamento PLS (bootstrapping - teste $t$ ) do modelo de mensuração e estrutural 
A avaliação do modelo estrutural se deu a partir da significância do coeficiente de regressão padronizado que indica o quanto uma variável latente afeta outra. Nesse sentido, vale ressaltar que a variável latente de $2^{\mathrm{a}}$ ordem Práticas Recomendadas afeta positivamente mas não significativamente a variável latente de $2^{\mathrm{a}}$ ordem Resultados Esperados, apresentando $t$ de student $(\mathrm{t}=4,192)$, representada no interior do retângulo na mesma ilustração.

Assim, a hipótese proposta no trabalho - H1 - A adoção de práticas recomendadas de gestão da terceirização de serviços de TI impacta positivamente nos resultados desta terceirização foi suportada, ou seja, a adoção de práticas recomendadas de gestão da terceirização de serviços de TI impacta positivamente nos resultados desta terceirização, mas não de forma significativa, conforme pode ser observado na tabela 36.

Tabela 36 - Coeficientes padronizados (paths) e valores $t$ student obtidos no modelo proposto

\begin{tabular}{lccccc}
\hline Relação Estrutural & $\begin{array}{c}\text { Coeficiente } \\
\text { Padronizado }\end{array}$ & $\begin{array}{c}\text { t-value } \\
\mathbf{>} \mathbf{1 , 9 9}\end{array}$ & $\mathbf{R}^{\mathbf{2}}$ & Hipótese & $\begin{array}{c}\text { Resultado da } \\
\text { Hipótese }\end{array}$ \\
\hline Práticas Recomendadas $->$ Melhores Resultados & 0,343 & 4,192 & 11,70 & H1 & Confirmada \\
\hline
\end{tabular}

A seguir são apresentadas as principais conclusões deste estudo respaldadas nas análises realizadas neste capítulo. 


\section{CONCLUSÕES}

A partir dos objetivos estabelecidos para esta pesquisa - tanto o geral, quanto os específicos foi possível avaliar a gestão da terceirização de serviços de TI e seus resultados. A pesquisa demonstrou que a adoção de práticas recomendadas de gestão baseados em modelos de GTI traz resultados positivos, porém pouco significativos para os resultados obtidos em decorrência da terceirização de serviços de TI. A seguir são apresentadas as conclusões:

\section{Principais práticas de gestão da terceirização de serviços de TI baseados nos modelos de GTI}

Dos 37 modelos de governança identificados por meio da revisão bibliográfica, 15 possuem aderência à GTI. Destes 15 modelos, 3 apresentaram forte similaridade em suas dimensões de abrangências e nas práticas de gestão de TI: o CObIT - versão 4.1; o eSCM-CL - versão 1.1;

e o ITIL - versão 3. É possível concluir que estes modelos englobam 23 dimensões que por sua vez abrangem quase todos os aspectos aos quais o processo de gestão da terceirização de serviços de TI está relacionado e com os quais o gestor de TI deve se preocupar durante a sua gestão. Os demais modelos de GTI identificados possuem práticas de gestão ligadas a assuntos específicos, ficando a sua aplicação restrita a determinadas situações em que a organização tenha a necessidade de aplicar, como por exemplo, o PMBoK para a gestão dos projetos.

Fernandes e Abreu (2008) e Mansur (2009) destacam que é possível utilizar de forma conjunta as práticas recomendadas de gestão existentes nos modelos estudados considerando, entretanto, a necessidade apresentada por cada organização.

Cabe ressaltar que, as práticas de gestão da terceirização de serviços de TI recomendadas pelos diferentes modelos de GTI também retratam as preocupações com os possíveis conflitos (relações) entre clientes e fornecedores.

\section{Resultados esperados com a terceirização de serviços de TI mencionados na literatura}

Em relação aos resultados esperados em uma terceirização de serviços de TI e com fundamentação na revisão bibliográfica realizada, foi possível observar que alcançar possíveis 
resultados positivos a partir do gerenciamento da terceirização de serviços de TI, é o foco não só do gestor de TI, como também da(s) equipe(s) envolvida(s).

Foram identificados 14 aspectos relacionados ao resultado da terceirização de serviços de TI, perante os quais o gestor de TI deve focar mecanismos de controle e medição que foram classificados em 8 categorias específicas: lucratividade, confiabilidade, credibilidade, competências do fornecedor, novos conhecimentos adquiridos em função da terceirização, maturidade, aumento de produtividade e satisfação, conforme apresentado no quadro 2 deste estudo.

Com base na literatura pesquisada, a inferência foi que dos 14 aspectos identificados, três se destacam em função de sua importância no processo de terceirização: a redução de custos, a melhoria do nível de serviço e o aumento da produtividade.

\section{Avaliação das práticas de gestão da terceirização de serviços de TI}

Antes de apresentar as principais conclusões sobre as práticas recomendadas de gestão da terceirização de serviços de TI, é oportuno destacar que as análises realizadas apontam que $73,2 \%$ das organizações pesquisadas utilizam ao menos um modelo de GTI e 26,8\% não utilizam nenhum modelo formal. Apesar dos gestores não adotarem modelos formais, os mesmos adotam práticas de gestão que fazem parte de modelos como o CobIT, e-SCM ou ITIL, o que permite afirmar que os gestores de TI possuem conhecimento sobre práticas de gestão que são utilizadas em função de possíveis experiências adquiridas ao longo das respectivas carreiras na área de TI.

Das 219 organizações que adotam formalmente algum modelo de GTI, 189 são de grande porte e 30 de médio porte, evidenciando uma tendência em adotar práticas provenientes de modelos formais de GTI, uma vez que as promessas emitidas pelas certificadoras destes modelos encorajam cada vez mais as organizações a utilizá-las.

Outro aspecto que merece destaque foi a predominância de uso do ITIL. Das 299 organizações pesquisadas, 157 utilizam-no de forma exclusiva ou conjunta, sendo que destas, 115 o fazem com contratos formais detalhados englobando cláusulas SLA. O segundo modelo 
mais utilizado é o CobIT, com 110 organizações, sendo que 80 possuem contrato com cláusulas que abrangem SLA.

Estes resultados demonstram que o uso de contratos com cláusulas SLA está atrelado à adoção de modelos de GTI formais por parte das organizações, a fim de se obterem melhores resultados, conforme pode ser observado na tabela 17. Isto denota a tendência dos gestores de TI em manter as responsabilidades (de ambas as partes - contratante e contratada) definidas da melhor forma possível, no que se refere ao objeto terceirizado.

Já em relação à avaliação das práticas recomendadas de gestão da terceirização de serviços de TI, a análise mostrou que, as 5 práticas adotadas excelentemente com maior frequência foram: "VP4-1.4 - Asseguro que o departamento jurídico acompanhe e participe de todos os processos de contratação dos serviços (alterações contratuais; litígios; etc.)" - 181 organizações adotando-a ( $\mathrm{n=299)}$ - seguido pelas práticas "VP 20-5.2 - Controlo e fiscalizo as licenças de uso de programas disponibilizados e utilizados pelo fornecedor do serviço dentro da empresa." - 155 organizações; "VP23-6.1 - Realizo controles financeiros periódicos (dos valores que foram acordados contratualmente com o que foi efetivamente entregue pelo fornecedor do serviço.)" - 151 organizações; "VP19-5.1 - Acompanho e avalio a infraestrutura de equipamentos disponibilizados e utilizados pelo fornecedor do serviço dentro da empresa." - 145 organizações; e "VP11-3.2 - Acompanho a qualidade dos serviços executados pelo fornecedor do serviço." - 144 organizações.

A prática de gestão adotada excelentemente com maior frequência (VP4 1.4) vem ao encontro do resultado obtido com o grau de formalidade implantado, o que permite concluir que não basta realizar contratos formais detalhado com SLA, é necessário também que o gestor de TI mantenha o departamento jurídico ciente de toda e qualquer alteração do contrato firmado.

Cabe ressaltar que os controles referentes à infraestrutura (licenças de uso de programas e equipamentos), aos controles financeiros, bem como à qualidade do serviço - em função de que práticas inerentes a estes assuntos são obrigatórias para as partes envolvidas - são fatores determinantes à qualidade de uma parceria de terceirização de serviços de TI e podem afetar diretamente o resultado a ser obtido (MANSUR, 2009). 
Duas práticas obtiveram destaque por não serem adotadas: "VP12-3.3 - Utilizo metodologia para o desenvolvimento do projeto (exemplo: PMBok, Prince2 etc.) no desenvolvimento de SI sob medida e/ou terceirização da implantação de pacotes de SI.” - 163 organizações; e "VP29-7.2 - Utilizo sistemas de informações computadorizados como ferramentas de apoio à gestão da terceirização." - 155 organizações.

A falta de uso de metodologias para o desenvolvimento do projeto pode causar diversos problemas e dificuldades, como a ausência de padronização no processo de desenvolvimento, inviabilidade do planejamento de metas e prazos, ausência de etapas de especificação, entre outras (CORBETT, 2004). Desta forma, a não adoção de práticas ligadas à metodologia pode ter corroborado negativamente ao cumprimento dos prazos, e conforme apresentado nas análises, 202 organizações obtiveram pouco ou nenhum resultado.

Igualmente importante, é citar o fato de que as análises das práticas recomendadas nesta pesquisa resultaram na formação de 5 grupos distintos de práticas: trabalho tecnológico, desenvolvimento do fornecedor, monitoramento de serviços, operações de serviços e estratégias de serviços.

É preciso mencionar que destes grupos, três apresentaram alta comunalidade com o construto de ordem superior denominado "práticas recomendadas", um apresentou média comunalidade e apenas um grupo apresentou baixa comunalidade, sendo que todos os grupos demonstraram correlações significativas entre eles, conforme pode ser observado na tabela 30 deste estudo. A partir destes resultados, é possível afirmar que há indicação de uma variabilidade de uso de práticas na gestão da terceirização de serviços de TI e que, dentre os três modelos de GTI estudados, a adoção por algum destes, pode ter (para as organizações) suas particularidades e especificidades considerando o tipo de gestão e controle que se pretende implementar.

\section{Análise dos dados de resultados da terceirização de serviços de TI}

Em relação aos resultados obtidos, a partir das análises realizadas, os cinco resultados "obtidos completamente" com maior frequência foram: "VR14-4.3 - A empresa obteve melhoria na qualidade dos dados/informações oriundos do sistema terceirizado (desenvolvido ou implantado)?" - 205 organizações (68,6\%); "VR11-3.3 - A empresa obteve aumento da

produtividade dos usuários finais (capacidade de realização dos serviços executados) em 
função do sistema terceirizado (desenvolvido ou implantado)?" - 199 organizações (66,6\%); "VR12-4.1 - Após a disponibilização do sistema terceirizado (desenvolvido ou implantado), houve um salto de qualidade na realização das atividades-fim dos usuários finais?" - 192 organizações (64,2\%); "VR5-2.1 - Os valores "orçados" para o projeto do sistema terceirizado (desenvolvido ou implantado) foram "realizados" (cumpridos na integra) até a entrega final?" - 186 organizações (62,2\%); e "VR9-3.1 - Houve aumento na capacidade de processamento dos dados em função do sistema terceirizado (desenvolvido ou implantado)?" - 181 organizações $(60,5 \%)$.

Estas observações possibilitam inferir que os resultados "obtidos completamente" com maior frequência pelas organizações, estão associados à adoção de contratos formais detalhados com uso de SLA.

Já em relação ao resultado "nenhum resultado" com maior frequência de apontamento, 25 organizações $(8,4 \%)$ não conseguiram obtê-lo e 177 organizações $(59,2 \%)$ conseguiram pouco resultado em se tratando de: "VR6-2.2 - Os prazos 'estipulados' para o projeto do sistema terceirizado (desenvolvido ou implantado) foram 'cumpridos na íntegra' até a entrega final?".

Com base nestes dados, a pesquisa também evidenciou que o maior problema vinculado à terceirização de serviços de TI é o aspecto relacionado ao prazo de entrega. Redução de custos e custos realizados acima do previsto, apesar de não terem sido apontados pela maioria das organizações pesquisadas como itens de resultado que obtiveram "pouco ou nenhum resultado", foram mencionados por quase 10\%. Portanto, o gestor deve estar atento a tais aspectos. Um estudo realizado pela Dynamics em 2008 apontou que um em cada três projetos de TI não atinge as expectativas dos contratantes e que os problemas mais comuns citados pelos 800 gerentes plenos e seniores de grandes organizações de oito países incluem entrega fora do prazo (62\%), problemas no orçamento (49\%) e manutenção e custo acima da expectativa (47\%) (CIO, 2008). Vale ressaltar que é comum as organizações quererem realizar mudanças no projeto ao longo do contrato, pois mesmo que pareçam mínimas, estas alterações podem ocasionar grandes modificações no esquema do projeto, influenciando tanto em custo quanto em prazo para a entrega (MANSUR, 2009). 


\section{Resultados da relação entre adoção de práticas recomendadas de gestão de TI e seus resultados esperados}

A relação entre práticas recomendadas de gestão da terceirização de serviços de TI e seus resultados esperados foi estabelecida em função da análise confirmatória por meio da modelagem de equações estruturais, resultando em um índice de explicação de 11,7\%, conforme pode ser observado na ilustração 7, ou seja, o foco somente em "controle" realizado pelo gestor de TI com a adoção conjunta de 32 práticas recomendadas indicadas pelos modelos de GTI, apesar de positiva, traz poucas contribuições significativas para o resultado da terceirização de serviços de TI.

Este baixo índice reflete o fato de que as práticas recomendadas para gestão da terceirização são consideradas apenas como mecanismos de auditoria, fiscalização e controle. Overbeek, Roos e Lindgreen (2005, apud Kooper, Maes e Lindgreen, 2009), afirmam que em função dos modelos de GTI terem sido concebidos por auditores em vez de profissionais de TI ou profissionais de negócio, faz com que haja demasiadas reflexões técnicas. Kooper, Maes e Lindgreen (2009) e Beijer e Kooper (2010) afirmam ainda, que os atuais modelos de GTI estão centrados exclusivamente em controles e no fato de serem baseados em quadros operacionais. Portanto, podemos inferir que a adoção das práticas recomendadas são necessárias, mas não suficientes para uma boa gestão de serviços de terceirização de TI.

Isto leva-nos a refletir que outros aspectos devem ser considerados. Aspectos como o arranjo contratual com o fornecedor, o contexto organizacional, o mercado no qual a organização está inserida, a questão da cultura organizacional, a experiência em gerenciar o projeto de terceirização de TI, o envolvimento dos usuários finais, etc. podem contribuir para obtenção de um melhor resultado. Cabe ressaltar que o aspecto sobre usuário final pode ter uma importância maior uma vez que o mesmo entende que a terceirização possa ser um meio de alcançar os objetivos dos negócios, ou seja, estão associados com algum tipo de desempenho ou melhoria de seus sistemas ou processos de negócios. 


\section{LIMITAÇÕES E SUGESTÕES PARA ESTUDO FUTURO}

\subsection{Limitações}

As conclusões apresentadas neste estudo devem servir de reflexão para os gestores de TI a partir de algumas limitações. Em relação ao método, o mesmo possui limitações em função de vieses do pesquisador e dos respondentes. O fato de existir a pesquisa já interfere nas respostas, uma vez que o tema pode suscitar intenções e interesses nos respondentes antes nunca imaginados.

É importante mencionar que os fatores de resultados esperados ligados à satisfação dizem respeito às percepções obtidas pelo gestor de TI sobre a entrega do serviço e como tal, é necessário ponderar sobre este aspecto numa eventual avaliação do resultado.

Outra questão é a operacionalização. É preciso levar em conta possíveis erros: de especificação, que é a omissão de variáveis importantes na análise; de medida, que é a imprecisão na mensuração dos valores "reais" devido à má interpretação dos respondentes ou escalas inapropriadas; e estatísticos, pelo percentual de confiabilidade das técnicas. A amostra não probabilística não permite extrapolações ou inferências além da amostra do estudo.

Vale lembrar que os aspectos que compõem o quadro avaliativo não foram definidos e expostos com a intenção final de constituírem-se como definitivos e exclusivos. Considerando as devidas limitações da pesquisa, é possível concluir que as mesmas formam um conjunto de resultados fortemente ligados ao assunto terceirização de serviços de TI. Estas limitações abrem possibilidades para estudos futuros e maior compreensão do tema.

\subsection{Sugestões para estudos futuros}

Os resultados apresentados foram obtidos por meio de pesquisa quantitativa e como sugestão, poderia ser realizada uma pesquisa qualitativa nas organizações já pesquisadas a fim de subsidiar alterações no instrumento de pesquisa, de forma a aprimorar o entendimento, aumentando a sua confiabilidade. A partir disto, seria interessante aplicar o questionário em outras regiões do Brasil a fim de verificar possíveis diferenças. Outra sugestão é a realização 
de um estudo que mensure o relacionamento entre modelos de GTI - práticas recomendadas e o grau de alinhamento estratégico alcançado e também que investigue quais são os outros aspectos que influenciam no resultado esperado da terceirização de serviços de TI, uma vez que, tão somente, em termos de adoção conjunta de 32 práticas recomendadas, o resultado de explicação para os resultados esperados foi baixo $(11,7 \%)$.

Por fim, na medida em que a GTI corresponde aos objetivos e estratégias organizacionais, as relações e interações entre as áreas de negócios, organizações parceiras e órgãos reguladores tendem a uma maior efetividade quanto à gestão das informações e transparência corporativa. Por este motivo, estruturar os processos de TI, tendo por referência não só a adoção de práticas de gestão, é uma forma dessas organizações se prepararem para as exigências dos acionistas, do mercado e da legislação em termos de práticas de GTI, assegurando que a área de TI esteja alinhada aos objetivos de negócio e que essa relação gere oportunidades de controle, de valor estratégico e de competitividade. 


\section{REFERÊNCIAS}

ABREU, Marcelo Faoro de. Os riscos da terceirização da TI e da adoção de novas TIs e suas relações com os riscos para as estratégias competitivas das organizações. 2009. 215 f. Tese (Doutorado em Administração) - Universidade Federal do Rio Grande do Sul, Rio Grande do Sul, 2009.

AGRASSO NETO, Manoel.; ABREU, Aline França de. Tecnologia da informação: manual de sobrevivência da nova empresa. São Paulo: Arte \& Ciência, 2003.

ALBERTIN, Alberto Luiz; ALBERTIN, Rosa Maria de Moura. Benefícios do uso de tecnologia de informação para o desempenho empresarial. Revista de Administração Pública (RAP). Rio de Janeiro. FGV. n. 42(2), p. 275-302, mar./abr. 2008.

ALBERTIN, Alberto Luiz; SANCHEZ, Otávio Próspero. Outsourcing de TI: impactos, dilemas, discussões e casos reais. Rio de Janeiro: Editora FGV, 2008.

ALBORZ, Shawn; SEDDON, Peter. B.; SCHEEPERS, Rens. Impact of configuration on it outsourcing relationships. $10^{\text {th }}$ Americas Conference on Information Systems AMCIS 2004, New York, USA, p. 3551-3560, 2004.

ALMEIDA, Gilberto Wildberger de; MELLO, Ricardo Coutinho. Uso de novas tecnologias de informação por profissionais da área de saúde. Revista de Administração Contemporânea, Rio de Janeiro, v. 8, n. 3, p. 09-27, 2004.

APTE, Uday M.; SOBOL, Marion G.; HANAOKA, Sho; SHIMADA, Tatsumi; SAARINEN, Timo; SALMELA, Timo; VEPSALAINEN, Ari P. J. IS outsourcing practices in the USA, Japan, and Finland: a comparative study. Journal of Information Technology, n. 12(4), p. 289-304. 1997.

ARANHA, Francisco; ZAMBALDI, Felipe. Análise fatorial em administração. São Paulo: Cengage Learning, 2008.

ARAUJO, Luis César G. de. Tecnologias de gestão organizacional. São Paulo: Atlas, 2001.

ARNETT, Kirk. P.; JONES, Mary C. Firms that choose outsourcing: a profile. Information \& Management, v. 1, n. 4, p. 179-88, 1994.

ARRUDA, Carlos Alberto; ARAÚJO, Marina S. B.; RIOS, Juan Fernando; SILVEIRA, Flávio P. A relação entre crescimento econômico e competitividade: um estudo da capacidade de previsão do global competitiveness report. Revista de Administração e Contabilidade da Unisinos. Vol. 6, No. 4, 2009, p. 285-298. 2009.

ASL. ASL BiSL FOUNDATION. Application services library, adapted to the IT-services world of the future. 2009. Disponível em:

http://www.aslbislfoundation.org/content/view/11/15/lang,en/. Acesso em: 14 out. 2009.

ASM. Applied Scientific Methods. 2010. Disponível em: http://www.asmllc.org/bpo_portuguese.htm. Acesso em: 14 dez. 2010. 
AUBERT, Benoit A.; DUSSAULT, Sylvie; PATRY, Michel; RIVARD, Suzanne. Managing the risk of it outsourcing. In: Proceedings of the $32^{\text {th }}$ Hawaii International Conference on System Sciences, Hawaii, 1999.

AUBERT, Benoit A.; HOUDE, Jean-Francois; PATRY, Michel; RIVARD, Suzanne Characteristics of IT outsourcing contracts. In: Proceedings of the $36^{\text {th }}$ Hawaii International Conference on System Sciences, Hawaii. 2002.

AUBERT, Benoit A.; RIVARD, Suzanne; PATRY, Michel. A transaction cost model of IT outsourcing. Information \& Managment, September, p. 1-12, 2004.

AURÉLIO, Buarque de Holanda Ferreira. Médio dicionário Aurélio. Rio de Janeiro: Nova Fronteira, 1980.

AXELSSON, B Björn; WYNSTRA, Finn. Buying business services. Chichester, R.U.: Wiley. 2002.

BAHLI, Bouchaib; RIVARD, Suzanne. An assessment of information technology outsourcing risk. International Conference on Information Systems ICIS, New Orleans, USA, p. 575-580. 2001.

BAILEY, James E.; PEARSON, Sammy W. Development of a tool for measuring and analyzing computer user satisfaction. Management Science, v. 29, n. 6, p. 519-529, 1983.

BARDIN, Laurence. Análise de conteúdo. Lisboa: Edições 70, 1997.

BARTHÉLEMY, Jérôme. The hard and soft sides of IT outsourcing management. European Management Journal, v. 21, n. 5, outubro, p. 539-548, 2003.

BARTOLOMÉ, Antonio; ALIAGA, Francisco. El impacto de las nuevas tecnologias en educacion. 2005. Disponível em: http://www.uv.es/aliaga/curriculum/Aliaga\&Bartolome2005-borrador.pdf. Acesso em: 23 out. 2009.

BEAL, Adriana. Manual de tecnologia da informação. São Paulo: Vydia Tecnologia, 2002.

BEIJER, Peter; KOOPER, Michiel. Information governance: beyond risk and compliance. PrimaVera Working Paper Series. University of Amsterdam. PrimaVera Working Paper 2010-05, 2010.

BENTLER, Peter M.; CHOU, Chih-Ping. Practical issues in structural modeling, in LONG, S. J. (ed.). Common problems/proper solutions: avoiding error in quantitative research. Beverly Hill: Sage, p. 161-192, 1988.

BERGAMASCHI, Sidnei. Modelos de gestão da terceirização de tecnologia de informação: um estudo exploratório. 2004. 197 f. Tese (Doutorado em Administração) Faculdade de Economia, Administração e Contabilidade, Universidade de São Paulo, São Paulo, 2004.

BERNSTORFF, Vitor Hugo; CUNHA, João Carlos da. O que as organizações buscam e alcançam com a terceirização da tecnologia da informação. In: XXIII Encontro Anual da ANPAD, 1999, Foz do Iguaçu PR ANAIS. ANPAD, 1999. 
BHATTACHARYA, Somnath; BEHARA Ravi S.; GUNDERSEN, David E. Business risk perspective on information systems outsourcing. Internacional Journal of Accounting Information Systems, 4, p. 75-93, 2003.

BIDO, Diógenes de Souza. Introdução à modelagem em equações estruturais. 2010. Disponível em: http://groups.google.com.br/group/mee-pls?hl=pt-br. Acesso em: 08 abr. 2010.

BILICH, Feruccio; SILVA, Ricardo da; RAMOS, Paulo. Análise de flexibilidade em economia da informação: modelagem de equações estruturais. Journal of Information Systems and Technology Management. Vol. 3, No. 2, 2006, p. 93-122. 2006.

BLANCO, Elías; SILVA, Bento Duarte da. Tecnologia educativa em Portugal: conceitos, origens, evolução, áreas de investigação e investigação. Revista Portuguesa de Educação. v. 6, n. 3, p. 37-55, 1993.

BON, Jan Van.; VERHEIJEN, Tieneke. Frameworks for IT management: an introduction. ITSMF. The IT Service management Forum. Van Haren Publishing. 2006.

BRAGA, Ataíde. Gerenciamento e desenvolvimento de fornecedores. 2009. Disponível em: http://www.ilos.com.br/site/index.php?option=com_content\&task=view\&id=734\&Itemid=22 5. Acesso em: 07 out. 2009.

BRAGG, Steven. M. Outsourcing: a guide to...selecting the correct business unit...negotiating the contract...maintaining control of the process. John Wiley \& Sons, Inc. Hoboken, New Jersey. 2006.

BRYMAM, Alan; CRAMER, Duncan. Análise de dados em ciências sociais: introdução as técnicas utilizando o SPSS. Oeiras. Celta Editora. 1992.

BROWN, Willian C. IT governance, architectural competency, and the Vasa. Information Management \& Computer Security, v. 14, n. 2, p. 140-154, 2006.

BROWN, Shona. L.; EISENHARDT, Kathleen M. Competing on the edge: strategy as structured chaos. Harvard Business School Press. 1997.

BROWN, Allen; GRANT, Gerald G. Framing the frameworks: a review of IT governance research. Communications of the Association for Information Systems, v. 15, p. 696-712, 2005 .

BSI. British Standards Institution. 2009. Disponível em:

http://www.bsigroup.com/en/Standards-and-Publications/. Acesso em: 16 out. 2009.

CABERO, Julio Almenara. Nuevas tecnologias, comunicacion y educacion. 1996. Disponível em: http://www.uib.es/depart/gte/revelec1.html. Acesso em: 07 out. 2008.

CALDER, Alan. IT governance: data security and BS 7799/ ISO 1779. Hardcover. Kogan Page. 2002.

CAMPANA, Angela Nogueira Neves Betanho; TAVARES, Maria da Consolação Gomes Cunha Fernandes; SILVA, Dirceu da. Modelagem de equações estruturais: apresentação de uma abordagem estatística multivariada para pesquisas em educação física. Motri. [online]. 
dez. 2009, vol.5, no.4, p.59-80. Disponível em: http://www.scielo.oces.mctes.pt/scielo.php?script=sci_arttext\&pid=S1646107X2009000400006\&lng=pt\&nrm=iso. Acesso em: 12 out. 2010.

CAMPOS FILHO, Maurício Prates de. Os sistemas de informação e as modernas tendências da tecnologia e dos negócios. Revista de Administração de Empresas, São Paulo, v. 34. n. 6. p. 33-45 nov./dez. 1994.

CANTÓN, Edméa Pujol. Governança de TI nas instituições financeiras no Brasil: uma avaliação detendências. 2008. 176 f. Dissertação (Mestrado em Administração) - Centro Estadual de Educação Tecnológica Paula Souza, São Paulo, 2008.

CARLSON, Walter M.; McNURLIN, Barbara C. Measuring the value of information systems: I/S analyzer special report. Technical Report. United Communications Group, Bethesda, MD, USA. 1989.

CARTLIDGE, Alison; HANNA, Ashley; RUDD, Colin; MACFARLANE, Ivor; WINDEBANK, John; RANCE, Stuart. Information technology infrastructure library (ITIL) V3. The UK Chapter of the itSMF. IT Service Management. 2007.

CARTWRIGHT, Roger I. Key concepts in information and communication technology. Palgrave Macmillan. 2005.

CARVALHO. Antonio Gledson de. Governança corporativa no Brasil em perspectiva. Revista de Administração. São Paulo: USP, v. 37, n. 3, jul./set. 2002.

CAVALCANTI, André Marques; CAVALCANTI FILHO, André Marques; LIMA, Telma Lúcia de Andrade. Modelo de gerenciamento de contratos de outsourcing baseados em SLA e prestação de serviços. XXVII Encontro Nacional de Engenharia da Produção. 2007.

CERVO, Amado L.; BERVIAN, Pedro A. Metodologia científica. 5. ed. São Paulo: Pearson Prentice Hall, 2002.

CHIESA, Vittorio. Global R\&D project management and organization: a taxonomy. Journal of Product Innovation Management, Vol. 17, n. 5, p. 341-59, 2000.

CHIN, Wynne W. The partial least squares approach to structural equation modeling. In: Marcoulides, G. A. (Ed.). Modern methods for business research. USA: Lawrence Erlbaum Associates, p. 295-336, 1998.

CHIN, Pauline O.; BROWN, George A.; HU, Qing. The impact of mergers \& acquisitions on IT governance structures: a case study. Journal of Global Information Management, v. 12, n. 4 , p. 50-74, 2004.

CHOU, David C.; CHOU, Amy Y. Information systems outsourcing life cycle and risks analysis. Computer Standards \& Interfaces [serial online]. V. 31(5), p.1036-1043. September 2009 
CIO. TI vive crise de confiança. 2008. Disponível em: http://cio.uol.com.br/gestao/2008/03/13/ti-vive-crise-de-confianca/. Acesso em: 12 dez. 2010.

CLARK, Thomas D.; ZMUD, Robert W.; McCRAY, Gordon E. The outsourcing of information services: transforming the nature of business in the information industry. Journal of Information Technology. p. 221-237. 1995.

COHEN, Sheldon. Psychological models of social support in the etiology of physical disease. Health Psychology, v. 7, p. 269-297. 1988.

COHEN, Linda; YOUNG, Allie. Multisourcing: moving beyond outsourcing to achieve growth and agility. Boston: Harvard Business School Press, 2006.

COLLINS, J. Stephanie; MILLEN, Robert A. Information systems outsourcing by large American industrial firms: choices and impacts. Information Resources Management Journal, v. 8, n.1, p.5-13. 1995.

COMPUTERWORD. Pesquisa diz que 66\% das empresas já adotaram ITIL. 2008. Disponível em: < http://computerworld.uol.com.br/gestao/2008/04/24/pesquisa-diz-que-66-das-empresasja-adotaram-itil/>. Acesso em: 12 dez. 2010.

COOPER, Ronald D.; SCHINDLER, Pamela S. Método de pesquisa em administração. 7. ed. São Paulo: Bookman, 2003

COPC-2000. COPC performance management system. Norma Básica COPC-2000. PSCI Versão 3.3. 2003.

CORBETT, Michael F. The outsourcing revolution: why it makes sense and how to do it right. Deaborn Trade Publishing, 2004.

Outsourcing facts. 2010. International Association of Outsourcing Professionals. Disponível em: http://www.outsourcingprofessional.org/content/23/196/1683/. Acesso em: 30 mar. 2010.

CRISTOFOLI, Fulvio; PRADO, Edmir Parada Vasques. Sourcing de serviços de TIC: um estudo longitudinal do setor industrial brasileiro. In: SIMPOI 2009, Sao Paulo. Anais do SIMPOI 2009, 2009. Disponível em:

< http://www.simpoi.fgvsp.br/arquivo/2009/artigos/E2009_T00438_PCN68728.pdf>. Acesso em: 08 out. 2010.

CRISTOFOLI, Fulvio; PRADO, Edmir Parada Vasques; TAKAOKA, Hiroo. Sourcing de serviços de TI: um estudo de caso do setor automobilístico brasileiro. XI SemeAd: Seminários em Administração FEA/USP. 2008.

CRUZ, Tadeu. Sistemas de informações gerencias: tecnologia da informação e a empresa do século XXI. São Paulo: Atlas, 1998.

CUGANESAN, Suresh; ROONEY, Jim; SILVI, Riccardo. Contractual and accounting controls in outsourcing agreements. Journal of Law and Financial Management. p. 8-17. 2006. 
DAVENPORT, Thomas H. Reengenharia de processos. Rio de Janeiro: Campus, 1994.

Ecologia da informação. São Paulo: Futura, 2000.

DAVIS, Kevin J. IT outsourcing relationships: an exploratory study of interorganizational control mechanism. In: Graduate School of Business Administration, Harvard University, Cambridge, MA, p. 310. 1996.

DE HAES, Steven; VAN GREMBERGEN, Wim. IT governance structures, processes and relational mechanisms: achieving IT/business alignment in a major Belgian financial group. Proceedings of the $38^{\text {th }}$ Hawaii International Conference on System Sciences, Hawaii, p. 1832. 2005

Information technology governance best practices in Belgian organisations. Proceedings of the $39^{\text {th }}$ Hawaii International Conference on System Sciences, Hawaii, p. 1427. 2006.

DEKLEVA, Sasha M. CFOs, CIOs and outsourcing. Computerworld, Vol. 28, n. 20, p. 96. 1994.

DELONE, William H.; McLEAN, Ephrain R. Information Systems Success: The quest for the dependent variable. Management Science, March, p.60-95. 1992.

DE TONI, Alberto; NASSIMBENI, Guido. Just-in-time purchasing: am empirical study of operational practices, supplier development and performance. Omega, v.28, n.6, p.631 -651, 2000.

DIBBERN, Jens; GOLES, Tim; HIRSCHHEIM, Rudy; BANDULA, Jayatilaka. Information systems outsourcing: a survey and analysis of the literature. Database for Advances in Information Systems, v. 34, n. 4. 2004.

DIROMUALDO, Anthony; GURBAXANI, Vijay. Strategic intent for IT outsourcing. Sloan Management Review. v. 39, n. 4, p.1-26. 1998.

DUTRA, Joel Souza. Gestão por competência. São Paulo: Atlas, 2003.

EARL, Michael J.; FEENY, David F. Is your cio adding value? Sloan Management Review, v.35, n.3, p.11-20, Spring 1994.

EFQM. European foundation of quality management. 2009. Disponível em: http://www.efqm.org. Acesso em: 04 nov. 2009.

FAVERO, Luiz Paulo; BELFIORE, Patrícia; SILVA, Fabiana Lopes da; CHAN, Betty Lilian. Análise de dados: modelagem multivariada para tomada de decisões. Rio de Janeiro: Elsevier, 2009.

FEENY, David F.; WILLCOCKS, Leslie P. Core IS capabilities for exploiting information technology. Sloan Management Review, Vol. 39, n..3, p. 9-21. 1998.

FERNANDES, Aguinaldo Aragon; ABREU, Vladimir Ferraz de. Implantando a governança de TI: da estratégia à gestão dos processos e serviços. Rio de Janeiro: Brasport, 2006. 
Implantando a governança de TI: da estratégia à gestão dos processos e serviços. 2. ed. Rio de Janeiro: Brasport, 2008.

FERNANDES, Aguinaldo Aragon; ALVES, Murilo Maia. Gerência estratégica da tecnologia da informação: obtendo vantagens competitivas. Rio de Janeiro: LTC - Livros Técnicos e Científicos. 1992.

FERREIRA, André Machado Dias; LAURINDO, Fernando José Barbin. O papel da tecnologia da informação (TI) e a influência dos processos de aprendizado e de geração de conhecimento: um estudo de caso em uma empresa do setor elétrico brasileiro. Revista Produto \& Produção, v. 9, n. 1, p. 54-75, 2008.

FINNEY, Sara Jane; DI STEFANO, Christine. Nonnormal and categorical data in structural equation models. In G.R. Hancock \& R.O. Mueller (Eds.). A second course in structural equation modeling (p. 269-314). Greenwich, 2006.

FORRESTER Research. Topic overview: outsourcing. Disponível em: http://www.forrester.com/Research/Document/Excerpt/0,7211,45576,00.html. Acesso em: 17 set. 2009.

GALLIERS, Robert D. Information systems and culture: applying 'stages of growth' concepts to development administration. Information Technology for Development. v. 8, n. 2, p. 89$100,1998$.

GALLIERS, Robert D.; SUTHERLAND, A. Information systems management and strategy formulation: the 'stages of growth' model revisited. In: Journal of Information Systems, v. 1, n. 2, p. 89-94. 1991.

GARTNER. Market trends: IT services. 2010. Gartner Group. Gartner INC. Disponível em : http://gartnergroup.com/DisplayDocument?id=838918\&ref=g_sitelink e http://www.theregister.co.uk/2005/05/27/_gartner_outsourcing/. Acesso em: 09 dez. 2010.

GARVER, Michael S.; MENTZER John T. Logistics research methods: Employing structural equation modelling to test for construct validity. Journal of Business Logistics, 20, p. 33-57. 1999.

GEFEN, David; STRAUB, Detmar W.; BOUDREAU, Marie-Claude. C. Structural equation modeling and regression: guidelines for research practice. Commun AIS, 4, p. 177. 2000.

GELLINGS, Cornelia. Outsourcing relationships: the contract as IT governance tool. Proceedings of the $40^{\text {th }}$ Hawaii International Conference on System Sciences, Hawaii, 2007.

GIBSON, James L.; IVANCEVICH, John M.; DONNELLY Jr., James H. Organizações: comportamento, estruturas, processos. São Paulo: Atlas, 1988.

GISBERT, Mercé; GONZÁLEZ, Angel Pio; JIMÉNEZ, Bonifacio; RALLO, Robert. Las nuevas tecnologias en la education. Disponível em: http://www.uib.es/depart/gte/grurehidi.html. Acesso em: 26 nov. 2009. 
GONÇALVES, José Ernesto Lima. Os impactos das novas tecnologias nas empresas prestadoras de serviços. Revista de Administração de Empresas, São Paulo, v. 1, n. 34, p. 63-81, jan./fev. 1994.

GOO, Jahyun; KISHORE, Rajiv; RAO, Raghav. Management of information technology outsourcing relationships: the role of service level agreements. International Conference on Information Systems ICIS, Washington, D.C., USA, p. 325-338. 2004.

GORLA, Narasimhaiah; LAU, Mei Bik. Will negative experiences impact future IT outsourcing? Journal of Computer Information Systems. Spring 2010.

GOTTFREDSON, Mark; PURYEAR, Rudy; PHILLIPS, Stephen. Strategic sourcing: from periphery to the core. Harvard Business Review, February, p. 132-9. 2005.

GREAVER II, Maurice. F. Strategic outsourcing. New York: AMA, 1999.

GREGIO, André Ricardo Abed; DUARTE, Luiz Otávio; MONTES, Antonio; BARBATO, Luiz Gustavo C.; HOEPERS, Cristine; STEDING-JESSEN, Klaus. Um estudo sobre taxonomias de vulnerabilidades. V Workshop dos Cursos de Computação Aplicada do INPE. 2005.2 Disponível em: http://mtcm18.sid.inpe.br/col/dpi.inpe.br/hermes2@1905/2005/10.04.04.11/doc/worcap-taxvulnerabilidades.pdf. Acesso em: 14 dez. 2009.

GRÖNROOS, Christian. Service management and marketing: customer management in service competition. 3. ed., John Wiley \& Sons Ltd, The Atrium, Southern Gate, Chichester, Inglaterra. 2007.

GROVER, Varun; CHEON, Myun Joong; TENG, James T. C. The effect of service quality and partnership on the outsourcing of information systems functions. Journal of Management Information Systems, Armonk, v. 12, n. 4, p. 89-116, Spring 1996.

HANDFIELD, Robert B.; KRAUSE, Daniel R.; SCANNELL, Thomas V.; MONCZKA, Robert M. Avoid the pitfalls in supplier development. Sloan Management Review, v.41, n.2, p.37-49, 2000.

HAIR JR., Joseph F.; BLACK, William C.; BABIN, Barry J.; ANDERSON, Rolph E.; TATHAM Ronald L.; Análise multivariada de dados. 6. ed. Porto Alegre: Bookman, 2009.

HAIR JR., Joseph F.; BABIN, Barry; MONEY, Arthur H.; SAMOUEL, Phillip. Fundamentos de métodos de pesquisa em administração. 7. Reimp. Porto Alegre: Bookman, 2005. Reimp. 2007.

HARDY, Gary. Using IT governance and COBIT to deliver value with IT and respond to legal, regulatory and compliance challenges. Information Security Technical Report. Elsevier, p. 55-61, March 2006.

HEFLEY, William E.; LOESCHE, Ethel A. The eSCM-CL v1.1 - part 1: the esourcing capability model for cliente organizations (eSCM-CL) v1.1 - model overview. Information Technology Services Qualification Center, Carnegie Mellon University, Pittsburgh. 2006.

HENDERSON, John C. Plugging into strategic partnerships: the critical IS connection. Sloan Management Review. v. 31, n. 3, p. 7 - 18. 1990. 
HITT, Lorin; BRYNJOLFSSON, Erik. Productivity, business profitability and consumer surplus: tree different measures of information technology value. MIS Quarterly. V. 20, n. 2, p. 121-142. 1996.

HSU, Chin-Chia; WU, Chih-Hung. The evaluation of the outsourcing of information systems: a survey of large nterprises. International Journal of Management. v. 23, n. 4, p. 817-830. December, 2006.

HYDER, Elaine B.; PAULK, Mark C.; HESTON, Keith M.; HEFLEY, Bill. The esourcing capability model for service providers (ESCM-SP): practice details. v. 2, n. 01. Pittsburg, PA: Carnegie Mellow University, 2006.

IAOP. International Association of Outsourcing Professional. 2010. Disponível em: http://www.outsourcingprofessional.org. Acesso em: 25 fev. 2010.

IBGC. Instituto Brasileiro de Governança Corporativa. 2009. Disponível em: http://www.ibgc.org.br/Home.aspx. Acesso em: 12 nov. 2009.

IBGE. Instituto Brasileiro de Geografia e Estatística. 2010. Disponível em: http://www.ibge.gov.br/home/. Acesso em: 10 jan. 2010.

IDC. International Data Corporation. Racionalização de custos impulsiona crescimento de outsourcing de TI. 2009. Disponível em: http://www.portalidc.com/?no=101000059:112008. Acesso em: 07 out. 2009.

- IDC Brazil IT Services Tracker. 2010. Disponível em: http://www.idclatin.com/about_idc.asp?ctr=bra. Acesso em: 18 jan. 2010.

IKENAGA, Cristiane Yayoko. Gestão da terceirização de serviços em TI: um estudo de caso. 2008. 135 f. Dissertação (Mestrado em Administração) - Centro Estadual de Educação Tecnológica Paula Souza, São Paulo, 2008.

IPMA. International Project Management Association. 2010. Disponível em: www.ipma.ch. Acesso em: 22 jan. 2010.

IPQ. Instituto Português de Qualidade. 2009. Disponível em: http://www.ipq.pt/custompage.aspx?modid=1296. Acesso em: 22 nov. 2009.

ISO. International Organization for Standardization. 2009. Disponível em: http://www.iso.org/iso/iso_catalogue.htm. Acesso em: 14 out. 2009.

ISACA. Information Systems Audit and Control Association. 2009. Disponível em: http://www.isaca.org/. Acesso em: 10 set. 2009.

ISACF. Information Systems Audit and Control Foundation. 2009. Disponível em: http://www.isaca.org. Acesso em: 10 set. 2009.

ISPL. The Information Services Procurement Library. 2009. Disponível em: http://projekte.fast.de/ISPL/. Acesso em: 21 dez. 2009.

ITGI. Framework control objectives management guidelines maturity models (CobIT 4.1). IT Governance Institute. 2007. 
About IT governance. IT Governance Institute. 2009. Disponível em: http://www.itgi.org/template_ITGI.cfm?Section=About_IT_Governance1\&Template=/Conte ntManagement/HTMLDisplay.cfm\&ContentID=19657. Acesso em: 30 set. 2009.

ITSMF. The IT Service Management Forum. 2009. Disponível em: http://www. http://www.itsmfi.org. Acesso em: 22 out. 2009.

JARVIS, Cheryl Burke; MACKENZIE, Scott B.; PODSAKOFF, Philip M. A critical review of construct indicators and measurement model misspecification in marketing and consumer research. Journal of Consumer Research, v.30, n.2, p.199-218, Set. 2003.

JENSEN, Michael C.; MECKLING, William H. Theory of the firm: managerial behavior, agency costs and ownership structure. Journal of Financial Economics, United States, v.3, n.4, p.305-360, oct. 1976.

JOHNSTON, Robert; CLARK, Grahan. Administração de operações de serviço. 1. ed. São Paulo: Atlas, 2002.

KALAKOTA, Ravi; ROBINSON, Marcia. e-Business: estratégias para alcançar o sucesso no mundo digital. Porto Alegre: Bookman, 2002.

KAPLAN, Robert S.; NORTON, David P. A estratégia em ação: balanced scorecard. 18. ed. Rio de Janeiro: Elsevier, 1997.

KERLINGER, Fred N. Metodologia da pesquisa em ciências sociais: um tratamento conceitual. São Paulo: EPU, 1979.

KERN, Thomas. The gestalt of an information technology outsourcing relationship: an exploratory analysis. International Conference on Information Systems ICIS, Atlanta, USA, p. 37-58. 1997.

KERN, Thomas; WILLCOCKS, Leslie P. Contracts, control and presentation in IT outsourcing: research in thirteen UK organizations. Journal of Global Information Management. Oct./dec., p. 15-29. 2000.

KLEPPER, Robert. The management of partnering development in i/s outsourcing. Journal of Information Technology. v. 10, p. 249-258. 1995.

KLEPPER, Robert; JONES, Wendell. Outsourcing information technology, systems \& services. New Jersey: Prentice-Hall, 1998.

KLERING, Luis Roque. Relação entre estágios de informatização e padrões de comportamento administrativo. In: Encontro Anual da Associação Nacional dos Programas de Pós Graduação em Administração - ENANPAD, 21. Rio das Pedras. Curitiba: ANPAD. p. 148-159. 1997.

KOOPER, Michiel; MAES, Rik; LINDGREEN, Edo Roos. Information governance: in search of the forgotten grail. PrimaVera Working Paper Series. University of Amsterdam. PrimaVera Working Paper 2009-02. 2009. 
KPMG. Global IT Project Management Survey: How committed are you? 2005. Disponível em: http://www.kpmg.com.au/Portals/0/irmpmqa-global-it-pm-survey2005.pdf. Acesso em: 22 nov. 2010.

KRAUSE, Daniel R. The antecedents of buying firm's efforts to improve suppliers. Journal of Operations Management, V.17, n. 2, p.205-224, 1999.

KUCHENBECKER, Norberto Fernando. O processo de terceirização e de qualificação de fornecedores. 2006. 265 f. Tese (Doutorado em Engenharia de Produção) - Universidade Federal de Santa Catarina, Florianópolis, 2006.

KUO, Chien-Hung. A Model of IS performance evaluation: an organization perspective. Information and Organization, v. 13, n. 3, p.153-202. 1996.

LAKATOS, Eva Maria; MARCONI, Marina de Andrade. Fundamentos de metodologia científica. 6. ed. - 4. reimpr. São Paulo: Atlas, 2007.

LACITY, Mary C.; HIRSCHHEIM, Rudy. The information systems outsourcing bandwagon. Sloan Management Review (Fall), p. 73-86. 1993.

LACITY, Mary C.; WILLCOCKS, Leslie P. An empirical investigation of information technology sourcing practices: lessons from experience," MIS Quarterly (September), p. 363-408. 1998.

Inside information technology outsourcing: a state-of-the-art report. Templeton Research, Templeton College, Oxford, 2000.

. Global information technology outsourcing: in search of business advantage. Chichester: John Wiley \& Sons, 2001.

LACITY, Mary C.; WILLCOCKS, Leslie P.; FEENY, David F. The value of selective IT sourcing. Sloan Management Review. v.37, p. 13-25 Spr, 1996.

LARSEN, Michael Holm; PEDERSEN, Mogens Kuhn; ANDERSEN, Kim Viborg. IT governance: reviewing 17 IT governance tools and analysing the case of novozymes A/S. Proceedings of the $39^{\text {th }}$ Hawaii International Conference on System Sciences, Hawaii, 2006.

LAUDON, Kenneth C; LAUDON, Jane P. Management information systems: managing the digital firm \& multimedia student. 10. ed. Prentice Hall, 2007.

LEE, Matthew K. O. IT outsourcing contracts: practical issues for management. Industrial Management \& Data Systems, v. 96, n. 1, p. 15-20. 1996.

LEE, Jae-Nam; KIM, Young-Gul. Effects of partnership quality on is outsourcing success: conceptual framework and empirical validation. Journal of Management Information Systems. v. 15, n. 4, Spring, p. 29-61. 1999.

LEITE, Jaci Correa. Terceirização em informática. São Paulo: Makron Books, 1995.

LEWIS, Lundy. Service level management for enterprise networks. Artech House, 1999. 
LIAO, Ying; LIAO, Kun; HUTCHINSON, Robert. A conceptual framework for prototyping outsourcing in new product development: a knowledge-based view. Journal of Manufacturing Technology Management, Vol. 21 Iss: 1, p.122 - 138. 2009.

$\mathrm{LOH}$, Lawrence. The economics and organizational of information technology governance: sourcing strategies for corporate information infrastructure. Massachusetts, 1993. Tese (Doutorado em Administração) - Alfred P. Sloan School, Massachusetts Institute of Technology, MIT. Disponível em: < http://hdl.handle.net/1721.1/12545>. Acesso em: 25 mar. 2009.

LODI, João Bosco. Governança corporativa: o governo da empresa e o conselho de administração. Rio de Janeiro: Campus, 2000.

LOHMÖLLER, Jan-Bernd. Latent variable path modeling with partial least squares. Heidelberger: Physica-Verlag, 1989.

LUNARDI, Guilherme Lerch. Um estudo empírico e analítico do impacto da governança de TI no desempenho organizacional. 2008. $201 \mathrm{f}$. Tese (Doutorado em Administração) Universidade Federal do Rio Grande do Sul, Rio Grande do Sul, 2008.

LÜNENDONK GMBH. Strategic data research - Strategic roadmap requirements strategic transformation services. 2009. Disponível em: http://www.luenendonk.de/engl_presse.php. Acesso em: 25 mar. 2009.

MAES, Rik. Reconsidering information management through a generic framework. Universiteit of Amsterdam. PrimaVera Working Paper. p. 99-115, 1999.

MAISEL, Lawrence. The balanced scorecard approach. Journal of Cost Management, Summer, p.75-85. 1992.

MAIZLISH, Bryan; HANDLER, Robert. IT portfolio management: step by step. New Jersey: John Wiley \& Sons, 2005.

MALHOTRA, Naresh K. Pesquisa de marketing: uma orientação aplicada. Porto Alegre: Bookman, 2001.

MANCINI, Lucas. Call center: estratégia para vencer. São Paulo: Summus Editorial, 2006.

MANSUR, Ricardo. Governança de TI: metodologias, frameworks e melhores práticas. Rio de Janeiro: Brasport, 2007.

Governança avançada de TI: na prática. Rio de Janeiro: Brasport, 2009.

MARTINS, Alaíde Barbosa; SANTOS, Celso Alberto Saibel. Uma metodologia para implantação de um sistema de gestão da segurança da informação. Journal of Information Systems and Technology Management. v. 2, n. 2, p. 121-136. 2005.

MATTAR, Fauze Najib. Pesquisa de marketing, 5. ed. São Paulo: Atlas, 1999.

MCFARLAN, F. Warren; McKENNEY, James L; PYBURN, Philip. The information archipelago-plotting a course. Harvard Business Review. v. 61, n. 1, p. 145-156, jan./feb. 1983. 
MCFARLAN, F. Warren; NOLAN, Richard L. How to manage on IT outsourcing alliance. Sloan Manegment Review. Winter, v. 36, n. 02, p. 09-23, 1995.

MINGAY, Simon; BITTINGER, Steve. Combine CobiT and ITIL for powerful IT governance. In Research Note, TG-16-1849, Gartner, 2002. Disponível em: <http://www.gartner.com/DisplayDocument?doc_cd=107369>. Acesso em: 04 out. 2009.

MINGOTI, Sueli Aparecida. Análise de dados através de métodos de estatística multivariada: uma abordagem aplicada. Belo Horizonte: Editora UFMG, 2005.

MORAES, Emerson augusto Priamo; MARIANO, Sandra R. Holanda. Uma revisão dos modelos de gestão em TI. In: IV Congresso Nacional de Excelência em Gestão, 2008.

MURRAY, Janet Y.; KOTABE, Masaaki. Sourcing strategies of US service companies: a modified transaction-cost analysis. Strategic Management Journal, v. 20, n. 9, p. 791-809, 1999.

MUSSON, David; JORDAN, Ernest. The benefits of IT governance. European Conference on Information Systems (ECIS). 2006. Disponível em: < http://is2.lse.ac.uk/asp/aspecis/20060041.pdf>. Acesso em: 20 nov. 2010.

NOLAN, Richard L. Managing de computer resource: a stage hypotesis. In: Communications of de ACM, v. 16, n. 7, p. 399-405, 1973.

Managing the crises in data processing. In: Harvard Business Review, v. 57, n. 2, p. 115-126, 1979.

OGC. Office of Government Commerce. 2009. Disponível em: http://www.ogc.gov.uk/. Acesso em: 19 dez. 2009.

OI. Outsourcing 2.0. 2006. The Outsourcing Institute. Disponível em: http://www.outsourcing.com/pdf_files/06-40XX_OutsourcingSpread_10-23_DJ1.pdf. Acesso em: 18 ago. 2009.

OLIVEIRA, Antonio Carlos Manfredini da Cunha. Tecnologia de informação: competitividade e políticas públicas. Revista de Administração de Empresas, São Paulo, v. 36, n. 2, p. 34-43, abr./jun, 1996.

OUD, Ernst Jan. The value to IT of using international standards. Information Systems Audit and Control Association. Information Systems control Journal, v. 3, 2005.

PASQUALI, Luiz. Instrumentos psicológicos: manual prático de elaboração. Brasília: LabPAM/IBAPP, 1999.

Análise fatorial para pesquisadores. Brasília: LabPam \& UnB, 2005.

PELANDA, Maurício L. Modelos de governança de tecnologia da informação adotados no Brasil: um estudo de casos múltiplos. 2006. 147f. Dissertação (Mestrado em Administração) - Universidade Metodista de São Paulo, São Paulo, 2006. 
PEREZ, Gilberto. Avaliação e escolha de fornecedores de serviços de TI: um estudo de casos múltiplos. 2003. 202 f. Dissertação (Mestrado em Administração) - Faculdade de Economia, Administração e Contabilidade, Universidade de São Paulo, São Paulo, 2003.

PETERSON, Ryan. Crafting information technology governance. Information Systems Management, v. 21, n. 4, p. 7-22, 2004.

PFEFFER, Jeffrey; SALANCIK, Gerald R., The external control of organizations: a resource dependence perspective. New York: Harper \& Row, 1978.

PMI. Project Management Institute. 2009. Disponível em: http://www.pmi.org/Pages/default.aspx. Acesso em 20 dez. 2009.

POPOO, Laura; LACITY, Mary C. The normative value of transaction cost economics: what manager have learned about TCE principles in the IT context. In HIRSCHHEIM, R; ARMIN, H.; DIBBERN, J. Information Systems Outsourcing: enduring themes, emergent patterns and future decisions. Berlin: Spring-Berlag, 2002.

POWER, Mark J.; DESOUZA, Kevin C.; BONIFAZI, Carlo. The outsourcing handbook: how to implement a succssful outsourcing process. London and Philadelphia: Kogan Page, 2006.

PRADO, Edmir Parada Vasques. Tecnologia de informação e sistemas: uma avaliação da terceirização de serviços em organizações do setor privado. 2005. $223 \mathrm{f}$. Tese (Doutorado em Administração) - Faculdade de Economia, Administração e Contabilidade. Universidade de São Paulo, São Paulo, 2005.

Análise de risco na terceirização da tecnologia de informação e comunicação. In: $2^{\circ}$ Encontro Nacional de Administração da Informação. Anais do $2^{\circ}$ Encontro Nacional de Administração da Informação, Recife, 2009.

PRADO, Edmir Parada Vasques; TAKAOKA, Hiroo. Arranjos contratuais na terceirização de serviços de TI em organizações do setor privado. In: Encontro Anual da Associação Nacional dos Programas de Pós Graduação em Administração - ENANPAD, 2006.

- Terceirização de serviços de tecnologia de informação em organizações brasileiras. REGE-USP , São Paulo, v. 15, n. 2, 2008 . Disponível em: http://www.revistasusp.sibi.usp.br/scielo.php?script=sci_arttext\&pid=S1809-

22762008000200008\&lng=pt\&nrm=iso. Acesso em: 29 Set 2010.

PRATES, Gláucia Aparecida; OSPINA, Marco Túlio. Tecnologia da informação em pequenas empresas: fatores de êxito, restrições e benefícios. Revista de Administração Contemporânea, Rio de Janeiro, v. 8, n. 2, p. 09-26, abr./jun, 2004.

RABELO, Flavio; SILVEIRA, José Maria da. Estruturas de governança e governança corporativa: avançando na direção da integração entre as dimensões competitivas e financeiras. IE/UNICAMP, Campinas, 1999. Disponível em: < http://www.eco.unicamp.br/Downloads/Publicacoes/TextosDiscussao/texto77.pdf $>$. Acesso em: 02 out. 2009.

RAU, Kenneth G. Effective governance of IT: design objectives, roles and relationships. Information Systems Management, v. 21, n. 4, p. 35-42, 2004. 
REINHARD, Nicolau. Evolução das ênfases gerenciais e de pesquisa na área de tecnologia de informática e de comunicação aplicada nas empresas. Revista de Administração, São Paulo, v. 31, n. 4, p. 5-6, out./dez, 1996.

REISE, Steven P.; WALLER, Niels G.; COMREY, Andrew L. Factor analysis and scale revision. Psychological Assessment, v. 12, pp. 287-297. 2000.

REPONEN, Tapio. Outsourcing or insourcing. In: Proceedings of the 14th International Conference on Information Systems. Orlando, Florida, pp. 103-116. 1993.

REZENDE, Denis Alcides; ABREU, Aline França de. Tecnologia da informação: aplicada a sistemas de informações empresariais. 3. ed. São Paulo: Atlas, 2003.

RICHARDSON, Roberto Jarry. Pesquisa social: métodos e técnicas. 3. ed. São Paulo: Atlas, 1999.

RIDLEY, Gail; YOUNG, Judy; CARROLL, Peter. COBIT and its utilization: a framework from the literature. Proceedings of the 37th Hawaii International Conference on System Sciences, 2004.

RIPIN, Kathy M.; SAYLES, Leonard R. Insider strategies for outsourcing information systems. Oxford University Press, Inc.. Oxford, New York. 1999.

RUBIN, Rachel. ITIL: Grito de Guerra. Revista Information Week, n.112 de 02 de março de 2004. Disponível em: http://issuu.com/search?q=ITIL\%3A\%200\%20GRITO Acesso em: 18 dez. 2009.

SAAD, Alfredo C. Terceirização de serviços de TI. Rio de Janeiro: Brasport, 2006

SACCOL, Amarolinda; LIBERALI NETO, Guilherme; MACADAR, Marie A.; PEDRON, Cristiane D.; CAZELLA, Silvio C. The impact of ERP systems on organizational strategic variables in Brazilian companies. Revista de Administração Contemporânea, Rio de Janeiro, v. 8, n. 1, p. 09-34, jan./mar, 2004.

SALLE, Mathias; DI-VITANTONIO, Giuliano. Business service management: the impact of IT governance models on IT management policies. Services Computing, 2006. SCC '06. IEEE International Conference. p.373-380, 2006.

SAMPAIO, Acácia Maria Negreiros Parente Capela; COSTA, Átila Mendes; PESSOA, Raimundo Wellington Araújo. O papel das tecnologias de informação na fidelização dos clientes: abordagem conceitual. XXVI ENEGEP - Fortaleza, CE, Brasil, 9 a 11 de Outubro de 2006. Disponível em:

http://www.abepro.org.br/biblioteca/ENEGEP2006_TR450301_7038.pdf. Acesso em: 04 jan. 2010.

SANCHEZ, A. M.; PEREZ, Manuela P. Flexibility in new product development: a survey of practices and its relationship with the product's technological complexity. Technovation, v. 23, p.139-45, 2003.

SANTOS, Jorge Luiz dos; KELM, Martinho Luís; ABREU, Aline França de. Um modelo de gestão por resultados segundo a teoria da agência - um estudo de caso: Banco do Estado de Santa Catarina S/A. São Paulo: Revista de Administração da USP, v. 36, n.3, jul-set, 2001. 
SANTOS, Milton; SILVEIRA, Maria Laura. O Brasil: território e sociedade no início do século XXI. Rio de Janeiro: Record, 2001.

SEBRAE. Serviço de Apoio às Micros e Pequenas Empresas. 2010a. Critérios de classificação de empresas. Disponível em: http://www.sebraesc.com.br/leis/default.asp?vcdtexto=4154\&\%5E\%5E. Acesso em: 10 jan. 2010.

- Ramos de atividade. 2010b. Disponível em: http://www.sebrae.com.br/momento/quero-abrir-um-negocio/defina-negocio/ramos-deatividade. Acesso em 16 fev. 2010.

SEI. The Carnegie Mellon software engineering institute. Disponível em: http://www.sei.cmu.edu. Acesso em: 04 nov. 2009.

SELLTIZ, Claire; JAHODA, Marie; DEUTSCH, Morton; COO, Stuart W. Métodos de pesquisa nas relações sociais. São Paulo: Editora da Universidade de São Paulo, 1975.

SIMONS, Robert. Levers of control: how managers use innovative control system to drive strategic renewal. Harvard Business School Press, 1995.

SMITH, Kim Langfield; SMITH, David; STRINGER, Carolyn. Managing the outsourcing relationship. Sydney: UNSW, 2000.

SOARES, Hebbertt de Farias. Importação de tecnologia gerencial para gestão do fornecimento de serviços de TI: um estudo sobre a aplicabilidade do modelo eSourcing Capability Model ao contexto institucional brasileiro. 2008. 190 f. Dissertação (Mestrado em Administração) - Faculdade de Economia, administração e Contabilidade. Universidade de São Paulo, São Paulo, 2008.

SOARES, Priscila Ferraz. Abordagens e métodos para a escolha de soluções de provimento de serviços de TI: análise e comparações. 2007. 215 f. Dissertação (Mestrado em Engenharia). Universidade Federal do Rio de Janeiro, Rio de Janeiro, 2007.

SOUZA, Cesar Alexandre de. Uso organizacional da tecnologia de informação: um estudo sobre a avaliação do grau de informatização de empresas industriais paulistas. 2004. 328 f. Tese (Doutorado em Administração) - Faculdade de Economia, Administração e Contabilidade. Universidade de São Paulo, São Paulo, 2004.

SPARROW, Elizabeth. Successful IT outsourcing: from choosing a provider to managing the project. Springer, 2003.

STAIR, Ralph M. Princípios de sistemas de informação. 2. ed. Rio de Janeiro: LTC, 1998.

STANDISH. Latest Standish group CHAOS report shows project success rates have improved by 50\%. The Standish Group, West Yarmouth, MA. 2003. Disponível em: http://www.highbeam.com/doc/1G1-99169967.html. Acesso em: 12 nov. 2010.

STEFANINI. Stefanini IT solutions. 2010. Disponível em: http://www.stefanini.com.br/BR/home.html. Acesso em: 02 jan. 2010. 
STM. Secretaria dos Transportes metropolitanos. Região Metropolitana de São Paulo RMSP. 2010. Disponível em:

http://www.stm.sp.gov.br/index.php?option=com_content\&view=article\&id=2024\&Itemid=2 01. Acesso em: 05 set. 2010.

STRAUB, Detmar; WEILL, Peter; SCHWAIG, Kathy Stewart. Strategy and IT outsourcing: a test of the strategic control model. Under review at The Journal of Information and Organization, 2006.

TURBAN, Efraim; MCLEAN, E Ephraim; WETHERBE, James C. Tecnologia da informação para gestão. transformado os negócios da economia digital. 3. ed. Porto Alegre: Editora Bookman, 2004.

VAN DER VALK, Wendy. Service procurement in manufacturing companies: results of three embedded case studies. Industrial Marketing Management, v. 37, n. 3, p. 301-315, 2008.

VAN GREMBERGEN, Wim; DE HAES, Steven. Enterprise governance of information technology: achieving strategic alignment and value. New York, NY: Springer, 2009.

VAN GREMBERGEN, Wim; DE HAES, Steven; AMALINCKX, Isabelle. Using COBIT and the balanced scorecard as instruments for service level management. Information Systems Control Journal, v. 4, 2003. Disponível em: < http://www.isaca.org/Journal/PastIssues/2003/Volume-4/Documents/jpdf034-UsingCOBITandBSC.pdf>. Acesso em: 12 jan. 2010 .

VAN GREMBERGEN, Wim.; DE HAES, Steven; GULDENTOPS, Erik. Structures, processes and relational mechanisms for IT governance. In: VAN GREMBERGEN, W. Strategies for information technology governance, Hershey: Idea group publishing, 2004.

VERHOEF, Chris. Quantifying the effects of IT-governance rules. Science of Computer Programming, v. 67, n. 2-3, p. 247-277, July, 2007.

VINZI, Vincenzo Esposito; CHIN, Wynne. W.; HENSELER, Jörg; WANG, Huiwen. Handbook of partial least squares: concepts, methods and applications. Springer Handbooks of Computational Statistics. Springer Heidelberg Dordrecht London New York, 2010.

WEBB, Phyl; POLLARD, Carol; RIDLEY, Gail. Attempting to define it governance: wisdom or folly? In: Proceedings of the $39^{\text {th }}$ Hawaii International Conference on System Sciences, Hawaii. 2006.

WEIL, Pierre. Don't just lead govern: how top-performing firms govern IT. MIS Quarterly Executive, v. 3, n. 1, p. 1-17, March 2004.

WEILL, Peter; ROSS, Jeanne W. IT governance: how top performers manage IT decisions rights for suoerior results. Boston, Harvard Business School Press, 2004.

How effective is your IT governance. Center of Information Systems Research, Research Briefing, MIT Sloan School of Management, 2005. Disponível em: < http://web.mit.edu/cisr/resbrfgs/2005_03_1B_HowEffIsYrITGov.pdf>. Acesso em: 04 out. 2010. 
Governança de tecnologia da informação. São Paulo: Makron Books, 2006.

WEILL, Peter; WOODHAM, Richard. Don't just lead, govern: implementing effective IT governance. Center for Information Systems Research. Working paper n. 326, 2002.

WILLCOCKS, Leslie P.; CHOI, Chong Ju. Co-operative partnership and 'total' it outsourcing: from contractual obligation to strategic alliance? European Management Journal. v.13, p. 67-68, 1995.

WILLCOCKS, Leslie P.; FEENY, David; OLSON, Nancy. Implementing core IS capabilities: Feeny-Willcocks IT governance and management framework revisited. European Management Journal, v. 24, n. 1, p. 28-37, 2006.

WILLCOCKS, Leslie P.; FITZGERALD, Guy. A business guide to outsourcing information technology. Business Intelligence, London, 1994.

WILLCOCKS, Leslie P.; LACITY, Mary C. Strategic sourcing of information systems: perspectives and practices. England: John Wiley \& Sons, 1997.

WILLCOCKS, Leslie P.; MARGETTS, Helen. Risk assessment and information systems. European Journal of Information Systems. v. 3, n. 2, p. 127-138, 1994.

WILLCOCKS, Leslie P.; SYKES, Richard. The role of the CIO and IT function in ERP. Communications of the ACM, v. 43, p. 32-37, 2000.

WOLD, H. Soft Modeling: the basic design and some extensions. In JÖRESKOG, K. G.; WOLD, H. (Ed.). Systems under indirect observation: causality, structure and prediction. Part II. Netherlands: North-Holland Publishing company, 1982.

WRIGHT, Peter; KROLL, Mark J.; PARNELL, John. Administração estratégica: conceitos. São Paulo: Atlas, 2000.

YOUNG, Raymond; JORDAN, E. The implications of Australian ICT governance standards for COBIT. The 2005 ISACA IT Governance International Conference: IT Audit - A Strategic Foundation for Corporate Governance, Auckland, New Zealand, 2005.

YU, Chong Ho. An introduction to computing and interpreting cronbach coefficient alpha in sas. 2001. Proceeding of $26^{\text {th }}$ SAS User Group International Conference. Disponível em: http://seamonkey.ed. asu.edu// alex/pub/cronbach.doc. Acesso em: 04 abr. 2009.

ZHAO, Yushan; CALANTONE, Roger J. The trend toward outsourcing in new product development: case studies in six firms. International Journal of Innovation Management, v. 7, n. 1, p.51-66, 2003.

ZWICKER, Ronaldo; SOUZA, Cesar Alexandre de; BIDO, Diógenes de Souza Bido. Uma revisão do modelo do grau de informatização de empresas: novas propostas de estimação e modelagem usando PLS (partial least squares). In: Encontro Anual da Associação Nacional dos Programas de Pós-Graduação em Administração - ENANPAD, 32. 2008, Rio de Janeiro. Anais. Rio de Janeiro: ANPAD, 2008. 


\section{APÊNDICES}

\section{Apêndice A - Quadros com os livros de práticas de gestão}

Abaixo estão indicados os livros utilizados dos modelos de governança de TI (CObIT; e-SCM-CL; e ITIL) como referência para extração das práticas de gestão da terceirização de serviços de TI.

\section{A1. Aquisição}

\begin{tabular}{|c|c|c|c|}
\hline Dimensão & Modelo & Livros de Governança de TI Correspondentes às Práticas de Gestão & $\begin{array}{c}\text { Código do } \\
\text { Livro }\end{array}$ \\
\hline \multirow{8}{*}{ 莺 } & CObIT & Procurement Control & AI5.1 \\
\hline & e-SCM-CL & Agreement Roles & agr04 \\
\hline & e-SCM-CL & Define SLAs \& Measures & agr05 \\
\hline & e-SCM-CL & Define Current State & opa01 \\
\hline & e-SCM-CL & Establish Sourcing Project & $\mathrm{p} \ln 01$ \\
\hline & CObIT & $\begin{array}{l}\text { Identification of External Legal, Regulatory and Contractual } \\
\text { Compliance Requirements }\end{array}$ & ME3.1 \\
\hline & e-SCM-CL & Sourcing Criteria & opa02 \\
\hline & e-SCM-CL & Sourcing Options & opa04 \\
\hline
\end{tabular}

\section{A2. Capacidade}

\begin{tabular}{|c|c|l|c|}
\hline Dimensão & Modelo & Livros de Governança de TI Correspondentes às Práticas de Gestão & $\begin{array}{c}\text { Código do } \\
\text { Livro }\end{array}$ \\
\hline \multirow{2}{*}{$*$} & e-SCM-CL & Capability Baselines & val02 \\
\cline { 2 - 4 } & CObIT & Personnel Competencies & PO7.2 \\
\cline { 2 - 4 } & CObIT & Dependence Upon Individuals & PO7.5 \\
\cline { 2 - 4 } & CObIT & Personnel Clearance Procedures & PO7.6 \\
\cline { 2 - 4 } & CObIT & Employee Job Performance Evaluation & PO7.7 \\
\hline
\end{tabular}

\section{A3. Comunicação}

\begin{tabular}{|c|l|l|c|}
\hline Dimensão & Modelo & Livros de Governança de TI Correspondentes às Práticas de Gestão & $\begin{array}{c}\text { Código do } \\
\text { Livro }\end{array}$ \\
\hline \multirow{2}{*}{ CObIT } & Board and Executive Reporting & ME1.5 \\
\cline { 2 - 4 } & CObIT & Integrated Reporting & ME3.4 \\
\cline { 2 - 4 } & ITIL & Report Service & $\begin{array}{c}\text { Servinual } \\
\text { Improvemen }\end{array}$ \\
\hline
\end{tabular}




\section{A4. Conhecimento}

\begin{tabular}{|c|c|c|c|}
\hline Dimensão & Modelo & Livros de Governança de TI Correspondentes às Práticas de Gestão & $\begin{array}{c}\text { Código do } \\
\text { Livro } \\
\end{array}$ \\
\hline \multirow{3}{*}{ ن⿺辶 } & e-SCM-CL & Personnel Competencies & ppl02 \\
\hline & e-SCM-CL & Provide Required Information & knw01 \\
\hline & ITIL & Knowledge Management & $\begin{array}{c}\text { Service } \\
\text { Transition }\end{array}$ \\
\hline
\end{tabular}

\section{A5. Contrato}

\begin{tabular}{|c|c|c|c|}
\hline Dimensão & Modelo & Livros de Governança de TI Correspondentes às Práticas de Gestão & $\begin{array}{c}\text { Código do } \\
\text { Livro }\end{array}$ \\
\hline \multirow{12}{*}{ 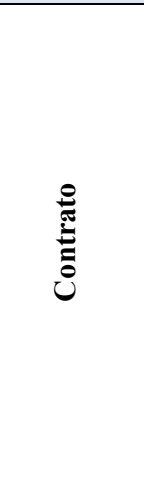 } & e-SCM-CL & Agreement Management & mgt04 \\
\hline & e-SCM-CL & Service Provider Management & gov02 \\
\hline & CObIT & Supervision & PO4.10 \\
\hline & CObIT & Supplier Contract Management & AI5.2 \\
\hline & CObIT & Monitoring Approach & ME1.1 \\
\hline & CObIT & Monitoring of Internal Control Framework & ME2.1 \\
\hline & CObIT & Supervisory Review & ME2.2 \\
\hline & CObIT & Control Exceptions & ME2.3 \\
\hline & CObIT & Control Self-assessment & ME2.4 \\
\hline & CObIT & Assurance of Internal Control & ME2.5 \\
\hline & CObIT & Internal Control at Third Parties & ME2.6 \\
\hline & CObIT & Remedial Actions & ME2.7 \\
\hline
\end{tabular}

\section{A6. Demanda}

\begin{tabular}{|c|c|c|c|}
\hline Dimensão & Modelo & Livros de Governança de TI Correspondentes às Práticas de Gestão & $\begin{array}{l}\text { Código do } \\
\text { Livro }\end{array}$ \\
\hline \multirow{9}{*}{ 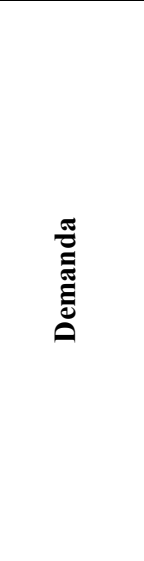 } & e-SCM-CL & Demand Identifi cation & opa03 \\
\hline & e-SCM-CL & Service Definition & $\mathrm{pln} 02$ \\
\hline & CObIT & IT Portfolio Management & PO1.6 \\
\hline & CObIT & Optimisation of Response to External Requirements & ME3.2 \\
\hline & ITIL & Demand Management & $\begin{array}{c}\text { Service } \\
\text { Strategy }\end{array}$ \\
\hline & ITIL & Capacity Management & $\begin{array}{c}\text { Service } \\
\text { Strategy }\end{array}$ \\
\hline & ITIL & Availability Management & $\begin{array}{c}\text { Service } \\
\text { Strategy }\end{array}$ \\
\hline & ITIL & Continuity Management Services & $\begin{array}{c}\text { Service } \\
\text { Strategy }\end{array}$ \\
\hline & ITIL & Compliance Requirement & $\begin{array}{c}\text { Service } \\
\text { Strategy }\end{array}$ \\
\hline
\end{tabular}




\section{A7. Desempenho}

\begin{tabular}{|l|l|l|c|}
\hline \multirow{2}{*}{ Dimensão } & Modelo & Livros de Governança de TI Correspondentes às Práticas de Gestão & $\begin{array}{c}\text { Código do } \\
\text { Livro }\end{array}$ \\
\hline \multirow{5}{*}{} & e-SCM-CL & Organizational Sourcing Performance & val01 \\
\cline { 2 - 4 } & e-SCM-CL & Improve Sourcing Processes & val04 \\
\cline { 2 - 4 } & e-SCM-CL & Evaluation Criteria & mot02 \\
\cline { 2 - 4 } & e-SCM-CL & Performance Monitoring & mot08 \\
\cline { 2 - 4 } & e-SCM-CL & Review Service Performance & PO1.3 \\
\cline { 2 - 4 } & CObIT & Assessment of Current Capability and Performance & PO10.13 \\
\cline { 2 - 4 } & CObIT & Project Performance Measurement, Reporting and Monitoring & DS2.4 \\
\cline { 2 - 4 } & CObIT & Supplier Performance Monitoring & DS3.2 \\
\cline { 2 - 4 } & CObIT & Current Performance and Capacity & DS3.5 \\
\cline { 2 - 4 } & CObIT & Future Performance and Capacity & ME1.4 \\
\cline { 2 - 4 } & CObIT & Monitoring and Reporting & ME3.3 \\
\cline { 2 - 4 } & CObIT & Performance Assessment & ME4.6 \\
\cline { 2 - 4 } & CObIT & Evaluation of Compliance With External Requirements & Continual \\
\cline { 2 - 4 } & CObIT & Performance Measurement & Service \\
\cline { 2 - 4 } & & & Improvement \\
\hline
\end{tabular}

\section{A8. Financeiro}

\begin{tabular}{|c|c|l|c|}
\hline \multirow{2}{*}{ Dimensão } & Modelo & Livros de Governança de TI Correspondentes às Práticas de Gestão & $\begin{array}{c}\text { Código do } \\
\text { Livro }\end{array}$ \\
\hline \multirow{4}{*}{} & e-SCM-CL & Financial Management & mgt03 \\
\cline { 2 - 4 } & CObIT & Financial Management Framework & PO5.1 \\
\cline { 2 - 4 } & CObIT & IT Budgeting & PO5.3 \\
\cline { 2 - 4 } & CObIT & Cost Management & PO5.4 \\
\cline { 2 - 4 } & CObIT & IT Accounting & DS6.2 \\
\cline { 2 - 4 } & CObIT & Cost Modelling and Charging & ME4.4 \\
\cline { 2 - 4 } & CObIT & Resource Management & Service \\
\cline { 2 - 4 } & ITIL & IT Financial Management & Strategy \\
\hline
\end{tabular}

\section{A9. Incidente}

\begin{tabular}{|c|c|c|c|}
\hline Dimensão & Modelo & Livros de Governança de TI Correspondentes às Práticas de Gestão & $\begin{array}{c}\text { Código do } \\
\text { Livro }\end{array}$ \\
\hline \multirow{3}{*}{ } & e-SCM-CL & Problem \& Incident Monitoring & mgt05 \\
\hline & CObIT & Service Desk & DS8.1 \\
\hline & ITIL & Incident Management & $\begin{array}{c}\text { Service } \\
\text { Operation }\end{array}$ \\
\hline
\end{tabular}


A10. Infraestrutura

\begin{tabular}{|c|c|l|c|}
\hline \multirow{2}{*}{ Dimensão } & Modelo & Livros de Governança de TI Correspondentes às Práticas de Gestão & $\begin{array}{c}\text { Código do } \\
\text { Livro }\end{array}$ \\
\hline \multirow{2}{*}{} & e-SCM-CL & Asset Management & tch01 \\
\cline { 2 - 4 } & CObIT & Infrastructure Maintenance & $\mathrm{AI} 3.3$ \\
\cline { 2 - 4 } & CObIT & IT Infrastructure Monitoring & DS13.3 \\
\cline { 2 - 4 } & CObIT & Physical Facilities Management 12.5 \\
\cline { 2 - 4 } & ITIL & Configuration Management and Service Asset & $\begin{array}{c}\text { Service } \\
\text { Transition }\end{array}$ \\
\hline
\end{tabular}

\section{A11. Mercado}

\begin{tabular}{|c|c|c|c|}
\hline Dimensão & Modelo & Livros de Governança de TI Correspondentes às Práticas de Gestão & $\begin{array}{l}\text { Código do } \\
\text { Livro }\end{array}$ \\
\hline \multirow{2}{*}{ 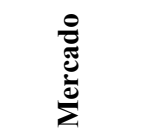 } & e-SCM-CL & Benchmark Sourcing Processes & val03 \\
\hline & CObIT & Monitor Future Trends and Regulations & PO3.3 \\
\hline
\end{tabular}

\section{A12. Mudança}

\begin{tabular}{|c|l|l|c|}
\hline \multirow{2}{*}{ Dimensão } & Modelo & Livros de Governança de TI Correspondentes às Práticas de Gestão & $\begin{array}{c}\text { Código do } \\
\text { Livro }\end{array}$ \\
\hline \multirow{5}{*}{} & e-SCM-CL & Prepare for Organizational Change & ocm01 \\
\cline { 2 - 4 } & e-SCM-CL & Human Resource Changes & ocm04 \\
\cline { 2 - 4 } & e-SCM-CL & Service Transition & tfr01 \\
\cline { 2 - 4 } & e-SCM-CL & Resources Transferred Out & tfr03 \\
\cline { 2 - 4 } & e-SCM-CL & Personnel Transferred Out & tfr04 \\
\cline { 2 - 4 } & e-SCM-CL & knowledge Transferred out & mgt06 \\
\cline { 2 - 4 } & e-SCM-CL & Service Delivery Change Management & mgt07 \\
\cline { 2 - 4 } & e-SCM-CL & Service Change Management & AI6.2 \\
\cline { 2 - 4 } & CObIT & Impact Assessment, Prioritisation and Authorisation & AI6.4 \\
\cline { 2 - 4 } & CObIT & Emergency Changes & AI7.9 \\
\cline { 2 - 4 } & CObIT & Change Status Tracking and Reporting & Service \\
\cline { 2 - 4 } & CObIT & Post-implementation Review & Transition \\
\cline { 2 - 4 } & ITIL & Change Management & \\
\hline
\end{tabular}

\section{A13. Nível de Serviço}

\begin{tabular}{|c|l|l|c|}
\hline Dimensão & Modelo & Livros de Governança de TI Correspondentes às Práticas de Gestão & $\begin{array}{c}\text { Código do } \\
\text { Livro }\end{array}$ \\
\hline \multirow{2}{*}{$\underbrace{}_{2}$} & CObIT & Monitoring and Reporting of Service Level Achievements & DS1.5 \\
\cline { 2 - 4 } & CObIT & Review of Service Level Agreements and Contracts & DS1.6 \\
\cline { 2 - 4 } & ITIL & Management Service Level & $\begin{array}{c}\text { Service } \\
\text { Design }\end{array}$ \\
\hline
\end{tabular}




\section{A14. Política}

\begin{tabular}{|c|c|l|c|}
\hline \multirow{2}{*}{ Dimensão } & Modelo & Livros de Governança de TI Correspondentes às Práticas de Gestão & $\begin{array}{c}\text { Código do } \\
\text { Livro }\end{array}$ \\
\hline \multirow{3}{*}{} & e-SCM-CL & Governance Model & app03 \\
\cline { 2 - 4 } & CObIT & IT Policies Management & PO6.3 \\
\cline { 2 - 4 } & CObIT & Policy, Standard and Procedures Rollout & PO6.4 \\
\cline { 2 - 4 } & CObIT & Monitoring Method & ME4.1 \\
\cline { 2 - 4 } & CObIT & Establishment of an IT Governance Framework & ME \\
\hline
\end{tabular}

\section{A15. Problema}

\begin{tabular}{|c|c|l|c|}
\hline Dimensão & Modelo & Livros de Governança de TI Correspondentes às Práticas de Gestão & $\begin{array}{c}\text { Código do } \\
\text { Livro }\end{array}$ \\
\hline \multirow{2}{*}{ e-SCM-CL } & Issue Management & rel04 \\
\cline { 2 - 5 } & CObIT & Integration of Configuration, Incident and Problem Management & DS10.4 \\
\cline { 2 - 5 } & ITIL & Problem Management & $\begin{array}{c}\text { Service } \\
\text { Operation }\end{array}$ \\
\hline
\end{tabular}

\section{A16. Qualidade}

\begin{tabular}{|c|c|l|c|}
\hline Dimensão & Modelo & Livros de Governança de TI Correspondentes às Práticas de Gestão & $\begin{array}{c}\text { Código do } \\
\text { Livro }\end{array}$ \\
\hline \multirow{2}{*}{$\underbrace{*}$} & e-SCM-CL & Evaluate Potential Service Providers & spe02 \\
\cline { 2 - 4 } & CObIT & Responsibility for IT Quality Assurance & PO4.7 \\
\cline { 2 - 4 } & CObIT & Quality Measurement, Monitoring and Review & PO8.6 \\
\cline { 2 - 4 } & CObIT & Positive Assurance of Compliance & ME3.4 \\
\cline { 2 - 4 } & CObIT & Independent Assurance & ME4.7 \\
\hline
\end{tabular}

\section{A17. Relacionamento}

\begin{tabular}{|l|l|l|c|}
\hline \multirow{2}{*}{ Dimensão } & Modelo & Livros de Governança de TI Correspondentes às Práticas de Gestão & $\begin{array}{c}\text { Código do } \\
\text { Livro }\end{array}$ \\
\hline \multirow{4}{*}{} & e-SCM-CL & Service Provider Interactions & rel01 \\
\cline { 2 - 4 } & e-SCM-CL & Service Provider Relationships & rel02 \\
\cline { 2 - 4 } & e-SCM-CL & Collaborative Relationships & rel06 \\
\cline { 2 - 4 } & e-SCM-CL & innovative Relationships & rel07 \\
\cline { 2 - 4 } & e-SCM-CL & Sourcing Approach & app01 \\
\cline { 2 - 4 } & e-SCM-CL & Internal Stakeholder Management & govel03 \\
\cline { 2 - 4 } & e-SCM-CL & Internal Relationships & DS2.1 \\
\cline { 2 - 4 } & CObIT & Identification of All Supplier Relationships & PS2.15 \\
\cline { 2 - 4 } & CObIT & Relationships & DS 2 \\
\cline { 2 - 4 } & CObIT & Supplier Relationship Management & \\
\hline
\end{tabular}


A18. Responsabilidade

\begin{tabular}{|c|l|l|c|}
\hline \multirow{2}{*}{ Dimensão } & Modelo & Livros de Governança de TI Correspondentes às Práticas de Gestão & $\begin{array}{c}\text { Código do } \\
\text { Livro }\end{array}$ \\
\hline \multirow{3}{*}{} & e-SCM-CL & Assign Sourcing Responsibilities & ppl01 \\
\cline { 2 - 4 } & e-SCM-CL & Defi ne Roles & ppl04 \\
\cline { 2 - 4 } & CObIT & Establishment of Roles and Responsibilities & PO4.6 \\
\cline { 2 - 4 } & CObIT & Key IT Personnel & PO4.13 \\
\cline { 2 - 4 } & CObIT & Contracted Staff Policies and Procedures & PO4.14 \\
\cline { 2 - 4 } & CObIT & Staffing of Roles & PO7.3 \\
\hline
\end{tabular}

\section{A.19 Risco}

\begin{tabular}{|c|c|c|c|}
\hline Dimensão & Modelo & Livros de Governança de TI Correspondentes às Práticas de Gestão & $\begin{array}{c}\text { Código do } \\
\text { Livro }\end{array}$ \\
\hline \multirow{9}{*}{ 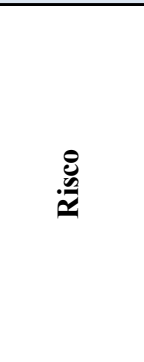 } & e-SCM-CL & Sourcing Risk Management & thr01 \\
\hline & e-SCM-CL & Impact \& Risk Analysis & app04 \\
\hline & CObIT & Responsibility for Risk, Security and Compliance & PO4.8 \\
\hline & CObIT & Enterprise IT Risk and Control Framework & PO6.2 \\
\hline & CObIT & IT Risk Management Framework & PO9.1 \\
\hline & CObIT & Risk Assessment & PO9.4 \\
\hline & CObIT & Maintenance and Monitoring of a Risk Action Plan & PO9.6 \\
\hline & CObIT & Supplier Risk Management & DS2.3 \\
\hline & CObIT & Risk Management & ME4.5 \\
\hline
\end{tabular}

\section{A20. Segurança}

\begin{tabular}{|c|c|l|c|}
\hline Dimensão & Modelo & Livros de Governança de TI Correspondentes às Práticas de Gestão & $\begin{array}{c}\text { Código do } \\
\text { Livro }\end{array}$ \\
\hline \multirow{2}{*}{$\overbrace{0}^{*}$} & e-SCM-CL & Security \& Privacy & thr04 \\
\cline { 2 - 4 } & CObIT & Management of IT Security & DS5.1 \\
\cline { 2 - 4 } & CObIT & Security Requirements for Data Management & DS11.6 \\
\cline { 2 - 4 } & ITIL & Security Management Information & $\begin{array}{c}\text { Service } \\
\text { Operation }\end{array}$ \\
\hline
\end{tabular}

\section{A21. Sistema de Informação}

\begin{tabular}{|c|c|c|c|}
\hline Dimensão & Modelo & Livros de Governança de TI Correspondentes às Práticas de Gestão & $\begin{array}{c}\text { Código do } \\
\text { Livro } \\
\end{array}$ \\
\hline \multirow{2}{*}{ 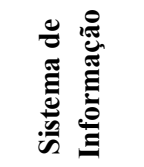 } & e-SCM-CL & Knowledge System & knw02 \\
\hline & e-SCM-CL & License Management & $\operatorname{tch} 02$ \\
\hline
\end{tabular}


A22. Treinamento

\begin{tabular}{|l|l|l|c|}
\hline \multirow{2}{*}{ Dimensão } & Modelo & Livros de Governança de TI Correspondentes às Práticas de Gestão & $\begin{array}{c}\text { Código do } \\
\text { Livro }\end{array}$ \\
\hline \multirow{2}{*}{} & CObIT & Personnel Training & PO7.4 \\
\cline { 2 - 4 } & CObIT & Identification of Education and Training Needs & DS7.1 \\
\cline { 2 - 4 } & CObIT & Delivery of Training and Education & DS7.2 \\
\cline { 2 - 4 } & CObIT & Evaluation of Training Received & DS7.3 \\
\hline
\end{tabular}

\section{A23. Valor}

\begin{tabular}{|c|c|l|c|}
\hline Dimensão & Modelo & Livros de Governança de TI Correspondentes às Práticas de Gestão & $\begin{array}{c}\text { Código do } \\
\text { Livro }\end{array}$ \\
\hline \multirow{3}{*}{$\underset{*}{*}$} & e-SCM-CL & Service Value Analysis & mgt10 \\
\cline { 2 - 4 } & CObIT & Benefit Management & PO5.5 \\
\cline { 2 - 4 } & CObIT & Maintenance of the IT Continuity Plan & DS4.4 \\
\cline { 2 - 4 } & CObIT & Value Delivery & ME4.3 \\
\hline
\end{tabular}



Apêndice B - Tela do gerenciador de e-mail - website AKNA

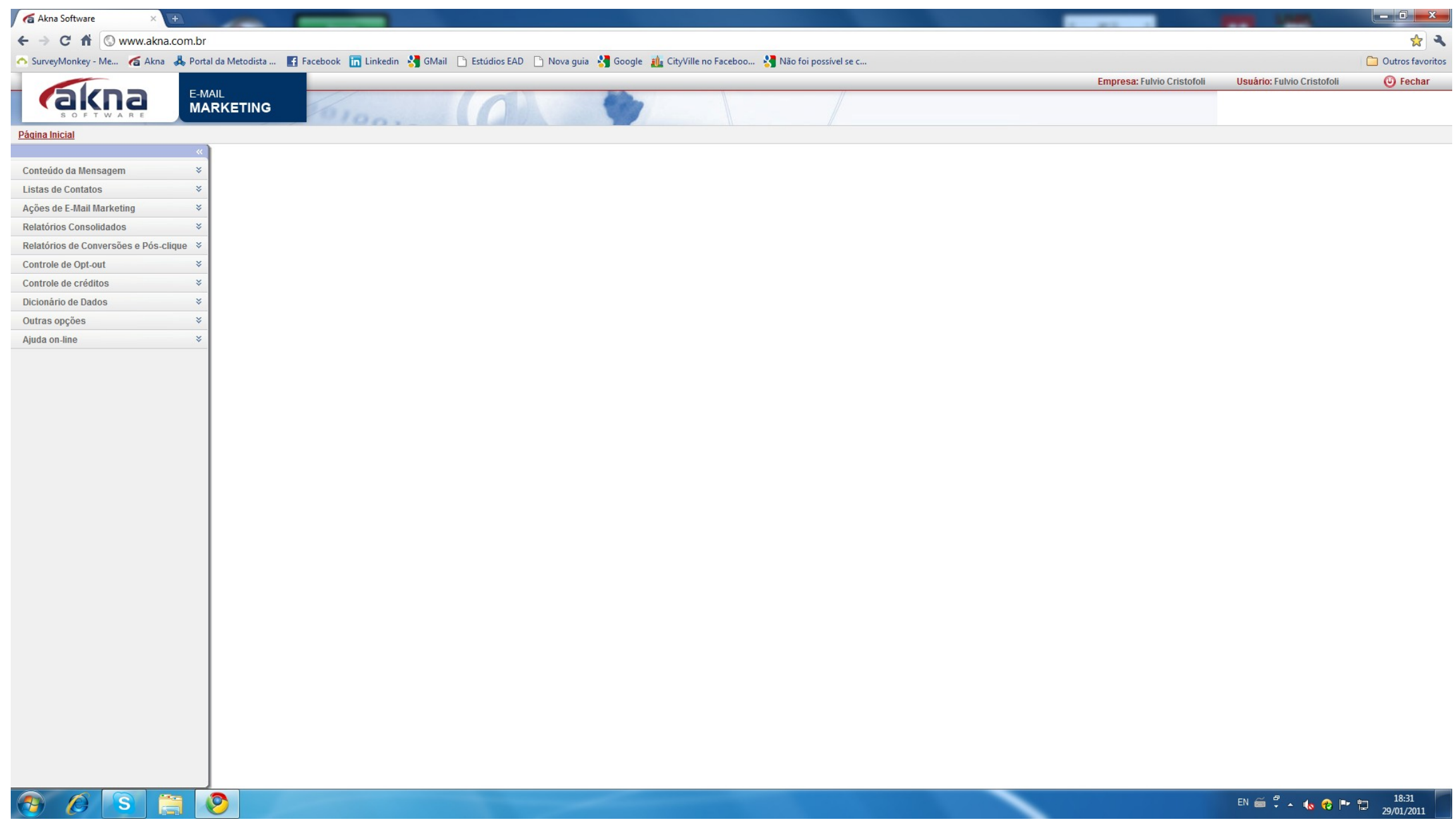




\section{Apêndice C - Tela do gerenciador do questionário eletrônico - website Survey Monkey}
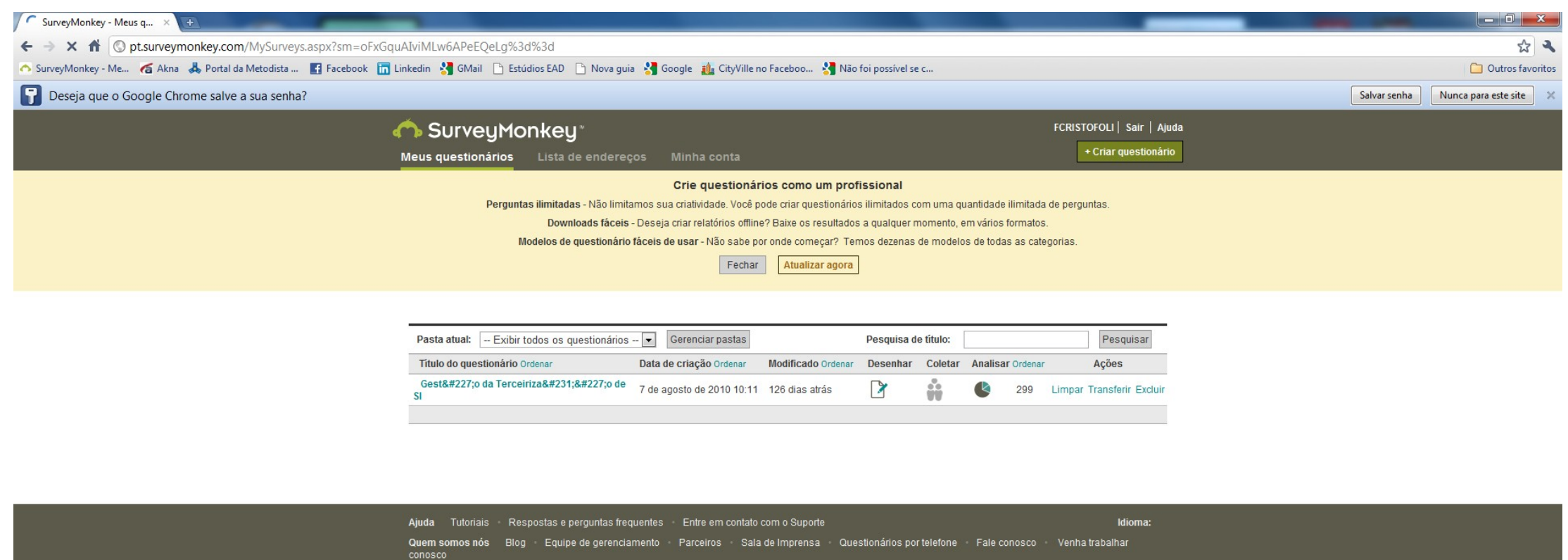


\section{Apêndice E - Termo de consentimento - questionário eletrônico}

\section{Termo de Consentimento Livre e Esclarecido}

Você está sendo convidado(a) para participar, como voluntário, em uma pesquisa acadêmica que será parte do desenvolvimento de uma Tese de Doutorado em Administração. A proposta da Tese consiste em analisar as práticas de gestão da terceirização de desenvolvimento de sistemas e/ou de implantação de sistemas e os resultados obtidos com a terceirização.

\section{A quem se destina esta pesquisa?}

\section{Empresas de Grande e Médio Porte (de todos os setores)}

Quem deve responder?

Diretores ou alta gerência da área de TI que gerenciam as terceirizações de TI da empresa

Ao respondê-lo, você estará refletindo sobre práticas adotadas em sua gestão, além de contribuir para a criação de um instrumento de gestão da terceirização para as organizações.

Esta pesquisa tem caráter exclusivamente acadêmico e didático, não havendo nenhum outro interesse oculto. A sua participação no estudo, respondendo ao questionário, não acarretará em nenhum desconforto, riscos ou represálias por parte da empresa onde trabalha.

Você tem total liberdade para se recusar a participar da pesquisa, bastando não responder ao questionário, que levará cerca de 10 a 15 minutos para ser respondido.

O material coletado na pesquisa poderá ser utilizado em futura publicação de livros bem como periódicos científicos. Cumpre-se destacar que o anonimato bem como o sigilo do respondente serão integralmente respeitados e que as informações decorrentes das respostas dadas serão utilizadas exclusivamente para atender aos objetivos da Tese. Não será divulgada nenhuma informação exclusiva da organização. Da mesma forma, comprometo-me em enviar-lhes os resultados do trabalho.

Contando com sua prestimosa ajuda na resposta ao questionário e, desde já manifestando meu sincero agradecimento, apresento-lhe minhas cordiais saudações.

\section{Informações sobre a Pesquisa:}

Título: Um Estudo Sobre a Gestão da Terceirização de Serviços de Tecnologia da Informação

Pesquisador responsável: Prof. Me. Fulvio Cristofoli

Telefone para Contato: $(\mathrm{XX}) \mathrm{XXXX}-\mathrm{XXXX}$

e-mail: cristofoli@usp.br - fulvio.cristofoli@metodista.br

Coloco-me à sua disposição para mais esclarecimentos sobre sua participação no estudo.

FEA - Faculdade de Economia, Administração e Contabilidade

USP - Universidade de São Paulo 


\section{Apêndice F - Instrumento completo utilizado para a pesquisa}

\begin{tabular}{|l|l|l|l|}
\hline Nome do respondente: & \multicolumn{2}{|l|}{ Cargo que ocupa: } \\
\hline Endereço de e-Mail: & Cidade: \\
\hline Empresa: & Telefone: $\left(\begin{array}{l|l}\text { ( ) } \\
\hline \text { Endereço: }\end{array}\right.$ & Ramal: \\
\hline CEP : & & Estado: \\
\hline
\end{tabular}

Deseja receber os resultados compilados desta pesquisa? ( ) Sim ( ) Não

\section{INSTRUÇÕES PARA O RESPONDENTE:}

Entende-se como:

Desenvolvimento de Sistemas de Informação Sob Medida: Todo e qualquer sistema de informação que a empresa possa utilizar no seu dia a dia, podendo ser por exemplo: Sistemas Administrativos (folha de pagamento, sistema financeiro), Sistemas de Apoio à Decisão etc.

Implantação de Pacotes de Sistemas de Informação: Todo e qualquer pacote ou sistema adquirido no mercado, como por exemplo: ERP's; CRM; Supply Chain; e-Commerce; e-Business;

Business Intelligence; Business Plan, etc. Podemos incluir dentro do processo de implantação de sistemas de informação, a "customização" realizada pelos fornecedores em determinados módulos adquiridos.

Setor de Atividade: ( ) Indústria ( ) Comércio ( ) Serviço

Quantidade Total de Funcionários da Empresa:

\begin{tabular}{|l|l|l|}
\hline & Terceirizado \\
\hline Quantidade total de funcionários na área de TI da empresa & \\
\hline $\begin{array}{l}\text { Quantidade total de funcionários alocados no Desenvolvimento de Sistemas de Informação Sob Medida e/ou Implantação de Pacotes de } \\
\text { Sistemas de Informação. }\end{array}$ & \\
\hline
\end{tabular}


Receita Líquida em 2009: ( ） De R\$ 0,00 a R\$240.000,00

( ) De R\$240.000,01 a R\$2.400.000,00

( ) De $R \$ 2.400 .000,01$ a $R \$ 10.000 .000,00$

( ) De R\$ 10.000.000,01 a R\$100.000.000,00

( ) De $R \$ 100.000 .000,01$ a $R \$ 200.000 .000,00$

( ) De R\$200.000.000,01 a R\$300.000.000,00

( ) Acima de $\mathrm{R} \$ 300.000 .000,00$

Gastos e Investimentos com Tecnologia da Informação (TI):

(\% da Receita Líquida da Empresa) - Ano Base 2009

Gastos e Investimentos em Terceirização do Desenvolvimento de Sistemas de Informação Sob Medida e/ou Terceirização da Implantação de Pacotes de Sistemas de Informação. (\% dos gastos e investimentos realizados em TI) - Ano Base 2009

Qual o número total de computadores instalados na empresa:

Qual o grau de formalidade estabelecido para a contratação de serviços terceirizados junto aos fornecedores?

( ) Informal (sem contrato). ( ) Contrato formal sem detalhamento (cláusulas padrão). （ ) Contrato formal detalhado - sem SLA. ( ) Contrato formal detalhado - com SLA.

Como gestor, você utiliza algum modelo de governança de TI ? （） Não （）CobIT （）ITIL （）Val IT （）e-SCM （） Outros:

Para a próxima etapa da pesquisa tratará de questões relacionadas a Gestão da Terceirização do Desenvolvimento de Sistemas de Informação Sob Medida e /ou Terceirização da Implantação de Pacotes de Sistemas de Informação. Para responder a esta parte do questionário, VOCÊ DEVE SE BASEAR NO PROJETO MAIS RELEVANTE PARA A EMPRESA QUE SE ENQUADRE EM:

- Desenvolvimento de Sistemas de Informações Sob Medida; ou

- Implantação de Pacotes de Sistemas de Informação.

Identifique o projeto ao qual você se baseará para responder a este questionário:

( ) Desenvolvimento de SI Sob Medida - Sistema completo （ ) Desenvolvimento de SI sob medida - Apenas Algumas Partes

( ) Implantação de Pacotes de SI-Sistema Completo

( ) Implantação de Pacotes de SI - Apenas Alguns Módulos

A seguir estão relacionadas práticas da Gestão da Terceirização do Desenvolvimento de Sistemas de Informação Sob Medida e/ou Terceirização da Implantação de Pacotes de Sistemas de Informação. Para cada uma das práticas, assinale com um " $x$ " no grau escolhido. 
Práticas adotadas pelo gestor de TI na Gestão da Terceirização do Desenvolvimento de Sistemas de Informação Sob Medida e/ou Terceirização da Implantação de Pacotes de Sistemas de Informação.

Enquanto gestor de TI, eu:

1.) Verifico todos os processos de aquisição referentes à terceirização do desenvolvimento de SI sob medida e/ou terceirização da implantação de pacotes de SI efetuados anteriormente.

2.) Documento todos os processos de contratação de serviços (aquisição; relatórios de conformidade; alterações contratuais; etc.), para estudos e ações futuras.

3.) Utilizo normas (próprias ou de melhores práticas de mercado) para seleção do fornecedor do serviço.

4.) Asseguro que o departamento jurídico acompanhe e participe de todos os processos de contratação dos serviços (alterações contratuais; litígios; etc.).

5.) Alinho as solicitações provenientes das áreas com as capacidades de atendimento do fornecedor do serviço.

6.) Analiso, controlo e documento as alterações solicitadas pelas áreas usuárias.

7.) Acompanho os SLA firmados.

8.) Controlo os planejamentos e/ou investimentos realizados pelo fornecedor do serviço durante a vigência do contrato a fim de comprovação da capacidade técnica e/ou produtiva.

9.) Acompanho a capacidade técnica do fornecedor do serviço.

10.) Utilizo métodos (próprios ou de melhores práticas de mercado) para avaliação do fornecedor do serviço.

11.) Acompanho a qualidade dos serviços executados pelo fornecedor do serviço.

12.) Utilizo metodologia para o desenvolvimento do projeto (exemplo: PMBok, Prince2, etc.) no desenvolvimento de SI sob medida e/ou terceirização da implantação de pacotes de SI.

13.) Reviso periodicamente o cumprimento dos serviços executados pelo fornecedor do serviço para conclusão de um conjunto de tarefas, passivo de aprovação e formalização.

14.) Atuo preventivamente e corretivamente com base nas avaliações sobre a qualidade dos serviços prestados pelo fornecedor do serviço.

15.) Mantenho atualizados os tópicos da matriz de risco relacionados à prestação de serviços pelo fornecedor do serviço.

\section{$\underline{\text { ADOÇÃO }}$}

Indique o grau de adoção do uso das

práticas para a gestão da terceirização.

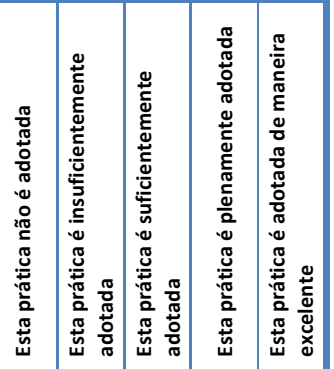


16.) Controlo eventuais problemas e incidentes decorrentes da prestação de serviços realizada pelo fornecedor.

17.) Discuto com o fornecedor do serviço as suas práticas de formulação de definição de escopo, metodologias empregadas e elaboração de entregáveis.

18.) Realizo com as áreas usuárias, as suas práticas de formulação de definição de escopo, metodologias sugeridas e demais processos inerentes.

19.) Acompanho e avalio a infraestrutura de equipamentos disponibilizados e utilizados pelo fornecedor do serviço dentro da empresa.

20.) Controlo e fiscalizo as licenças de uso de programas disponibilizados e utilizados pelo fornecedor do serviço dentro da empresa.

21.) Acompanho o uso de técnicas ou tecnologias utilizadas pelo fornecedor do serviço a fim de garantir que não causem problemas futuros para a empresa (exemplo: uso de uma linguagem de programação inadequada).

22.) Monitoro o fornecedor do serviço a fim de que cumpram as políticas que regem o gerenciamento da terceirização da TI.

23.) Realizo controles financeiros periódicos. (dos valores que foram acordados contratualmente com o que foi efetivamente entregue pelo fornecedor do serviço).

24.) Controlo periodicamente $o$ orçamento destinado ao serviço contratado (a fim de que reflita as prioridades estabelecidas pela empresa).

25.) Acompanho as ações desenvolvidas pelo fornecedor do serviço para garantir que agreguem valor ao negócio da empresa.

26.) Utilizo as melhores (boas) práticas de gestão de $\mathrm{TI}$ adotadas pelo mercado como base de comparação e avaliação dos serviços prestados.

27.) Monitoro periodicamente o cumprimento das atribuições e responsabilidades do fornecedor do serviço (ratificar o contratado).

28.) Avalio periodicamente procedimentos de conduta, acompanhando o relacionamento entre os usuários envolvidos no projeto e funcionários do fornecedor do serviço.

29.) Utilizo sistemas de informações computadorizados como ferramentas de apoio à gestão da terceirização.

30.) Certifico que o fornecedor do serviço capacita e acompanha a formação da equipe disponibilizada para a prestação de cada serviço (em cada processo).

31.) Promovo canais regulares de comunicação, acompanhando a comunicação entre os usuários envolvidos e o fornecedor do serviço.

32.) Mantenho os funcionários das áreas usuárias capacitados, de acordo com a necessidade gerada pelo fornecimento do serviço.

Existe(m) alguma(s) prática(s) que você, como gestor, utiliza e que não esteja(m) descrita(s) acima? Qual(is) é(são)?

Qual(is) o(s) grau(s) de adoção?

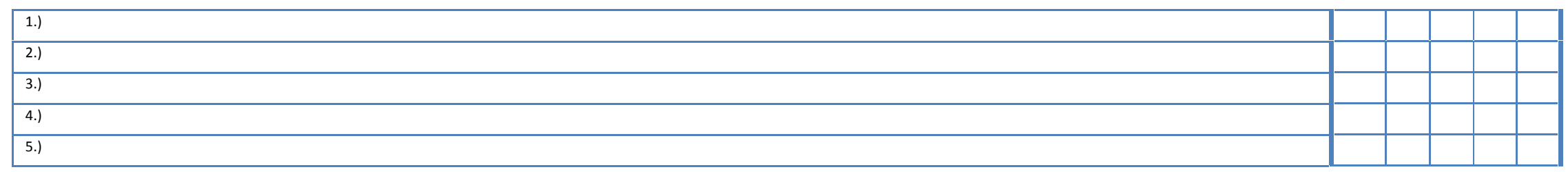

Atenção, esta é a última parte do questionário.

Não se esqueça, para responder a esta parte do questionário, você deve se basear no projeto mais relevante para a empresa que se enquadre em: Desenvolvimento de Sistemas de Informações Sob Medida; ou Implantação de Pacotes de Sistemas de Informação E QUE ESTE PROJETO JÁ TENHA SIDO CONCLUÍDO, pois nesta parte, queremos saber os resultados que a sua 
empresa obteve efetivamente com a Terceirização do Desenvolvimento de Sistemas de Informação Sob Medida e /ou Terceirização da Implantação de Pacotes de Sistemas de Informação, ou seja, queremos saber de você, se em função da terceirização, a empresa obteve o resultado esperado ou não (dentro de uma escala de 1 a 10) em relação a alguns itens.

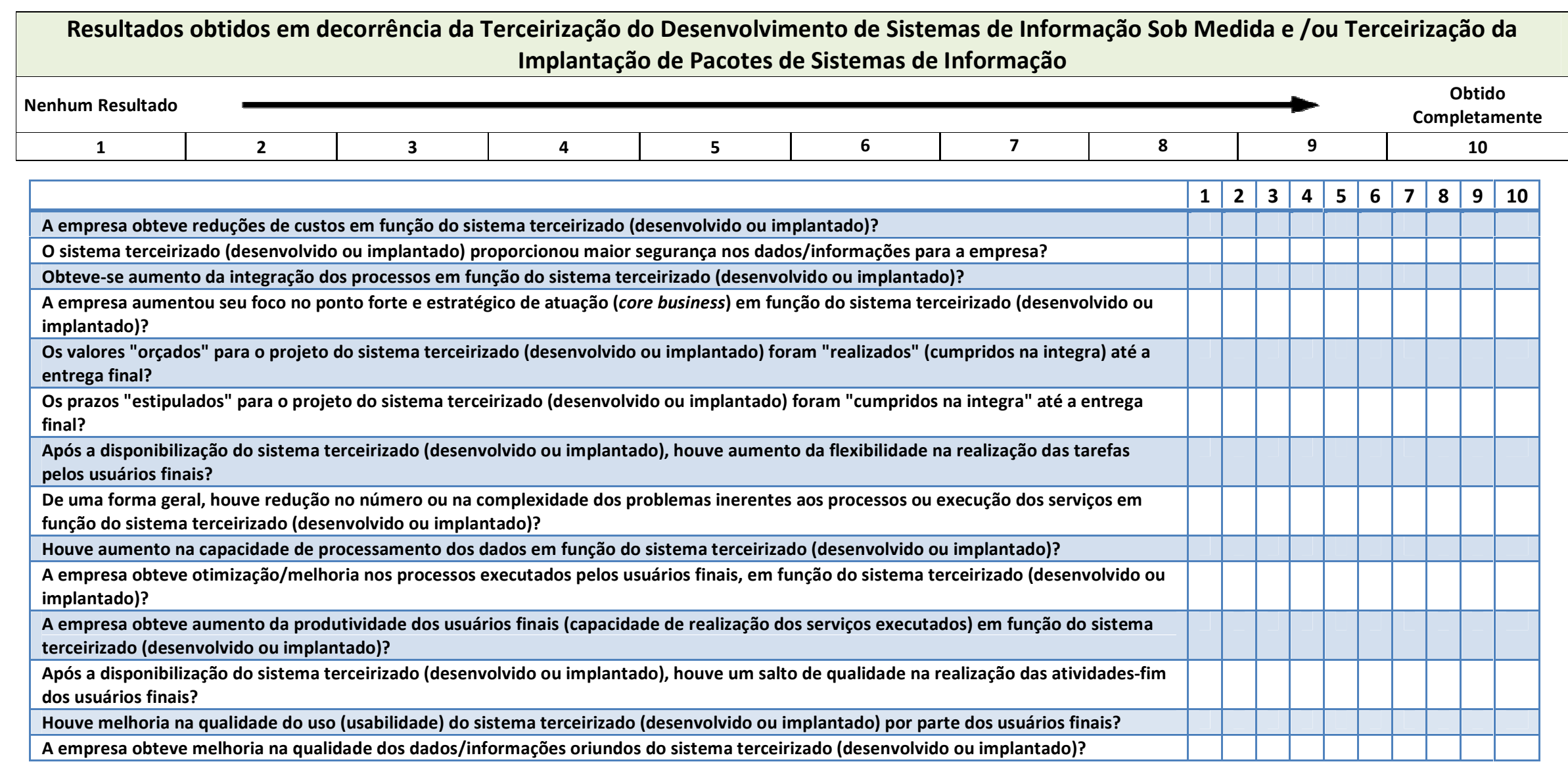

A seguir, deixamos um espaço para que você possa inserir quaisquer comentários a respeito da pesquisa e/ou das questões. Por favor, fique a vontade. 
Apêndice G - Relação das práticas recomendadas - por ordem das mais adotadas de maneira excelente

\begin{tabular}{|c|c|c|c|c|c|c|c|}
\hline & Prática Recomendada & $\begin{array}{c}\text { Esta prática não } \\
\text { é adotada }\end{array}$ & \begin{tabular}{|c|} 
Esta prática é \\
insuficientemente \\
adotada
\end{tabular} & $\begin{array}{c}\text { Esta prática é } \\
\text { suficientemente } \\
\text { adotada }\end{array}$ & $\begin{array}{c}\text { Esta prática é } \\
\text { plenamente } \\
\text { adotada }\end{array}$ & $\begin{array}{c}\text { Esta prática é } \\
\text { adotada de } \\
\text { maneira } \\
\text { excelente }\end{array}$ & $\begin{array}{c}\text { Média } \\
\text { Ponderada }\end{array}$ \\
\hline VP04-1.4 & Asseguro que o departamento juridico acompanhe e participe de todos os processos de contratação dos serviços & 16 & 8 & 38 & 56 & 181 & 85,0 \\
\hline VP20-5.2 & $\begin{array}{l}\text { Controlo e fiscalizo as licenças de uso de programas disponibilizados e utilizados pelo fornecedor do serviço dentro da } \\
\text { empresa. }\end{array}$ & 13 & 17 & 45 & 69 & 155 & 82,2 \\
\hline VP23-6.1 & $\begin{array}{l}\text { Realizo controles financeiros periódicos. (dos valores que foram acordados contratualmente com o que foi efetivamente } \\
\text { entregue pelo fornecedor do serviço). }\end{array}$ & 4 & 9 & 50 & 85 & 151 & 84,5 \\
\hline VP19-5.1 & $\begin{array}{l}\text { Acompanho e avalio a infraestrutura de equipamentos disponibilizados e utilizados pelo fornecedor do serviço dentro da } \\
\text { empresa. }\end{array}$ & 9 & 14 & 53 & 78 & 145 & 82,2 \\
\hline VP11-3.2 & Acompanho a qualidade dos serviços executados pelo fornecedor do serviço. & 1 & 7 & 58 & 89 & 144 & 84,3 \\
\hline VP21-5.3 & $\begin{array}{l}\text { Acompanho o uso de técnicas ou tecnologias utilizadas pelo fornecedor do serviço a fim de garantir que não causem } \\
\text { problemas futuros para a empresa (exemplo: uso de una linguagem de programąąo inadequada). }\end{array}$ & 6 & 15 & 172 & 64 & 42 & 67,9 \\
\hline VP24-6.2 & $\begin{array}{l}\text { Controlo periodicamente o orçamento destinado ao serviço contratado (a fim de que reflita as prioridades estabelecidas } \\
\text { pela empresa). }\end{array}$ & 8 & 10 & 43 & 198 & 40 & 76,6 \\
\hline VP07-2.3 & Acompanho os SLA's firmados. & 10 & 16 & 47 & 191 & 35 & 74,8 \\
\hline VP09-2.5 & Acompanho a capacidade técnica do fornecedor do serviço. & 2 & 11 & 65 & 190 & 31 & 75,6 \\
\hline $\mathrm{VP} 06-2.2$ & Analiso, controlo e documento as alteraçōes solicitadas pelas áreas usuárias. & 6 & 9 & 62 & 191 & 31 & 75,3 \\
\hline VP18-4.5 & $\begin{array}{l}\text { Realizo com as áreas usuárias, as suas práticas de formulação de definiç̃o de escopo, metodologias sugeridas e demais } \\
\text { processos inerentes. }\end{array}$ & 5 & 13 & 58 & 193 & 30 & 75,1 \\
\hline VP17-4.4 & $\begin{array}{l}\text { Discuto com o fornecedor do serviço as suas práticas de formulação de definição de escopo, metodologias empregadas } \\
\text { e elaboração de entregáveis. }\end{array}$ & 6 & 16 & 54 & 193 & 30 & 74,8 \\
\hline VP25-6.3 & $\begin{array}{l}\text { Acompanho as ações desenvolvidas pelo fornecedor do serviço para garantir que agreguem valor ao negócio da } \\
\text { empresa. }\end{array}$ & 3 & 12 & 173 & 84 & 27 & 67,8 \\
\hline VP16-4.3 & Controlo eventuais problemas e incidentes decorrentes da prestação de serviços realizada pelo fornecedor. & 3 & 14 & 169 & 89 & 24 & 67,6 \\
\hline VP3-1.3 & Utilizo normas (próprias ou de melhores práticas de mercado) para seleção do formecedor do serviço. & 5 & 15 & 56 & 200 & 23 & 74,5 \\
\hline VP08-2.4 & $\begin{array}{l}\text { Controlo os planejamentos e/ou investimentos realizados pelo fornecedor do serviço durante a vigência do contrato a fim } \\
\text { de comprovaçâo da capacidade técnica e/ou produtiva. }\end{array}$ & 8 & 20 & 53 & 195 & 23 & 73,5 \\
\hline VP22-5.4 & Monitoro o fornecedor do serviço a fim de que cumpram as politicas que regem o gerenciamento da terceirização da TI. & 4 & 15 & 166 & 91 & 23 & 67,4 \\
\hline VP10-3.1 & Utilizo métodos (próprios ou de melhores práticas de mercado) para avaliação do fornecedor do serviço. & 5 & 16 & 66 & 190 & 22 & 73,7 \\
\hline VP27-6.5 & $\begin{array}{l}\text { Monitoro periodicamente o cumprimento das atribuiç̄oses e responsabilidades do fornecedor do serviço (ratificar o } \\
\text { contratado). }\end{array}$ & 6 & 15 & 166 & 90 & 22 & 66,9 \\
\hline VP02-1.2 & $\begin{array}{l}\text { Documento todos os processos de contratação de serviços (aquisição; relatórios de conformidade; alterações } \\
\text { contratuais; etc.), para estudos e ações futuras. }\end{array}$ & 6 & 17 & 56 & 199 & 21 & 73,9 \\
\hline VP26-6.4 & $\begin{array}{l}\text { Utilizo as melhores (boas) práticas de gestão de TI adotadas pelo mercado como base de comparação e avaliação dos } \\
\text { serviços prestados. }\end{array}$ & 14 & 22 & 60 & 182 & 21 & 71,4 \\
\hline VP05-2.1 & Alinho as solicitações provenientes das áreas com as capacidades de atendimento do fornecedor do serviço. & 2 & 15 & 175 & 87 & 20 & 67,0 \\
\hline VP28-7.1 & $\begin{array}{l}\text { Avalio periodicamente procedimentos de conduta, acompanhando o relacionamento entre os usuários envolvidos no } \\
\text { projeto e funcionários do fornecedor do serviç. }\end{array}$ & 9 & 16 & 181 & 73 & 20 & 65,1 \\
\hline VP01-1.1 & $\begin{array}{l}\text { Verifico todos os processos de aquisição referentes à terceirização do desenvolvimento de SI sob medida e/ou } \\
\text { terceirização da implantação de pacotes de SI efetuados anteriormente. }\end{array}$ & 3 & 14 & 179 & 85 & 18 & 66,5 \\
\hline VP15-4.2 & Mantenho atualizados os tópicos da matriz de risco relacionados à prestação de serviços pelo fornecedor do serviço. & 17 & 143 & 65 & 57 & 17 & 54,1 \\
\hline VP13-3.4 & $\begin{array}{l}\text { Reviso periodicamente o cumprimento dos serviços executados pelo fornecedor do serviço para conclusão de um } \\
\text { conjunto de tarefas, passivo de aprovação e formalizaçăo. }\end{array}$ & 3 & 16 & 73 & 193 & 14 & 73,1 \\
\hline VP31-7.4 & $\begin{array}{l}\text { Promovo canais regulares de comunicação, acompanhando a comunicação entre os usuários envolvidos e o fornecedor } \\
\text { do serviço. }\end{array}$ & 8 & 27 & 72 & 179 & 13 & 70,6 \\
\hline VP32-7.5 & $\begin{array}{l}\text { Mantenho os funcionários das áreas usuárias capacitados, de acordo com a necessidade gerada pelo fornecimento do } \\
\text { serviço. }\end{array}$ & 5 & 15 & 180 & 86 & 13 & 65,6 \\
\hline VP14-4.1 & $\begin{array}{l}\text { Atuo preventivamente e corretivamente com base nas avaliações sobre a qualidade dos serviços prestados pelo } \\
\text { fornecedor do serviço. }\end{array}$ & 4 & 23 & 188 & 77 & 7 & 63,8 \\
\hline VP29-7.2 & Utilizo sistemas de informações computadorizados como ferramentas de apoio à gestão da terceirização. & 155 & 76 & 31 & 30 & 7 & 37,0 \\
\hline VP12-3.3 & $\begin{array}{l}\text { Utilizo metodologia para o desenvolvimento do projeto (exemplo: PMBok, Prince2, etc.) no desenvolvimento de SI sob } \\
\text { medida e/ou terceiriząăo da implantąăo de pacotes de SI. }\end{array}$ & 163 & 61 & 38 & 30 & 7 & 36,9 \\
\hline VP30-7.3 & $\begin{array}{l}\text { Certifico que o fornecedor do serviço capacita e acompanha a formação da equipe disponbilizada para a prestação de } \\
\text { cada serviço (em cada processo). }\end{array}$ & 31 & 176 & 60 & 26 & 6 & 46,5 \\
\hline
\end{tabular}


Apêndice H - Relação das práticas recomendadas - por ordem das que não são adotadas

\begin{tabular}{|c|c|c|c|c|c|c|c|}
\hline & Prática Recomendada & $\begin{array}{c}\text { Esta prática não } \\
\text { é adotada }\end{array}$ & $\mid \begin{array}{c}\text { Esta prática é } \\
\text { insuficientemente } \\
\text { adotada }\end{array}$ & $\begin{array}{c}\text { Esta prática é } \\
\text { suficientemente } \\
\text { adotada }\end{array}$ & $\begin{array}{c}\text { Esta prática é } \\
\text { plenamente } \\
\text { adotada }\end{array}$ & $\begin{array}{c}\text { Esta prática é } \\
\text { adotada de } \\
\text { maneira } \\
\text { excelente } \\
\end{array}$ & $\begin{array}{c}\text { Média } \\
\text { Ponderada }\end{array}$ \\
\hline VP12-3.3 & Utilizo metodologia para o desenvolvimento do projeto (exemplo: PMBok, Prince2, etc.) no desenvolvimento de SI sob & 163 & 61 & 38 & 30 & 7 & 36,9 \\
\hline VP29-7.2 & Utilizo sistemas de informações computadorizados como ferramentas de apoio à gestão da terceirização. & 155 & 76 & 31 & 30 & 7 & 37,0 \\
\hline VP30-7.3 & $\begin{array}{l}\text { Certifico que o fornecedor do serviço capacita e acompanha a formação da equipe disponibilizada para a prestação de } \\
\text { cada serviço (em cada processo). }\end{array}$ & 31 & 176 & 60 & 26 & 6 & 46,5 \\
\hline VP15-4.2 & Mantenho atualizados os tópicos da matriz de risco relacionados à prestação de serviços pelo fornecedor do serviço. & 17 & 143 & 65 & 57 & 17 & 54,1 \\
\hline VP04-1.4 & $\begin{array}{l}\text { Asseguro que o departamento juríico acompanhe e participe de todos os processos de contratação dos serviços } \\
\text { (alterações contratuais; litigios; etc.). }\end{array}$ & 16 & 8 & 38 & 56 & 181 & 85,0 \\
\hline VP26-6.4 & $\begin{array}{l}\text { Utilizo as melhores (boas) práticas de gestão de TI adotadas pelo mercado como base de comparação e avaliação dos } \\
\text { serviços prestados. }\end{array}$ & 14 & 22 & 60 & 182 & 21 & 71,4 \\
\hline VP20-5.2 & $\begin{array}{l}\text { Controlo e fiscalizo as licenças de uso de programas disponibilizados e utilizados pelo fornecedor do serviço dentro da } \\
\text { empresa. }\end{array}$ & 13 & 17 & 45 & 69 & 155 & 82,2 \\
\hline $\mathrm{VP} 07-2.3$ & Acompanho os SLA's firmados. & 10 & 16 & 47 & 191 & 35 & 74,8 \\
\hline VP28-7.1 & $\begin{array}{l}\text { Avalio periodicamente procedimentos de conduta, acompanhando o relacionamento entre os usuários envolvidos no } \\
\text { projeto e funcionários do fornecedor do serviço. }\end{array}$ & 9 & 16 & 181 & 73 & 20 & 65,1 \\
\hline VP19-5.1 & $\begin{array}{l}\text { Acompanho e avalio a infraestrutura de equipamentos disponibilizados e utilizados pelo fornecedor do serviço dentro da } \\
\text { empresa. }\end{array}$ & 9 & 14 & 53 & 78 & 145 & 82,2 \\
\hline VP31-7.4 & $\begin{array}{l}\text { Promovo canais regulares de comunicação, acompanhando a comunicação entre os usuários envolvidos e o fornecedor } \\
\text { do serviço. }\end{array}$ & 8 & 27 & 72 & 179 & 13 & 70,6 \\
\hline VP08-2.4 & $\begin{array}{l}\text { Controlo os planejamentos e/ou investimentos realizados pelo fornecedor do serviço durante a vigência do contrato a fim } \\
\text { de comprovação da capacidade técnica e/ou produtiva. }\end{array}$ & 8 & 20 & 53 & 195 & 23 & 73,5 \\
\hline VP24-6.2 & $\begin{array}{l}\text { Controlo periodicamente o orçamento destinado ao serviço contratado (a fim de que reflita as prioridades estabelecidas } \\
\text { pela empresa). }\end{array}$ & 8 & 10 & 43 & 198 & 40 & 76,6 \\
\hline VP27-6.5 & $\begin{array}{l}\text { Monitoro periodicamente o cumprimento das atribuições e responsabilidades do fornecedor do serviço (ratificar o } \\
\text { contratado). }\end{array}$ & 6 & 15 & 166 & 90 & 22 & 66,9 \\
\hline VP21-5.3 & $\begin{array}{l}\text { Acompanho o uso de técnicas ou tecnologias utilizadas pelo fornecedor do serviço a fim de garantir que não causem } \\
\text { problemas futuros para a empresa (exemplo: uso de uma linguagem de programação inadequada). }\end{array}$ & 6 & 15 & 172 & 64 & 42 & 67,9 \\
\hline VP02-1.2 & $\begin{array}{l}\text { Documento todos os processos de contratação de serviços (aquisição; relatórios de conformidade; alterações } \\
\text { contratuais; etc.), para estudos e açōes futuras. }\end{array}$ & 6 & 17 & 56 & 199 & 21 & 73,9 \\
\hline VP17-4.4 & $\begin{array}{l}\text { Discuto como fornecedor do serviço as suas práticas de formulação de definição de escopo, metodologias empregadas } \\
\text { e elaboraçăo de entregaveis. }\end{array}$ & 6 & 16 & 54 & 193 & 30 & 74,8 \\
\hline VP06-2.2 & Analiso, controlo e documento as alterações solicitadas pelas áreas usuárias. & 6 & 9 & 62 & 191 & 31 & 75,3 \\
\hline VP32-7.5 & $\begin{array}{l}\text { Mantenho os funcionários das áreas usuárias capacitados, de acordo com a necessidade gerada pelo formecimento do } \\
\text { serviço. }\end{array}$ & 5 & 15 & 180 & 86 & 13 & 65,6 \\
\hline VP10-3.1 & Utilizo métodos (próprios ou de melhores práticas de mercado) para avaliação do fornecedor do serviço. & 5 & 16 & 66 & 190 & 22 & 73,7 \\
\hline VP3-1.3 & Utilizo normas (próprias ou de melhores práticas de mercado) para seleção do fornecedor do serviço. & 5 & 15 & 56 & 200 & 23 & 74,5 \\
\hline VP18-4.5 & $\begin{array}{l}\text { Realizo com as áreas usuárias, as suas práticas de formulação de definição de escopo, metodologias sugeridas e demais } \\
\text { processos inerentes. }\end{array}$ & 5 & 13 & 58 & 193 & 30 & 75,1 \\
\hline VP14-4.1 & $\begin{array}{l}\text { Atuo preventivamente e corretivamente com base nas avaliações sobre a qualidade dos serviços prestados pelo } \\
\text { fornecedor do serviço. }\end{array}$ & 4 & 23 & 188 & 77 & 7 & 63,8 \\
\hline VP22-5.4 & Monitoro o fornecedor do serviço a fim de que cumpram as politicas que regem o gerenciamento da terceirzzação da TI. & 4 & 15 & 166 & 91 & 23 & 67,4 \\
\hline VP23-6.1 & $\begin{array}{l}\text { Realizo controles financeiros periódicos. (dos valores que foram acordados contratualmente com o que foi efetivamente } \\
\text { entregue pelo fornecedor do serviço). }\end{array}$ & 4 & 9 & 50 & 85 & 151 & 84,5 \\
\hline VP01-1.1 & $\begin{array}{l}\text { Verifico todos os processos de aquisição referentes à terceirzzação do desenvolvimento de SI sob medida e/ou } \\
\text { terceirização da implantação de pacotes de SI efettuados anteriormente. }\end{array}$ & 3 & 14 & 179 & 85 & 18 & 66,5 \\
\hline VP16-4.3 & Controlo eventuais problemas e incidentes decorrentes da prestação de serviços realizada pelo fornecedor. & 3 & 14 & 169 & 89 & 24 & 67,6 \\
\hline VP25-6.3 & $\begin{array}{l}\text { Acompanho as ações desenvolvidas pelo fornecedor do serviço para garantir que agreguem valor ao negócio da } \\
\text { empresa. }\end{array}$ & 3 & 12 & 173 & 84 & 27 & 67,8 \\
\hline VP13-3.4 & $\begin{array}{l}\text { Reviso periodicamente o cumprimento dos serviços executados pelo fornecedor do serviço para conclusão de um } \\
\text { conjunto de tarefas, passivo de aprovação e formalização. }\end{array}$ & 3 & 16 & 73 & 193 & 14 & 73,1 \\
\hline VP05-2.1 & Alinho as solicitações provenientes das áreas com as capacidades de atendimento do fornecedor do serviço. & 2 & 15 & 175 & 87 & 20 & 67,0 \\
\hline VP09-2.5 & Acompanho a capacidade técnica do fornecedor do servị̣o. & 2 & 11 & 65 & 190 & 31 & 75,6 \\
\hline VP11-3.2 & Acompanho a qualidade dos serviços executados pelo fornecedor do serviço. & 1 & 7 & 58 & 89 & 144 & 84,3 \\
\hline
\end{tabular}




\section{Apêndice I - Relação dos resultados obtidos em decorrência da terceirização de serviços} de TI - por ordem do índice "nenhum resultado"

\begin{tabular}{|c|c|c|c|c|c|c|c|}
\hline \multicolumn{2}{|r|}{ Resultados Obtidos } & \multirow{2}{*}{$\begin{array}{c}\text { Nenhum } \\
\text { resultado }\end{array}$} & \multirow{2}{*}{\begin{tabular}{|c|c|}
$\begin{array}{c}\text { Pouco } \\
\text { Resultado }\end{array}$ \\
2
\end{tabular}} & \multirow{2}{*}{\begin{tabular}{|c|}
$\begin{array}{c}\text { Resultado } \\
\text { Mediano }\end{array}$ \\
3 \\
\end{tabular}} & \multirow{2}{*}{\begin{tabular}{|c|} 
Acima da \\
Média \\
mas não \\
completa \\
mente \\
4
\end{tabular}} & \multirow{2}{*}{\begin{tabular}{|c|}
$\begin{array}{c}\text { Obtido } \\
\text { Completa } \\
\text { mente }\end{array}$ \\
5 \\
\end{tabular}} & \multirow{2}{*}{$\begin{array}{c}\text { Média } \\
\text { Ponderada }\end{array}$} \\
\hline & & & & & & & \\
\hline VR6-2.2 & $\begin{array}{l}\text { Os prazos "estipulados" para o projeto do sistema terceirizado (desenvolvido ou implantado) } \\
\text { foram "cumpridos na integra" até a entrega final? }\end{array}$ & 25 & 177 & 36 & 44 & 17 & 49,9 \\
\hline VR5-2.1 & $\begin{array}{l}\text { Os valores "orçados" para o projeto do sistema terceirizado (desenvolvido ou implantado) foram } \\
\text { "realizados" (cumpridos na integra) até a entrega final? }\end{array}$ & 10 & 18 & 33 & 52 & 186 & 85,5 \\
\hline VR1-1.1 & $\begin{array}{l}\text { A empresa obteve reduções de custos em função do sistema terceirizado (desenvolvido ou } \\
\text { implantado)? }\end{array}$ & 6 & 12 & 25 & 214 & 42 & 78,1 \\
\hline VR9-3.1 & $\begin{array}{l}\text { Houve aumento na capacidade de processamento dos dados em função do sistema terceirizado } \\
\text { (desenvolvido ou implantado)? }\end{array}$ & 5 & 7 & 19 & 87 & 181 & 88,6 \\
\hline VR7-2.3 & $\begin{array}{l}\text { Após a disponibilização do sistema terceirizado (desenvolvido ou implantado), houve aumento da } \\
\text { flexibilidade na realização das tarefas pelos usuários finais? }\end{array}$ & 3 & 11 & 28 & 215 & 42 & 78,6 \\
\hline VR4-1.4 & $\begin{array}{l}\text { A empresa aumentou seu foco no ponto forte e estratégico de atuação (core business) em função } \\
\text { do sistema terceirizado (desenvolvido ou implantado)? }\end{array}$ & 3 & 9 & 33 & 190 & 64 & 80,0 \\
\hline VR3-1.3 & $\begin{array}{l}\begin{array}{l}\text { Obteve-se aumento da integração dos processos em função do sistema terceirizado } \\
\text { (desenvolvido ou implantado)? }\end{array} \\
\end{array}$ & 3 & 7 & 30 & 198 & 61 & 80,3 \\
\hline VR2-1.2 & $\begin{array}{l}\text { O sistema terceirizado (desenvolvido ou implantado) proporcionou maior segurança nos } \\
\text { dados/informaçoses para a empresa? }\end{array}$ & 2 & 8 & 28 & 203 & 58 & 80,3 \\
\hline VR11-3.3 & $\begin{array}{l}\text { A empresa obteve aumento da produtividade dos usuários finais (capacidade de realização dos } \\
\text { serviços executados) em função do sistema terceirizado (desenvolvido ou implantado)? }\end{array}$ & 2 & 4 & 27 & 67 & 199 & 90,3 \\
\hline VR8-2.4 & $\begin{array}{l}\text { De uma forma geral, houve redução no número ou na complexidade dos problemas inerentes aos } \\
\text { processos ou execução dos serviços em função do sistema terceirizado (desenvolvido ou } \\
\text { implantado)? }\end{array}$ & 1 & 11 & 27 & 198 & 62 & 80,4 \\
\hline VR13-4.2 & $\begin{array}{l}\text { Houve melhoria na qualidade do uso (usabilidade) do sistema terceirizado (desenvolvido ou } \\
\text { implantado) por parte dos usuários finais? }\end{array}$ & 1 & 6 & 29 & 179 & 84 & 82,4 \\
\hline VR10-3.2 & $\begin{array}{l}\text { A empresa obteve otimização/melhoria nos processos executados pelos usuários finais, em função } \\
\text { do sistema terceirizado (desenvolvido ou implantado)? }\end{array}$ & 1 & 4 & 21 & 182 & 91 & 83,7 \\
\hline VR12-4.1 & $\begin{array}{l}\text { Após a disponibilização do sistema terceirizado (desenvolvido ou implantado), houve um salto de } \\
\text { qualidade na realização das atividades-fim dos usuários finais? }\end{array}$ & 0 & 8 & 30 & 69 & 192 & 89,5 \\
\hline VR14-4.3 & $\begin{array}{l}\text { A empresa obteve melhoria na qualidade dos dados/informações oriundos do sistema terceirizado } \\
\text { (desenvolvido ou implantado)? }\end{array}$ & 0 & 3 & 23 & 68 & 205 & 91,5 \\
\hline
\end{tabular}




\section{Apêndice J - Relação dos resultados obtidos em decorrência da terceirização de serviços de TI - por ordem do índice "obtido completamente"}

\begin{tabular}{|c|c|c|c|c|c|c|c|}
\hline & Resultados Obtidos & $\begin{array}{c}\text { Nenhum } \\
\text { resultado } \\
1\end{array}$ & $\begin{array}{c}\text { Pouco } \\
\text { Resultado }\end{array}$ & \begin{tabular}{|c|} 
Resultado \\
Mediano
\end{tabular} & \begin{tabular}{|c}
$\begin{array}{c}\text { Acima da } \\
\text { Média } \\
\text { mas não } \\
\text { completa } \\
\text { mente }\end{array}$ \\
4
\end{tabular} & \begin{tabular}{|c|}
$\begin{array}{c}\text { Obtido } \\
\text { Completa } \\
\text { mente }\end{array}$ \\
5
\end{tabular} & $\begin{array}{c}\text { Média } \\
\text { Ponderada }\end{array}$ \\
\hline VR14-4.3 & $\begin{array}{l}\text { A empresa obteve melhoria na qualidade dos dados/informações oriundos do sistema terceirzado } \\
\text { (desenvolvido ou implantado)? }\end{array}$ & 1 & 2 & 23 & 68 & 205 & Ponderada \\
\hline VR11-3.3 & $\begin{array}{l}\text { A empresa obteve aumento da produtividade dos usuários finais (capacidade de realização dos } \\
\text { serviços executados) em função do sistema terceirizado (desenvolvido ou implantado)? }\end{array}$ & 2 & 4 & 27 & 67 & 199 & 90,3 \\
\hline VR12-4.1 & $\begin{array}{l}\text { Após a disponibilização do sistema terceirizado (desenvolvido ou implantado), houve um salto de } \\
\text { qualidade na realização das atividades-fim dos usuários finais? }\end{array}$ & 0 & 8 & 30 & 69 & 192 & 89,5 \\
\hline VR5-2.1 & $\begin{array}{l}\text { Os valores "orçados" para o projeto do sistema terceirizado (desenvolvido ou implantado) foram } \\
\text { "realizados" (cumpridos na integra) até a entrega final? }\end{array}$ & 10 & 18 & 33 & 52 & 186 & 85,5 \\
\hline VR9-3.1 & $\begin{array}{l}\text { Houve aumento na capacidade de processamento dos dados em função do sistema terceirizado } \\
\text { (desenvolvido ou implantado)? }\end{array}$ & 5 & 7 & 19 & 87 & 181 & 88,6 \\
\hline VR10-3.2 & $\begin{array}{l}\text { A empresa obteve otimização/melhoria nos processos executados pelos usuários finais, em função } \\
\text { do sistema terceirizado (desenvolvido ou implantado)? }\end{array}$ & 1 & 4 & 21 & 182 & 91 & 83,7 \\
\hline VR13-4.2 & $\begin{array}{l}\text { Houve melhoria na qualidade do uso (usabilidade) do sistema terceirizado (desenvolvido ou } \\
\text { implantado) por parte dos usuários finais? }\end{array}$ & 1 & 6 & 29 & 179 & 84 & 82,4 \\
\hline VR4-1.4 & $\begin{array}{l}\text { A empresa aumentou seu foco no ponto forte e estratégico de atuação (core business) em função } \\
\text { do sistema terceirizado (desenvolvido ou implantado)? }\end{array}$ & 3 & 9 & 33 & 190 & 64 & 80,0 \\
\hline VR8-2.4 & $\begin{array}{l}\text { De uma forma geral, houve redução no número ou na complexidade dos problemas inerentes aos } \\
\text { processos ou execução dos serviços em função do sistema terceirzado (desenvolvido ou } \\
\text { implantado)? }\end{array}$ & 1 & 11 & 27 & 198 & 62 & 80,4 \\
\hline VR3-1.3 & $\begin{array}{l}\text { Obteve-se aumento da integração dos processos em função do sistema terceirizado } \\
\text { (desenvolvido ou implantado)? }\end{array}$ & 3 & 7 & 30 & 198 & 61 & 80,3 \\
\hline VR2-1.2 & $\begin{array}{l}\text { O sistema terceirizado (desenvolvido ou implantado) proporcionou maior segurança nos } \\
\text { dados/informações para a empresa? }\end{array}$ & 2 & 8 & 28 & 203 & 58 & 80,3 \\
\hline VR1-1.1 & $\begin{array}{l}\text { A empresa obteve reduções de custos em função do sistema terceirizado (desenvolvido ou } \\
\text { implantado)? }\end{array}$ & 6 & 12 & 25 & 214 & 42 & 78,1 \\
\hline VR7-2.3 & $\begin{array}{l}\text { Após a disponibilização do sistema terceirizado (desenvolvido ou implantado), houve aumento da } \\
\text { flexibilidade na realização das tarefas pelos usuários finais? }\end{array}$ & 3 & 11 & 28 & 215 & 42 & 78,6 \\
\hline VR6-2.2 & $\begin{array}{l}\text { Os prazos "estipulados" para o projeto do sistema terceirizado (desenvolvido ou implantado) } \\
\text { foram "cumpridos na integra" até a entrega final? }\end{array}$ & 25 & 177 & 36 & 44 & 17 & 49,9 \\
\hline
\end{tabular}




\section{Apêndice K - Resultados da terceirização de serviços de TI por setor e por grau de formalidade}

K1. VR1-1.1 - A empresa obteve reduções de custos em função do sistema terceirizado (desenvolvido ou implantado)?

\begin{tabular}{|c|c|c|c|c|c|c|c|c|c|}
\hline \multirow{2}{*}{\multicolumn{2}{|c|}{ VE13 - Grau de formalidade - Contratacão }} & & & \multicolumn{5}{|c|}{ VR1-1.1 - A empresa obteve reduções de custos em função do sistema terceirizado } & \multirow[b]{2}{*}{ Total } \\
\hline & & & & $\begin{array}{c}\text { Nenhum } \\
\text { Resultado }\end{array}$ & $\begin{array}{c}\text { Pouco } \\
\text { Resultado } \\
\end{array}$ & $\begin{array}{l}\text { Resultado } \\
\text { Mediano }\end{array}$ & $\begin{array}{c}\text { Acima da } \\
\text { Média mas } \\
\text { não } \\
\text { completamen } \\
\text { te }\end{array}$ & $\begin{array}{c}\text { Obtido } \\
\text { Completame } \\
\text { nte }\end{array}$ & \\
\hline \multirow[t]{5}{*}{ Informal (sem contrato) } & VE2 - Setor & Indústria & $\begin{array}{l}\text { Count } \\
\% \text { of Total }\end{array}$ & & & $\begin{array}{r}1 \\
25.0 \%\end{array}$ & $\begin{array}{r}1 \\
25,0 \%\end{array}$ & & $\begin{array}{r}2 \\
50,0 \%\end{array}$ \\
\hline & & Comércio & Count & & & 1 & 0 & & 1 \\
\hline & & & $\%$ of Total & & & $25,0 \%$ &, $0 \%$ & & $25,0 \%$ \\
\hline & & Serviço & $\begin{array}{l}\text { Count } \\
\% \text { of Total }\end{array}$ & & & $\begin{array}{r}1 \\
25,0 \%\end{array}$ & $\begin{array}{r}0 \\
0 \%\end{array}$ & & $\begin{array}{r}1 \\
25,0 \%\end{array}$ \\
\hline & Total & & $\begin{array}{l}\text { Count } \\
\% \text { of Total }\end{array}$ & & & $\begin{array}{r}3 \\
75,0 \%\end{array}$ & $\begin{array}{r}1 \\
25,0 \%\end{array}$ & & $\begin{array}{r}4 \\
100,0 \%\end{array}$ \\
\hline \multirow{7}{*}{$\begin{array}{l}\text { Contrato formal sem } \\
\text { detallhamento (cláusulas } \\
\text { padrão) }\end{array}$} & VE2 - Setor & Indústria & $\begin{array}{l}\text { Count } \\
\% \text { of Total }\end{array}$ & $\begin{array}{r}2 \\
3.0 \%\end{array}$ & $\begin{array}{r}1 \\
1.5 \%\end{array}$ & $\begin{array}{r}2 \\
3.0 \%\end{array}$ & $\begin{array}{r}18 \\
27.3 \%\end{array}$ & $\begin{array}{r}5 \\
76 \%\end{array}$ & $\begin{array}{r}28 \\
42.4 \%\end{array}$ \\
\hline & & Comércio & Count & 0 & 0 & 1 & 7 & 1 & 9 \\
\hline & & & $\%$ of Total &, $0 \%$ &, $0 \%$ & $1,5 \%$ & $10,6 \%$ & $1,5 \%$ & $13,6 \%$ \\
\hline & & Serviço & Count & 1 & 4 & 2 & 20 & 2 & 29 \\
\hline & & & $\%$ of Total & $1,5 \%$ & $6,1 \%$ & $3,0 \%$ & $30,3 \%$ & $3,0 \%$ & $43,9 \%$ \\
\hline & Total & & Count & 3 & 5 & 5 & 45 & 8 & 66 \\
\hline & & & $\%$ of Total & $4,5 \%$ & $7,6 \%$ & $7,6 \%$ & $68,2 \%$ & $12,1 \%$ & $100,0 \%$ \\
\hline \multirow{8}{*}{$\begin{array}{l}\text { Contrato formal } \\
\text { detalhado - sem SLA }\end{array}$} & VE2 - Setor & Indústria & Count & & 2 & 4 & 16 & 6 & 28 \\
\hline & & & $\%$ of Total & & $3,5 \%$ & $7,0 \%$ & $28,1 \%$ & $10,5 \%$ & $49,1 \%$ \\
\hline & & Comércio & Count & & 1 & 0 & 6 & 2 & 9 \\
\hline & & & $\%$ of Total & & $1,8 \%$ &, $0 \%$ & $10,5 \%$ & $3,5 \%$ & $15,8 \%$ \\
\hline & & Serviço & Count & & 1 & 0 & 17 & 2 & 20 \\
\hline & & & $\%$ of Total & & $1,8 \%$ &, $0 \%$ & $29,8 \%$ & $3,5 \%$ & $35,1 \%$ \\
\hline & Total & & Count & & 4 & 4 & 39 & 10 & 57 \\
\hline & & & $\%$ of Total & & $7,0 \%$ & $7,0 \%$ & $68,4 \%$ & $17,5 \%$ & $100,0 \%$ \\
\hline \multirow{8}{*}{$\begin{array}{l}\text { Contrato formal } \\
\text { detalhado - com SLA }\end{array}$} & VE2 - Setor & Indústria & Count & 1 & 1 & 2 & 65 & 13 & 82 \\
\hline & & & $\%$ of Total & ,6\% &, $6 \%$ & $1,2 \%$ & $37,8 \%$ & $7,6 \%$ & $47,7 \%$ \\
\hline & & Comércio & Count & 0 & 0 & 2 & 14 & 4 & 20 \\
\hline & & & $\%$ of Total & $.0 \%$ & $.0 \%$ & $1,2 \%$ & $8,1 \%$ & $2,3 \%$ & $11,6 \%$ \\
\hline & & Serviço & Count & 2 & 2 & 9 & 50 & 7 & 70 \\
\hline & & & $\%$ of Total & $1,2 \%$ & $1,2 \%$ & $5,2 \%$ & $29,1 \%$ & $4,1 \%$ & $40,7 \%$ \\
\hline & Total & & Count & 3 & 3 & 13 & 129 & 24 & 172 \\
\hline & & & $\%$ of Total & $1,7 \%$ & $1,7 \%$ & $7,6 \%$ & $75,0 \%$ & $14,0 \%$ & $100,0 \%$ \\
\hline
\end{tabular}

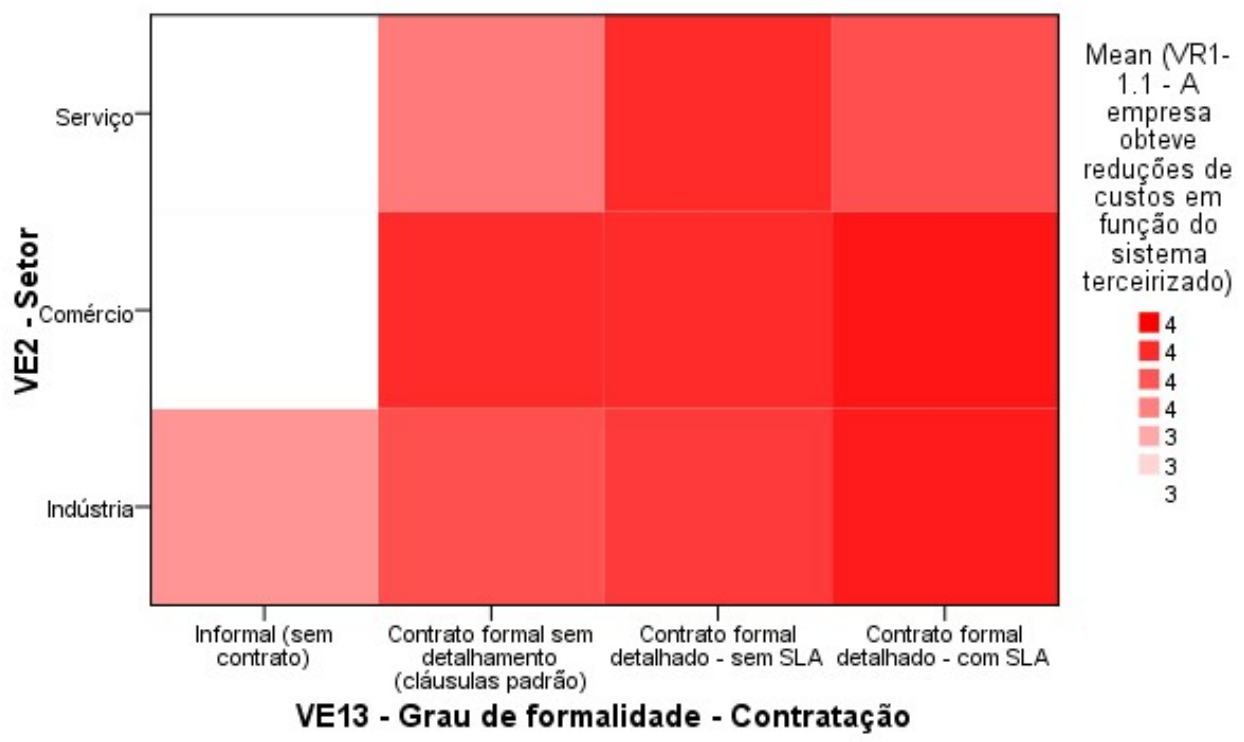


K2. VR2-1.2 - O sistema terceirizado (desenvolvido ou implantado) proporcionou maior segurança nos dados/informações para a empresa?

VE2 - Setor * VR2-1.2 - O sistema terceirizado (desenvolvido ou implantado) proporcionou maior segurança * VE13 - Grau de formalidade - Contratação

\begin{tabular}{|c|c|c|c|c|c|c|c|c|c|}
\hline \multirow{2}{*}{\multicolumn{2}{|c|}{ VE13 - Grau de formalidade - Contratacäo }} & & & \multicolumn{5}{|c|}{$\begin{array}{c}\text { VR2-1.2 - O sistema terceirizado (desenvolvido ou implantado) proporcionou maior } \\
\text { segurança }\end{array}$} & \multirow[b]{2}{*}{ Total } \\
\hline & & & & $\begin{array}{l}\text { Nenhum } \\
\text { Resultado }\end{array}$ & $\begin{array}{c}\text { Pouco } \\
\text { Resultado } \\
\end{array}$ & $\begin{array}{l}\text { Resultado } \\
\text { Mediano }\end{array}$ & $\begin{array}{c}\text { Acima da } \\
\text { Média mas } \\
\text { não } \\
\text { completamen } \\
\text { te } \\
\end{array}$ & $\begin{array}{c}\text { Obtido } \\
\text { Completame } \\
\text { nte }\end{array}$ & \\
\hline \multirow[t]{8}{*}{ Informal (sem contrato) } & VE2 - Setor & Indústria & Count & & & 1 & 1 & & 2 \\
\hline & & & $\%$ of Total & & & $25,0 \%$ & $25,0 \%$ & & $50,0 \%$ \\
\hline & & Comércio & Count & & & 0 & 1 & & 1 \\
\hline & & & $\%$ of Total & & &, $0 \%$ & $25,0 \%$ & & $25,0 \%$ \\
\hline & & Serviço & Count & & & 1 & 0 & & 1 \\
\hline & & & $\%$ of Total & & & $25,0 \%$ &, $0 \%$ & & $25,0 \%$ \\
\hline & Total & & Count & & & 2 & 2 & & 4 \\
\hline & & & $\%$ of Total & & & $50,0 \%$ & $50,0 \%$ & & $100,0 \%$ \\
\hline \multirow{8}{*}{$\begin{array}{l}\text { Contrato formal sem } \\
\text { detalhamento (cláusulas } \\
\text { padrão) }\end{array}$} & VE2 - Setor & Indústria & Count & 0 & 1 & 4 & 18 & 5 & 28 \\
\hline & & & $\%$ of Total &, $0 \%$ & $1,5 \%$ & $6,1 \%$ & $27,3 \%$ & $7,6 \%$ & $42,4 \%$ \\
\hline & & Comércio & Count & 0 & 1 & 0 & 6 & 2 & 9 \\
\hline & & & $\%$ of Total &, $0 \%$ & $1,5 \%$ &, $0 \%$ & $9,1 \%$ & $3,0 \%$ & $13,6 \%$ \\
\hline & & Serviço & Count & 2 & 3 & 3 & 15 & 6 & 29 \\
\hline & & & $\%$ of Total & $3,0 \%$ & $4,5 \%$ & $4,5 \%$ & $22,7 \%$ & $9,1 \%$ & $43,9 \%$ \\
\hline & Total & & Count & 2 & 5 & 7 & 39 & 13 & 66 \\
\hline & & & $\%$ of Total & $3,0 \%$ & $7,6 \%$ & $10,6 \%$ & $59,1 \%$ & $19,7 \%$ & $100,0 \%$ \\
\hline \multirow{8}{*}{$\begin{array}{l}\text { Contrato formal } \\
\text { detalhado - sem SLA }\end{array}$} & VE2 - Setor & Indústria & Count & & & 4 & 15 & 9 & 28 \\
\hline & & & $\%$ of Total & & & $7,0 \%$ & $26,3 \%$ & $15,8 \%$ & $49,1 \%$ \\
\hline & & Comércio & Count & & & 0 & 7 & 2 & 9 \\
\hline & & & $\%$ of Total & & &, $0 \%$ & $12,3 \%$ & $3,5 \%$ & $15,8 \%$ \\
\hline & & Serviço & Count & & & 3 & 13 & 4 & 20 \\
\hline & & & $\%$ of Total & & & $5,3 \%$ & $22,8 \%$ & $7,0 \%$ & $35,1 \%$ \\
\hline & Total & & Count & & & 7 & 35 & 15 & 57 \\
\hline & & & $\%$ of Total & & & $12,3 \%$ & $61,4 \%$ & $26,3 \%$ & $100,0 \%$ \\
\hline \multirow{8}{*}{$\begin{array}{l}\text { Contrato formal } \\
\text { detalhado - com SLA }\end{array}$} & VE2 - Setor & Indústria & Count & & 1 & 4 & 61 & 16 & 82 \\
\hline & & & $\%$ of Total & &, $6 \%$ & $2,3 \%$ & $35,5 \%$ & $9,3 \%$ & $47,7 \%$ \\
\hline & & Comércio & Count & & 1 & 0 & 17 & 2 & 20 \\
\hline & & & $\%$ of Total & &, $6 \%$ &, $0 \%$ & $9,9 \%$ & $1,2 \%$ & $11,6 \%$ \\
\hline & & Serviço & Count & & 1 & 8 & 49 & 12 & 70 \\
\hline & & & $\%$ of Total & & $.6 \%$ & $4,7 \%$ & $28,5 \%$ & $7,0 \%$ & $40,7 \%$ \\
\hline & Total & & Count & & 3 & 12 & 127 & 30 & 172 \\
\hline & & & $\%$ of Total & & $1,7 \%$ & $7,0 \%$ & $73,8 \%$ & $17,4 \%$ & $100,0 \%$ \\
\hline
\end{tabular}

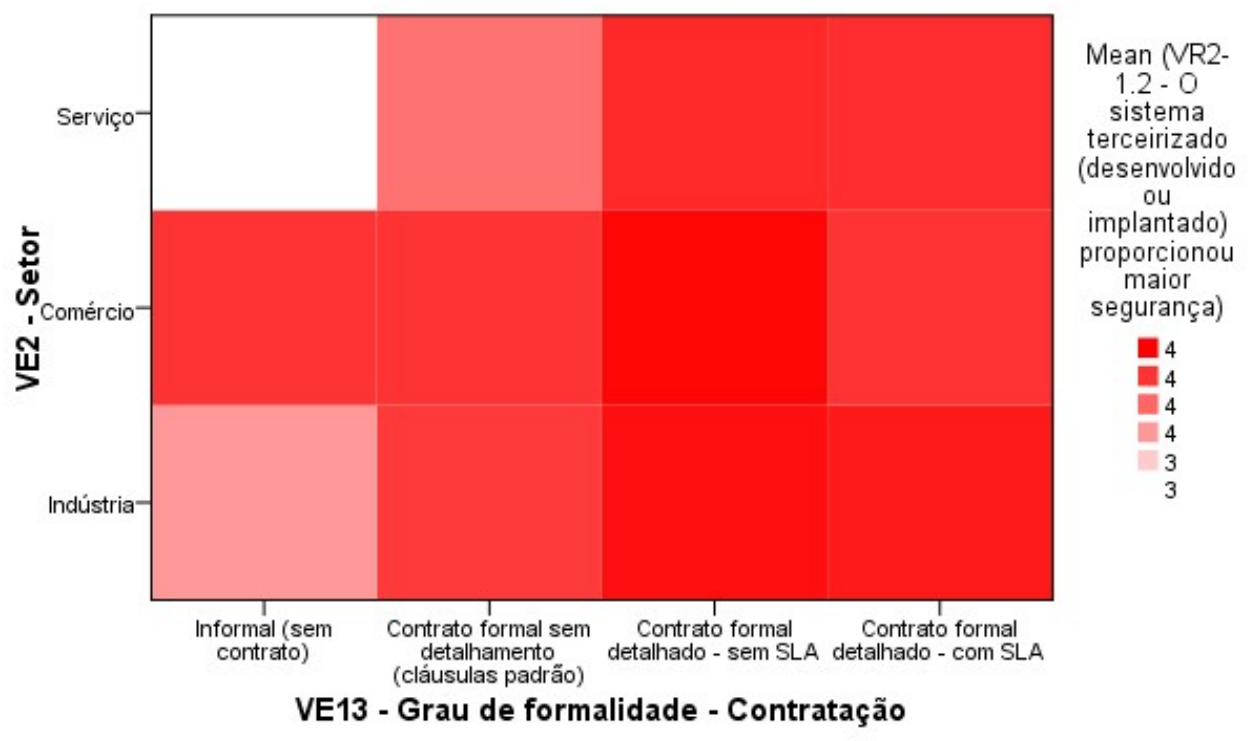


K3. VR3-1.3 - Obteve-se aumento da integração dos processos em função do sistema terceirizado (desenvolvido ou implantado)?

VE2 - Setor * VR3-1.3 - Obteve-se aumento da integração dos processos em função do sistema terceirizado * VE13 - Grau de formalidade - Contratação

\begin{tabular}{|c|c|c|c|c|c|c|c|c|c|}
\hline \multirow{2}{*}{\multicolumn{2}{|c|}{ VE13 - Grau de formalidade - Contratacäo }} & & & \multicolumn{5}{|c|}{$\begin{array}{l}\text { VR3-1.3 - Obteve-se aumento da integração dos processos em função do sistema } \\
\text { terceirizado }\end{array}$} & \multirow[b]{2}{*}{ Total } \\
\hline & & & & $\begin{array}{c}\text { Nenhum } \\
\text { Resultado }\end{array}$ & $\begin{array}{c}\text { Pouco } \\
\text { Resultado } \\
\end{array}$ & $\begin{array}{l}\text { Resultado } \\
\text { Mediano }\end{array}$ & $\begin{array}{c}\text { Acima da } \\
\text { Média mas } \\
\text { não } \\
\text { completamen } \\
\text { te } \\
\end{array}$ & $\begin{array}{c}\text { Obtido } \\
\text { Completame } \\
\text { nte }\end{array}$ & \\
\hline \multirow[t]{8}{*}{ Informal (sem contrato) } & VE2 - Setor & Indústria & Count & & & 0 & 2 & & 2 \\
\hline & & & $\%$ of Total & & &, $0 \%$ & $50,0 \%$ & & $50,0 \%$ \\
\hline & & Comércio & Count & & & 1 & 0 & & 1 \\
\hline & & & $\%$ of Total & & & $25,0 \%$ &, $0 \%$ & & $25,0 \%$ \\
\hline & & Serviço & Count & & & 1 & 0 & & 1 \\
\hline & & & $\%$ of Total & & & $25,0 \%$ &, $0 \%$ & & $25,0 \%$ \\
\hline & Total & & Count & & & 2 & 2 & & 4 \\
\hline & & & $\%$ of Total & & & $50,0 \%$ & $50,0 \%$ & & $100,0 \%$ \\
\hline \multirow{8}{*}{$\begin{array}{l}\text { Contrato formal sem } \\
\text { detalhamento (cláusulas } \\
\text { padrão) }\end{array}$} & VE2 - Setor & Indústria & Count & 1 & 0 & 5 & 17 & 5 & 28 \\
\hline & & & $\%$ of Total & $1,5 \%$ &, $0 \%$ & $7,6 \%$ & $25,8 \%$ & $7,6 \%$ & $42,4 \%$ \\
\hline & & Comércio & Count & 0 & 0 & 1 & 5 & 3 & 9 \\
\hline & & & $\%$ of Total &, $0 \%$ &, $0 \%$ & $1,5 \%$ & $7,6 \%$ & $4,5 \%$ & $13,6 \%$ \\
\hline & & Serviço & Count & 2 & 1 & 5 & 15 & 6 & 29 \\
\hline & & & $\%$ of Total & $3,0 \%$ & $1,5 \%$ & $7,6 \%$ & $22,7 \%$ & $9,1 \%$ & $43,9 \%$ \\
\hline & Total & & Count & 3 & 1 & 11 & 37 & 14 & 66 \\
\hline & & & $\%$ of Total & $4,5 \%$ & $1,5 \%$ & $16,7 \%$ & $56,1 \%$ & $21,2 \%$ & $100,0 \%$ \\
\hline \multirow{8}{*}{$\begin{array}{l}\text { Contrato formal } \\
\text { detalhado - sem SLA }\end{array}$} & VE2 - Setor & Indústria & Count & & 2 & 3 & 14 & 9 & 28 \\
\hline & & & $\%$ of Total & & $3,5 \%$ & $5,3 \%$ & $24,6 \%$ & $15,8 \%$ & $49,1 \%$ \\
\hline & & Comércio & Count & & 0 & 0 & 7 & 2 & 9 \\
\hline & & & $\%$ of Total & &, $0 \%$ &, $0 \%$ & $12,3 \%$ & $3,5 \%$ & $15,8 \%$ \\
\hline & & Serviço & Count & & 2 & 0 & 15 & 3 & 20 \\
\hline & & & $\%$ of Total & & $3,5 \%$ &, $0 \%$ & $26,3 \%$ & $5,3 \%$ & $35,1 \%$ \\
\hline & Total & & Count & & 4 & 3 & 36 & 14 & 57 \\
\hline & & & $\%$ of Total & & $7,0 \%$ & $5,3 \%$ & $63,2 \%$ & $24,6 \%$ & $100,0 \%$ \\
\hline \multirow{8}{*}{$\begin{array}{l}\text { Contrato formal } \\
\text { detalhado - com SLA }\end{array}$} & VE2 - Setor & Indústria & Count & & 2 & 4 & 57 & 19 & 82 \\
\hline & & & $\%$ of Total & & $1,2 \%$ & $2,3 \%$ & $33,1 \%$ & $11,0 \%$ & $47,7 \%$ \\
\hline & & Comércio & Count & & 0 & 1 & 16 & 3 & 20 \\
\hline & & & $\%$ of Total & & $.0 \%$ &, $6 \%$ & $9,3 \%$ & $1,7 \%$ & $11,6 \%$ \\
\hline & & Serviço & Count & & 0 & 9 & 50 & 11 & 70 \\
\hline & & & $\%$ of Total & & $.0 \%$ & $5,2 \%$ & $29,1 \%$ & $6,4 \%$ & $40,7 \%$ \\
\hline & Total & & Count & & 2 & 14 & 123 & 33 & 172 \\
\hline & & & $\%$ of Total & & $1,2 \%$ & $8,1 \%$ & $71,5 \%$ & $19,2 \%$ & $100,0 \%$ \\
\hline
\end{tabular}

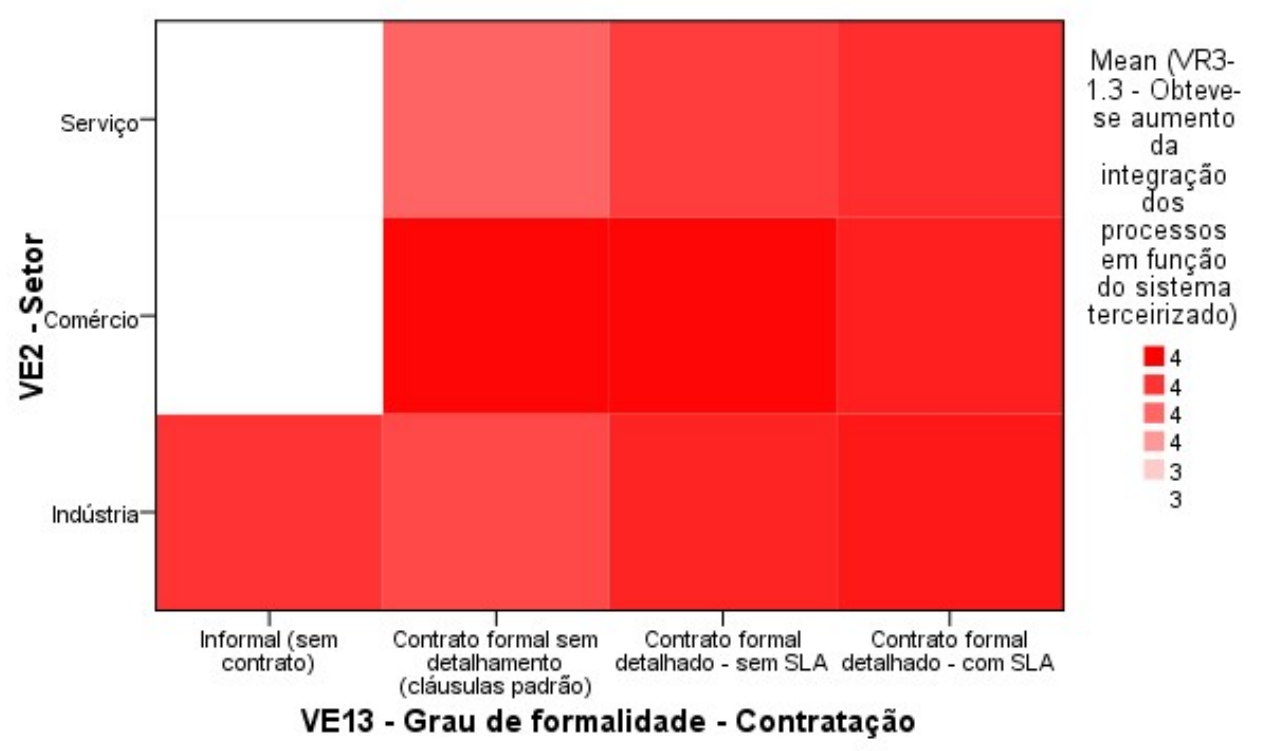


K4. VR4-1.4 - A empresa aumentou seu foco no ponto forte e estratégico de atuação (core business) em função do sistema terceirizado (desenvolvido ou implantado)?

\begin{tabular}{|c|c|c|c|c|c|c|c|c|c|}
\hline & & & & \multicolumn{5}{|c|}{ VR4-1.4-A empresa aumentou seu foco no ponto forte e estratégico de atuação } & \multirow[b]{2}{*}{ Total } \\
\hline VE13-Grau de formalidad & - Contratacão & & & $\begin{array}{l}\text { Nenhum } \\
\text { Resultado }\end{array}$ & $\begin{array}{c}\text { Pouco } \\
\text { Resultado }\end{array}$ & $\begin{array}{l}\text { Resultado } \\
\text { Mediano }\end{array}$ & $\begin{array}{c}\text { Acima da } \\
\text { Média mas } \\
\text { não } \\
\text { completamen } \\
\text { te }\end{array}$ & $\begin{array}{c}\text { Obtido } \\
\text { Completame } \\
\text { nte }\end{array}$ & \\
\hline \multirow[t]{8}{*}{ Informal (sem contrato) } & VE2 - Setor & Indústria & Count & & 0 & 0 & 2 & & 2 \\
\hline & & & $\%$ of Total & & $.0 \%$ &, $0 \%$ & $50,0 \%$ & & $50,0 \%$ \\
\hline & & Comércio & Count & & 0 & 1 & 0 & & 1 \\
\hline & & & $\%$ of Total & & $.0 \%$ & $25,0 \%$ &, $0 \%$ & & $25,0 \%$ \\
\hline & & Serviço & Count & & 1 & 0 & 0 & & 1 \\
\hline & & & $\%$ of Total & & $25,0 \%$ &, $0 \%$ &, $0 \%$ & & $25,0 \%$ \\
\hline & Total & & Count & & 1 & 1 & 2 & & 4 \\
\hline & & & $\%$ of Total & & $25,0 \%$ & $25,0 \%$ & $50,0 \%$ & & $100,0 \%$ \\
\hline \multirow{8}{*}{$\begin{array}{l}\text { Contrato formal sem } \\
\text { detalhamento (cláusulas } \\
\text { padrão) }\end{array}$} & VE2 - Setor & Indústria & Count & & 0 & 6 & 15 & 7 & 28 \\
\hline & & & $\%$ of Total & & $.0 \%$ & $9,1 \%$ & $22,7 \%$ & $10,6 \%$ & $42,4 \%$ \\
\hline & & Comércio & Count & & 0 & 1 & 7 & 1 & 9 \\
\hline & & & $\%$ of Total & & $.0 \%$ & $1,5 \%$ & $10,6 \%$ & $1,5 \%$ & $13,6 \%$ \\
\hline & & Serviço & Count & & 2 & 5 & 14 & 8 & 29 \\
\hline & & & $\%$ of Total & & $3,0 \%$ & $7,6 \%$ & $21,2 \%$ & $12,1 \%$ & $43,9 \%$ \\
\hline & Total & & Count & & 2 & 12 & 36 & 16 & 66 \\
\hline & & & $\%$ of Total & & $3,0 \%$ & $18,2 \%$ & $54,5 \%$ & $24,2 \%$ & $100,0 \%$ \\
\hline \multirow{8}{*}{$\begin{array}{l}\text { Contrato formal } \\
\text { detalhado - sem SLA }\end{array}$} & VE2 - Setor & Indústria & Count & 0 & 3 & 2 & 12 & 11 & 28 \\
\hline & & & $\%$ of Total &, $0 \%$ & $5,3 \%$ & $3,5 \%$ & $21,1 \%$ & $19,3 \%$ & $49,1 \%$ \\
\hline & & Comércio & Count & 0 & 0 & 1 & 6 & 2 & 9 \\
\hline & & & $\%$ of Total &, $0 \%$ &, $0 \%$ & $1,8 \%$ & $10,5 \%$ & $3,5 \%$ & $15,8 \%$ \\
\hline & & Serviço & Count & 1 & 0 & 2 & 15 & 2 & 20 \\
\hline & & & $\%$ of Total & $1,8 \%$ &, $0 \%$ & $3,5 \%$ & $26,3 \%$ & $3,5 \%$ & $35,1 \%$ \\
\hline & Total & & Count & 1 & 3 & 5 & 33 & 15 & 57 \\
\hline & & & $\%$ of Total & $1,8 \%$ & $5,3 \%$ & $8,8 \%$ & $57,9 \%$ & $26,3 \%$ & $100,0 \%$ \\
\hline \multirow{8}{*}{$\begin{array}{l}\text { Contrato formal } \\
\text { detalhado - com SLA }\end{array}$} & VE2 - Setor & Indústria & Count & 1 & 2 & 7 & 57 & 15 & 82 \\
\hline & & & $\%$ of Total & $6 \%$ & $1,2 \%$ & $4,1 \%$ & $33,1 \%$ & $8,7 \%$ & $47,7 \%$ \\
\hline & & Comércio & Count & 0 & 0 & 0 & 18 & 2 & 20 \\
\hline & & & $\%$ of Total &, $0 \%$ &, $0 \%$ &, $0 \%$ & $10,5 \%$ & $1,2 \%$ & $11,6 \%$ \\
\hline & & Serviço & Count & 1 & 1 & 8 & 44 & 16 & 70 \\
\hline & & & $\%$ of Total &, $6 \%$ &, $6 \%$ & $4,7 \%$ & $25,6 \%$ & $9,3 \%$ & $40,7 \%$ \\
\hline & Total & & Count & 2 & 3 & 15 & 119 & 33 & 172 \\
\hline & & & $\%$ of Total & $1,2 \%$ & $1,7 \%$ & $8,7 \%$ & $69,2 \%$ & $19,2 \%$ & $100,0 \%$ \\
\hline
\end{tabular}

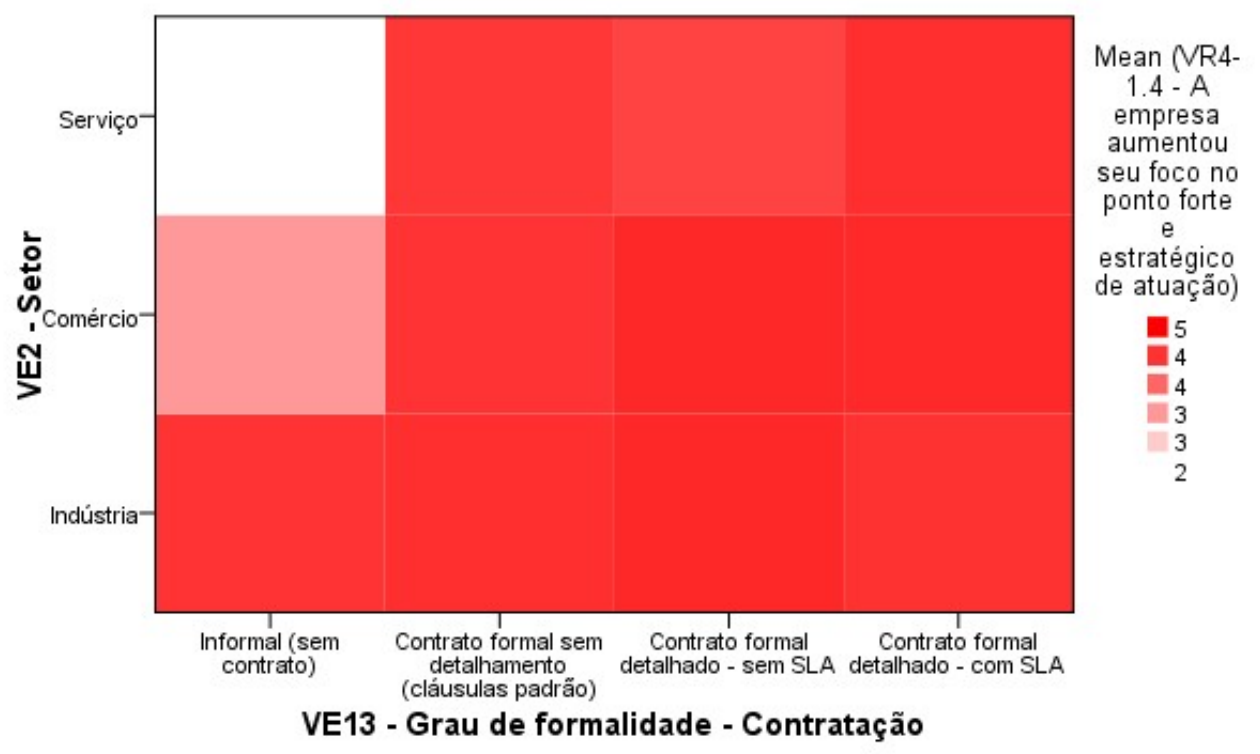


K5. VR5-2.1 - Os valores "orçados" para o projeto do sistema terceirizado (desenvolvido ou implantado) foram "realizados" (cumpridos na integra) até a entrega final?

\begin{tabular}{|c|c|c|c|c|c|c|c|c|c|}
\hline \multirow{2}{*}{\multicolumn{2}{|c|}{ VE13 - Grau de formalidade - Contratacão }} & & & \multicolumn{5}{|c|}{ VR5-2.1 - Os valores "orçados" para o projeto do sistema terceirizado } & \multirow[b]{2}{*}{ Total } \\
\hline & & & & $\begin{array}{l}\text { Nenhum } \\
\text { Resultado }\end{array}$ & $\begin{array}{c}\text { Pouco } \\
\text { Resultado }\end{array}$ & $\begin{array}{l}\text { Resultado } \\
\text { Mediano }\end{array}$ & $\begin{array}{c}\text { Acima da } \\
\text { Média mas } \\
\text { não } \\
\text { completamen } \\
\text { te }\end{array}$ & $\begin{array}{c}\text { Obtido } \\
\text { Completame } \\
\text { nte }\end{array}$ & \\
\hline \multirow[t]{8}{*}{ Informal (sem contrato) } & VE2 - Setor & Indústria & Count & 1 & & 0 & 0 & 1 & 2 \\
\hline & & & $\%$ of Total & $25,0 \%$ & &, $0 \%$ &, $0 \%$ & $25,0 \%$ & $50,0 \%$ \\
\hline & & Comércio & Count & 0 & & 1 & 0 & 0 & 1 \\
\hline & & & $\%$ of Total &, $0 \%$ & & $25,0 \%$ &, $0 \%$ &, $0 \%$ & $25,0 \%$ \\
\hline & & Serviço & Count & 0 & & 0 & 1 & 0 & 1 \\
\hline & & & $\%$ of Total &, $0 \%$ & &, $0 \%$ & $25,0 \%$ & $.0 \%$ & $25,0 \%$ \\
\hline & Total & & Count & 1 & & 1 & 1 & 1 & 4 \\
\hline & & & $\%$ of Total & $25,0 \%$ & & $25,0 \%$ & $25,0 \%$ & $25,0 \%$ & $100,0 \%$ \\
\hline \multirow{8}{*}{$\begin{array}{l}\text { Contrato formal sem } \\
\text { detalhamento (cláusulas } \\
\text { padrão) }\end{array}$} & VE2 - Setor & Indústria & Count & 1 & 3 & 6 & 5 & 13 & 28 \\
\hline & & & $\%$ of Total & $1,5 \%$ & $4,5 \%$ & $9,1 \%$ & $7,6 \%$ & $19,7 \%$ & $42,4 \%$ \\
\hline & & Comércio & Count & 0 & 1 & 4 & 1 & 3 & 9 \\
\hline & & & $\%$ of Total & $.0 \%$ & $1,5 \%$ & $6,1 \%$ & $1,5 \%$ & $4,5 \%$ & $13,6 \%$ \\
\hline & & Serviço & Count & 3 & 3 & 4 & 4 & 15 & 29 \\
\hline & & & $\%$ of Total & $4,5 \%$ & $4,5 \%$ & $6,1 \%$ & $6,1 \%$ & $22,7 \%$ & $43,9 \%$ \\
\hline & Total & & Count & 4 & 7 & 14 & 10 & 31 & 66 \\
\hline & & & $\%$ of Total & $6,1 \%$ & $10,6 \%$ & $21,2 \%$ & $15,2 \%$ & $47,0 \%$ & $100,0 \%$ \\
\hline \multirow{8}{*}{$\begin{array}{l}\text { Contrato formal } \\
\text { detalhado - sem SLA }\end{array}$} & VE2 - Setor & Indústria & Count & 0 & 0 & 4 & 11 & 13 & 28 \\
\hline & & & $\%$ of Total &, $0 \%$ &, $0 \%$ & $7,0 \%$ & $19,3 \%$ & $22,8 \%$ & $49,1 \%$ \\
\hline & & Comércio & Count & 0 & 1 & 0 & 1 & 7 & 9 \\
\hline & & & $\%$ of Total &, $0 \%$ & $1,8 \%$ &, $0 \%$ & $1,8 \%$ & $12,3 \%$ & $15,8 \%$ \\
\hline & & Serviço & Count & 1 & 3 & 0 & 2 & 14 & 20 \\
\hline & & & $\%$ of Total & $1,8 \%$ & $5,3 \%$ &, $0 \%$ & $3,5 \%$ & $24,6 \%$ & $35,1 \%$ \\
\hline & Total & & Count & 1 & 4 & 4 & 14 & 34 & 57 \\
\hline & & & $\%$ of Total & $1,8 \%$ & $7,0 \%$ & $7,0 \%$ & $24,6 \%$ & $59,6 \%$ & $100,0 \%$ \\
\hline \multirow{8}{*}{$\begin{array}{l}\text { Contrato formal } \\
\text { detalhado - com SLA }\end{array}$} & VE2 - Setor & Indústria & Count & 2 & 3 & 4 & 12 & 61 & 82 \\
\hline & & & $\%$ of Total & $1,2 \%$ & $1,7 \%$ & $2,3 \%$ & $7,0 \%$ & $35,5 \%$ & $47,7 \%$ \\
\hline & & Comércio & Count & 0 & 1 & 1 & 5 & 13 & 20 \\
\hline & & & $\%$ of Total & $.0 \%$ &, $6 \%$ &, $6 \%$ & $2,9 \%$ & $7,6 \%$ & $11,6 \%$ \\
\hline & & Serviço & Count & 2 & 3 & 9 & 10 & 46 & 70 \\
\hline & & & $\%$ of Total & $1,2 \%$ & $1,7 \%$ & $5,2 \%$ & $5,8 \%$ & $26,7 \%$ & $40,7 \%$ \\
\hline & Total & & Count & 4 & 7 & 14 & 27 & 120 & 172 \\
\hline & & & $\%$ of Total & $2,3 \%$ & $4,1 \%$ & $8,1 \%$ & $15,7 \%$ & $69,8 \%$ & $100,0 \%$ \\
\hline
\end{tabular}

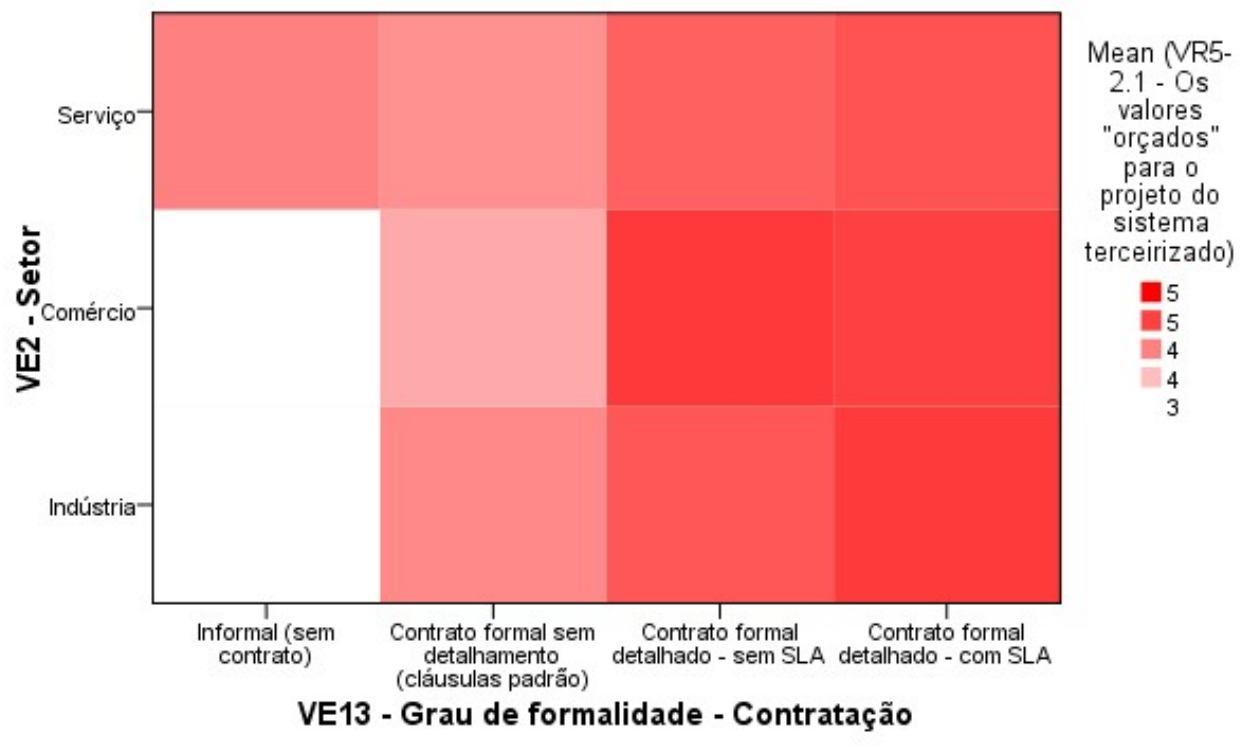


K6. VR6-2.2 - Os prazos "estipulados" para o projeto do sistema terceirizado (desenvolvido ou implantado) foram "cumpridos na íntegra" até a entrega final?

VE2 - Setor * VR6-2.2 - Os prazos "estipulados" para o projeto do sistema terceirizado * VE13 - Grau de formalidade - Contratação Crosstabulation

\begin{tabular}{|c|c|c|c|c|c|c|c|c|c|}
\hline \multirow{2}{*}{\multicolumn{2}{|c|}{ VE13 - Grau de formalidade - Contratacão }} & & & \multicolumn{5}{|c|}{ VR6-2.2 - Os prazos "estipulados" para o projeto do sistema terceirizado } & \multirow[b]{2}{*}{ Total } \\
\hline & & & & $\begin{array}{l}\text { Nenhum } \\
\text { Resultado }\end{array}$ & $\begin{array}{c}\text { Pouco } \\
\text { Resultado }\end{array}$ & $\begin{array}{l}\text { Resultado } \\
\text { Mediano }\end{array}$ & $\begin{array}{c}\text { Acima da } \\
\text { Média mas } \\
\text { não } \\
\text { completamen } \\
\text { te }\end{array}$ & $\begin{array}{c}\text { Obtido } \\
\text { completame } \\
\text { nte }\end{array}$ & \\
\hline \multirow[t]{8}{*}{ Informal (sem contrato) } & VE2 - Setor & Indústria & Count & 1 & 1 & 0 & & & 2 \\
\hline & & & $\%$ of Total & $25,0 \%$ & $25,0 \%$ &, $0 \%$ & & & $50,0 \%$ \\
\hline & & Comércio & Count & 0 & 0 & 1 & & & 1 \\
\hline & & & $\%$ of Total &, $0 \%$ & $.0 \%$ & $25,0 \%$ & & & $25,0 \%$ \\
\hline & & Serviço & Count & 0 & 1 & 0 & & & 1 \\
\hline & & & $\%$ of Total & $.0 \%$ & $25,0 \%$ &, $0 \%$ & & & $25,0 \%$ \\
\hline & Total & & Count & 1 & 2 & 1 & & & 4 \\
\hline & & & $\%$ of Total & $25,0 \%$ & $50,0 \%$ & $25,0 \%$ & & & $100,0 \%$ \\
\hline \multirow{8}{*}{$\begin{array}{l}\text { Contrato formal sem } \\
\text { detalhamento (cláusulas } \\
\text { padrão) }\end{array}$} & VE2 - Setor & Indústria & Count & 2 & 16 & 6 & 2 & 2 & 28 \\
\hline & & & $\%$ of Total & $3,0 \%$ & $24,2 \%$ & $9,1 \%$ & $3,0 \%$ & $3,0 \%$ & $42,4 \%$ \\
\hline & & Comércio & Count & 1 & 3 & 2 & 3 & 0 & 9 \\
\hline & & & $\%$ of Total & $1,5 \%$ & $4,5 \%$ & $3,0 \%$ & $4,5 \%$ &, $0 \%$ & $13,6 \%$ \\
\hline & & Serviço & Count & 5 & 12 & 6 & 5 & 1 & 29 \\
\hline & & & $\%$ of Total & $7,6 \%$ & $18,2 \%$ & $9,1 \%$ & $7,6 \%$ & $1,5 \%$ & $43,9 \%$ \\
\hline & Total & & Count & 8 & 31 & 14 & 10 & 3 & 66 \\
\hline & & & $\%$ of Total & $12,1 \%$ & $47,0 \%$ & $21,2 \%$ & $15,2 \%$ & $4,5 \%$ & $100,0 \%$ \\
\hline \multirow{8}{*}{$\begin{array}{l}\text { Contrato formal } \\
\text { detalhado - sem SLA }\end{array}$} & VE2 - Setor & Indústria & Count & 0 & 15 & 4 & 7 & 2 & 28 \\
\hline & & & $\%$ of Total &, $0 \%$ & $26,3 \%$ & $7,0 \%$ & $12,3 \%$ & $3,5 \%$ & $49,1 \%$ \\
\hline & & Comércio & Count & 1 & 7 & 0 & 0 & 1 & 9 \\
\hline & & & $\%$ of Total & $1,8 \%$ & $12,3 \%$ &, $0 \%$ &, $0 \%$ & $1,8 \%$ & $15,8 \%$ \\
\hline & & Serviço & Count & 3 & 15 & 0 & 2 & 0 & 20 \\
\hline & & & $\%$ of Total & $5,3 \%$ & $26,3 \%$ &, $0 \%$ & $3,5 \%$ &, $0 \%$ & $35,1 \%$ \\
\hline & Total & & Count & 4 & 37 & 4 & 9 & 3 & 57 \\
\hline & & & $\%$ of Total & $7,0 \%$ & $64,9 \%$ & $7,0 \%$ & $15,8 \%$ & $5,3 \%$ & $100,0 \%$ \\
\hline \multirow{8}{*}{$\begin{array}{l}\text { Contrato formal } \\
\text { detalhado - com SLA }\end{array}$} & VE2 - Setor & Indústria & Count & 8 & 50 & 7 & 13 & 4 & 82 \\
\hline & & & $\%$ of Total & $4,7 \%$ & $29,1 \%$ & $4,1 \%$ & $7,6 \%$ & $2,3 \%$ & $47,7 \%$ \\
\hline & & Comércio & Count & 0 & 13 & 3 & 3 & 1 & 20 \\
\hline & & & $\%$ of Total &, $0 \%$ & $7,6 \%$ & $1,7 \%$ & $1,7 \%$ & $6 \%$ & $11,6 \%$ \\
\hline & & Serviço & Count & 4 & 44 & 7 & 9 & 6 & 70 \\
\hline & & & $\%$ of Total & $2,3 \%$ & $25,6 \%$ & $4,1 \%$ & $5,2 \%$ & $3,5 \%$ & $40,7 \%$ \\
\hline & Total & & Count & 12 & 107 & 17 & 25 & 11 & 172 \\
\hline & & & $\%$ of Total & $7.0 \%$ & $62,2 \%$ & $9,9 \%$ & $14.5 \%$ & $6.4 \%$ & $100,0 \%$ \\
\hline
\end{tabular}

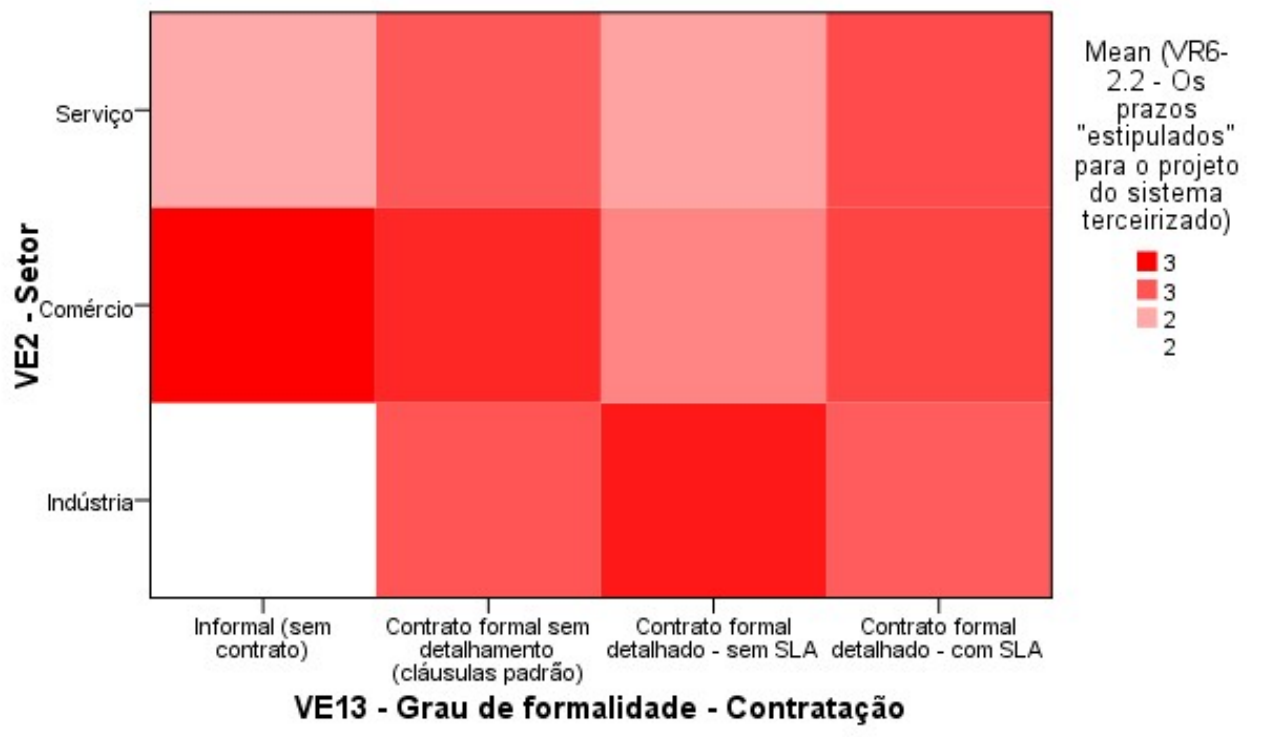


K7. VR7-2.3 - Após a disponibilização do sistema terceirizado (desenvolvido ou implantado), houve aumento da flexibilidade na realização das tarefas pelos usuários finais?

VE2 - Setor * VR7-2.3 - Após a disponibilização do sistema terceirizado (desenvolvido ou implantado), houve aumento da flexibilidade * VE13 - Grau de formalidade

\begin{tabular}{|c|c|c|c|c|c|c|c|c|c|}
\hline \multirow{2}{*}{\multicolumn{2}{|c|}{ VE13-Grau de formalidade - Contratacão }} & \multirow[b]{3}{*}{ Indústria } & \multirow[b]{3}{*}{$\begin{array}{l}\text { Count } \\
\% \text { of Total }\end{array}$} & \multicolumn{5}{|c|}{$\begin{array}{l}\text { VR7-2.3 - Após a disponibilização do sistema terceirizado (des envolvido ou } \\
\text { implantado), houve aumento da flexibilidade }\end{array}$} & \multirow{2}{*}{$\frac{\text { Total }}{2}$} \\
\hline & & & & \multirow[t]{2}{*}{$\begin{array}{c}\text { Nenhum } \\
\text { Resultado }\end{array}$} & \multirow[t]{2}{*}{$\begin{array}{c}\text { Pouco } \\
\text { Resultado }\end{array}$} & \multirow{2}{*}{$\begin{array}{r}\begin{array}{c}\text { Resultado } \\
\text { Mediano }\end{array} \\
0 \\
, 0 \%\end{array}$} & $\begin{array}{c}\text { Acima da } \\
\text { Média mas } \\
\text { não } \\
\text { completamen } \\
\text { te }\end{array}$ & \multirow[t]{2}{*}{$\begin{array}{c}\text { Obtido } \\
\text { Completame } \\
\text { nte }\end{array}$} & \\
\hline Informal (sem contrato) & VE2 - Setor & & & & & & $\begin{array}{r}2 \\
50,0 \%\end{array}$ & & $\begin{array}{r}2 \\
50,0 \%\end{array}$ \\
\hline & & Comércio & $\begin{array}{l}\begin{array}{l}\text { Count } \\
\% \text { of Total }\end{array} \\
\end{array}$ & & & $\begin{array}{r}0 \\
, 0 \% \\
\end{array}$ & $\begin{array}{r}1 \\
25,0 \% \\
\end{array}$ & & $\begin{array}{r}1 \\
25,0 \% \\
\end{array}$ \\
\hline & & Serviço & $\begin{array}{l}\text { Count } \\
\% \text { of Total }\end{array}$ & & & $\begin{array}{r}1 \\
25,0 \%\end{array}$ & $\begin{array}{r}0 \\
, 0 \%\end{array}$ & & $\begin{array}{r}1 \\
25,0 \%\end{array}$ \\
\hline & Total & & $\begin{array}{l}\text { Count } \\
\% \text { of Total }\end{array}$ & & & $\begin{array}{r}1 \\
25,0 \%\end{array}$ & $\begin{array}{r}3 \\
75,0 \%\end{array}$ & & $\begin{array}{r}4 \\
100,0 \%\end{array}$ \\
\hline \multirow[t]{4}{*}{$\begin{array}{l}\text { Contrato formal sem } \\
\text { detallamamento (cláusulas } \\
\text { padrão) }\end{array}$} & VE2 - Setor & Indústria & $\begin{array}{l}\text { Count } \\
\% \text { of Total }\end{array}$ & & $\begin{array}{r}1 \\
1,5 \% \\
\end{array}$ & $\begin{array}{r}4 \\
6,1 \% \\
\end{array}$ & $\begin{array}{r}18 \\
27,3 \% \\
\end{array}$ & $\begin{array}{r}5 \\
7,6 \% \\
\end{array}$ & $\begin{array}{r}28 \\
42,4 \% \\
\end{array}$ \\
\hline & & Comércio & $\begin{array}{l}\text { Count } \\
\% \text { of Total }\end{array}$ & & $\begin{array}{r}0 \\
.0 \%\end{array}$ & $\begin{array}{r}1 \\
1,5 \%\end{array}$ & $\begin{array}{r}7 \\
10,6 \%\end{array}$ & $\begin{array}{r}1 \\
1,5 \%\end{array}$ & $\begin{array}{r}9 \\
13,6 \%\end{array}$ \\
\hline & & Serviço & $\begin{array}{l}\text { Count } \\
\% \text { of Total }\end{array}$ & & $\begin{array}{r}3 \\
4,5 \%\end{array}$ & $\begin{array}{r}4 \\
6,1 \%\end{array}$ & $\begin{array}{r}17 \\
25,8 \%\end{array}$ & $\begin{array}{r}5 \\
7,6 \%\end{array}$ & $\begin{array}{r}29 \\
43,9 \%\end{array}$ \\
\hline & Total & & $\begin{array}{l}\text { Count } \\
\% \text { of Total }\end{array}$ & & $\begin{array}{r}4 \\
6,1 \%\end{array}$ & $\begin{array}{r}9 \\
13,6 \%\end{array}$ & $\begin{array}{r}42 \\
63,6 \%\end{array}$ & $\begin{array}{r}11 \\
16,7 \%\end{array}$ & $\begin{array}{r}66 \\
100,0 \%\end{array}$ \\
\hline \multirow[t]{4}{*}{$\begin{array}{l}\text { Contrato formal } \\
\text { detalhado - sem SLA }\end{array}$} & VE2 - Setor & Indústria & $\begin{array}{l}\text { Count } \\
\% \text { of Total }\end{array}$ & $\begin{array}{r}1 \\
1,8 \%\end{array}$ & $\begin{array}{r}1 \\
1,8 \%\end{array}$ & $\begin{array}{r}3 \\
5,3 \%\end{array}$ & $\begin{array}{r}17 \\
29,8 \%\end{array}$ & $\begin{array}{r}6 \\
10,5 \%\end{array}$ & $\begin{array}{r}28 \\
49,1 \%\end{array}$ \\
\hline & & Comércio & $\begin{array}{l}\text { Count } \\
\% \text { of Total }\end{array}$ & $\begin{array}{r}0 \\
.0 \%\end{array}$ & $\begin{array}{r}0 \\
.0 \%\end{array}$ & $\begin{array}{r}0 \\
.0 \%\end{array}$ & $\begin{array}{r}7 \\
12,3 \%\end{array}$ & $\begin{array}{r}2 \\
3,5 \%\end{array}$ & $\begin{array}{r}9 \\
15,8 \%\end{array}$ \\
\hline & & Serviço & $\begin{array}{l}\text { Count } \\
\% \text { of Total }\end{array}$ & $\begin{array}{r}0 \\
.0 \%\end{array}$ & $\begin{array}{r}2 \\
3,5 \%\end{array}$ & $\begin{array}{r}2 \\
3,5 \%\end{array}$ & $\begin{array}{r}16 \\
28,1 \%\end{array}$ & $\begin{array}{r}0 \\
, 0 \%\end{array}$ & $\begin{array}{r}20 \\
35,1 \%\end{array}$ \\
\hline & Total & & $\begin{array}{l}\text { Count } \\
\% \text { of Total }\end{array}$ & $\begin{array}{r}1 \\
1,8 \%\end{array}$ & $\begin{array}{r}3 \\
5,3 \%\end{array}$ & $\begin{array}{r}5 \\
8,8 \%\end{array}$ & $\begin{array}{r}40 \\
70,2 \%\end{array}$ & $\begin{array}{r}8 \\
14,0 \%\end{array}$ & $\begin{array}{r}57 \\
100,0 \%\end{array}$ \\
\hline \multirow[t]{4}{*}{$\begin{array}{l}\text { Contrato formal } \\
\text { detalhado - com SLA }\end{array}$} & VE2 - Setor & Indústria & $\begin{array}{l}\text { Count } \\
\% \text { of Total }\end{array}$ & $\begin{array}{r}2 \\
1,2 \% \\
\end{array}$ & $\begin{array}{r}0 \\
.0 \%\end{array}$ & $\begin{array}{r}5 \\
2,9 \% \\
\end{array}$ & $\begin{array}{r}64 \\
37,2 \%\end{array}$ & $\begin{array}{r}11 \\
6,4 \%\end{array}$ & $\begin{array}{r}82 \\
47,7 \%\end{array}$ \\
\hline & & Comércio & $\begin{array}{l}\text { Count } \\
\% \text { of Total }\end{array}$ & $\begin{array}{r}0 \\
.0 \%\end{array}$ & $\begin{array}{r}0 \\
0 \%\end{array}$ & $\begin{array}{r}3 \\
1,7 \%\end{array}$ & $\begin{array}{r}16 \\
9,3 \%\end{array}$ & $\begin{array}{r}1 \\
, 6 \%\end{array}$ & $\begin{array}{r}20 \\
11,6 \%\end{array}$ \\
\hline & & Serviço & $\begin{array}{l}\text { Count } \\
\% \text { of Total }\end{array}$ & $\begin{array}{r}0 \\
0 \%\end{array}$ & $\begin{array}{r}4 \\
2,3 \%\end{array}$ & $\begin{array}{r}5 \\
2,9 \%\end{array}$ & $\begin{array}{r}50 \\
29,1 \%\end{array}$ & $\begin{array}{r}11 \\
6,4 \%\end{array}$ & $\begin{array}{r}70 \\
40,7 \%\end{array}$ \\
\hline & Total & & $\begin{array}{l}\text { Count } \\
\% \text { of Total }\end{array}$ & $\begin{array}{r}2 \\
1,2 \%\end{array}$ & $\begin{array}{r}4 \\
2,3 \%\end{array}$ & $\begin{array}{r}13 \\
7,6 \%\end{array}$ & $\begin{array}{r}130 \\
75,6 \%\end{array}$ & $\begin{array}{r}23 \\
13,4 \%\end{array}$ & $\begin{array}{r}172 \\
100,0 \%\end{array}$ \\
\hline
\end{tabular}

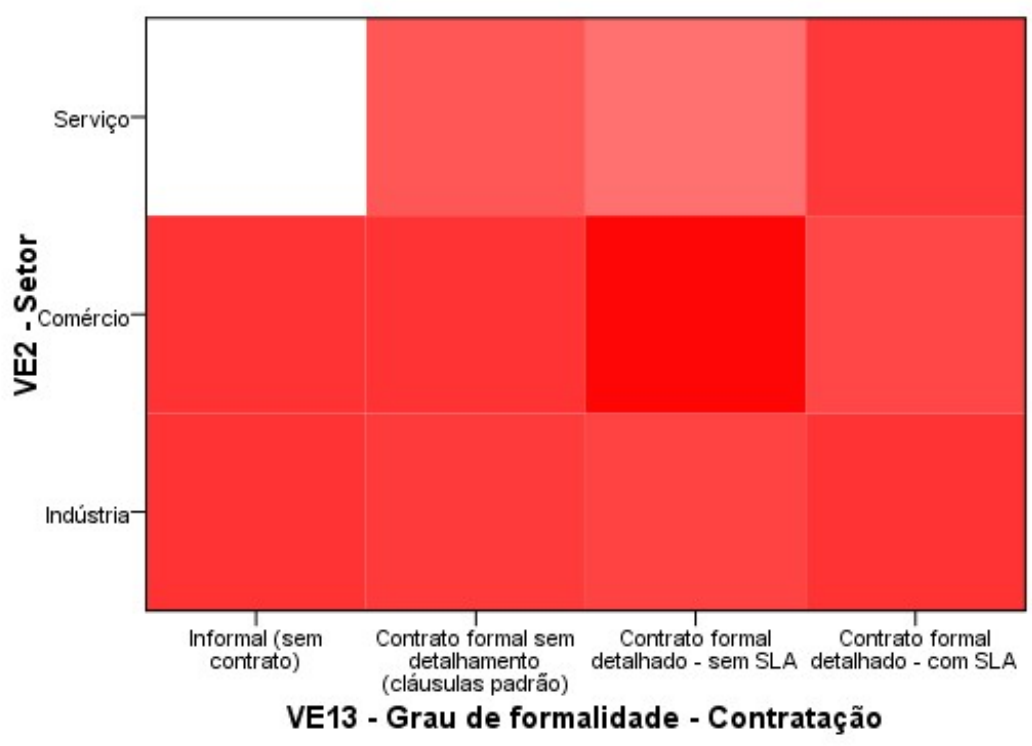

Mean (VR7-2.3 -

$$
\text { Após a }
$$

disponibilização

do sistema

terceirizado

(desenvolvido ou

implantado)

houve aumento

da flexibilidade)

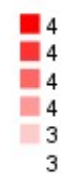

VE13 - Grau de formalidade - Contratação 
K8. VR8-2.4 - De uma forma geral, houve redução no número ou na complexidade dos problemas inerentes aos processos ou execução dos serviços em função do sistema terceirizado (desenvolvido ou implantado)?

VE2 - Setor * VR8-2.4 - De uma forma geral, houve redução no número ou na complexidade * VE13 - Grau de formalidade - Contratação Crosstabulation

\begin{tabular}{|c|c|c|c|c|c|c|c|c|c|}
\hline \multirow{2}{*}{\multicolumn{2}{|c|}{ VE13 - Grau de formalidade - Contratacão }} & & & \multicolumn{5}{|c|}{ VR8-2.4 - De uma forma geral, houve redução no número ou na complexidade } & \multirow[b]{2}{*}{ Total } \\
\hline & & & & \multirow[t]{2}{*}{$\begin{array}{c}\text { Nenhum } \\
\text { Resultado }\end{array}$} & $\begin{array}{c}\text { Pouco } \\
\text { Resultado } \\
\end{array}$ & $\begin{array}{l}\text { Resultado } \\
\text { Mediano }\end{array}$ & \begin{tabular}{|c} 
Acima da \\
Média mas \\
não \\
completamen \\
te
\end{tabular} & $\begin{array}{c}\text { Obtido } \\
\text { Completame } \\
\text { nte }\end{array}$ & \\
\hline \multirow[t]{5}{*}{ Informal (sem contrato) } & VE2 - Setor & Indústria & $\begin{array}{l}\text { Count } \\
\% \text { of Total }\end{array}$ & & & $\begin{array}{r}0 \\
, 0 \%\end{array}$ & $\begin{array}{r}2 \\
50,0 \%\end{array}$ & & $\begin{array}{r}2 \\
50,0 \%\end{array}$ \\
\hline & & Comércio & Count & & & $\begin{array}{r}1 \\
250 \%\end{array}$ & $\begin{array}{r}0 \\
0 \%\end{array}$ & & $\begin{array}{r}1 \\
250 \%\end{array}$ \\
\hline & & Serviço & $\begin{array}{l}\text { \% of Total } \\
\text { Count }\end{array}$ & & & $\begin{array}{r}25,0 \% \\
0\end{array}$ & $\begin{array}{r}, 0 \% \\
1\end{array}$ & & $\begin{array}{r}25,0 \% \\
1\end{array}$ \\
\hline & & & $\%$ of Total & & &, $0 \%$ & $25,0 \%$ & & $25,0 \%$ \\
\hline & Total & & $\begin{array}{l}\text { Count } \\
\% \text { of Total }\end{array}$ & & & $\begin{array}{r}1 \\
25,0 \%\end{array}$ & $\begin{array}{r}3 \\
75,0 \%\end{array}$ & & $\begin{array}{r}4 \\
100,0 \%\end{array}$ \\
\hline \multirow{8}{*}{$\begin{array}{l}\text { Contrato formal sem } \\
\text { detalhamento (clauusulas } \\
\text { padrão) }\end{array}$} & VE2 - Setor & Indústria & Count & 1 & 0 & 4 & 17 & 6 & 28 \\
\hline & & & $\%$ of Total & $1,5 \%$ & $0 \%$ & $6,1 \%$ & $25,8 \%$ & $9,1 \%$ & $42,4 \%$ \\
\hline & & Comércio & Count & 0 & 0 & 1 & 5 & 3 & 9 \\
\hline & & & $\%$ of Total & $.0 \%$ & $.0 \%$ & $1,5 \%$ & $7,6 \%$ & $4,5 \%$ & $13,6 \%$ \\
\hline & & Serviço & Count & 0 & 5 & 3 & 11 & 10 & 29 \\
\hline & & & $\%$ of Total &, $0 \%$ & $7,6 \%$ & $4,5 \%$ & $16,7 \%$ & $15,2 \%$ & $43,9 \%$ \\
\hline & Total & & Count & 1 & 5 & 8 & 33 & 19 & 66 \\
\hline & & & $\%$ of Total & $1,5 \%$ & $7,6 \%$ & $12,1 \%$ & $50,0 \%$ & $28,8 \%$ & $100,0 \%$ \\
\hline \multirow{8}{*}{$\begin{array}{l}\text { Contrato formal } \\
\text { detalhado - sem SLA }\end{array}$} & VE2 - Setor & Indústria & Count & & 1 & 4 & 16 & 7 & 28 \\
\hline & & & $\%$ of Total & & $1,8 \%$ & $7,0 \%$ & $28,1 \%$ & $12,3 \%$ & $49,1 \%$ \\
\hline & & Comércio & Count & & 0 & 0 & 7 & 2 & 9 \\
\hline & & & $\%$ of Total & & $.0 \%$ &, $0 \%$ & $12,3 \%$ & $3,5 \%$ & $15,8 \%$ \\
\hline & & Serviço & Count & & 1 & 0 & 16 & 3 & 20 \\
\hline & & & $\%$ of Total & & $1,8 \%$ &, $0 \%$ & $28,1 \%$ & $5,3 \%$ & $35,1 \%$ \\
\hline & Total & & Count & & 2 & 4 & 39 & 12 & 57 \\
\hline & & & $\%$ of Total & & $3,5 \%$ & $7,0 \%$ & $68,4 \%$ & $21,1 \%$ & $100,0 \%$ \\
\hline \multirow{8}{*}{$\begin{array}{l}\text { Contrato formal } \\
\text { detalhado - com SLA }\end{array}$} & VE2 - Setor & Indústria & Count & & 1 & 3 & 60 & 18 & 82 \\
\hline & & & $\%$ of Total & &, $6 \%$ & $1,7 \%$ & $34,9 \%$ & $10,5 \%$ & $47,7 \%$ \\
\hline & & Comércio & Count & & 1 & 1 & 16 & 2 & 20 \\
\hline & & & $\%$ of Total & &, $6 \%$ &, $6 \%$ & $9,3 \%$ & $1,2 \%$ & $11,6 \%$ \\
\hline & & Serviço & Count & & 2 & 10 & 47 & 11 & 70 \\
\hline & & & $\%$ of Total & & $1,2 \%$ & $5,8 \%$ & $27,3 \%$ & $6,4 \%$ & $40,7 \%$ \\
\hline & Total & & Count & & 4 & 14 & 123 & 31 & 172 \\
\hline & & & $\%$ of Total & & $2,3 \%$ & $8,1 \%$ & $71,5 \%$ & $18,0 \%$ & $100,0 \%$ \\
\hline
\end{tabular}

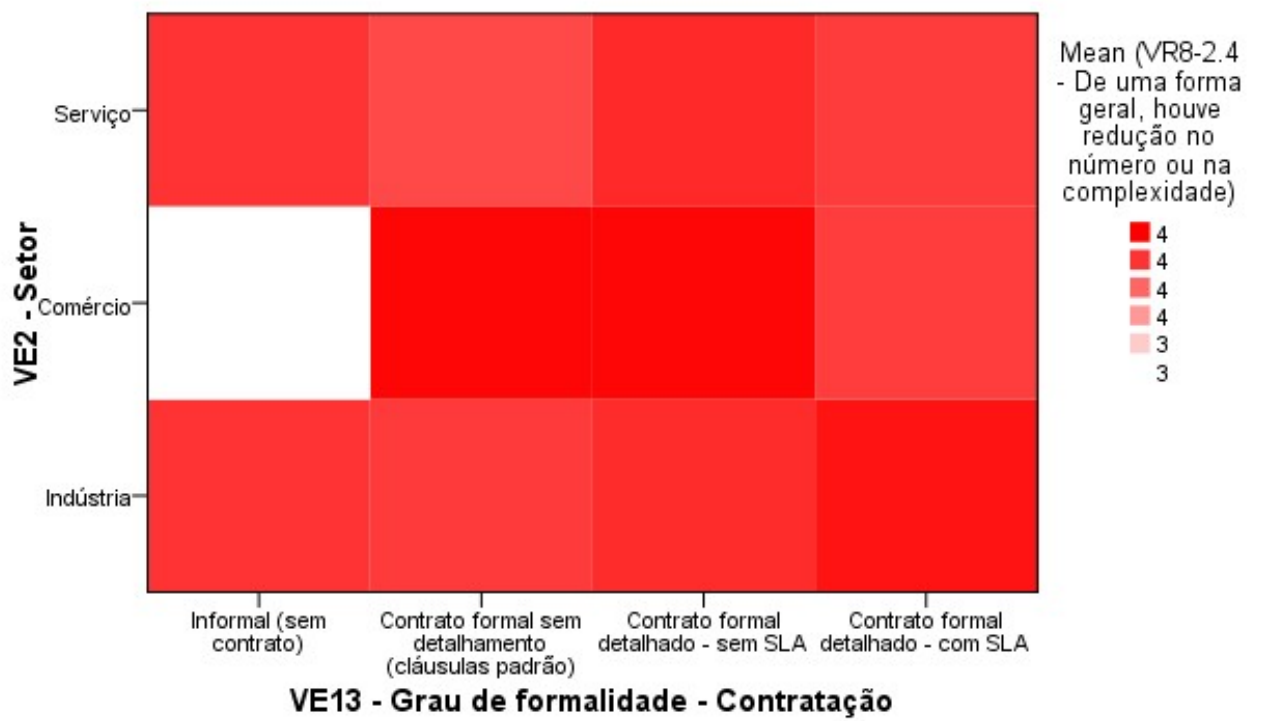


K9. VR9-3.1 - Houve aumento na capacidade de processamento dos dados em função do sistema terceirizado (desenvolvido ou implantado)?

\begin{tabular}{|c|c|c|c|c|c|c|c|c|c|}
\hline \multirow{2}{*}{\multicolumn{2}{|c|}{ VE13-Grau de formalidade - Contratacão }} & & & \multicolumn{5}{|c|}{ VR9-3.1 - Houve aumento na capacidade de processamento dos dados } & \multirow[b]{2}{*}{ Total } \\
\hline & & & & $\begin{array}{c}\text { Nenhum } \\
\text { Resultado }\end{array}$ & $\begin{array}{c}\text { Pouco } \\
\text { Resultado }\end{array}$ & $\begin{array}{l}\text { Resultado } \\
\text { Mediano }\end{array}$ & $\begin{array}{c}\text { Acima da } \\
\text { Média mas } \\
\text { não } \\
\text { completamen } \\
\text { te }\end{array}$ & $\begin{array}{c}\text { Obtido } \\
\text { Completame } \\
\text { nte }\end{array}$ & \\
\hline \multirow[t]{8}{*}{ Informal (sem contrato) } & VE2 - Setor & Indústria & Count & & & & 1 & 1 & 2 \\
\hline & & & $\%$ of Total & & & & $25,0 \%$ & $25,0 \%$ & $50,0 \%$ \\
\hline & & Comércio & Count & & & & 1 & 0 & 1 \\
\hline & & & $\%$ of Total & & & & $25,0 \%$ &, $0 \%$ & $25,0 \%$ \\
\hline & & Serviço & Count & & & & 0 & 1 & 1 \\
\hline & & & $\%$ of Total & & & &, $0 \%$ & $25,0 \%$ & $25,0 \%$ \\
\hline & Total & & Count & & & & 2 & 2 & 4 \\
\hline & & & $\%$ of Total & & & & $50,0 \%$ & $50,0 \%$ & $100,0 \%$ \\
\hline \multirow{8}{*}{$\begin{array}{l}\text { Contrato formal sem } \\
\text { detalhamento (cláusulas } \\
\text { padrão) }\end{array}$} & VE2 - Setor & Indústria & Count & 3 & 0 & 4 & 11 & 10 & 28 \\
\hline & & & $\%$ of Total & $4,5 \%$ & $.0 \%$ & $6,1 \%$ & $16,7 \%$ & $15,2 \%$ & $42,4 \%$ \\
\hline & & Comércio & Count & 0 & 1 & 0 & 6 & 2 & 9 \\
\hline & & & $\%$ of Total &, $0 \%$ & $1,5 \%$ &, $0 \%$ & $9,1 \%$ & $3,0 \%$ & $13,6 \%$ \\
\hline & & Serviço & Count & 0 & 2 & 1 & 11 & 15 & 29 \\
\hline & & & $\%$ of Total & $.0 \%$ & $3,0 \%$ & $1,5 \%$ & $16,7 \%$ & $22,7 \%$ & $43,9 \%$ \\
\hline & Total & & Count & 3 & 3 & 5 & 28 & 27 & 66 \\
\hline & & & $\%$ of Total & $4,5 \%$ & $4,5 \%$ & $7,6 \%$ & $42,4 \%$ & $40,9 \%$ & $100,0 \%$ \\
\hline \multirow{8}{*}{$\begin{array}{l}\text { Contrato formal } \\
\text { detalhado - sem SLA }\end{array}$} & VE2 - Setor & Indústria & Count & & 0 & 5 & 7 & 16 & 28 \\
\hline & & & $\%$ of Total & &, $0 \%$ & $8,8 \%$ & $12,3 \%$ & $28,1 \%$ & $49,1 \%$ \\
\hline & & Comércio & Count & & 0 & 2 & 2 & 5 & 9 \\
\hline & & & $\%$ of Total & & $.0 \%$ & $3,5 \%$ & $3,5 \%$ & $8,8 \%$ & $15,8 \%$ \\
\hline & & Serviço & Count & & 1 & 0 & 5 & 14 & 20 \\
\hline & & & $\%$ of Total & & $1,8 \%$ &, $0 \%$ & $8,8 \%$ & $24,6 \%$ & $35,1 \%$ \\
\hline & Total & & Count & & 1 & 7 & 14 & 35 & 57 \\
\hline & & & $\%$ of Total & & $1,8 \%$ & $12,3 \%$ & $24,6 \%$ & $61,4 \%$ & $100,0 \%$ \\
\hline \multirow{8}{*}{$\begin{array}{l}\text { Contrato formal } \\
\text { detalhado - com SLA }\end{array}$} & VE2 - Setor & Indústria & Count & 1 & 1 & 1 & 20 & 59 & 82 \\
\hline & & & $\%$ of Total & ,6\% & $6 \%$ & $6 \%$ & $11,6 \%$ & $34,3 \%$ & $47,7 \%$ \\
\hline & & Comércio & Count & 1 & 0 & 0 & 6 & 13 & 20 \\
\hline & & & $\%$ of Total & $6 \%$ & $.0 \%$ &, $0 \%$ & $3,5 \%$ & $7,6 \%$ & $11,6 \%$ \\
\hline & & Serviço & Count & 0 & 2 & 6 & 17 & 45 & 70 \\
\hline & & & $\%$ of Total &, $0 \%$ & $1,2 \%$ & $3,5 \%$ & $9,9 \%$ & $26,2 \%$ & $40,7 \%$ \\
\hline & Total & & Count & 2 & 3 & 7 & 43 & 117 & 172 \\
\hline & & & $\%$ of Total & $1,2 \%$ & $1,7 \%$ & $4,1 \%$ & $25,0 \%$ & $68,0 \%$ & $100,0 \%$ \\
\hline
\end{tabular}

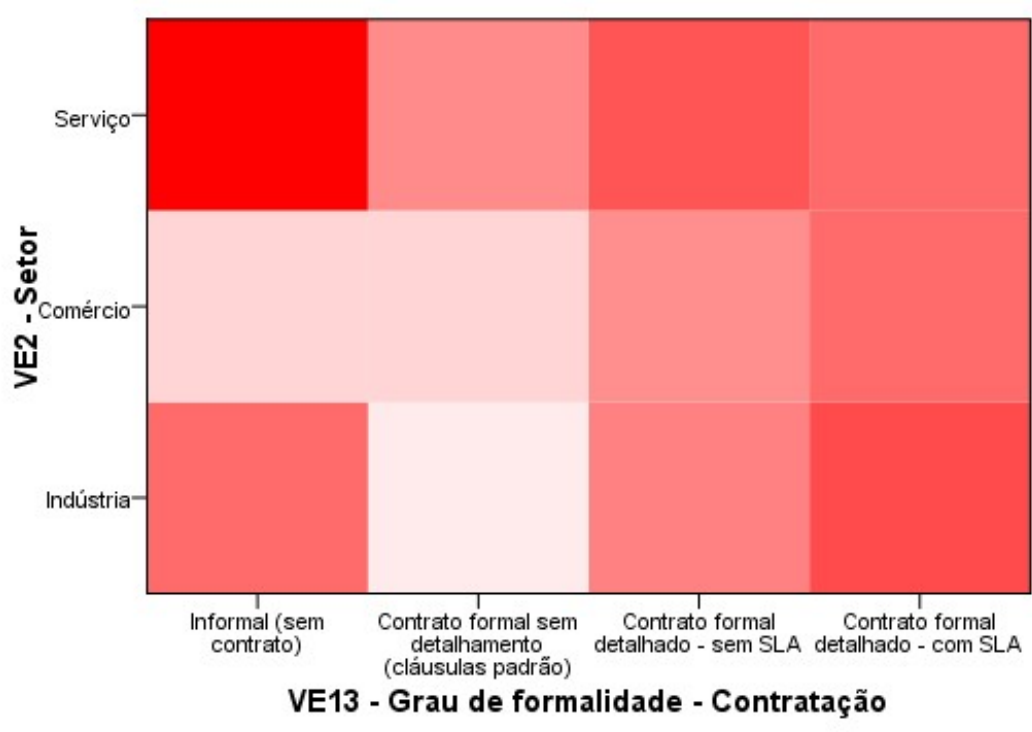

Mean NR9-3.1

- Houve

aumento na

capacidade de

processamento

dos dados)

$\mathbf{0} 5$
5
$\mathbf{4}$
5
4
4
4
4
4 
K10. VR10-3.2 - A empresa obteve otimização/melhoria nos processos executados pelos usuários finais, em função do sistema terceirizado (desenvolvido ou implantado)?

VE2 - Setor * VR10-3.2 - A empresa obteve otimização/melhoria nos processos executados pelos usuários * VE13 - Grau de formalidade - Contratação

\begin{tabular}{|c|c|c|c|c|c|c|c|c|c|}
\hline \multirow{2}{*}{\multicolumn{2}{|c|}{ VE13 - Grau de formalidade - Contratacão }} & & & \multicolumn{5}{|c|}{$\begin{array}{l}\text { VR10-3.2 - A empresa obteve otimização/melhoria nos processos executados pelos } \\
\text { usuários }\end{array}$} & \multirow[b]{2}{*}{ Total } \\
\hline & & & & \multirow[t]{3}{*}{$\begin{array}{c}\text { Nenhum } \\
\text { Resultado }\end{array}$} & $\begin{array}{c}\text { Pouco } \\
\text { Resultado }\end{array}$ & $\begin{array}{l}\text { Resultado } \\
\text { Mediano }\end{array}$ & $\begin{array}{c}\text { Acima da } \\
\text { Média mas } \\
\text { não } \\
\text { completamen } \\
\text { te } \\
\end{array}$ & $\begin{array}{c}\text { Obtido } \\
\text { Completame } \\
\text { nte }\end{array}$ & \\
\hline \multirow[t]{8}{*}{ Informal (sem contrato) } & VE2 - Setor & Indústria & Count & & & & 1 & 1 & 2 \\
\hline & & & $\%$ of Total & & & & $25,0 \%$ & $25,0 \%$ & $50,0 \%$ \\
\hline & & Comércio & Count & & & & 1 & 0 & 1 \\
\hline & & & $\%$ of Total & & & & $25,0 \%$ & $.0 \%$ & $25,0 \%$ \\
\hline & & Serviço & Count & & & & 0 & 1 & 1 \\
\hline & & & $\%$ of Total & & & &, $0 \%$ & $25,0 \%$ & $25,0 \%$ \\
\hline & Total & & Count & & & & 2 & 2 & 4 \\
\hline & & & $\%$ of Total & & & & $50,0 \%$ & $50,0 \%$ & $100,0 \%$ \\
\hline \multirow{8}{*}{$\begin{array}{l}\text { Contrato formal sem } \\
\text { detalhamento (cláusulas } \\
\text { padrão) }\end{array}$} & VE2 - Setor & Indústria & Count & & 0 & 4 & 14 & 10 & 28 \\
\hline & & & $\%$ of Total & &, $0 \%$ & $6,1 \%$ & $21,2 \%$ & $15,2 \%$ & $42,4 \%$ \\
\hline & & Comércio & Count & & 0 & 0 & 6 & 3 & 9 \\
\hline & & & $\%$ of Total & & $.0 \%$ &, $0 \%$ & $9,1 \%$ & $4,5 \%$ & $13,6 \%$ \\
\hline & & Serviço & Count & & 2 & 4 & 10 & 13 & 29 \\
\hline & & & $\%$ of Total & & $3,0 \%$ & $6,1 \%$ & $15,2 \%$ & $19,7 \%$ & $43,9 \%$ \\
\hline & Total & & Count & & 2 & 8 & 30 & 26 & 66 \\
\hline & & & $\%$ of Total & & $3,0 \%$ & $12,1 \%$ & $45,5 \%$ & $39,4 \%$ & $100,0 \%$ \\
\hline \multirow{8}{*}{$\begin{array}{l}\text { Contrato formal } \\
\text { detalhado - sem SLA }\end{array}$} & VE2 - Setor & Indústria & Count & & & 2 & 17 & 9 & 28 \\
\hline & & & $\%$ of Total & & & $3,5 \%$ & $29,8 \%$ & $15,8 \%$ & $49,1 \%$ \\
\hline & & Comércio & Count & & & 0 & 6 & 3 & 9 \\
\hline & & & $\%$ of Total & & &, $0 \%$ & $10,5 \%$ & $5,3 \%$ & $15,8 \%$ \\
\hline & & Serviço & Count & & & 1 & 15 & 4 & 20 \\
\hline & & & $\%$ of Total & & & $1,8 \%$ & $26,3 \%$ & $7,0 \%$ & $35,1 \%$ \\
\hline & Total & & Count & & & 3 & 38 & 16 & 57 \\
\hline & & & $\%$ of Total & & & $5,3 \%$ & $66,7 \%$ & $28,1 \%$ & $100,0 \%$ \\
\hline \multirow{8}{*}{$\begin{array}{l}\text { Contrato formal } \\
\text { detalhado - com SLA }\end{array}$} & VE2 - Setor & Indústria & Count & 1 & 2 & 1 & 52 & 26 & 82 \\
\hline & & & $\%$ of Total &, $6 \%$ & $1,2 \%$ &, $6 \%$ & $30,2 \%$ & $15,1 \%$ & $47,7 \%$ \\
\hline & & Comércio & Count & 0 & 0 & 0 & 18 & 2 & 20 \\
\hline & & & $\%$ of Total &, $0 \%$ & $.0 \%$ &, $0 \%$ & $10,5 \%$ & $1,2 \%$ & $11,6 \%$ \\
\hline & & Serviço & Count & 0 & 0 & 9 & 42 & 19 & 70 \\
\hline & & & $\%$ of Total & $.0 \%$ & $.0 \%$ & $5,2 \%$ & $24,4 \%$ & $11,0 \%$ & $40,7 \%$ \\
\hline & Total & & Count & 1 & 2 & 10 & 112 & 47 & 172 \\
\hline & & & $\%$ of Total & $.6 \%$ & $1,2 \%$ & $5,8 \%$ & $65,1 \%$ & $27,3 \%$ & $100,0 \%$ \\
\hline
\end{tabular}

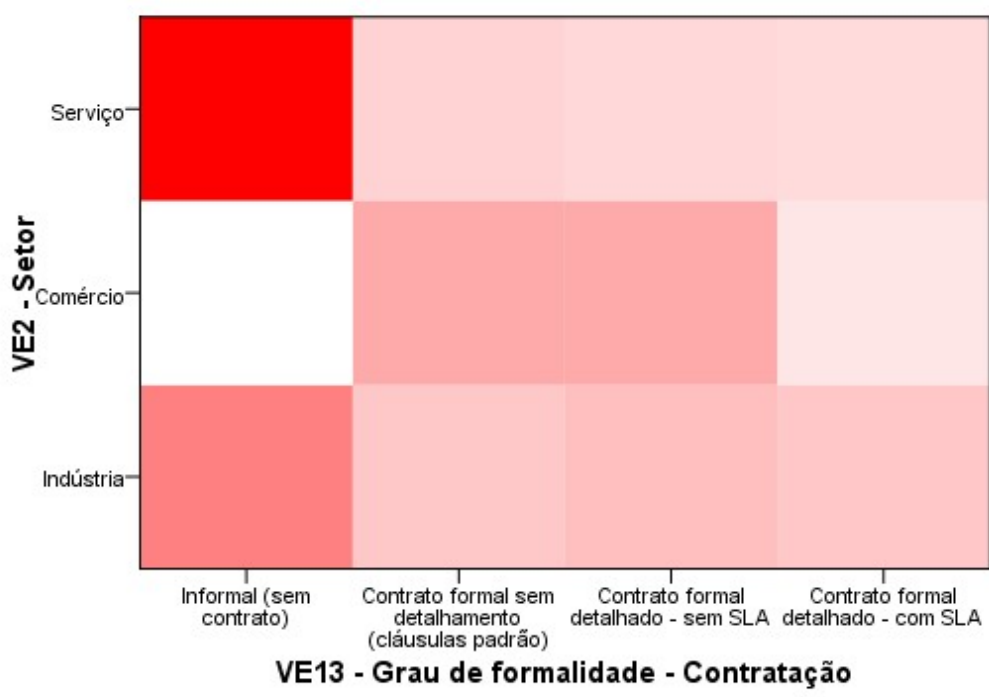

Mean NR10-3.2 - A empresa obteve otimização/melhoria

nos processos executados pelos usuários)

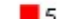

5
-5

5
-14
-4

$\begin{array}{r}4 \\ -4 \\ \hline\end{array}$ 
K11. VR11-3.3 - A empresa obteve aumento da produtividade dos usuários finais (capacidade de realização dos serviços executados) em função do sistema terceirizado (desenvolvido ou implantado)?

\begin{tabular}{|c|c|c|c|c|c|c|c|c|c|}
\hline \multirow{2}{*}{\multicolumn{2}{|c|}{ VE13 - Grau de formalidade - Contratacão }} & & & \multicolumn{5}{|c|}{ VR11-3.3-Aempresa obteve aumento da produtividade dos usuários finais } & \multirow[b]{2}{*}{ Total } \\
\hline & & & & $\begin{array}{c}\text { Nenhum } \\
\text { Resultado }\end{array}$ & $\begin{array}{c}\text { Pouco } \\
\text { Resultado }\end{array}$ & $\begin{array}{l}\text { Resultado } \\
\text { Mediano }\end{array}$ & $\begin{array}{c}\text { Acima da } \\
\text { Média mas } \\
\text { não } \\
\text { completamen } \\
\text { te }\end{array}$ & $\begin{array}{c}\text { Obtido } \\
\text { Completame } \\
\text { nte }\end{array}$ & \\
\hline \multirow[t]{8}{*}{ Informal (sem contrato) } & VE2 - Setor & Indústria & Count & & & & 1 & 1 & 2 \\
\hline & & & $\%$ of Total & & & & $25,0 \%$ & $25,0 \%$ & $50,0 \%$ \\
\hline & & Comércio & Count & & & & 1 & 0 & 1 \\
\hline & & & $\%$ of Total & & & & $25,0 \%$ &, $0 \%$ & $25,0 \%$ \\
\hline & & Serviço & Count & & & & 0 & 1 & 1 \\
\hline & & & $\%$ of Total & & & &, $0 \%$ & $25,0 \%$ & $25,0 \%$ \\
\hline & Total & & Count & & & & 2 & 2 & 4 \\
\hline & & & $\%$ of Total & & & & $50,0 \%$ & $50,0 \%$ & $100,0 \%$ \\
\hline \multirow{8}{*}{$\begin{array}{l}\text { Contrato formal sem } \\
\text { detalhamento (cláusulas } \\
\text { padrão) }\end{array}$} & VE2 - Setor & Indústria & Count & 2 & 0 & 5 & 11 & 10 & 28 \\
\hline & & & $\%$ of Total & $3,0 \%$ & $.0 \%$ & $7,6 \%$ & $16,7 \%$ & $15,2 \%$ & $42,4 \%$ \\
\hline & & Comércio & Count & 0 & 0 & 2 & 4 & 3 & 9 \\
\hline & & & $\%$ of Total & $.0 \%$ & $.0 \%$ & $3,0 \%$ & $6,1 \%$ & $4,5 \%$ & $13,6 \%$ \\
\hline & & Serviço & Count & 0 & 1 & 4 & 7 & 17 & 29 \\
\hline & & & $\%$ of Total &, $0 \%$ & $1,5 \%$ & $6,1 \%$ & $10,6 \%$ & $25,8 \%$ & $43,9 \%$ \\
\hline & Total & & Count & 2 & 1 & 11 & 22 & 30 & 66 \\
\hline & & & $\%$ of Total & $3,0 \%$ & $1,5 \%$ & $16,7 \%$ & $33,3 \%$ & $45,5 \%$ & $100,0 \%$ \\
\hline \multirow{8}{*}{$\begin{array}{l}\text { Contrato formal } \\
\text { detalhado - sem SLA }\end{array}$} & VE2 - Setor & Indústria & Count & & 0 & 5 & 6 & 17 & 28 \\
\hline & & & $\%$ of Total & & $.0 \%$ & $8,8 \%$ & $10,5 \%$ & $29,8 \%$ & $49,1 \%$ \\
\hline & & Comércio & Count & & 0 & 0 & 3 & 6 & 9 \\
\hline & & & $\%$ of Total & &, $0 \%$ &, $0 \%$ & $5,3 \%$ & $10,5 \%$ & $15,8 \%$ \\
\hline & & Serviço & Count & & 1 & 0 & 4 & 15 & 20 \\
\hline & & & $\%$ of Total & & $1,8 \%$ &, $0 \%$ & $7,0 \%$ & $26,3 \%$ & $35,1 \%$ \\
\hline & Total & & Count & & 1 & 5 & 13 & 38 & 57 \\
\hline & & & $\%$ of Total & & $1,8 \%$ & $8,8 \%$ & $22,8 \%$ & $66,7 \%$ & $100,0 \%$ \\
\hline \multirow{8}{*}{$\begin{array}{l}\text { Contrato formal } \\
\text { detalhado - com SLA }\end{array}$} & VE2 - Setor & Indústria & Count & & 1 & 3 & 14 & 64 & 82 \\
\hline & & & $\%$ of Total & & $6 \%$ & $1,7 \%$ & $8,1 \%$ & $37,2 \%$ & $47,7 \%$ \\
\hline & & Comércio & Count & & 0 & 2 & 5 & 13 & 20 \\
\hline & & & $\%$ of Total & &, $0 \%$ & $1,2 \%$ & $2,9 \%$ & $7,6 \%$ & $11,6 \%$ \\
\hline & & Serviço & Count & & 1 & 6 & 11 & 52 & 70 \\
\hline & & & $\%$ of Total & &, $6 \%$ & $3,5 \%$ & $6,4 \%$ & $30,2 \%$ & $40,7 \%$ \\
\hline & Total & & Count & & 2 & 11 & 30 & 129 & 172 \\
\hline & & & $\%$ of Total & & $1,2 \%$ & $6,4 \%$ & $17,4 \%$ & $75,0 \%$ & $100,0 \%$ \\
\hline
\end{tabular}

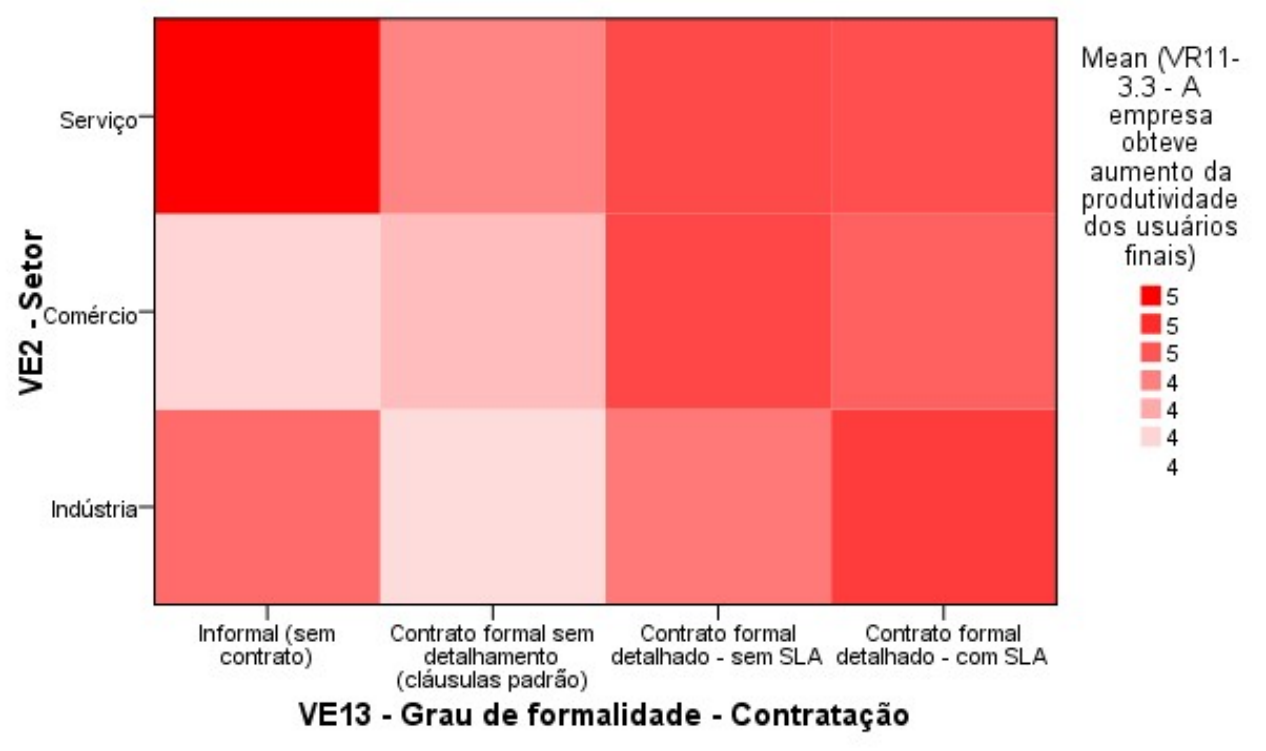


K12. VR12-4.1 - Após a disponibilização do sistema terceirizado (desenvolvido ou implantado), houve um salto de qualidade na realização das atividades-fim dos usuários finais?

VE2 - Setor * VR12-4.1 - Após a disponibilização do sistema terceirizado, houve um salto de qualidade * VE13 - Grau de formalidade - Contratação

\begin{tabular}{|c|c|c|c|c|c|c|c|c|}
\hline \multirow{2}{*}{\multicolumn{2}{|c|}{ VE13 - Grau de formalidade - Contratacão }} & & & \multicolumn{4}{|c|}{$\begin{array}{l}\text { VR12-4.1 - Após a dis ponibilização do sistema terceirizado, houve } \\
\text { um salto de qualidade }\end{array}$} & \multirow[b]{2}{*}{ Total } \\
\hline & & & & $\begin{array}{c}\text { Pouco } \\
\text { Resultado }\end{array}$ & $\begin{array}{l}\text { Resultado } \\
\text { Mediano }\end{array}$ & $\begin{array}{c}\text { Acima da } \\
\text { Média mas } \\
\text { não } \\
\text { completamen } \\
\text { te }\end{array}$ & $\begin{array}{c}\text { Obtido } \\
\text { Completame } \\
\text { nte }\end{array}$ & \\
\hline \multirow[t]{8}{*}{ Informal (sem contrato) } & \multirow[t]{6}{*}{ VE2 - Setor } & Indústria & Count & & 0 & 1 & 1 & 2 \\
\hline & & & $\%$ of Total & &, $0 \%$ & $25,0 \%$ & $25,0 \%$ & $50,0 \%$ \\
\hline & & Comércio & Count & & 1 & 0 & 0 & 1 \\
\hline & & & $\%$ of Total & & $25,0 \%$ &, $0 \%$ &, $0 \%$ & $25,0 \%$ \\
\hline & & Serviço & Count & & 0 & 0 & 1 & 1 \\
\hline & & & $\%$ of Total & &, $0 \%$ &, $0 \%$ & $25,0 \%$ & $25,0 \%$ \\
\hline & \multirow[t]{2}{*}{ Total } & & Count & & 1 & 1 & 2 & 4 \\
\hline & & & $\%$ of Total & & $25,0 \%$ & $25,0 \%$ & $50,0 \%$ & $100,0 \%$ \\
\hline \multirow{8}{*}{$\begin{array}{l}\text { Contrato formal sem } \\
\text { detalhamento (cláusulas } \\
\text { padrão) }\end{array}$} & \multirow[t]{6}{*}{ VE2 - Setor } & Indústria & Count & 2 & 2 & 10 & 14 & 28 \\
\hline & & & $\%$ of Total & $3,0 \%$ & $3,0 \%$ & $15,2 \%$ & $21,2 \%$ & $42,4 \%$ \\
\hline & & Comércio & Count & 0 & 4 & 3 & 2 & 9 \\
\hline & & & $\%$ of Total &, $0 \%$ & $6,1 \%$ & $4,5 \%$ & $3,0 \%$ & $13,6 \%$ \\
\hline & & Serviço & Count & 2 & 5 & 7 & 15 & 29 \\
\hline & & & $\%$ of Total & $3,0 \%$ & $7,6 \%$ & $10,6 \%$ & $22,7 \%$ & $43,9 \%$ \\
\hline & \multirow[t]{2}{*}{ Total } & & Count & 4 & 11 & 20 & 31 & 66 \\
\hline & & & $\%$ of Total & $6,1 \%$ & $16,7 \%$ & $30,3 \%$ & $47,0 \%$ & $100,0 \%$ \\
\hline \multirow{8}{*}{$\begin{array}{l}\text { Contrato formal } \\
\text { detalhado - sem SLA }\end{array}$} & \multirow[t]{6}{*}{ VE2 - Setor } & Indústria & Count & 0 & 3 & 10 & 15 & 28 \\
\hline & & & $\%$ of Total &, $0 \%$ & $5,3 \%$ & $17,5 \%$ & $26,3 \%$ & $49,1 \%$ \\
\hline & & Comércio & Count & 0 & 0 & 2 & 7 & 9 \\
\hline & & & $\%$ of Total &, $0 \%$ &, $0 \%$ & $3,5 \%$ & $12,3 \%$ & $15,8 \%$ \\
\hline & & Serviço & Count & 1 & 1 & 4 & 14 & 20 \\
\hline & & & $\%$ of Total & $1,8 \%$ & $1,8 \%$ & $7,0 \%$ & $24,6 \%$ & $35,1 \%$ \\
\hline & \multirow[t]{2}{*}{ Total } & & Count & 1 & 4 & 16 & 36 & 57 \\
\hline & & & $\%$ of Total & $1,8 \%$ & $7,0 \%$ & $28,1 \%$ & $63,2 \%$ & $100,0 \%$ \\
\hline \multirow{8}{*}{$\begin{array}{l}\text { Contrato formal } \\
\text { detalhado - com SLA }\end{array}$} & \multirow[t]{6}{*}{ VE2 - Setor } & Indústria & Count & 1 & 3 & 14 & 64 & 82 \\
\hline & & & $\%$ of Total &, $6 \%$ & $1,7 \%$ & $8,1 \%$ & $37,2 \%$ & $47,7 \%$ \\
\hline & & Comércio & Count & 0 & 2 & 5 & 13 & 20 \\
\hline & & & $\%$ of Total &, $0 \%$ & $1,2 \%$ & $2,9 \%$ & $7,6 \%$ & $11,6 \%$ \\
\hline & & Serviço & Count & 2 & 9 & 13 & 46 & 70 \\
\hline & & & $\%$ of Total & $1,2 \%$ & $5,2 \%$ & $7,6 \%$ & $26,7 \%$ & $40,7 \%$ \\
\hline & \multirow{2}{*}{\multicolumn{2}{|c|}{ Total }} & Count & 3 & 14 & 32 & 123 & 172 \\
\hline & & & $\%$ of Total & $1,7 \%$ & $8,1 \%$ & $18,6 \%$ & $71,5 \%$ & $100,0 \%$ \\
\hline
\end{tabular}

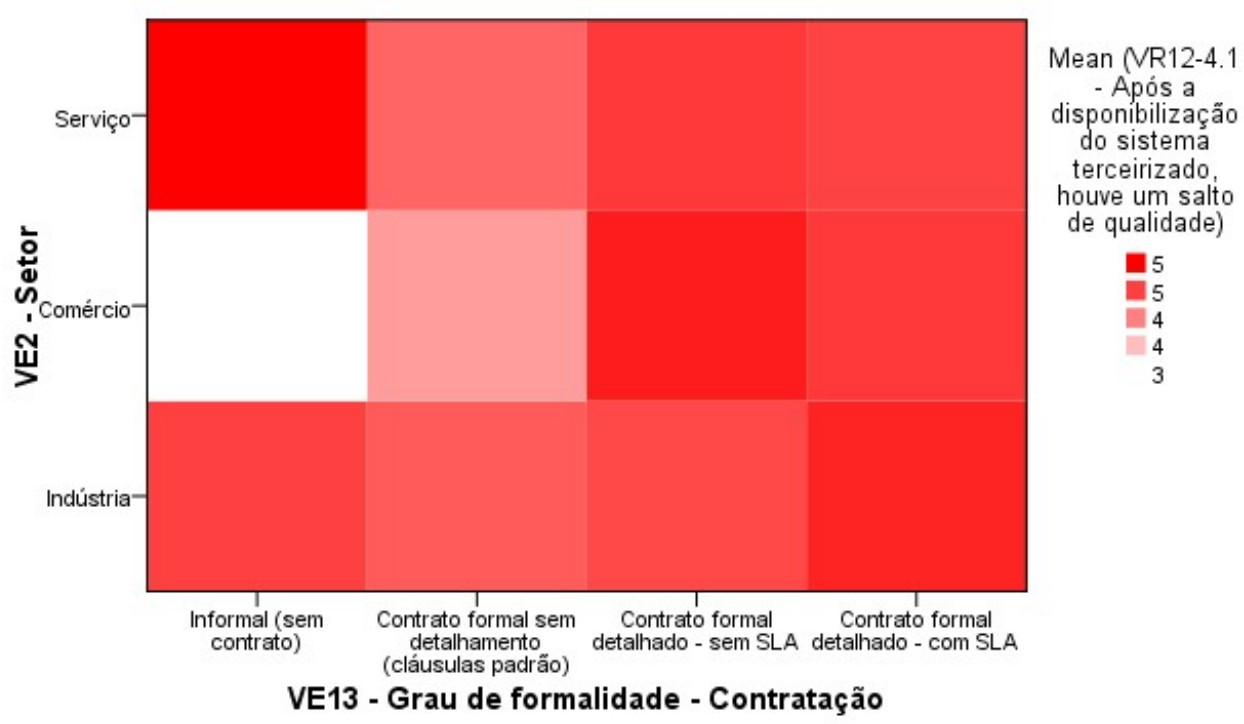


K13. VR13-4.2 - Houve melhoria na qualidade do uso (usabilidade) do sistema terceirizado (desenvolvido ou implantado) por parte dos usuários finais?

\begin{tabular}{|c|c|c|c|c|c|c|c|c|c|}
\hline \multirow{2}{*}{\multicolumn{2}{|c|}{ VE13 - Grau de formalidade - Contratacão }} & & & \multicolumn{5}{|c|}{ VR13-4.2 - Houve melhoria na qualidade do uso (us abilidade) do sistema } & \multirow[b]{2}{*}{ Total } \\
\hline & & & & $\begin{array}{l}\text { Nenhum } \\
\text { Resultado }\end{array}$ & $\begin{array}{c}\text { Pouco } \\
\text { Resultado }\end{array}$ & $\begin{array}{l}\text { Resultado } \\
\text { Mediano }\end{array}$ & $\begin{array}{c}\text { Acima da } \\
\text { Média mas } \\
\text { não } \\
\text { completamen } \\
\text { te }\end{array}$ & $\begin{array}{c}\text { Obtido } \\
\text { Completame } \\
\text { nte }\end{array}$ & \\
\hline \multirow[t]{8}{*}{ Informal (sem contrato) } & VE2 - Setor & Indústria & Count & & & 1 & 1 & 0 & 2 \\
\hline & & & $\%$ of Total & & & $25,0 \%$ & $25,0 \%$ &, $0 \%$ & $50,0 \%$ \\
\hline & & Comércio & Count & & & 1 & 0 & 0 & 1 \\
\hline & & & $\%$ of Total & & & $25,0 \%$ &, $0 \%$ &, $0 \%$ & $25,0 \%$ \\
\hline & & Serviço & Count & & & 0 & 0 & 1 & 1 \\
\hline & & & $\%$ of Total & & &, $0 \%$ &, $0 \%$ & $25,0 \%$ & $25,0 \%$ \\
\hline & Total & & Count & & & 2 & 1 & 1 & 4 \\
\hline & & & $\%$ of Total & & & $50,0 \%$ & $25,0 \%$ & $25,0 \%$ & $100,0 \%$ \\
\hline \multirow{8}{*}{$\begin{array}{l}\text { Contrato formal sem } \\
\text { detalhamento (cláusulas } \\
\text { padrão) }\end{array}$} & VE2 - Setor & Indústria & Count & 1 & 1 & 3 & 14 & 9 & 28 \\
\hline & & & $\%$ of Total & $1,5 \%$ & $1,5 \%$ & $4,5 \%$ & $21,2 \%$ & $13,6 \%$ & $42,4 \%$ \\
\hline & & Comércio & Count & 0 & 0 & 3 & 3 & 3 & 9 \\
\hline & & & $\%$ of Total & $0 \%$ & $.0 \%$ & $4,5 \%$ & $4,5 \%$ & $4,5 \%$ & $13,6 \%$ \\
\hline & & Serviço & Count & 0 & 1 & 4 & 11 & 13 & 29 \\
\hline & & & $\%$ of Total &, $0 \%$ & $1,5 \%$ & $6,1 \%$ & $16,7 \%$ & $19,7 \%$ & $43,9 \%$ \\
\hline & Total & & Count & 1 & 2 & 10 & 28 & 25 & 66 \\
\hline & & & $\%$ of Total & $1,5 \%$ & $3,0 \%$ & $15,2 \%$ & $42,4 \%$ & $37,9 \%$ & $100,0 \%$ \\
\hline \multirow{8}{*}{$\begin{array}{l}\text { Contrato formal } \\
\text { detalhado - sem SLA }\end{array}$} & VE2 - Setor & Indústria & Count & & 0 & 6 & 15 & 7 & 28 \\
\hline & & & $\%$ of Total & &, $0 \%$ & $10,5 \%$ & $26,3 \%$ & $12,3 \%$ & $49,1 \%$ \\
\hline & & Comércio & Count & & 0 & 1 & 4 & 4 & 9 \\
\hline & & & $\%$ of Total & &, $0 \%$ & $1,8 \%$ & $7,0 \%$ & $7,0 \%$ & $15,8 \%$ \\
\hline & & Serviço & Count & & 1 & 0 & 14 & 5 & 20 \\
\hline & & & $\%$ of Total & & $1,8 \%$ &, $0 \%$ & $24,6 \%$ & $8,8 \%$ & $35,1 \%$ \\
\hline & Total & & Count & & 1 & 7 & 33 & 16 & 57 \\
\hline & & & $\%$ of Total & & $1,8 \%$ & $12,3 \%$ & $57,9 \%$ & $28,1 \%$ & $100,0 \%$ \\
\hline \multirow{8}{*}{$\begin{array}{l}\text { Contrato formal } \\
\text { detalhado - com SLA }\end{array}$} & VE2 - Setor & Indústria & Count & & 0 & 2 & 58 & 22 & 82 \\
\hline & & & $\%$ of Total & & $.0 \%$ & $1,2 \%$ & $33,7 \%$ & $12,8 \%$ & $47,7 \%$ \\
\hline & & Comércio & Count & & 1 & 1 & 15 & 3 & 20 \\
\hline & & & $\%$ of Total & &, $6 \%$ & $6 \%$ & $8,7 \%$ & $1,7 \%$ & $11,6 \%$ \\
\hline & & Serviço & Count & & 2 & 7 & 44 & 17 & 70 \\
\hline & & & $\%$ of Total & & $1,2 \%$ & $4,1 \%$ & $25,6 \%$ & $9,9 \%$ & $40,7 \%$ \\
\hline & Total & & Count & & 3 & 10 & 117 & 42 & 172 \\
\hline & & & $\%$ of Total & & $1,7 \%$ & $5,8 \%$ & $68,0 \%$ & $24,4 \%$ & $100,0 \%$ \\
\hline
\end{tabular}

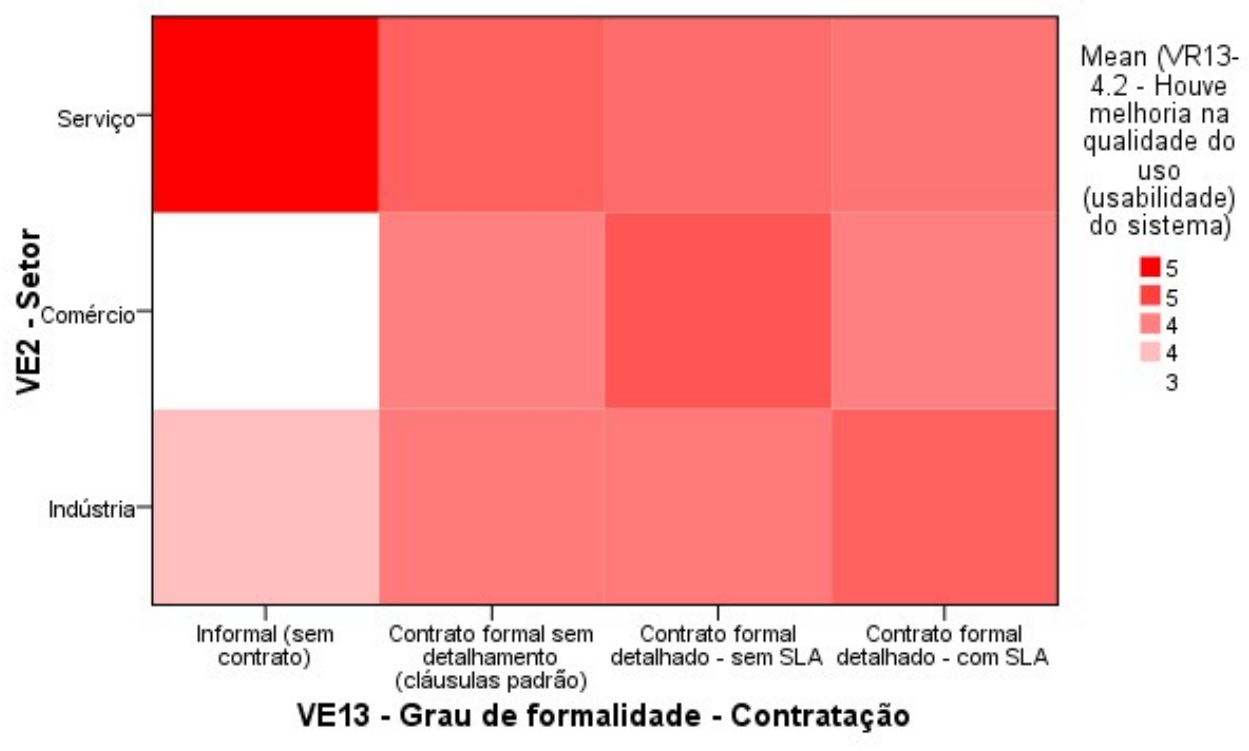


K14. VR14-4.3 - A empresa obteve melhoria na qualidade dos dados/informações oriundos do sistema terceirizado (desenvolvido ou implantado)?

VE2 - Setor * VR14-4.3 - A empresa obteve melhoria na qualidade dos dados/informações * VE13 - Grau de formalidade - Contratação Crosstabulation

\begin{tabular}{|c|c|c|c|c|c|c|c|c|}
\hline \multirow{2}{*}{\multicolumn{2}{|c|}{ VE13 - Grau de formalidade - Contratacão }} & & & \multicolumn{4}{|c|}{$\begin{array}{c}\text { VR14-4.3 - A empresa obteve melhoria na qualidade dos } \\
\text { dados/informaçóes }\end{array}$} & \multirow[b]{2}{*}{ Total } \\
\hline & & & & $\begin{array}{c}\text { Pouco } \\
\text { Resultado }\end{array}$ & $\begin{array}{l}\text { Resultado } \\
\text { Mediano }\end{array}$ & $\begin{array}{c}\text { Acima da } \\
\text { Média mas } \\
\text { não } \\
\text { completamen } \\
\text { te }\end{array}$ & $\begin{array}{c}\text { Obtido } \\
\text { Completame } \\
\text { nte }\end{array}$ & \\
\hline \multirow[t]{8}{*}{ Informal (sem contrato) } & \multirow[t]{6}{*}{ VE2 - Setor } & Indústria & Count & & 0 & 2 & 0 & 2 \\
\hline & & & $\%$ of Total & &, $0 \%$ & $50,0 \%$ &, $0 \%$ & $50,0 \%$ \\
\hline & & Comércio & Count & & 1 & 0 & 0 & 1 \\
\hline & & & $\%$ of Total & & $25,0 \%$ &, $0 \%$ &, $0 \%$ & $25,0 \%$ \\
\hline & & Serviço & Count & & 0 & 0 & 1 & 1 \\
\hline & & & $\%$ of Total & &, $0 \%$ &, $0 \%$ & $25,0 \%$ & $25,0 \%$ \\
\hline & \multirow[t]{2}{*}{ Total } & & Count & & 1 & 2 & 1 & 4 \\
\hline & & & $\%$ of Total & & $25,0 \%$ & $50,0 \%$ & $25,0 \%$ & $100,0 \%$ \\
\hline \multirow{8}{*}{$\begin{array}{l}\text { Contrato formal sem } \\
\text { detalhamento (cláusulas } \\
\text { padrão) }\end{array}$} & \multirow[t]{6}{*}{ VE2 - Setor } & Indústria & Count & 0 & 4 & 8 & 16 & 28 \\
\hline & & & $\%$ of Total &, $0 \%$ & $6,1 \%$ & $12,1 \%$ & $24,2 \%$ & $42,4 \%$ \\
\hline & & Comércio & Count & 0 & 2 & 3 & 4 & 9 \\
\hline & & & $\%$ of Total &, $0 \%$ & $3,0 \%$ & $4,5 \%$ & $6,1 \%$ & $13,6 \%$ \\
\hline & & Serviço & Count & 1 & 4 & 8 & 16 & 29 \\
\hline & & & $\%$ of Total & $1,5 \%$ & $6,1 \%$ & $12,1 \%$ & $24,2 \%$ & $43,9 \%$ \\
\hline & \multirow[t]{2}{*}{ Total } & & Count & 1 & 10 & 19 & 36 & 66 \\
\hline & & & $\%$ of Total & $1,5 \%$ & $15,2 \%$ & $28,8 \%$ & $54,5 \%$ & $100,0 \%$ \\
\hline \multirow{8}{*}{$\begin{array}{l}\text { Contrato formal } \\
\text { detalhado - sem SLA }\end{array}$} & \multirow[t]{6}{*}{ VE2 - Setor } & Indústria & Count & & 2 & 6 & 20 & 28 \\
\hline & & & $\%$ of Total & & $3,5 \%$ & $10,5 \%$ & $35,1 \%$ & $49,1 \%$ \\
\hline & & Comércio & Count & & 0 & 3 & 6 & 9 \\
\hline & & & $\%$ of Total & &, $0 \%$ & $5,3 \%$ & $10,5 \%$ & $15,8 \%$ \\
\hline & & Serviço & Count & & 1 & 2 & 17 & 20 \\
\hline & & & $\%$ of Total & & $1,8 \%$ & $3,5 \%$ & $29,8 \%$ & $35,1 \%$ \\
\hline & \multirow[t]{2}{*}{ Total } & & Count & & 3 & 11 & 43 & 57 \\
\hline & & & $\%$ of Total & & $5,3 \%$ & $19,3 \%$ & $75,4 \%$ & $100,0 \%$ \\
\hline \multirow{8}{*}{$\begin{array}{l}\text { Contrato formal } \\
\text { detalhado - com SLA }\end{array}$} & \multirow[t]{6}{*}{ VE2 - Setor } & Indústria & Count & 1 & 1 & 17 & 63 & 82 \\
\hline & & & $\%$ of Total &, $6 \%$ &, $6 \%$ & $9,9 \%$ & $36,6 \%$ & $47,7 \%$ \\
\hline & & Comércio & Count & 0 & 1 & 4 & 15 & 20 \\
\hline & & & $\%$ of Total &, $0 \%$ & ,6\% & $2,3 \%$ & $8,7 \%$ & $11,6 \%$ \\
\hline & & Serviço & Count & 1 & 7 & 15 & 47 & 70 \\
\hline & & & $\%$ of Total &, $6 \%$ & $4,1 \%$ & $8,7 \%$ & $27,3 \%$ & $40,7 \%$ \\
\hline & \multirow{2}{*}{\multicolumn{2}{|c|}{ Total }} & Count & 2 & 9 & 36 & 125 & 172 \\
\hline & & & $\%$ of Total & $1,2 \%$ & $5,2 \%$ & $20,9 \%$ & $72,7 \%$ & $100,0 \%$ \\
\hline
\end{tabular}

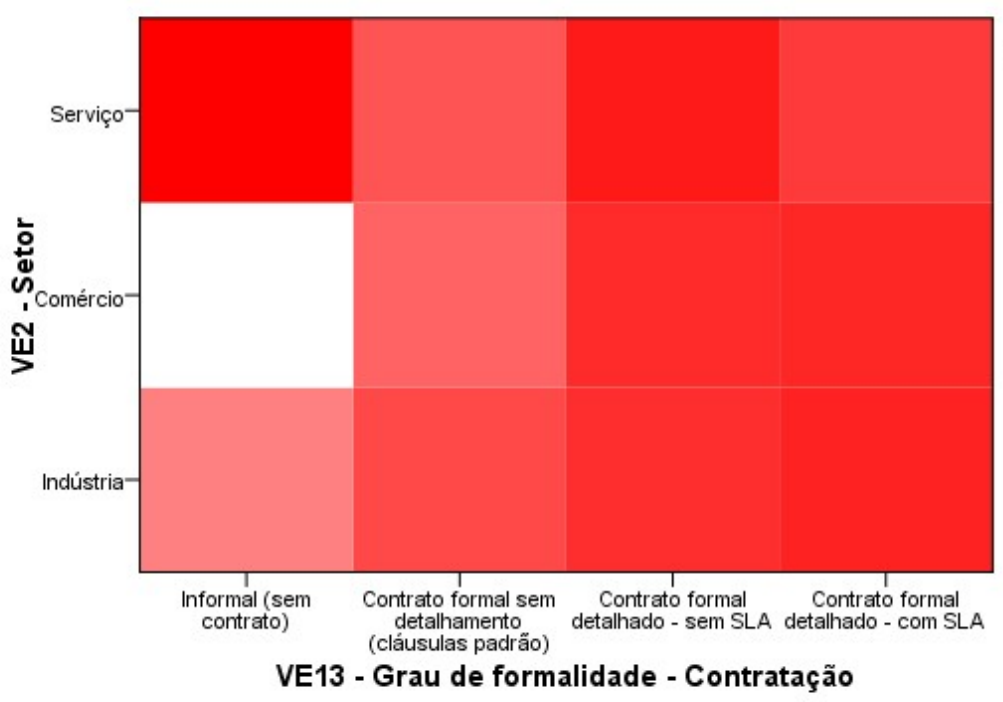

Mean (VR14-4.3 - A

empresa obteve

melhoria na

qualidade dos

dados/informaçōes)

5
5
$-\square$
4
4
3 
Apêndice L - Gráfico scree plot - práticas recomendadas

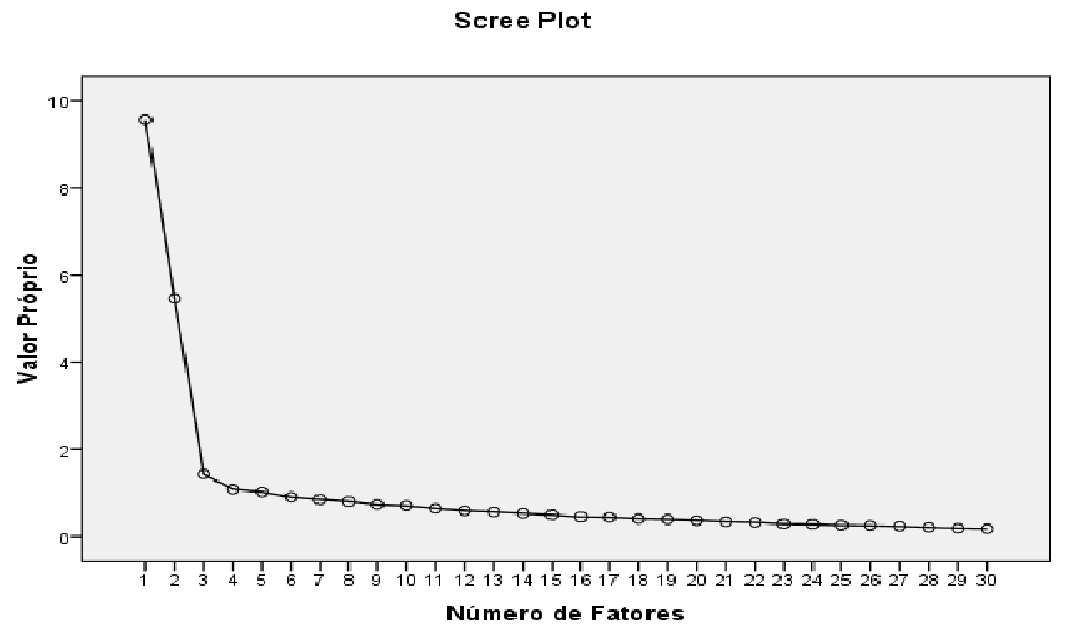




\section{Apêndice M - Medida de adequação da amostra - práticas recomendadas}

\begin{tabular}{|c|c|c|c|c|c|c|c|c|c|c|c|c|c|c|c|}
\hline & & & & & & & & & & & & & & & \\
\hline & & & 1.3 & 1.4 & & & & & 2.5 & 3.1 & 3.2 & 3.3 & 3.4 & 4.1 & 4.2 \\
\hline VP1-1.1 & & ,069 & 030 & ,153 &,- 099 &,- 092 & 038 &,- 213 &, 144 & & &,- 091 & & & \\
\hline VP? 12 & 060 & &,- 290 & 056 & 047 & 072 & - & 105 & 081 &,- 014 & 076 &,- 087 &,- 083 & -063 & -063 \\
\hline & & & $9^{933^{a}}$ & & & & & & & & & & & & \\
\hline & 53 & 056 &,- 208 & 40 & & &,$- 0<1$ &, 112 & ,014 & & & & & &,- 069 \\
\hline VP5-2.1 &,- 099 &, 047 &,- 031 &,- 070 &, $933^{\mathrm{a}}$ &,- 164 &,- 091 &, 072 &,- 039 &, 133 &,- 027 &,- 049 &, 025 &,- 150 &, 039 \\
\hline &,- 092 &,- 072 & ,025 &, 063 &,- 164 &, $923^{a}$ &,- 303 & 107 & 011 & 044 & 104 & ,015 & & 175 &,- 002 \\
\hline & ,038 &,- 022 &,- 105 &,- 021 &,- 091 &,- 303 &, $936^{a}$ &,- 165 & ,102 &,- 084 &,- 044 &,- 137 &,- 066 &,- 016 &,- 005 \\
\hline &,- 213 &,- 195 &,- 011 &, 112 & &, 107 &,- 16 &, $908^{a}$ &,- 351 & & & & & &,- 086 \\
\hline &, 144 &, 081 &,- 027 &, 014 &,- 039 &,- 011 &, 102 &,- 351 & & & & & & & ,048 \\
\hline &,- 070 &,- 014 &,- 040 & 030 & ,133 & 044 &,- 084 & ,015 &,- 094 & & & & & &,- 024 \\
\hline &, 019 &,- 076 &,- 033 &,- 052 &,- 027 &,- 104 &,- 044 &, 008 &,- 027 &,- 261 & &, 037 & & &, 323 \\
\hline &,- 091 &,- 087 & ,035 &,- 042 &,- 049 & ,015 &,- 137 &,- 035 &,- 018 & ,234 & 037 & &,- 144 & ,106 &,- 039 \\
\hline & 205 &,- 083 & ,047 & 035 &, 025 & ,196 &,- 066 &, 103 &,- 038 &,- 054 &,- 167 &,- 144 & &,- 221 &, 073 \\
\hline &,- 110 &,- 063 &,- 010 &,- 049 &,- 150 &,- 175 &,- 016 &, 051 &,- 055 &,- 048 & ,006 &, 106 &,- 221 & &,- 263 \\
\hline VP15-4.2 &,- 075 &,- 063 & ,014 &,- 069 & ,039 &,- 002 &,- 005 &,- 086 & ,048 &,- 024 & ,323 &,- 039 & ,073 &,- 263 &, $874^{a}$ \\
\hline
\end{tabular}

\begin{tabular}{|c|c|c|c|c|c|c|c|c|c|c|c|c|c|c|c|}
\hline & \multicolumn{4}{|c|}{ VP16- VP18- VP19- VP20- } & \multicolumn{2}{|c|}{ - VP21- VP22- } & 8120 & $\sqrt{1520}$ & $8120^{-}$ & & & \multicolumn{4}{|c|}{ - VP30- VP31- VP32- } \\
\hline & 4.3 & 4.5 & 5.1 & 5.2 & 5.3 & 5.4 & 6.1 & 6.3 & 6.4 & 6.5 & 7.1 & 7.2 & 7.3 & 7.4 & 7.5 \\
\hline & & & & & & & & & & & & & &,- 021 & 192 \\
\hline & & & & & 007 & & & 62 & & & & & ,125 &,- 034 & 080 \\
\hline P19-5.1 &, 100 &,- 132 &, $906^{\mathrm{a}}$ &,- 311 &,- 023 & 030 & 025 &, 054 & 158 & 080 & 038 & 007 & 024 &,- 127 & -315 \\
\hline & 049 &, 105 & 311 & &,- 185 & & &, 026 & & & & & & & 173 \\
\hline &,- 073 &,- 007 &,- 023 &,- 185 & & $-, 20\rangle$ & , &,- 217 & , & , 041 & &,- 107 &, 020 & & 073 \\
\hline &,- 243 &, 044 & 039 &,- 009 &,- 289 &, $905^{\mathrm{a}}$ &,- 088 &, 125 &,- 032 &,- 088 &,- 019 & 034 &,- 111 & 055 &,- 035 \\
\hline &, 154 & -121 &, 025 &,- 015 &, 038 &,- 088 &, $950^{\mathrm{a}}$ &, 055 &,- 070 &,- 056 &,- 053 & 073 &,- 010 &,- 105 & 093 \\
\hline & -,050 &,- 062 &, 054 &, 026 &,- 217 &, 125 &, 055 &, $915^{\mathrm{a}}$ & &,- 150 &,- 058 &,- 001 &, 042 &,- 079 &,- 184 \\
\hline &, 04 &, 04 &,- 158 &,- 180 & ,136 &,- 0 &,- 0 &,- 1 & &,- 111 & & &, 1 &,- 109 &,- 024 \\
\hline &,- 112 &, 018 & ,089 & ,062 & ,041 &,- 088 & &,- 150 & & &,- 332 &,- 090 & & &,- 003 \\
\hline & ,039 &, 011 &,- 038 &,- 056 &,- 149 &,- 019 &,- 053 &,- 058 & &,- 332 &, $925^{\mathrm{a}}$ &,- 070 &,- 026 & &,- 146 \\
\hline &, 114 &,- 029 &, 002 &, 079 &,- 107 & ,034 &, 073 &,- 001 &, 010 &,- 090 &,- 070 &, $835^{\mathrm{a}}$ &,- 206 &,- 073 &, 003 \\
\hline &,- 006 &, 125 & 024 & ,034 & 026 &,- 111 &,- 010 & 042 &, 115 &,- 162 &,- 026 &,- 206 &, $789^{a}$ &,- 263 &,- 078 \\
\hline &,- 021 &,- 034 &,- 121 & ,019 & ,031 &, 055 &,- 105 &,- 079 &,- 109 &, 173 &,- 164 &,- 073 &,- 263 &, $917^{\mathrm{a}}$ &,- 096 \\
\hline VP32-7.5 &,- 192 &,- 080 &,- 315 &, 173 & ,073 &,- 035 & ,093 &,- 184 &,- 024 &,- 003 &,- 146 & ,003 &,- 078 &,- 096 &, $867^{a}$ \\
\hline
\end{tabular}


Apêndice N - Gráfico scree plot - resultados esperados

Scree Plot

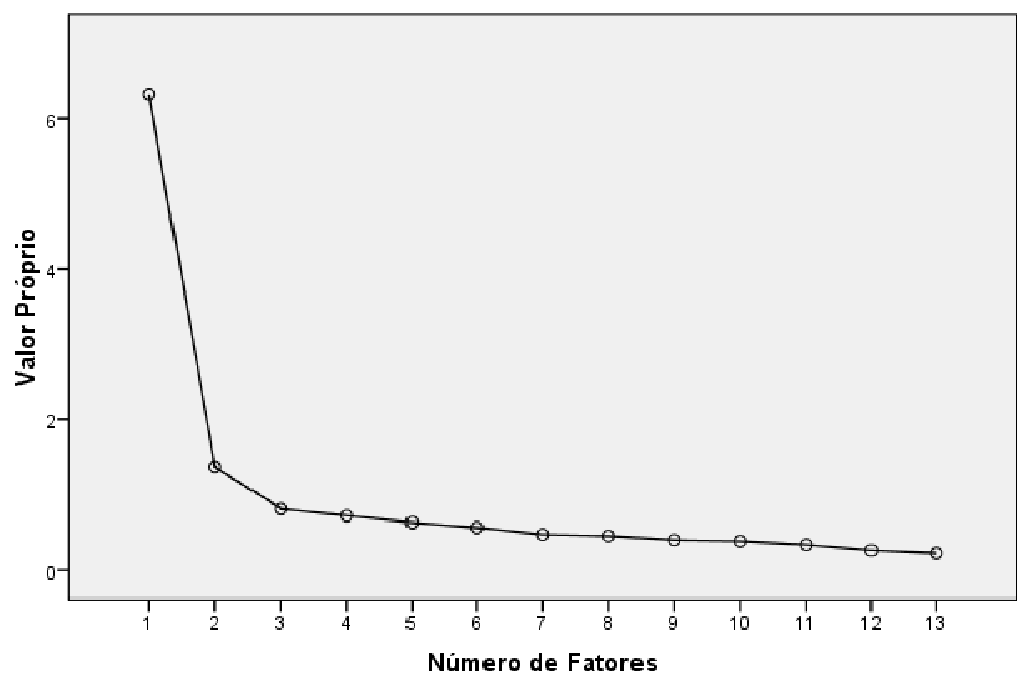


Apêndice $O$ - Medida de adequação da amostra - resultados esperados

\begin{tabular}{lccccccccccccc}
\hline & VR1- & VR2- & VR3- & VR4- & VR5- & VR7- & \multicolumn{1}{c}{ VR8- } & \multicolumn{1}{c}{ VR9- VR10- VR11- VR12- VR13- VR14- } \\
& $\mathbf{1 . 1}$ & $\mathbf{1 . 2}$ & $\mathbf{1 . 3}$ & $\mathbf{1 . 4}$ & $\mathbf{2 . 1}$ & $\mathbf{2 . 3}$ & $\mathbf{2 . 4}$ & $\mathbf{3 . 1}$ & $\mathbf{3 . 2}$ & $\mathbf{3 . 3}$ & $\mathbf{4 . 1}$ & $\mathbf{4 . 2}$ & $\mathbf{4 . 3}$ \\
\hline VR1-1.1 &, $944^{\mathrm{a}}$ &,- 155 &, 016 &,- 184 &,- 072 &,- 082 &,- 129 &, 080 &,- 012 &, 053 &,- 143 &,- 093 &,- 115 \\
\hline VR2-1.2 &,- 155 &, $903^{\mathrm{a}}$ &,- 343 &, 088 &, 074 &,- 003 &,- 107 &,- 055 &,- 124 &, 150 &,- 144 &,- 051 &,- 175 \\
\hline VR3-1.3 &, 016 &,- 343 &, $909^{\mathrm{a}}$ &,- 200 &,- 017 &, 112 &,- 163 &, 041 &,- 019 &,- 162 &,- 061 &,- 141 &, 049 \\
\hline VR4-1.4 &,- 184 &, 088 &,- 200 &, $909^{\mathrm{a}}$ &,- 079 &,- 253 &,- 100 &, 000 &,- 178 &, 035 &, 009 &, 046 &,- 017 \\
\hline VR5-2.1 &,- 072 &, 074 &,- 017 &,- 079 &, $905^{\mathrm{a}}$ &, 072 &,- 007 &,- 197 &, 139 &, 000 &,- 121 &,- 081 &,- 220 \\
\hline VR7-2.3 &,- 082 &,- 003 &, 112 &,- 253 &, 072 &, $926^{\mathrm{a}}$ &,- 095 &,- 093 &,- 183 &,- 009 &,- 071 &,- 130 &,- 043 \\
\hline VR8-2.4 &,- 129 &,- 107 &,- 163 &,- 100 &,- 007 &,- 095 &, $934^{\mathrm{a}}$ &, 039 &,- 220 &,- 141 &, 098 &,- 210 &,- 041 \\
\hline VR9-3.1 &, 080 &,- 055 &, 041 &, 000 &,- 197 &,- 093 &, 039 &, $903^{\mathrm{a}}$ &, 029 &,- 383 &,- 117 &,- 099 &,- 011 \\
\hline VR10-3.2 &,- 012 &,- 124 &,- 019 &,- 178 &, 139 &,- 183 &,- 220 &, 029 &, $929^{\mathrm{a}}$ &, 008 &,- 111 &,- 109 &,- 018 \\
\hline VR11-3.3 &, 053 &, 150 &,- 162 &, 035 &, 000 &,- 009 &,- 141 &,- 383 &, 008 &, $889^{\mathrm{a}}$ &,- 311 &,- 086 &,- 235 \\
\hline VR12-4.1 &,- 143 &,- 144 &,- 061 &, 009 &,- 121 &,- 071 &, 098 &,- 117 &,- 111 &,- 311 &, $922^{\mathrm{a}}$ &, 032 &,- 285 \\
\hline VR13-4.2 &,- 093 &,- 051 &,- 141 &, 046 &,- 081 &,- 130 &,- 210 &,- 099 &,- 109 &,- 086 &, 032 &, $947^{\mathrm{a}}$ &, 038 \\
\hline VR14-4.3 &,- 115 &,- 175 &, 049 &,- 017 &,- 220 &,- 043 &,- 041 &,- 011 &,- 018 &,- 235 &,- 285 &, 038 &, $928^{\mathrm{a}}$ \\
\hline
\end{tabular}




\section{Apêndice $\mathbf{P}$ - Sintaxe utilizada para a análise paralela de Horn no SPSS - práticas recomendadas}

correlation v1 to $v 30 /$ matrix out ('C:Idata.cor ') / missing = listwise.

factor var $=\mathrm{v} 1$ to $\mathrm{v} 30 /$ matrix out $(\mathrm{cor}=$ 'C: idata.cor').

matrix.

mget $/$ type $=$ corr /file='C:Idata.cor' .

call eigen (cr,eigvect,eigval).

compute loadings $=$ eigvect $* \operatorname{sqrt}($ mdiag $($ eigval $))$.

compute $\mathrm{fm}=$ make $($ nrow $(\mathrm{cr}), 2,-9999)$.

compute fm $(1,2)=(\operatorname{mssq}(\mathrm{cr})-\operatorname{ncol}(\mathrm{cr})) /(\operatorname{ncol}(\mathrm{cr}) *(\mathrm{ncol}(\mathrm{cr})-1))$.

loop \#m = 1 to $\operatorname{col}(\mathrm{cr})-1$.

compute a = loadings $(:, 1: \# \mathrm{~m})$.

compute partcov $=\mathrm{cr}-(\mathrm{a} * \mathrm{t}(\mathrm{a}))$.

compute $\mathrm{d}=\operatorname{mdiag}(1 /(\operatorname{sqrt}(\operatorname{diag}(\operatorname{partcov}))))$.

compute $\mathrm{pr}=\mathrm{d} *$ partcov $* \mathrm{~d}$.

compute fm $(\# \mathrm{~m}+1,2)=(\mathrm{mssq}(\mathrm{pr})-\mathrm{ncol}(\mathrm{cr})) /(\mathrm{ncol}(\mathrm{cr}) *(\mathrm{ncol}(\mathrm{cr})-1))$.

end loop.

* identifying the smallest fm value $\&$ its location (= the \# of factors).

compute $\operatorname{minfm}=\mathrm{fm}(1,2)$.

compute nfactors $=0$.

loop \#s = 1 to $\operatorname{nrow}(\mathrm{fm})$.

compute fm(\#s,1) = \#s -1.

do if $(\mathrm{fm}(\# \mathrm{~s}, 2)<\operatorname{minfm})$.

compute $\operatorname{minfm}=\mathrm{fm}(\# \mathrm{~s}, 2)$.

compute nfactors $=\# \mathrm{~s}-1$.

end if.

end loop.

print eigval /title="Eigenvalues".

print fm /title="Velicer's Average Squared Correlations".

print minfm /title="The smallest average squared correlation is".

print nfactors /title="The number of components is".

end matrix.

set mxloops $=9000$ length $=$ none printback $=$ none width $=80$ seed $=1953125$.

matrix.

* enter your specifications here.

compute Ncases $=299$.

compute Nvars $=30$.

compute Ndatsets $=1000$.

compute percent $=95$.

* computing random data correlation matrices \& eigenvalues.

compute evals $=$ make (nvars, ndatsets,-9999).

compute $\mathrm{nm} 1=1 /$ (ncases- 1$)$.

loop \#nds $=1$ to ndatsets.

compute $\mathrm{x}=\operatorname{sqrt}(2 *(\ln ($ uniform(ncases, nvars $)) *-1)) \& *$

$\cos (6.283185 *$ uniform(ncases,nvars) $)$.

compute $\mathrm{vcv}=\mathrm{nm} 1 *(\operatorname{sscp}(\mathrm{x})-((\mathrm{t}(\operatorname{csum}(\mathrm{x})) * \operatorname{csum}(\mathrm{x})) /$ ncases $))$.

compute $d=\operatorname{inv}(\operatorname{mdiag}(\operatorname{sqrt}(\operatorname{diag}(\operatorname{vcv}))))$. 
compute evals(:,\#nds $)=\operatorname{eval}(\mathrm{d} * \mathrm{vcv} * \mathrm{~d})$.

end loop.

* identifying the eigenvalues corresponding to the desired percentile.

compute num $=\operatorname{rnd}(($ percent $*$ ndatsets $) / 100)$.

compute results $=\{\mathrm{t}(1$ :nvars $), \mathrm{t}(1$ :nvars $), \mathrm{t}(1$ :nvars $)\}$.

loop \#root $=1$ to nvars.

compute ranks $=$ rnkorder(evals $(\#$ root, $:))$.

loop \#col = 1 to ndatsets.

do if $(\operatorname{ranks}(1, \# \operatorname{col})=$ num $)$.

compute results(\#root,3) = evals(\#root,\#col).

break.

end if.

end loop.

end loop.

compute results $(:, 2)=$ rsum $($ evals $) /$ ndatsets.

compute specifs $=$ \{ncases; nvars; ndatsets; percent $\}$.

print specifs /title="Specifications for this Run:"

/rlabels="Ncases" "Nvars" "Ndatsets" "Percent".

print results /title="Random Data Eigenvalues"

/clabels="Root" "Means" "Prcntyle".

end matrix. 


\section{Apêndice Q - Sintaxe utilizada para a análise paralela de Horn no SPSS - resultados esperados}

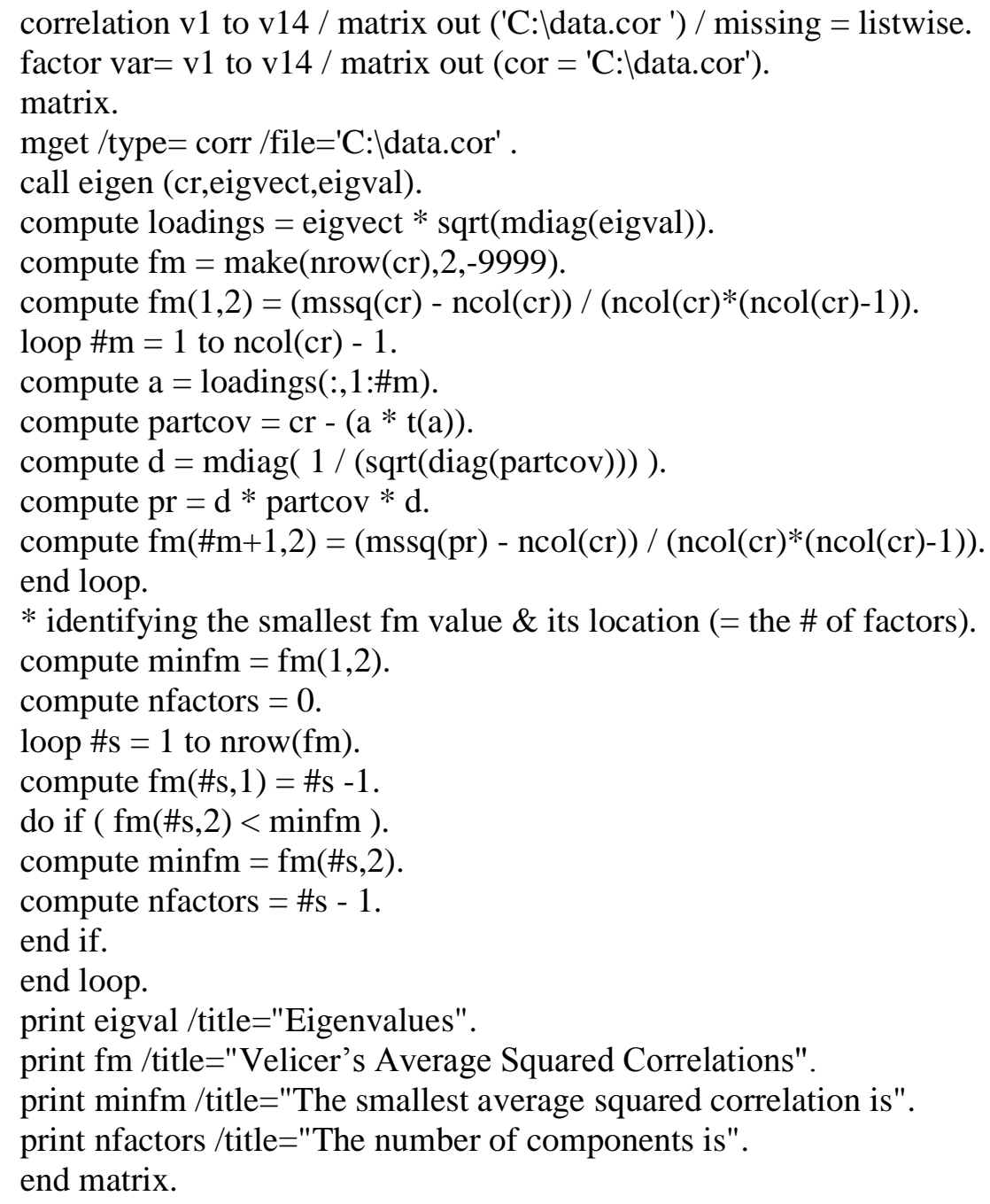

set mxloops $=9000$ length $=$ none printback $=$ none width $=80$ seed $=1953125$.

matrix.

* enter your specifications here.

compute Ncases $=299$.

compute Nvars $=32$.

compute Ndatsets $=1000$.

compute percent $=95$.

* computing random data correlation matrices \& eigenvalues.

compute evals $=$ make (nvars, ndatsets,-9999).

compute $\mathrm{nm} 1=1 /$ (ncases- 1 ).

loop \#nds = 1 to ndatsets.

compute $\mathrm{x}=\operatorname{sqrt}(2 *(\ln ($ uniform(ncases, nvars $)) *-1)) \& *$

$\cos (6.283185 *$ uniform(ncases,nvars) $)$. 
compute $\mathrm{vcv}=\mathrm{nm} 1 *(\operatorname{sscp}(\mathrm{x})-((\mathrm{t}(\operatorname{csum}(\mathrm{x})) * \operatorname{csum}(\mathrm{x})) / \mathrm{ncases}))$.

compute $\mathrm{d}=\operatorname{inv}(\operatorname{mdiag}(\operatorname{sqrt}(\operatorname{diag}(\mathrm{vcv}))))$.

compute evals(:,\#nds $)=\operatorname{eval}(\mathrm{d} * \mathrm{vcv} * \mathrm{~d})$.

end loop.

* identifying the eigenvalues corresponding to the desired percentile.

compute num $=\operatorname{rnd}(($ percent $*$ ndatsets $) / 100)$.

compute results $=\{\mathrm{t}(1$ :nvars $), \mathrm{t}(1$ :nvars $), \mathrm{t}(1$ :nvars $)\}$.

loop \#root $=1$ to nvars.

compute ranks $=$ rnkorder(evals $(\#$ root,::)).

loop \#col = 1 to ndatsets.

do if $(\operatorname{ranks}(1, \# \mathrm{col})=$ num $)$.

compute results (\#root,3) = evals(\#root,\#col).

break.

end if.

end loop.

end loop.

compute results $(:, 2)=$ rsum(evals) $/$ ndatsets.

compute specifs $=$ \{ncases; nvars; ndatsets; percent $\}$.

print specifs /title $=$ "Specifications for this Run:"

/rlabels="Ncases" "Nvars" "Ndatsets" "Percent".

print results /title="Random Data Eigenvalues"

/clabels="Root" "Means" "Prcntyle".

end matrix. 